\title{
PLACE-BASED CONSERVATION: PERSPECTIVES FROM THE SOCIAL SCIENCES
}

Place-based conservation: Advancing social theory and practice ............................... Daniel Williams, William Stewart, and Linda Kruger

Part 1: Conceptual issues of place-based conservation ....................................29

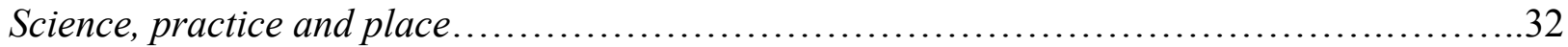

Daniel Williams

Conservation that connects multiple scales of place.....................................57 Courtney Flint

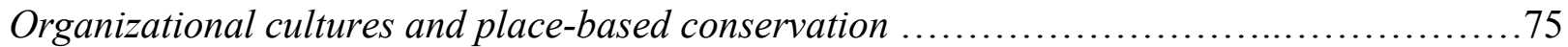

Patricia Stokowski

Community, place, and conservation ........................................... 100

Gene Theodori and Gerard Kyle

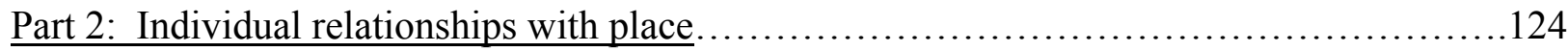

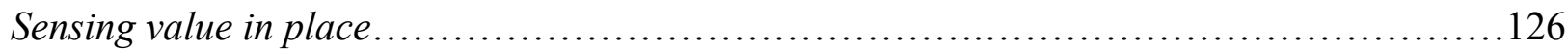

Herb Schroeder

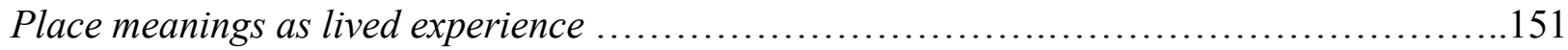

James Barkley

Personal experience and public place creation .........................................171

Tyra Olstad

Volunteer meanings in the making of place

Ben Amsden, Rich Stedman, and Linda Kruger

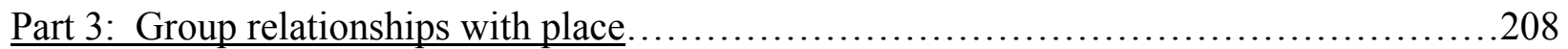

Integrating divergent representations of place into decision contexts.......................211

Damon Hall, Susan Gilbertz, Cristi Horton, and Tarla Rai Peterson

Sharing stories of place to foster social learning.......................................235

William Stewart, Troy Glover, and James Barkley 
Rural property, collective action, and place-based conservation

259

Paul Van Auken and Shaun Golding

Whose sense of place? A political ecology of amenity development..........................280 Patrick Hurley

Part 4: Techniques for place-based conservation.........................................

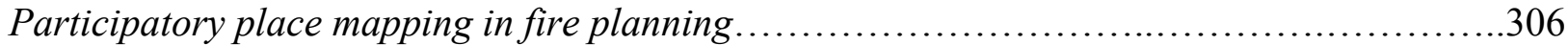

Michael Cacciapaglia and Laurie Yung

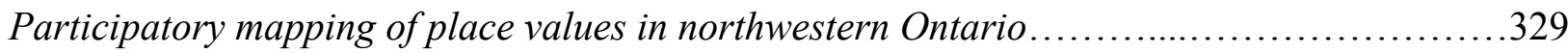

Norman McIntyre, Perrine Lesueur and Jeff Moore

Place mapping to protect cultural landscapes on tribal lands

354

Alan Watson, Steve Carver, Roian Van Ness, Tim Waters, Kari Gunderson, and Brett Davis

Community-based place attachment to public land.

Neal Christensen and Jim Burchfield

Conclusion: Challenges for the practice of place-based conservation...........................

The Authors and their Affiliations .404

Glossary. .406 


\title{
Place-Based Conservation: Advancing Social Theory and Practice
}

\author{
Daniel Williams, William Stewart and Linda Kruger
}

Place has become an increasingly prominent topic in natural resource management and conservation practice with growing influence on many aspects of resource management from adaptive, multi-scaled ecosystem management to public participatory GIS, place-based conservation legislation, and community-based collaboration. Managers increasingly talk about managing for sense of place and special places, measuring place attachment among visitors and community residents, and instituting collaborative place-based planning processes (Kruger \& Jakes, 2003). The concept of place resonates surprisingly well with professionals and the public involved in the management of wildlands, regional tourism planning, as well as community issues of sprawl, open space preservation, and community development (Williams, 2008). In addition, the emergence of place in conservation practice has been spurred on by work in the various social and ecological disciplines, from restoration ecology, marine science and computer science to education, public health, and community development.

Sensing this conceptual shift, conservation decision-making across land management agencies has evolved to address issues of place. The leadership team of the Pacific Northwest Region of the Forest Service recently put "valuing places" at the top of its strategic agenda as a core management task. The Deschutes National Forest in Oregon is incorporating sense of place values in an evolving ecosystem services framework for stewardship decision-making (Hall, Farnum, Slider, \& Ludlow, 2009). As part of their management plan development, The New River Gorge National River in West Virginia, administered by the National Park Service, completed a dialogue with their stakeholders regarding the meaning and values connected to the 
park to publically represent the shared sense of stewardship and nuance commitment to its mission. Yet another federal land management agency, he US Army Corps of Engineers, is incorporating place meanings and their implications for management in their watershed projects along Illinois’ Kaskaskia River (Leahy \& Anderson, 2010). Although these are isolated examples of place-based conservation, the concept of valuing places involves transformative changes in the practice of natural resource conservation that remain unknown to most natural resource managers. A key aim of this book is to bring clarity to both the conceptual foundations and emerging practices that underlie a place-based conservation.

Despite its apparently intuitive appeal in conservation practice, place is a deceptively complex and elusive idea that continues to befuddle researchers and scientists (Casey, 1998). On the one hand, it would be difficult to navigate much less make sense of the world without an ability to distinguish places and recognize the names we give them. Place names function as a powerful geographic short-hand for conveying abundant material and locational significance. On the other hand we give little thought to the way places come into being and change over time. We often speak of named places as if their existence is obvious, natural, and enduring. Yet places are created and continuously transformed by human discourse and action. Who first named the Rocky Mountains and where exactly do they begin and end? What images, ideas, histories and human practices does the "Rocky Mountain West" or the "Rocky Mountain Front" bring to mind and how have these images evolved? We rarely delve into the social processes that create and transform places, yet if we are to advance place-based conservation such understanding is essential. The aims of this introductory chapter are to provide an initial orientation to three questions: 
- What is place? Specifically, how has the concept of place been understood in social science?

- Why place-based conservation? In what sense has conservation practice not been placebased and why should anyone care?

- How do the various sections of the book connect place to practice?

\section{What is Place?}

In everyday life, place is a ubiquitous taken-for-granted experience. Humans naturally divide the world they experience into more or less discrete, yet hierarchically nested places. As suggested earlier it would be hard to carry on almost any conversation without employing place names, yet we rarely stop to think about the social processes that brought them into being and all that they have come to signify. Take Portland, Oregon for example. When did Portland become Portland, the place? In the vicinity of Portland, the Columbia River serves as the boundary between Oregon and Washington. The Columbia River is also a place, with meaning drawn from among other sources, the narration given to it by Lewis and Clark and the story of their expedition two centuries ago. Oregon, Washington, Portland, and the Columbia River had no meaning to Anglo-Europeans before the Lewis and Clark Expedition, but were created as a result of their expedition. In addition, we must not forget the native peoples who occupied the area known by these names today; they had their own working maps and place names that were meaningful to them and helped guide the early American explorers.

Put simply, places are meaningful locations (Cresswell, 2004). A place is not only materially "carved out" of space, it is "also interpreted, narrated, understood, felt, and imagined ... the meaning or value of the same place is labile -- flexible in the hands of different people or cultures, malleable over time, and inevitably contested" (Gieryn, 2000, p. 465). The above 
characterization reflects something of a working consensus among scholars (Agnew \& Duncan, 1989; Cresswell, 2004) that place embodies three elements. First, there is an obvious materiality to places. Water indeed flows through the Columbia River Gorge to the Pacific Ocean. Second, places have geographic location, in other words, humanly imposed (socially negotiated) boundaries, which are themselves embedded in and embed places of larger and smaller scales. The city of Portland has politically negotiated boundaries and is nested within the American political entity called Oregon. Third, places are meaningful in that humans invest them with meaning in the form of stories - for instance the stories of Lewis and Clark as well as the largely untold or mis-told stories of the native peoples who have long occupied the region. Unlike a resource, which has only utility for a purpose, places have a storied past - both natural and human - which is what ultimately distinguishes the idea of place from mere physical (material) space. Each place is unique in the world with its own history, its own stories and meanings that are pliable in the hands of different people and across time.

A social science perspective of place emphasizes this third element, meaning. In social theory originating from human geographers, place is often contrasted with space. Space is largely understood as an abstract geographic location. In contrast, place adds meanings to spaces and recognizes that place is socially created and constantly transformed by human action. Meaning is important because it distinguishes place from mere space. "Space is what place becomes when the unique gathering of things, meanings, and values sucked out. Put positively, place is space filled by people, practices, objects and representations" (Gieryn, 2000, p. 465). Places are literally and figuratively created by the collective actions of users and managers each trying in some way to establish, maintain, or negotiate among varying senses of the place. Because places are constituted by people through their material and discursive practices, they can 
be described as socially constructed and politically contested. Stated differently, through family, community, and cultural histories, people construct their place meanings. Without sensing their own authorship, people often think of their place meanings as inherent characteristics of the physical world. The meanings are felt as "out there" rather than as being "inside one's head." It is this socially negotiated quality that makes place ideas so powerful for understanding public lands management. At its core, place-based conservation is about a sustained dialogue to understand, represent, and share the various layers of meaning attributed to a given locale.

In addition to this three part description of place, there are different terminologies and inflections associated with the place topic. Sense of place is a term often favored by architects, designers, planners, and some human geographers. Sometimes sense of place seems to refer to simply the images, beliefs, ideas, or cognitions linked to a geographic location. What typically distinguishes sense of place from a mere listing of perceptions and images of place comes from designers and literary writers talking about evoked feelings and suggestions that some places exude positive feelings, harmony, or character. As a result sense of place may connote authentic or high quality places. For example, Kunstler (1993) writes about the "geography of nowhere" as a critique of America's bland suburban, retail, and freeway landscapes that lack any palpable sense of place. This idealized connotation of authenticity makes sense of place popular within certain radical environmental philosophies (e.g., bioregionalism, deep ecology) that suggest human beings are estranged from place, have lost their sense of place in the world, and/or their connection to the "community of life" (Grumbine, 1992; McGinnis, 1999).

Sense of place often comes with an implied normative or prescriptive quality. It is actually difficult to limit a characterization of place to just descriptive meaning. Consider everyday encounters in which people characterize places - a back yard, wildlife refuge, 
neighborhood park, or 40 acres of farmland. These descriptions would each have their implied "right" and "wrong" behavior for the given place. Gieryn (2000) referred to such qualities as the normative landscape. By this he emphasizes the ways that places have established social expectations about what is considered "in place" and "out of place" or what is acceptable versus deviant behavior in that place. By centering conservation dialogue forums on place meanings, the conflicting normative elements of right and wrong behavior surface within contexts of the place meaning. This is different than in traditional forums where normative assertions surface independent of their meanings and detached from contexts that make sense of them.

Place attachment is a term often attributed to Tuan's (1974) idea of topophilia (love of place) and focuses on how strongly people feel a sense of connection to a particular place. Place attachment captures in a quantitative but somewhat narrow form, the important distinction between valuing a place for the goods and services that might be associated with it versus the deeper emotional and symbolic relationships people form with place. Early application of place attachment to resource management sought to move beyond the commodity or consumer view of resource management in which the resource was merely a storehouse or venue for satisfying material or emotional needs. Research has produced well-tested survey methods for measuring the strength of individual levels of attachment (Williams \& Vaske, 2003) to account for different public preferences for management of specific places. Place attachment is sometimes mischaracterized as simply positive regard for a place without an understanding ofthe meaning behind the attachment. Often people do not merely prefer one place over another, they cherish certain places, like they would cherish their children. These kinds of strong emotions usually develop over time and with experience and are deeply implicated in one's identity. 
Finally, social science is not only concerned with the elements that constitute place (materiality, location, and meaning), it also recognizes place as a "fundamental means through which we make sense of the world and through which we act" (Sack, 1992, p. 1). In other words place structures our knowledge of the world and our activity in it. Sack illustrates this point (see Figure 1) by contrasting the elements that make up a place with alternative perspectives from which to understand a place. His model divides the elements of place (what he calls forces) into nature (materiality) and culture (further divided into social relations and meaning). In addition to the horizontal plane of elements in Figure 1, Sack describes a vertical plane or perspective that distinguishes forms of knowledge. Such perspectives vary between views from somewhere (subjective everyday experience) and views from nowhere (scientific or technical perspectives). In addition, as one moves closer to nowhere, views begin to separate into distinct domains of knowledge or disciplines. Most technical knowledge aims to be highly generalizable from place to place and thus seeks a view from nowhere. But generalizability comes at the cost of fragmentation of knowledge into isolated disciplinary lenses. Thus, in recent decades social scientists have championed the view from somewhere - emphasizing the importance of context, local conditions, and place specific culture in shaping knowledge (Finnegan, 2008; Fischer, 2000). Within the social sciences, greater emphasis on place provides an important way to reassert the role of the direct, subjective and emplaced experience of the world as a legitimate form of knowledge for consideration in decision-making. This assertion of the importance of local context to "make sense of the world" has been an important factor in advancing a placebased approach to conservation. 
Insert Figure 1 here

\section{Why Place-Based Conservation?}

Even though place has broad appeal, it is still important to understand the social and intellectual forces driving a place-based approach to conservation practice. First, in what sense has conservation practice not been place-based? Second, why is place-based conservation intuitively appealing to the public as well as managers? To answer the the first question we need to examine the shifting intellectual outlook on the role of science and technical analysis in the rational management of natural resources. Understanding the second question requires us to examine contemporary social trends shaping perceptions of landscape values and the pace of landscape change.

\section{The Transformative Character of Place-Based Conservation}

It is difficult to appreciate just how transformative place thinking is to both conservation science and practice, especially within the context of multiple use public lands management. It is a transformation that has been underway since the emergence of New Perspectives (Salwasser, 1990) and Ecosystem Management (Robertson, 1992) in the late 1980s and early 1990s. Section I of this book details the major issues surrounding the transformation of place-based conservation. Some researchers have gone so far as to describe it as a paradigm shift in resource management from valuing commodities to valuing more holistic entities ranging from communities (Rolston \& Coufal, 1991), to ecosystems (Freemuth, 1998), to places (Williams \& 
Stewart, 1998). While these various formulations of the changing paradigm have much in common - they are all in some way or another post-utilitarian (Williams, 2002a) -- place has emerged as one of the most inclusive ways to frame the changing practice of natural resource conservation.

From 1901-1909, the "golden era" of American conservationism, three principles of practice were established that became entrenched in agency culture connected to public land management (Nash, 2001). Led by President Theodore Roosevelt with inspiration for scientific efficiency inspired by his Chief Forester, Gifford Pinchot, more than 100 million acres of public land were set aside to manage for the public good. Two core principles of their utilitarian conservation were to: (1) use scientific principles to drive land management decisions in order to be independent from the whims of public values, and (3) become independent of the federal appropriations process by relying on revenue from sales of natural resources for agency funding (Dana \& Fairfax, 1980, ch. 3). These principles were not forcibly questioned until the 1950's when societal values for public lands expanded beyond market-based commodities (e.g., timber, forage, minerals) and agencies were pressured to consider a wider range of values in their decision-making (Culhane, 1981; Twight, 1983). With decades of privileging technical efficiency and discounting public values, place-based conservation has been counter-intuitive to traditions of several professions involved with land management (Sarewitz, 2004; Priscoli \& Wolf, 2009). However, in the past few decades, land management agencies have tangled with numerous "wicked problems" that defy scientific solutions and underscore the need to re-invent the practice of conservation as a more participatory and inclusive endeavor (Yaffee, 1996).

As an agency with a particularly strong agency culture and professional identity built upon scientific expertise, the US Forest Service began to question its core traditions and seek 
pathways for transformation in the 1980's. What started as "New Perspectives" involved two fundamental changes to conservation practice that had guided multiple-use resource management from Pinchot's time (Williams \& Patterson, 1996). The first change expanded the spatialtemporal unit of analysis beyond the site and stand level of traditional forest practice (e. g., silviculture) and, began to examine resource management from the perspective of a dynamic multi-scaled ecosystem. The second change expanded consideration to include whole ecosystems and values beyond the almost exclusive focus on economic or utilitarian considerations (as exemplified by its centralized linear program for forest planning - FORPLAN) to embrace a wider array of ecological and public values.

Place-based conservation is centered on public representation and democratizing scientific processes. Forums for public values and place meanings are explicitly structured to encourage the complexity of place meanings to emerge and become shared (Kruger \& Shannon, 2000). Whereas science is about a de-personalized and objective knowledge, place meanings are personalized and subjective. Hence public understanding of place meanings is intimately tied to community-based contexts in which the meanings have been developed. Because place meanings are explicitly personal - we recognize ownership of place meanings - the case for accumulated meanings is much easier to negotiate. Whereas in traditional conservation, science asserts a truth in the context of facts and collected evidence, place-based conservation is about negotiating multiple layers of meanings in a single geographic location (see various applications of placebased conservation in Farnum \& Kruger, 2008; Farnum, Hall \& Kruger, 2005).

A key to understanding the transformative implications of place-based conservation is to recognize place as a social analogue to the ecosystem concept. Both concepts (place and ecosystem) recognize that society values natural resources in ways not easily or necessarily 
captured by the commodity and production metaphors of "use" and "yield." Both try to localize and contextualize knowledge. Both pay attention to history and geographic scale. Recognizing the processes and meanings that constitute sense of place, however, adds a significant human role in making and using the landscape without reducing humans to one species among many. Negotiating a shared sense of place that incorporates both natural and social history allows managers to find common ground without pigeonholing people into utilitarian, environmentalist, or romantic preservationist positions. That is, it may be possible to build a level of consensus around sense of place because it naturally leads to a discussion of desired future conditions of a resource in both ecological and human terms (Williams \& Stewart, 1998, p. 23).

These changes in conservation practice are also reflected in a broader conceptual shift in the sciences and philosophy in which the concepts of place, scale, and spatiality are taken more seriously (Finnegan, 2008; Schneider, 2001; Wright, 2005). Over the past two decades, place ideas have arisen throughout the social and natural sciences in ways that elucidate a more holistic, systemic and embedded view of reality. This is certainly the case in the social sciences where geography is being rediscovered not only by other social sciences including economics, psychology, sociology, political science, communications, and anthropology, but within geography itself. Similarly in ecology and urban and regional planning -- where landscape and place have always had currency -- spatiality is taken more seriously (Healey, 1997). This change has elevated the importance of space, time, and context. It is a shift away from the reductionistic views of science that reached ascendancy in the mid $20^{\text {th }}$ century based upon the intellectual foundation of traditional utilitarian conservation.

Adopting new ecological perspectives on content and scale of analysis is only part of the transformation. What makes valuing or conserving places truly transformative is that it 
challenges cherished notions of objective science and knowledge that have traditionally legitimized conservation practice. Put another way, place challenges the supremacy of Enlightenment science and reason that underwrites utilitarian conservation. The Enlightenment ideal of science involves an epistemology (theory of knowledge) variously described as promoting a singular "God's-Eye" (Hayles, 1995) or "view from nowhere" (Nagel, 1987; Sack, 1992) that is "insufficiently enlightened about its own conception of reason" (Schmidt, 1998, p. 420). To put this in spatial or place specific terms, the Enlightenment understanding of science promotes a "placeless" universal orientation to the world (Figure 1). It does this by continually seeking a more distant point of view further from somewhere (the intimate realm of everyday experience) and toward a more remote, and objective point of view that is virtually nowhere (Sack, 1992). Though profoundly useful for gaining certain forms of generalizable knowledge, the drive for a universal 'God's-Eye' view inevitably obscures the particular meanings and relationships endemic to a specific place. Objects and features of a place become components of abstract categories (forest types, recreation opportunity classes, fuel conditions). This limitation was evident to the Forest Service policy team that reviewed the first round of national forest planning (Larson, et al., 1990) in that the highly abstract models such as FORPLAN held little meaning for the public, with output that was difficult to comprehend even for the planners running these models.

In addition, moving from the highly subjective but integrated knowledge of place, to the more distant, but objective description of place tends to fragment knowledge along disciplinary and theoretical lines. In Figure 1, Sack (1992) uses the image of an inverted cone rising and expanding above the horizontal plane to illustrate how the process of abstraction isolates and segments our understandings of places. From his model we can better appreciate how 
conservation science and practice has been dominated by deploying the abstract technical lenses closer to nowhere. Nature was largely viewed through a lens of "yield" (e.g., as factory or farm) and neglected larger-scale ecological processes and interactions. Social relations (value preferences and trade-offs) were examined through the technical lenses of microeconomics, management science, and linear programming in the vain hope of avoiding political controversies. Meanings were largely limited to matters of tangible goods and services, neglecting historical, cultural and spiritual meanings and values. Yet the uses, meanings, and values of a place are often generated closer to somewhere. The more managers sought the view from nowhere the harder it was to include the somewhere in their model (what could be called the indigenous sense of place), which nevertheless remained an important part of the whole they sought to value in conservation practices.

In sum, places encompass a variety of uses, meanings, and values for individuals, groups, and cultures that are difficult to identify using conventional scientific, technical tools for resource analysis. Any particular tract of public land may be home to "local" people; an exotic human-less "other" to foreigners and tourists, or a genetic reservoir to scientists and environmentalists. There is no single objective condition of the landscape with inexorable implications for management. To counteract the narrowing effect of the view from nowhere, Entrikin (1991) suggests seeking points of view between somewhere and nowhere, which he describes as a position of "betweenness" - informed by scientific discourse, but also historically and spatially specific. What is emerging as place-based conservation is only beginning to explore conservation practices that might be more sensitive to incorporating the view from somewhere more completely in decision-making.. 


\section{The Intuitive Appeal of Place-Based Conservation}

Interest in place extends well beyond obscure academic debates about Enlightenment science and the view from nowhere. The idea of place has popular and professional appeal (see Beatley \& Manning, 1997; Kruger \& Jakes, 2003; Lippard, 1997; Spretnak, 1997; Mason, 2008). Though place ideas have been widely used in geography, architecture, and regional planning since the early 1970s (see Healey, 1997) the growing emphasis on collaborative ecosystem management has amplified interest in place concepts within the natural resources field (Nie \& Fiebig, 2010; Williams, 2008; Kruger \& Williams, 2008). Treating nature as a collection of products or commodities to be sold, or isolating properties of the environment in order to study them scientifically leaves many people, lay and professional, with a sense that the larger whole, the 'place' itself, has somehow been lost along the way. This was much of the reaction described in the Forest Service's own critique of its technical approach to forest planning (Larson et al., 1990). Though "New Perspectives" and "Ecosystem Management" attempted to put traditional conservation science into a broader spatial and historic context, it has not fully addressed the richness of human meanings and relationships to the land that people express and want to see represented in the planning process.

A key driving force behind the increasing discussion of place can be found in public angst about globalization and the accelerating pace of change in contemporary society (Cresswell, 2004; Massey, 2005; Sheppard, 2002). The experience and meaning of known and cherished places is increasingly transformed by seemingly uncontrollable distant global scale processes - from climate change and oil spills to economic interdependence, transnational corporate capitalism, and ubiquitous travel and migration. Concerns about the character and quality of places have increased with the spread of mass culture and consumption. For many 
people the social, technological, and economic forces of globalization appear to have weakened local distinctiveness. In addition, relatively inexpensive transportation and new information technologies enable more people to experience ever more parts of the world through international trade, travel, and the media.

Ironically, the impact of globalization has been to make places more important, not less important (Massey, 2005; Sheppard, 2002; Zimmer, 2006). With the spread of globalization, what were once taken-for-granted, subconscious meanings of a place now come to the surface and seem threatened by nearly every proposed change to the local landscape. Proposals for new land uses - whether theme parks, prisons, wildlife preserves, timber harvests, land exchanges, or shopping malls - become symbols of external threats to the local sense of place. Such proposals communicate a sense of place defined by the outsider (e.g., the scientist, government official, corporation, or special interest group) and thus represent the power of the outsider over the local (Williams \& Stewart, 1998).

At the same time that globalization threatens local control over place, it invites more and more stakeholders to make claims on what a place means and how it should be used (Williams \& Van Patten, 2006). In other words, a more globalized, diverse culture supports a more expansive set of place meanings. Ironically, some of these more distant claims may recognize a place (e.g., as wilderness or a world heritage designation) in ways that go beyond traditionally prescribed meanings that favor some other form of development. In this way globalization is sometimes seen as a benign force for the protection of sense of place values otherwise threatened by indigenous or corporate exploitation rather than a dangerous and destabilizing force reshaping places from afar (Williams, 2002b). 


\section{Advancing Place-Based Conservation: Organization of the book}

Utilitarian conservation has evolved over more than a century, with science playing a central role in the evolution process (Hays, 1999). Because of the traditions of privileging science in public lands decision-making, the voices of scientific expertise have asserted new domain and expanded their influence (Sarewitz, 2004). In the past 50 years, conservation decision forums have embraced ecology, wildlife biology, atmospheric sciences, watershed hydrology, economics, and operations research, to name a few "views from nowhere" that have gained recognition and acceptance in the practice of conservation. While the addition of these objective perspectives has expanded their relevance, public values about place meanings - the "views from somewhere" - have been pushed to the periphery (Williams \& Stewart, 1998).

Scientific advancement has improved our understanding of the material and locational aspects of environments. We have come to appreciate the materiality of a host of environmental conditions, including the effects of different soil types on the flow of water, genetic variability in sub-species of birds, and impacts of wildfire on the carbon cycle, to name a few. In addition, we have developed capacities to identify and describe locations on the Earth's surface in ways not imaginable 100 years ago. Such capacities have led the way to enhance identification of critical habitats, coordinate land management across ownership boundaries, and have easily coupled our locational prowess with advancement in the sciences. To be sure, advancement in understanding the material and locational characteristics of environments are indeed worthwhile as part of a matrix of information relevant to conservation practice. By knowing the material and locational characteristics of an environment we know two of the three elements necessary for place-based conservation (Gieryn, 2000). However even with such advancement, we are still missing the core component of place-based conservation. 
To gain a "view from somewhere," we need to understand meanings attributed to environments by people who live, work, play, and otherwise occupy the environments. Without such meanings, the objective points of science will not provide a "view from somewhere." The meanings people and communities attribute to environments should be a significant force behind the visions and goals for place-based conservation. The traditions of resource planning do not recognize the need to incorporate meanings that provide "views from somewhere." The context for most environmental controversies is not centered on a place's meaning, but on the technicalities of process. Yaffee (1994) provides an excellent account of the technical processes surrounding logging in the Pacific Northwest during the 1970-80's, and among other points, centers the discourse on processes stemming from scientific uncertainty, jurisdictional ambiguity, and agency culture, that ultimately avoids discourse and inclusion of place meanings. As a response to limitations of traditional practices of conservation, this book provides a primer to build capacity for addressing place meanings in the practice of conservation.

The book is divided into four parts that create space for place meanings in the practice of conservation. The first section provides a foundation for explaining the conceptual issues of place-based conservation through the lens of the social sciences. The concept of "place" has been used across many disciplines, and is often used synonymously with geographic location. For example in their edited book Place Matters, Wright and Scholz (2005) portray geospatial configurations as being essential to understand advancement in marine fisheries conservation in particular locales of the Pacific Northwest. In this case, "place" refers to the physical geography of specific locations on the ocean's floor. Place also has been used by ecologists to connote the natural history of any given site. For example in an edited book The Ecology of Place, Billick and Price (2010) champion the virtues of ecological research focused on small field sites and the 
thoroughness of scientifically studying a single site, or in their terms, development of a "placecentered database.” Because the concept has been applied in such distinct ways and has been integrated with everyday language, it is beneficial to distinguish our use of "place" in ways that justify, clarify, and shape sensitivities regarding social scientific approaches to place. In particular, the chapters of the first section provide a basis for to appreciate roles for science, multiple geographic scales, organizational and agency cultures, and community relationships to place.

The second section of the book portrays the individual relationships that people develop with the environments they experience. These relationships are the essence of place, and authors discuss felt value, lived experience, and deep-seated intimacy of relationships with place. Rather than being technical and rational, the concepts of this section portray human's relationships with environments as emotional, storied, and highly personal. The challenge suggested by this section is that connecting place to conservation requires bringing together emotions, feelings, and intangible qualities of place using planning tools that generally have regarded such qualities at the margin of relevance. The purpose of this section is to assert that a distinct and littleunderstood set of information is central to place-based conservation.

The third section explores ways to make human relationships with place more visible. Whereas the second section details the nature of human relationships with place, the third section asserts the need for these relationships to be known, shared, and negotiated in public discussion. In the making of places, an important question to ask is "whose place meanings are these?" Place-based conservation embraces complexity in the representation of place meanings and is sensitive to ownership of place meanings. The point of this section is not about garnering more input from citizens nor about encouraging more citizens to become active as stakeholders, it is 
about changing the quality of the information the public and stakeholders are being asked to provide. This section posits that place-based conservation is about innovation in public participation strategies, and emphasizes the importance of place-making in the process of decision-making. In other words, place meanings are not just what people bring to public forums, but include those meanings that are created through public discourse. Structured stakeholder dialogue allows participants to share their appreciation of and understanding for places they live, work, and play and ultimately create a public memory of places.

The fourth section is the most explicit about techniques to connect place meanings to material and locational characteristics of environments. The techniques depict ways to integrate Gieryn's (2000) three elements of place: material, location, and meaning. The strategies of this section may be familiar to many planners (e.g., geographic information systems mapping, mailback questionnaires), however they function to strengthen dialogue amongst stakeholders through purposeful conversations about place. Acts of listening and learning about stakeholder relationships with place is a cornerstone of place-based conservation. Although place meanings are ostensibly descriptions of deep-seated and personal relationships with environments, there are implied norms for behavior that accompany place meanings. Gieryn (2000) suggests that normative expectations are an important part of most place meanings, and by telling one's stories of place, one also tells of the proper behavior or way to respect an environment. In the techniques of this fourth section, fostering trust in stakeholder relations is an important outcome. With personal meanings of environments being a central part of place-based conservation, it is important to cultivate trust while sharing the material and locational characteristics of place meanings. 


\section{Conclusion}

We hope this book provides a foundation for gaining a better understanding of placebased conservation through lenses of the social sciences. Although there is not a single social science approach to place, the collective whole of the book reflects place as a social science construct, and provides some distinct contrasts to other approaches of understanding and applying a practice of place. The articulation of place as a social science construct asserts a more human-centered approach to conservation. Place-based conservation, compared to traditional utilitarian conservation, makes room for the full array of place values and meanings rather than depending on market economics or inferences from scientific models. A recurrent theme throughout the book is that place-based conservation puts the personalization of knowledge and place meanings up front without any pretense that value is a property somehow objectively discovered or scientifically assessed "out there." A refreshing result of such a starting point is that common ground can be explored in that values and meanings have potential to be transformed and improved through dialogue and to accumulate without necessarily competing with each other. To be sure, place-based conservation recognizes the potential the conflict, and works to build understanding and respect among stakeholders.

Place-based conservation has begun to catch on among land managers as they have increasingly recognized that they are not simply managing the mix and flow of goods and services provided by public lands and, instead, they are managing places that the public has come to know and value. However, it often remains unclear how to translate the intuitive appeal of place into practice. Because the research on place is quite diverse, diffuse, and often contradictory (Patterson \& Williams, 2005) one aim of this book is to provide a resource for researchers and practitioners to help build the conceptual grounding necessary to work with these 
ideas effectively. We also perceive something deeper and more fundamental at work in these ideas and employ the theories and tools of social science to help guide conservation practice to become more place-based.

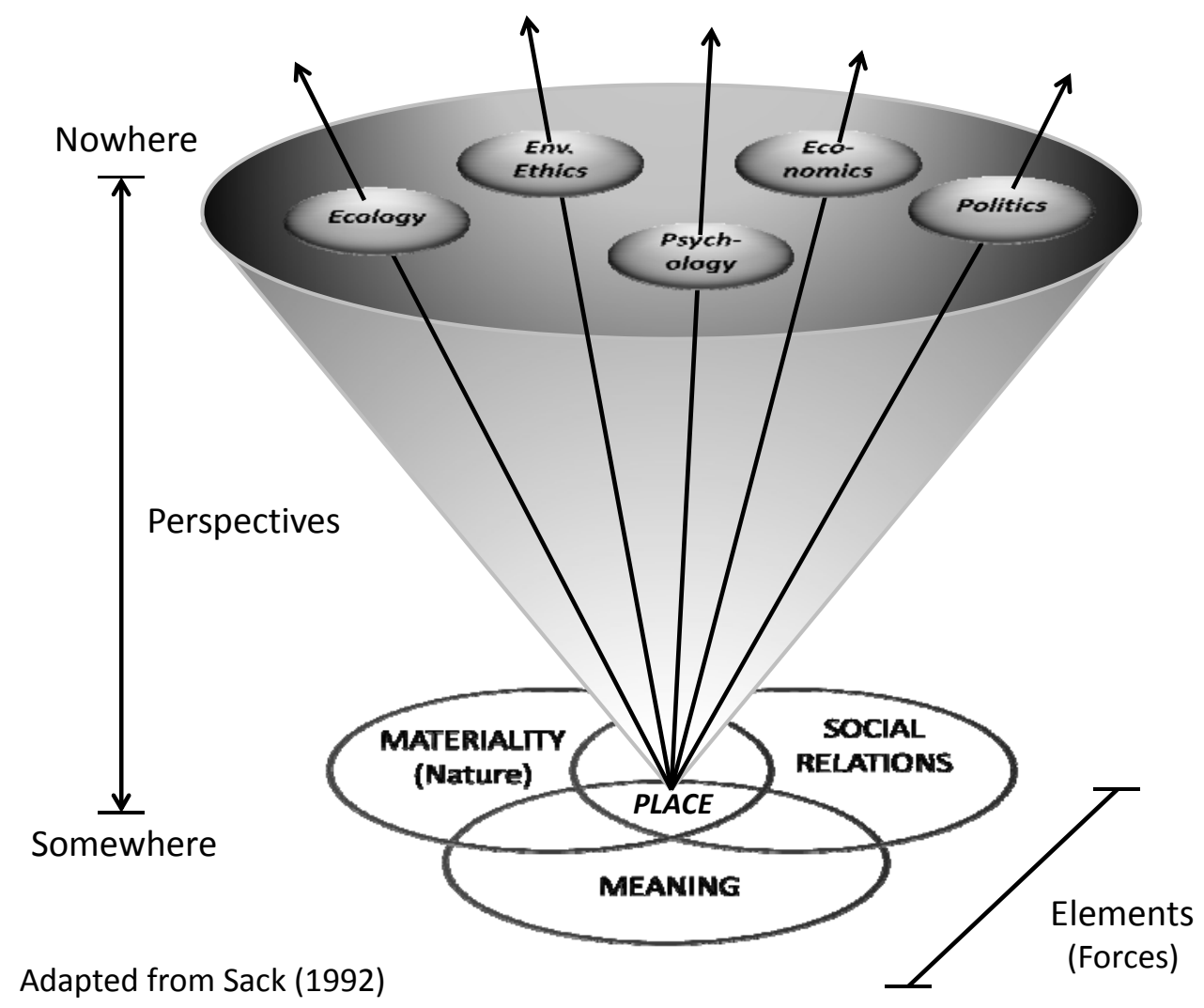

Figure 1. The Role of Place in Creating Knowledge 


\section{References}

Agnew, J. A., \& Duncan, J. S. (1989). Introduction. In J. A. Agnew \& J. S. Duncan (Eds.), The power of place: Bringing together geographical and sociological imaginations (pp. 1-8). Boston, MA: Unwin Hyman.

Ansell, C. \& Gash, A. (2007). Collaborative governance in theory and practice. Journal of Public Administration Research and Practice, 18, 543-571.

Beatley, T., \& Manning, K. (1997). The ecology of place: Planning for environment, ecology and community. Washington, DC: Island Press.

Billick, I. \& Price, M. (2010). The ecology of place: Contributions of place-based research to ecological understanding. Chicago, IL: University of Chicago Press.

Brown, T. C., Bergstrom, J. C., \& Loomis, J. B. (2007). Defining, valuing, and providing ecosystem goods and services. Natural Resources Journal, 47, 329-376.

Casey, E. S. (1998). The fate of place: A philosophical history. Berkeley, CA: University of California Press.

Cheng, A. S., Kruger, L. E., \& Daniels, S. E. (2003). "Place" as an integrating concept in natural resource politics: Propositions for a social science research agenda. Society and Natural Resources, 16(2), 87-104.

Cresswell, T. (2004). Place: A short introduction. Oxford, UK: Blackwell.

Cross, J. E. (2001). What is sense of place? Paper presented at the 12th Headwater's Conference (Nov 2-4), Gunnison, CO: Western State College

Culhane, P. (1981). Public lands politics: Interest group influence on the Forest Service and the Bureau of Land Management. Baltimore, MD: Resources for the Future.

Dana, S. \& Fairfax, S. (1980). Forest and range policy: Its development in the United States. New York, NY: McGraw-Hill.

Entrikin, J. N. (1991). The betweenness of place: Towards a geography of modernity. Baltimore, MD: Johns Hopkins.

Farnum, J., Hall, T., \& Kruger, L. (2005). Sense of Place in Natural Resources Recreation and Tourism: An evaluation and assessment of research findings (PNW-GTR-660). Portland, OR: USDA Forest Service, Pacific Northwest Research Station.

Farnum, J. \& Kruger, L. (2008). Place-Based Planning: Innovations and applications from four western forests. Gen.Tech.Rep. PNW-GTR-741. Portland, OR: U.S. Department of Agriculture, Forest Service, Pacific Northwest Research Station. 
Finnegan, D. A. (2008). The spatial turn: Geographical approach in the history of science. Journal of the History of Biology, 41, 369-388.

Fischer, F. (2000). Citizens, experts, and the environment: The politics of local knowledge. Durham, NC: Duke University Press.

Freemuth, J. (1998). Ecosystem management and its place in the National Park System. Denver University Law Review, 74, 697-747.

Gieryn, T. F. (2000). A space for place in sociology. Annual Review of Sociology, 26, 463-496.

Grumbine, R. E. (1992). Ghost bears: Exploring the biodiversity crisis. Washington, DC: Island Press.

Hall, T., Farnum, J., Slider, T., \& Ludlow, K. (2009). New Approaches to Forest Planning: Inventorying and Mapping Place Values in the Pacific Northwest Region (PNW-RN-562). Portland, OR: USDA Forest Service, Pacific Northwest Research Station.

Hayles, N. K. (1995). Searching for common ground. In M. E. Soule \& G. Lease (Eds.), Reinventing nature? Response to postmodern deconstruction (pp. 47-63). Washington, DC: Island Press.

Hays, S. (1999). Conservation and the gospel of efficiency: The progressive conservation movement, 1890-1920. Pittsburgh, PA: University of Pittsburgh Press.

Healey, P. (1997). Collaborative planning: Shaping places in fragmented societies. Vancouver, BC: University of British Columbia Press.

Hein, L., van Koppen, K., de Groot, R. S., \& van Ierland, E. C. (2006). Spatial scales, stakeholders and the valuation of ecosystem services. Ecological Economics, 57, 209-228.

Kruger, L. E., Hall, T. E., \& Stiefel, M. C. (Eds.) (2008), Understanding concepts of place in recreation and management (PNW-GTR-744). Portland, OR: USDA Forest Service, Pacific Northwest Research Station.

Kruger, L. E., \& Jakes, P. J. (2003). The importance of place: Advances in science and application. Forest Science, 49(6), 819-821.

Kruger, L. E., \& Shannon, M. A. (2000). Getting to know ourselves and our places through participation in civic social assessment. Society and Natural Resources, 13, 461-478.

Kruger, L. E., \& Williams D. R. (2007). Place and place-based planning. In L. E. Kruger, R. Mazza, \& K. Lawrence (Eds.), Proceedings: National workshop on recreation research management (USDA Forest Service PNW-GTR-698, pp. 83-88). Portland, OR: Pacific Northwest Research Station.

Kunstler, J., H. (1993). The geography of nowhere: The rise and decline of America's man-made landscapes. New York: Simon and Schuster. 
Larsen, G., et al. (1990). Synthesis of the Critique of Land Management Planning. Washington, DC: USDA Forest Service.

Leahy, J.E. and Anderson, D.H. 2010. “Cooperation gets it done”: Social capital in natural resource management along the Kaskaskia River. Society and Natural Resources, 23(3), 224-229.

Lippard, L. R. (1997). The Lure of the Local: Sense of place in a multicentered society. New York: New Press.

Mason, R. J. (2008). Collaborative Land Use Management: The quieter revolution in placebased planning. Lanham, MD: Rowen \& Littlefield.

Massey, D. (2005). For space. Thousand Oaks, CA: Sage.

Masuda, J. R., \& Garvin, T. (2008). Whose heartland? The politics of place in a rural-urban interface. Journal of Rural Studies, 24, 112-123.

McGinnis, M. V., House, F., \& Jordan, W., III. (1999). Bioregional restoration: Re-establishing an ecology of shared identity. In. M. V. McGinnis (Ed.), Bioregionalism (pp. 205-222) London: Routledge.

Nagel, T. (1986). The View from Nowhere. New York: Oxford University Press.

Nash, R. (2001). Wilderness and the American Mind, Fourth Edition. New Haven, CT: Yale University Press.

Nie, M. (2003). Drivers of natural resource-based political conflict. Policy Sciences, 36, 3/4, 307-341.

Nie, M., \& Fiebig, M. (2010). Managing the national forests through place-based legislation. Ecology Law Quarterly, 37, 1-52.

Priscoli, J. \& Wolf, D. (2009). Managing and Transforming Water Conflicts. NY: Cambridge University Press.

Robertson, F. D. (1992). Ecosystem management of the national forests and grasslands (Policy letter 1220-1 June 4). Washington, DC: USDA Forest Service.

Rolston, H., III., \& J. Coufal, J. (1991). A forest ethic and multivalue forest management. Journal of Forestry, 89(4), 35-40.

Sack, R. D. (1992). Place, Modernity, and the Consumer's World. Baltimore, MD: Johns Hopkins University Press.

Sarewitz, D. (2004). How science makes environmental controversies worse. Environmental Science and Policy, 7, 385-403.

Salwasser, H. (1990). Gaining perspective: Forestry for the future. Journal of Forestry, 88(11), 35-38. 
Schmidt, J. (1998). Civility, enlightenment, and society: Conceptual confusions and Kantian remedies. American Political Science Review, 92, 419-427.

Schneider, D. C. (2001). The rise of the concept of scale in ecology. BioScience, 51, 545-553.

Sheppard, E. (2002). The spaces and times of globalization: Place, scale, networks, and positionality. Economic Geography, 78, 307-330.

Spretnak, C. (1997). The Resurgence of the Real: Body, nature, and place in a hypermodern world. Reading, MA: Addison-Wesley Publishing Company.

Tuan, Y. F. (1974). Topophilia: A study of environmental perception, attitudes, and values. Englewood Cliffs, NJ: Prentice-Hall.

Twight, B. (1983). Organizational Values and Political Power: The Forest Service versus the Olympic National Park. State College, PA: Pennsylvania State University Press.

Williams, B. A., \& Metheny, A. R. (1995). Democracy, dialogue, and environmental disputes: The contested languages of social regulation. New Haven, CT: Yale University Press.

Williams, D. R. (2008). Pluralities of place: A user's guide to place concepts, theories, and philosophies in natural resource management. In L. Kruger, T. E. Hall, \& M. C. Stiefel (Eds.), Understanding concepts of place in recreation and management (PNW-GTR-744, pp. 7-30). Portland, OR: USDA Forest Service, Pacific Northwest Research Station.

Williams, D. R. (2002a). Post-utilitarian forestry: What's place got to do with it? In Proceedings of the Human Dimensions of Natural Resources in the West Conference (Alta, WY, October 18-21, pp. 114-123). Fort Collins, CO: Colorado State University, College of Natural Resources.

Williams, D. R. (2002b). The social construction of Arctic wilderness: Place meanings, value pluralism, and globalization. In A. Watson, L. Alessa, \& J. Sproull (Compilers), Wilderness in the circumpolar north: Searching for compatibility in traditional, ecotourism and ecological values (Anchorage, AK, May 15-16, 2001, USDA, Forest Service, Proc. RMRSP-26, pp. 120-132). Ogden, UT: Rocky Mountain Research Station.

Williams, D. R., \& Patterson, M. E. (1996). Environmental meaning and ecosystem management: Perspectives from environmental psychology and human geography. Society and Natural Resources, 9(5), 507-521.

Williams, D. R., \& Patterson, M. E. (1999). Environmental psychology: Mapping landscape meanings for ecosystem management. In H. K. Cordell \& J. C. Bergstrom (Eds.), Integrating social sciences and ecosystem management: Human dimensions in assessment, policy and management (pp. 141-160). Champaign, IL: Sagamore Press.

Williams, D. R., Patterson, M. E., Roggenbuck, J. W., \& Watson, A. E. (1992). Beyond the commodity metaphor: Examining emotional and symbolic attachment to place. Leisure Sciences, 14, 29-46. 
Williams, D. R., \& Stewart, S. I. (1998). Sense of place: An elusive concept that is finding a home in ecosystem management. Journal of Forestry, 96(5), 18-23.

Williams, D. R., \&Van Patten, S. R. (2006). Home and away? Creating identities and sustaining places in a multicentered world. In N. McIntyre, D. R. Williams, \& K. E. McHugh, K. (Eds.), Multiple dwelling and tourism: Negotiating place, home and identity (pp. 32-50). Cambridge, MA: CABI Publishing.

Williams, D. R., \& Vaske, J. J. (2003). The measurement of place attachment: Validity and generalizability of a psychometric approach. Forest Science, 49(6), 830-840.

Williams, D. R., \& Watson, A. E. (2007). Wilderness values: Perspectives from non-economic social science. In A. Watson, J. Sproull, \& L. Dean (Eds.), Science and stewardship to protect and sustain wilderness values: Eighth World Wilderness Congress symposium (Anchorage, AK, September 30-October 6, USDA Forest Service RMRS-P-49, pp. 123133). Fort Collins, CO: Rocky Mountain Research Station.

Wulfhorst, J. D., Rimbey, N., \& Darden, T. (2003). Sharing the rangelands, competing for sense of place. American Behavioral Scientist, 50, 166-186.

Wright, D. J., \& Scholz, A. (Ed.) (2005). Place matters: Geospatial tool for marine science, conservation and management in the Pacific Northwest. Corvallis, OR: Oregon State University Press.

Yaffee, S. (1994).The Wisdom of the Spotted Owl: Policy lessons for a new century. Covelo, CA: Island Press.

Young, I. M. (1996). Communication and the other: Beyond deliberative democracy. In S. Benhabib (Ed.), Democracy and difference: Contesting the boundaries of the political (pp. 121-135). Princeton, NJ: Princeton University Press.

Yung, L., Freimund, W. A., \& Belsky, J. M. (2003). The politics of place: Understanding meaning, common ground, and political difference on the Rocky Mountain Front. Forest Science, 49(6), 853-866.

Zimmerer, K. S. (Ed.). (2006). Globalization and the new geographies of conservation. Chicago, IL: University of Chicago Press. 


\section{Part One: Conceptual Issues in Place-Based Conservation}

This introductory section includes four chapters to orient readers and introduce concepts related to place-based practice. The chapters converge on the idea that place-based practice in environmental and natural resource management involves a fundamental rethinking of its institutional context. Collectively the chapters develop several critiques of traditional land-use practice, and each adapts the concept of place as holding promise to address the problems. The critiques cover an array of well-known problems including science as an institutional practice, barriers to collaboration across multiple jurisdictions and geographic scales, idiosyncrasies of institutional cultures, and the complexity of legal structures that guide organizations involved in practice. Across the chapters place constitutes a converging inter-organizational venue for considering the combined roles and practices that diverse actors (e.g., visitors, residents, experts, agencies, institutions, non-governmental organizations, and political jurisdictions) play in shaping a locale. Each paper highlights the imperative to develop new models of governing in shared spaces.

One of the key ideas motivating place-based practice has been the emergence of complexity theory as a conceptual framework for the management of dynamic social-ecological systems. In "Science, practice and place," Daniel Williams notes that science fails to simplify natural resource practice because it informs problems with an integrated, context (place) independent view of knowledge. Williams argues that place helps scientists and managers address the plural and uncertain character of knowledge. Drawing on place as a knowledge framework, place-based practice is conceived as the collective wisdom of networked actors and institutions governing complex systems, each informing one another in a collaborative form of 
rationality that operates both horizontally (place to place) and vertically (upwards and downwards in geographic scale).

Place-based practice has emergent qualities that invite creativity in the governance of landscapes across multiple scales. Illustrating this creativity in institutional planning, Courtney Flint's chapter "Decision-making to connect multiple scales of place" positions place as a way to explore networks and interactions across multiple scales of governance. Recognizing that many rural communities are challenged to assert their influence on regional land-use practice, Flint provides argument and evidence of changing place-based practice to forge new multi-scalar relationships that engage various levels of governance and results in new structures for decisionmaking. These structures are dynamic and flexible depending on relationships between institutional learning, social networks, and landscape disturbances.

For many reasons practitioners have realized the need to deviate from rational models of decision-making to explore other pathways, and include other kinds of information, in their planning processes. In her chapter "Organizational cultures and place in resource planning and management," Patricia Stokowski discusses the relationships between agency culture and surrounding society, highlighting the ways that institutional behavior is explained by this interaction. She explains that land-use planning processes have unique histories of discourses as part of the competing interaction between agency staff and community. She argues for focusing on the discursive practices of agencies and other organizations as participants in place-making.

In "Community, place, and decision-making," Gene Theodori and Gerard Kyle examine the concept of community as a key, but often poorly understood venue in decision-making. They argue that community subsumes much of what constitutes place - as a material locale imbued with history and meaning - but which can be differentiated from place by the critical additional 
ingredient of group solidarity and shared identity of community members. Their analysis of community-based natural resource management suggests that place-based planning should be strongly influenced by factors of community so conceived.

These introductory chapters provide a broad picture of the rationale for place-based practice. They each portray a significant problem that traditional planning models are not equipped to address. The point of these chapters is not to get dismayed by the critique, but to understand place-based practice as capable of addressing the critiques. Because place concepts highlight diverse kinds of knowledge, multiple geographic scales, and peculiarities across institutional cultures and legal jurisdictions, the introductory chapters converge on place as a response to the critique of traditional models, and collectively suggest a combined framework to fit the remaining chapters of the book. 


\title{
Science, Practice and Place
}

\author{
Daniel Williams
}

\section{Bridging the Science-Practice Gap}

In my role as a research social scientist employed by a public land management agency I regularly participate in meetings of experts gathered together with the goal of narrowing the science-practice gap. Typical sessions have dealt with a range of practice domains from managing endangered fisheries, to constructing future scenarios for fire and fuels management, to designing regional approaches to managing high elevation wilderness trails. Practical differences aside, these efforts appear to have common institutional underpinnings when viewed from a social science perspective. In this chapter I will argue the science-practice gap persists and even widens over time, not out of some lack of commitment or failure to communicate on the part of scientists and practitioners. Instead the problem reflects fundamental differences between the nature of science, which seeks to transcend place, and the nature of practice, which is by necessity place-based. In other words, it is impossible to close the gap between science and practice because the former seeks context (place) independent principles whereas the latter requires context dependent synthesis.

As one case example I participated in meeting to discuss how to bridge the sciencepractice gap concerning fire effects on endangered fisheries. The meeting brought together scientists from several federal agencies to respond to managers needs for better information to help them make decisions about managing wildfire in riparian areas, especially when such fires threaten endangered fish species. In keeping with complexity theory in ecology, much was made of dynamic landscape processes and identifying criteria for defining a resilient landscape. The 
research ecologists pointed out ever greater complexity of the phenomenon (patchy, multiscaled, dynamic landscapes) in which the right prescription for any one stream network was elusive if not indeterminate. According to these ecologists no singular riparian condition could be described as necessarily better or healthier than another because the viability of endangered fish populations actually hinged on a dynamic spatial variety in which some patches (streams) were in the process of becoming better habitat for a given species and some worse habitat. Adding to the complexity and uncertainty for management prescriptions, one could arrive at very contradictory recommendations depending on one's disciplinary focus. For example, because stream culverts are impediments to the adaptive dynamics sought by systems ecologists (culverts being iconic stand-ins for everything that disrupts the movement of fish populations through a system of branching streams), removing them would increase the connectivity of streams (ostensibly a good thing for the survival of threatened and endangered species). But if a manager happens to be more worried about the spread of invasive aquatic species, removing culverts also makes it easier for such species to spread (ostensibly a bad thing).

Instead of clarifying best management practices, new science often leaves managers more confused about best practice. Best practice in any given situation is often contingent on conditions and actions in adjacent landscapes as well as interactions at both high and lower scales of decision making. In managing complex systems, the broader challenge then is figuring out how each manager, acting on his or her best understanding of a particular part of the system is most able to take into account the knowledge and past and present actions of other managers who themselves take similar partially informed actions.

This science-practice conundrum originates in part from the assumption that scientific understanding produces an increasingly definitive and integrated body of knowledge. But 
contrary to widely accepted views of science, which build on the assumption of an ability to achieve a "gods-eye" (objective and integrated) grasp of the world, every scientist occupies a somewhat unique (subjective) position or place within the world by virtue of culture, history, training, and personal experience that limits and conditions that scientist's knowledge of it. Likewise in the real world of action where citizens and practitioners are embedded, knowledge is always partial and incomplete and likely over time to grow more fragmented than integrated. Put another way:

[Even] after the best of scientific studies a judgment must be made about the relevance of a piece of scientific research to a manager's ... practical question at hand. In this judgment science is not at all helpful ... [H]ow to integrate the kind of knowledge that science can give with the practical judgment about what the [managerial] situation requires [remains one of the] great unresolved questions (Hummel, 1994, p. 314).

To address this "great unresolved question" requires an exploration of the realm of practice. My intention here is to begin such an exploration by examining how place concepts illuminate the challenges we face in trying to bridge the gap between science and practice. This paper will argue that place-oriented inquiry and practice are the keys to overcoming the ever present if not ever expanding science-practice gap. I hope to show that place can better frame the problem and help managers and scientists appreciate the inevitably plural and partial (incomplete and uncertain) character of all knowledge. In addition, I will suggest what I hope are more productive ways forward that not only embrace this pluralism and partiality but find greater efficacy and advantage in the fact that all practitioners are differently positioned to perceive and act on the world (i.e., context dependency). Thus, rather than trying to inform all problems with 
an integrated top-down view of knowledge, informed action can be conceived as guided by the collective wisdom of networked actors and institutions governing complex systems, each informing one another in a collaborative form of rationality that operates both horizontally (place to place) and vertically (upwards and downwards in scale).

\section{Why Science Fails to Simply Practice}

The idea that science can perfect environmental decision making is still largely taken for granted in the professional cultures and institutions of environmental management. Among social scientists, however, it has received considerable scrutiny (Allen et al., 2001; Flyvbjerg, 2001; Sarewitz, 2004). Drawing from anthropology and ecology, for example, Tainter and colleagues (Allen et al., 2001; Tainter 1988) point to social/institutional limits on managing complex systems by examining how complexity has contributed to the collapse of civilizations in the past. In particular, Tainter (1988) details the history of collapse to develop the argument that the evolution of a complex social-ecological system (i.e., a given society and its resource base) tends over time to outstrip that society's own institutional capacity to manage such systems. As a society grows and matures the cost-to-benefit ratio of problem solving escalates because the solutions to new and emerging problems always come at a higher cost or require proportionally more inputs than the problems already solved. Because human societies tend to apply the easiest (cheapest) solutions first, over time problem solving becomes progressively more costly (that is we experience a diminishing return on problem solving - sometimes to the point of collapse or a deliberate adoption of simplification). While society can subsidize the management of complexity to some degree using energy or technology, the situation still leaves the practitioner with the cognitive challenge of complexity (e.g., the need to synthesize and integrate the exponential growth of knowledge at multiple scales). 
Drawing from contemporary political science, Sarewitz (2004) argues that science makes environmental controversies worse for three reasons. First, science supplies contesting parties with their own bodies of relevant and legitimate facts (a problem only compounded by the universal access to information and data via the internet). Second, the necessity of looking at nature through a variety of disciplinary lenses also brings with it a variety of normative-ethical lenses. Third, scientific uncertainty persists and grows, not for a lack of increasing scientific understanding, but for a lack of coherence among competing scientific understandings amplified by the various political, cultural, and institutional contexts within which the science is carried out. In sum, social analysis of the science-practitioner nexus suggests that knowledge complexity decreases institutional efficiency, increases scientific uncertainty, and amplifies policy conflict.

\section{Place and Pluralism}

The persistent if not widening gap between science and practice cannot be solved by calls for more science, better science, or more focused science. Nor can it be solved by simply finding more effective ways to communicate and deliver new science to practice. More fundamentally, continuing to address the gap from an exclusively context independent, top-down, unidirectional, from-science-to-practice mindset exacerbates the problem. In this hierarchically dominated model, knowledge will always expand much faster than our individual and collective capacities to absorb, process, and apply it to particular situations and circumstances. But knowledge need not be conceived as a collection of ideas, facts, and values waiting to be integrated into some grand unifying model that presumably any manager could easily and effectively apply. What might we gain by conceiving the structure of knowledge not in context-independent disciplinary terms but in context dependent spatial-ecological terms, as embedded in and distributed across 
places and the people who occupy and interact with those places, organized not by discipline or algorithms but by relational geography? What leverage on this problem might be gained by viewing knowledge as something produced and articulated in a network of embedded, partially informed practitioners organized within both vertical and horizontal planes of relationships?

Two key features of such a spatial/relational view of knowledge are the irreducible pluralism of knowledge (contra the unity of all knowledge) and the subjective positionality (contra "gods-eye" objectivism) of observer-actors embedded in both vertical and horizontal relations to the world. While these ideas challenge the naturalistic (positivist) epistemology common in most ecological science in favor of some form of constructivist epistemology (see Allen et al., 2001; Hayles, 1995), they also regard knowledge as ecologically relational (situational and relative) to where one is positioned within a social-ecological field. Accordingly, all observers or actors have only a partial (incomplete) understanding owing to their ultimately unique positioning within spatial-temporal reality. This unique positioning also means that there is no unified position from which all knowledge can be integrated into a single understanding: hence there will always be multiple competing understandings of the world. Rather than view plurality as a failure, grasping the world from multiple, competing vantage points enriches each perspective and reveals assumptions that may have otherwise remained hidden especially to those who occupy the dominant roles (Hayles, 1995).

Geography and spatial studies highlight three varieties of knowledge pluralism. The typical way in which pluralism is recognized and studied involves an ontological focus on place (Patterson \& Williams, 2005). In most discussions, place is typically conceived as a location or container of material and ideational relationships to the world, that is, a socially constructed site that organizes and constitutes human material and social relationships and meaning. Ontological 
pluralism is strongly associated with cultural differences and competing systems of meaning across groups of stakeholders and domains of expertise. It represents the pluralism in the nature of what exists; that is, the contents of reality and, per place, where those contests are located. We often experience it as the different meanings, uses, and values people hold for a place and it is often discussed in terms of competing "senses of a place" held by various groups of stakeholders (Williams, 2002).

Whereas research on place is typically occupied with ontological descriptions, some philosophers and geographers have drawn on place and spatiality to advance an epistemic perspective on knowledge - place as a way of seeing and thinking about the world (Entrikin, 1991; Sack, 1992). Place facilitates multiple perspectives or ways of knowing that highlight multiple, differently disciplined context independent (objective, scientific) and context dependent (subjective, local) lenses or positions through which knowledge may be generated. Such epistemological perspectives are proposed to help transcend what geographers regard as a deep and long-running tension within Western intellectual traditions between universalist (context independent) and particularist (context dependent) views of knowledge (See also Fischer, 2000; Flyvbjerg, 2001; Williams, 2002). As Sack (1992, p. 1) has argued, place is more than mere setting or container of reality. It is integral to how human beings experience and organize their world, a "fundamental means through which we make sense of the world and through which we act." Likewise for Hayles (1995) our positioned, embodied, human-situated interaction with the world conditions how we can understand of the world.

The geographic discourse on place and spatiality highlight this tension and provide some insights into how natural resource management might address it. Specifically, place helps to tackle the growing disciplinary fragmentation of knowledge, bridge the epistemological divide 
between local/contextual knowledge and global/generalizable knowledge, and validate and organize knowledge originating in a bottom up synthesis of networks of actors. The knowledge and wisdom required to manage complex social-ecological systems is not likely to emerge out of top-down expert driven knowledge systems (which become too unwieldy and expensive) but through the combined and less formally coordinated efforts of more embedded practitioners (managers) learning though their own local efforts. In other words the future of practice and problems solving is more likely to be organized and directed from what Entrikin (1991) refers to as the epistemological position of betweenness - informed by top-down scientific discourse but also invigorated through bottom-up engagement in which practitioners play a more prominent role in the production and validation of knowledge.

The third variety of pluralism is axiological. Axiological pluralism focuses on various normative lenses or prescriptive statements and valuations about place. It seeks to recognize the diverse social processes for prescribing particular valuations, preferences, and choices. These may range from the technical lenses of economics and decision science, to legal-political systems and institutions, to moral-ethical systems embedded in culture, religion, and moral philosophy. Axiological pluralism contrasts particularly with monistic theories of value (See Norton, 1996) that dominate the fields of economics and rational choice theory in political science. Accordingly all goods are assumed to be commensurable on a single value dimension such as utility or money. Within natural resource management the monistic approach reached its zenith with operations research thinking in which experts would identify the "outcomes" of plan alternatives, economists would measure their values, and analysts would calculate the best, most efficient alternative. In contrast various pluralist theories of value have been proposed (Anderson, 1993; Price, 2004) to highlight the incommensurability of values. Reconciling the plurality of values 
for places cannot be reduced to a singular metric as in economics, it requires reconciling a plurality of social processes and institutional arrangements by which society orders, evaluates, and decides about their relative production, maintenance, and distribution.

The interaction of the three dimensions (ontological, the epistemological, and the axiological) contribute to pluralism with each dimension. For example, the Enlightenmentinspired pursuit of universal, context independent knowledge has constrained the ontological meanings and values of nature to the tangible utilitarian realm, epistemologically narrowed what counts as legitimate means to knowledge, and marginalized the context dependent knowledge of place and the particular (Entrikin, 1991). This same impulse for context independent knowledge has also constrained the methods for adjudicating among competing values and preferences in natural resource policy and management (Williams, 2002). For practice the core challenge is to recognize the diverse ways in which a community or society orders or chooses among alternative courses of action and learns how to negotiate within and across these different kinds of pluralism. In other words, practice requires social institutions that can recognize and negotiate among pluralistic conceptions of the good and the political and pragmatic task of adjudicating among competing representations of a place produced as a result of ontological and epistemological pluralism.

Place is important for understanding the persistence of the science-practice gap and the irreconcilable ubiquity of knowledge pluralism. When dealing with complex social-ecological systems all attempts to close the gap and overcome plurality and uncertainty ultimately rely on being able to attain a universal, context independent, gods-eye view of reality. Alternatively, adopting a spatial or place-based perspective helps to recognize that all knowledge - even exalted scientific knowledge - is to a significant degree local or context dependent because all 
observers and actors - by virtue of their biography and geography - occupy a particular, delimited position from which to observe the world. Still, our diverse pluralistic culture must somehow manage to co-exit in shared spaces despite our unrelenting differences (Healey, 1997; Kemmis, 1990). Pluralism operates in the realm of practice by recognizing and profiting from different kinds of knowledge and skills. Natural resource practice requires the cultivation of the capacity, habit, or knack for collective sense-making that moves beyond the mere application of science and technical know-how. In other words, it is through real world practice, embedded in actual places that knowledge pluralism and value differences are ultimately reconciled.

The point here is not to argue against investing in science, only that it is unreasonable to expect those investments alone to deliver efficient and effective solutions to complex problems. At the very least we need to recognize that those who are engaged in practice cannot be expected to absorb all the latest, often conflicting, science that might apply to their practice. Rather what is being argued here is that we need to develop strategies for using and accessing the accumulated wisdom of the practitioners themselves as they go about their work and help them to harmonize their local efforts across adjacent spaces and at different spatial scales. Addressing the sciencepractice gap requires a rethinking of how practical knowledge is produced and applied. This rethinking needs to happen on two levels. At one level we need to address how individual practitioners learn and interact. At another level it involves a shift in how we conceive the tasks of management and governance writ large.

\section{Place and Practice}

Given chronic system complexity and ambiguity (plurality) and limited institutional and cognitive capacities to process ever grander, yet stubbornly thin models of reality, one strategy for addressing the science-practice gap is to elevate practice as a form of knowledge production 
and management. Place and spatiality facilitate such an elevation by highlighting different ways of knowing and acting that emphasize "knowledge nested in a context of time and local circumstance" (Fisher, 2000, p. 69). A number of social scientists (Fisher, 2000; Flyvbjerg, 2001; Scott, 1998) have focused on a kind of epistemic pluralism that can be found in the Aristotelian intellectual virtues of epiteme (abstract scientific knowledge), techne (the kind of technical knowledge found in a craft), and (depending on the author) phronesis or mētis (prudent, practical wisdom). These authors make the case that we could do more to integrate and profit from the practical and informal knowledge that exists among both occupants/users of places and emplaced professional practitioners.

Scott (1998) characterizes local, practical knowledge as the lost art of mêtis - local, experiential knowledge that resists simplification into the kind of deductive principles that can be readily transferred through book learning - which has been systematically replaced by stateinspired projects of rational management. Scott documents numerous examples of "natural and social failures of thin, formulaic simplifications" imposed on society through the agency of state power (his first case example deals with the failures of utilitarian logic that inspired monocropped, even-aged forestry in early modern Europe). He notes that large scale processes and events are inevitably far more complex than any models we can devise to map them. What these schemes "ignore - and often suppress - are precisely the practical skills that underwrite any complex activity ... variously called know-how ... common sense, experience, a knack or mētis" (p. 311). Rather than a dialogue existing between practical knowledge and formal scientific knowledge, he argues that the state has sought hegemony over the former as a form of social control. 
A good example of this distinction has to do with the application of fire science. One of the most exalted topics in fire science is fire behavior modeling, which is intended to help fire fighters anticipate how a wildfire will spread. But as one highly experienced fire manager once explained, he would never rely on such models, which he saw as over-simplified and exceedingly poor at factoring in local topography and meteorology. He would much rather rely on his years of experience fighting wildfires in his district as well as the experience he brought from many years on the fire line in different settings.

A line of reasoning similar to Scott is offered by Flyvbjerg $(2001,2006)$. But whereas Scott examines "how certain [state inspired] schemes to improve the human condition have failed," Flybjerg directs his gaze more generally at "why social inquiry fails" and "how it can succeed again." Flybjerg (2001) builds his argument by comparing Aristotle's term phronesis (practical wisdom) to episteme and techne. Whereas episteme refers to knowledge that is abstract and universal and techne describes the know-how associated with practicing a craft, Flyvbjerg seeks to resurrect the idea of phronesis as the domain of the social sciences in sharp contrast to the natural science model rooted in episteme and techne. Flyvbjerg employs Aristotle's phronesis to highlight the comparative advantages of practical wisdom that comes from "an intimate familiarity with the contingences and uncertainties of various forms of social practice embedded in complex social settings" (Caterino \& Schram, 2006, p. 9). Phronesis concerns the kinds of value judgments and decisions that are "so commonly involved in political and administrative practices that any attempts to reduce them [to episteme or techne] or comprehend them in those terms are misguided" (Flyvbjerg, 2006, p. 68). According to Flyvbjerg, phronesis was deemed most important to Aristotle because it balances instrumental rationality with value-rationality, a balance Aristotle deemed crucial to the sustained happiness of citizens in any society. Yet it is 
that very balance that has been upset by the dominance of instrumental rationalities behind episteme and techne as evidenced in part by the fact that modern languages no longer have a word containing a variant of phronesis.

In comparing Scott's use of mètis to Flyvbjerg's phronesis, mētis appears closer to the idea of local knowledge or wisdom. It is not as refined and systematized as techne (which by Scott's reckoning is more universal, organized, and ultimately expressible in the form of rules, principles, and propositions), but rooted in a history of local problem solving. For Flyvbjerg, phronesis is tied more closely to political/administrative skills involved in reasoning about values, the good life, and the exercise of power. Both emphasize emplaced knowledge and stand in contrast to the "god's-eye" view from nowhere or what Scott calls "thin simplifications" that "can never generate a functioning community, city or economy" (p 310). Both kinds of knowledge exist among practitioners and can be cultivated within organizations and institutions.

A key argument of Flyvbjerg is that social science (and I would add practice) should not seek to emulate natural science by trying to build predictive models, but instead focus on casestudy knowledge, which typically reveals a kind of practical wisdom emphasizing value rationality and power rather than the maximization of specific outcomes or objectives (typically prescribed from above). This kind of practical wisdom is difficult to organize from above. Rather it emerges from and is refined and validated by systems of networked learners. In other words, practical wisdom is shaped and evaluated by the practitioners themselves rather than produced and transmitted via expert systems (though experts can certainly help in this effort). Finally, such a distributed, bottom up system of knowledge creation helps to counter the otherwise diminishing returns and escalating costs of traditional hierarchically directed information systems. 
Flyvbjerg makes a number of recommendations for how to practice what he calls "social science that matters," which, at its core, involves doing context dependent case study research. Aristotelian phronesis involves deep knowledge of circumstances, concrete examples, and case exemplars. This doesn't necessarily exclude generalization, but such generalizations are more often built from the examination of many particular cases. Examples of fields we might emulate are business and law, where practical knowledge is developed around learning cases and developing the judgment or wisdom for how to creatively apply cases to the situation at hand.

A second recommendation is to balance instrumental/technical rationality with what Flyvbjerg calls value rationality. The goal is to increase the capacity of individuals, organizations, and society to think and act in value rational terms. This forces researchers to face the contextual nature of problems instead of assuming some universal foundation. Validity comes from testing assumptions through the comparison of contexts (e.g., different positionality) where interpretations are built on validity claims that can be examined and deliberated. His third recommendation is to make power a core part of analyses. Who gains and who loses?

What kinds of power relations are involved? Are there possibilities to change these power relations and would it be desirable to do so? What kinds of power relations apply to those asking the questions? In other words, who governs and what governmental rationalities are at work? Such a focus is in stark contrast to our utilitarian history in natural resource management, which has avoided power questions in the vain hope that technical rationality would render them irrelevant.

Fourth, in addition to asking the usual why questions, we should ask how questions that reveal narrative: how did this situation come to be? The key idea here is that history and narrative are fundamental to social inquiry and practice. Historical narrative helps us anticipate 
situations before we encounter them. Narrative is also important in distinguishing a place-based approach from a resource orientation. Places have histories, both natural and social, whereas resources focus on utility in the present and future. The very idea of resource is to decontextualize what is there, to strip the landscape of history, and eliminate any past or preexisting meaning as a constraint on its use. In building narrative one must acknowledge the past in consideration of the future.

Finally, social science should be directed at building dialogue with diverse stakeholders. The aim of social science, according to Flyvbjerg is to provide input into the ongoing social dialogue and practice in a society, rather than producing generalized, unequivocally verified knowledge. Social science knowledge should not be privileged - it must enter into the dialogue, not take it over.

Flyvbjerg's recommendations, though intended more for individual social science researchers, could also be applied to the training and preparation of practitioners. Many professional fields from business to law, medicine, and planning employ and teach case-based knowledge. For example, clinical knowledge in a profession such as medicine is nurtured through the accumulation of experience from the careful analysis and treatment of many actual cases. Over time the practitioner is expected to learn how to diagnose and treat conditions by drawing on case-based experience. In important ways, what distinguishes the professions from the academic disciplines is their relatively greater emphasis on learning from real-world practice. Professional knowledge builds much more on inductive, situational, bottom-up learning than topdown, deductive extension of theory to practice.

Part of the challenge of such a bottom up knowledge system involves the structuring the interactions among practitioners. Professionals of one sort or another spend a great deal of time 
sharing their case knowledge. But applying this to complex social-ecological systems suggests another aspect of case-based knowledge. In such contexts, the health of the overall system depends on the combined actions of many practitioners each responsible for various parts whether divided by geography (e.g., a wilderness) or by resource (e.g., wildlife) and/or process or function (e.g., wildfire). The overall performance of a system at any scale depends on the collective actions or inactions of managers distributed across space, scales, and functions.

The solution is not likely to be found in traditional approaches to the transfer of knowledge from expert to practice, but by learning to take into account the actions and individual partial understandings of diverse practitioners distributed cross resource specialties, landscapes, and scales. By thinking about practice as emplaced knowing we can begin to recognize the practitioner as part of a network of practitioners and rethink knowledge/learning as a distributed product/process of learning that takes place within a community of practice.

As understood in the field of knowledge management, practice communities constitute groups of people who share a concern or interest in some domain of activity and learn how to do it better through regular interaction (Wenger, 1998). According to Wenger, three characteristics are crucial to distinguishing communities of practice from other kinds of communities. First, they have an identity defined by a shared domain of interest such that shared competence distinguishes members from nonmembers. Members value their collective competence and learn from each other, even if few people outside the community value or even recognize their expertise. Second, they act as a community with respect to their domain by engaging in joint activities and discussions, helping each other, and sharing information. They build relationships that enable members to learn from each other. Third, members of a community of practice develop a shared practice in something. They develop a shared repertoire of resources, 
experiences, stories, tools, and ways of addressing recurring problems. This takes time and sustained interaction.

In sum, it is at least as important to help practitioners better organize themselves as communities of practice as it is to produce the next scientific synthesis of knowledge, which by necessity will emphasize context independent knowledge. Practice communities draw from members' knowledge and experience to advance situation-specific problem solving. They might do this by requesting information from community members, seeking out people with specific experiences suited to a particular problem at hand, making site visits, documenting cases and solutions, and mapping knowledge and gaps in knowledge.

\section{Place and Governance}

Thus far I have described the science-practice gap as a knowledge problem without much regard to the institutional or governing structures within which practice is ultimately carried out. While a pluralist conception of knowledge gives greater recognition to the wisdom and experience of emplaced practitioners (and citizens), learning and operating in real places and developing context dependent knowledge also needs to be addressed at an institutional or governance level. An expanded conception of practice that nevertheless remains embedded primarily within the existing institutional structures of hierarchical governance will do little to escape the vice of complexity and uncertainty. Recognizing this, Scott (1998) concludes his work by making a case for $m \bar{e} t i s$-friendly institutional structures that emphasize plurality and diversity. He notes that in natural systems, diversity is "demonstrably more stable, more selfsufficient and less vulnerable" (p. 353). As with complex natural systems, mētis-friendly institutions benefit from diversity, redundancy, and decentralization. 
Within natural resource management many have turned to various forms of adaptive management (Stankey et al., 2005) or adaptive governance (Scholz \& Stiftel, 2005) as a placebased strategy for addressing the chronic insufficiency of knowledge in the face of complexity, uncertainty, and change of the sort faced by natural resource managers. In theory adaptive management involves multi-scalar, place-sensitive policy experimentation (and by implication more case/context sensitive knowledge). As often practiced, however, adaptive management tends to privilege formal scientific knowledge (episteme) over other forms of knowledge held by practitioners and citizens and is insufficiently adaptive in its conceptions of value (Norton, 1999). As a pragmatic approach to adjudicating among the plurality of competing management prescriptions for a place or landscape, it "pays little attention to the question of what types of institutional structures and processes are required for the approach to work on a large scale basis" (McCain \& Lee, 1996, p. 446). It also tends to be costly and time consuming, making it less attractive as a way to improve the benefit/cost ratio of problem solving. Recognizing that effective institutions for adaptive management defy standardization (Stankey et al., 2005, p. 5152), the concept of adaptive governance has been put forward to emphasize the importance of context and the value of institutional diversity in sustaining complex social-ecological systems (Folke et al., 2005).

The emerging discourse on adaptive governance coming out of ecological systems theory conveys strongly prescriptive ideals in citing such positive virtues of institutional diversity, wider public participation, and enlarged social capacity and flexibility to respond to unplanned change. A separate but less normatively disposed discourse examining how governance practices have evolved in response to global scale social complexity has also emerged in sociology (Ilcan \& Phillips, 2008; Urry, 2003) and public administration (Pierre, 2000; Pierre \& Peters, 2005; 
Rhodes, 1997). First and foremost, governance is distinguished from government. The traditional notion of government is "state-centric" and addresses how government institutions "steer" society and the economy. Governance tends to be associated with a "society-centric" examination of the co-ordination and self-governance through networks and partnerships. What was previously thought of as the indisputable role of government is increasingly seen as the province of various societal institutions (Pierre, 2000). Accordingly, much of contemporary governance takes place outside formal government institutions and bureaucracies and involves increasingly complex linkages and collaborations among multiple public and private organizations (see also Flint this volume). The governance of complex systems emphasizes the need to reconcile traditional top-down hierarchical public administration built on vertical lines of authority with emerging complex, social networks of actors, stakeholders, and governmental and nongovernmental organizations interconnected by horizontal lines of interaction. These perspectives contrast with Progressive era institutions of governance that are not as well suited to the administration of modern social-ecological systems marked by dynamic, multi-scaled complexity.

Traditional models of governance start with the organization as the basic building block in a system in which top officials direct management practice to accomplish program goals. This literature describes the ways in which government has increasingly come to rely on partnerships and networks to accomplish its program, at least in part, driven by increasingly complex global scale social interactions. The growth of governance by complex networks of governmental and non-governmental actors and institutions has been propelled by as sense that government has become "'overloaded,' that is, unable to resolve all the tasks and demands placed upon it by society" (Pierre, 2000, p. 4). Some have gone so far as to suggest idea that government has 
largely been replaced by "self-organizing" markets and networks of organizations and actors (Rhodes, 1997).

Such a view of governance comports well with the view of complex adaptive systems, in which pluralism and uncertainty dominate and institutional capacities struggle to keep pace with complexity. The challenge of governing in the face of excessive complexity and uncertainty can be addressed, particularly at a local scale, when self-organizing networks of practitioners, institutions, organizations, NGOs, and various kinds of expertise and citizen interests come together and begin to govern the system. Flint (this volume) provides a good illustration of emergent governance regimes in her examination of mountain pine beetle problem in north central Colorado. She notes that in the context of such large scale ecological disturbance new governance relationships are being forged involving both large scale regulatory institutions at the state and federal level and locally emplaced residents, interest groups, government agencies and organizations drawing on existing and emerging networks to address place-specific issues in response to the regional beetle outbreak.

One potential downside to place-based practice is the potential for parochial interests to trump larger scale policy interests, i.e., the NIMBY (not-in-my-backyard) response to many environmental policies. Recognizing this problem, Williams and Metheny (1995) show how different models of democracy play different roles depending on scale. At larger scales traditional interest group politics provides a way to settle on the basic rules to guide more local decision making. At the local scale, context specific dialogic processes dominate because decisions begin to matter to local constituencies in ways that at a larger scale are generally obscure and remote to all but the most committed interest groups. It is only when decision 
making takes on specific, local consequences that most people are likely to recognize what is at stake.

Others argue that at the local level place provides an important basis for forming a polity (e.g., Kemmis, 1990). Whatever social differences exist regarding the management of a place, there is often at least a shared concern for that particular place. In other words, place focused deliberation promotes some degree of commonality among stakeholders to make possible and motivate political action as propinquity encourages people to "make sense together while living differently" (Healey, 1997). A key task of any area governance process is to work toward some shared, pragmatic sense of place.

\section{Conclusion}

Faced with irreducible pluralism in the knowledge and meanings of places, irreconcilable diversity in the practice and products of science, and incommensurable differences in valuation what practitioner wouldn't wish for some all-powerful analytic tool to close the gap between knowledge and practice? But framing the science-practice gap as one of access to and consolidation of knowledge in a top-down conception of expertise is a major source of the problem, as society confronts the diminishing rates of return on the cost of knowledge acquisition so conceived. Clearly, investing in science and the expansion of knowledge will always be important, but it is unreasonable to expect those investments alone to yield increasing efficiencies in solving complex problems. Those engaged in practice cannot be expected to absorb or master all the latest science that might apply to their practice. Place helps us rethink the science-practice nexus by putting more emphasis on the capacity of emplaced and experienced agents to act and learn in a networked system in which horizontal linkages are given greater emphasis. In a model of hierarchical governance, practice entails the execution of direction from 
above. In the networked, partnered, deliberative model of governance, knowledge is emergent from a network of actors, each actor possessing some partial, context dependent knowledge (rich in particulars of the situation) but less cognizant of horizontally adjacent understandings and understandings that operate at different scales.

A focus on specific places helps to ameliorate the disciplinary fragmentation of knowledge. First, it confronts the subjective positioning of scientific observers reminding us of the inherent selectivity of all representations of knowledge. Second, by helping to organize and validate knowledge originating in a bottom up synthesis of networked practitioners it reduces the epistemic tension between local/context-dependent and global/context-independent knowledge. Finally, a place perspective can help to address the capacity limits of top-down, expert driven knowledge systems by recognizing and capitalizing on the accumulated wisdom of emplaced practitioners acquiring and sharing case specific knowledge. 


\section{References}

Allen, T. F. H., Tainter, J. A., Pires, C., and Hoekstra, T. W. (2001). Dragnet ecology - "just the facts ma'am": The privilege of science in a postmodern world. BioScience, 51, 475-485.

Anderson, E. (1993). Values in ethics and economics. Cambridge, MA: Harvard University Press.

Caterino, B., \& Schram S. F. (2006). Introduction: Reframing the debate. In Schram S. F., \& Caterino, B. (eds.), Making political science matter: Debating knowledge, research and method (pp. 1-13). New York: New York University Press.

Entrikin, J. N. (1991). The betweenness of place: Towards a geography of modernity. Baltimore, MD: John Hopkins University Press.

Fisher, F. (2000). Citizens, experts and the environment: The politics of local knowledge. Durham, NC: Duke University Press.

Flyvbjerg, B. (2001). Making social science matter: Why social inquiry fails and how it can succeed again. New York: Cambridge University Press.

Flyvbjerg, B. (2006). A perestroikan straw man answers back: David Laitin and phronetic political science. In Schram S. F., \& Caterino, B. (eds.), Making political science matter: Debating knowledge, research and method (pp. 56-85). New York: New York University Press.

Folke, C., Han, T., Olsson, P., \& Norberg, J. (2005). Adaptive governance of social-ecological systems. Annual Review of Environmental Resources, 30, 441-73.

Hayles, N. K. (1995). Searching for common ground. In Soule, M. E., \& Lease, G. (eds.), Reinventing nature? Response to postmodern deconstruction (pp. 47-63). Washington, DC: Island Press.

Healey, P. (1997). Collaborative planning: Shaping places in fragmented societies. Vancouver, BC: University of British Columbia Press.

Hummel, R. P. (1994). Commentary. Public Administration Review, 54, 314.

Ilcan, S. and Phillips, L. (2008). Governing through global networks: Knowledge mobilities and participatory development. Current Sociology, 56, 711-734.

Kemmis, D. (1990). Community and the politics of place. Norman, OK: University of Oklahoma Press.

McLain, R. J., \& Lee, R. G. (1996). Adaptive management: Promises and pitfalls. Environmental Management, 20, 437-488. 
Norton, B. G. (1996). Integration or reduction: Two approaches to environmental values. In Light, A., \& Katz, E. (eds.), Environmental pragmatism (pp. 105-138). London: Routledge.

Norton, B. G. (1999). Pragmatism, adaptive management, and sustainability. Environmental Values, 8, 451-466.

Norton, B., G., \& Steinemann, A. C. (2001). Environmental values and adaptive management. Environmental Values, 10, 473-506.

Patterson, M. E., \& Williams, D. R. (2005). Maintaining research traditions on place: Diversity of thought and scientific progress. Journal of Environmental Psychology, 25, 361-380.

Pierre, J. (ed.) (2000). Debating governance: Authority, steering and democracy. New York: Oxford University Press.

Pierre, J. \& Peters, B. G. (2005). Governing complex societies. New York: Palgrave Macmillan.

Price, M. (2004). Ecology, economics, and the value of nature. In Daston, L., \& Vidal, F. (eds.), The moral authority of nature (pp. 182-204). Chicago: Chicago University Press.

Rhodes, R. A. W. (1997). Understanding governance. Philadelphia: Open University Press.

Sack, R. D. (1992). Place, modernity and the consumer's world. Baltimore, MD: Johns Hopkins University Press.

Sarewitz, D. (2004). How science makes environmental controversies worse. Environmental Science and Policy, 7, 385-403.

Scholz, J. T., \& Steiftel, B. (eds.) (2005). Adaptive governance and water conflict. Washington, DC: RFF Press.

Scott, J. C. (1998). Seeing like a state: How certain schemes to improve the human condition have failed. New Haven, CT: Yale University Press.

Stankey, G. H., Clark, R. N., \& Bormann, B. T. (2005). Adaptive management of natural resources: Theory, concepts and management institutions (General Technical Report PNW-GTR-654). Portland, OR: USDA Forest Service, Pacific Northwestern Research Station. 73p.

Tainter, J. A. (1988). Collapse of complex societies. Cambridge, UK: Cambridge University Press.

Urry, J. (2003). Global complexity. Cambridge, UK: Polity Press. 
Wenger, E. (1998). Communities of practice: Learning, meaning, and identity. Cambridge, UK: Cambridge University Press.

Williams, B. A., \& Metheny, A. R (1995). Democracy, dialogue, and environmental disputes: The contested languages of social regulation. New Haven, CT: Yale University Press.

Williams, D. R. (2002). Post-utilitarian forestry: What's place got to do with it? In Proceedings of the Human Dimensions of Natural Resources in the West Conference (Alta, WY, October 18-21, pp. 114-123). Fort Collins, CO: Colorado State University, College of Natural Resources. 


\section{Conservation that connects multiple scales of place \\ Courtney Flint}

Places are not static, bounded spots on the earth. As people carry out their everyday lives, their interactions are continually creating and changing places. People-place interactions have been well documented in the literature, particularly how interactions within places shape local identities, social organization, natural resource decision making, and the meanings of places across landscapes (Brandenburg and Carroll, 1995; Cheng, Kruger, and Daniels, 2003; Kemmis, 1990; Williams and Stewart 1998;). This chapter extends these investigations of place to consider extra-local linkages across space and scale in shaping place-oriented decision making drawing on human geography and community sociology literatures and observations of resource management governance in the context of forest disturbance in Colorado.

Staeheli (2003, p. 162) described place as the result of a "layering of activities that constantly make and remake it." Drawing on Massey's (1979) geologic metaphor, Staeheli (2003) highlighted the role of human activity over time in constructing and constituting places. Yet place is more than a mere product of human action, it is also a dynamic process. In other words, places are always "becoming" (Pred, 1984). This dynamic notion of place relies on an appreciation that decisions and actions at individual, household, neighborhood, community, regional, national, and global levels construct and shape the meanings and implications of places (Massey, 1994).

Without a doubt, global and state scale processes and pressures certainly influence the position and character of places. But places, or more importantly the people and institutions within and among places, are not merely at the mercy of larger scale processes (Castree, 2003). 
People take action to influence broader scales, particularly to deliberately shape the nature of their own place.

People acting in places are not simply marionettes whose actions and life chances are dictated by movements of the world economy and global politics. In other words, people acting in a place have a degree of 'agency' to control their destinies and those of the places they reside in. So local action cannot only react to global pressures but also act back on them (Castree 2003, p. 180).

This notion of reaching out beyond the confines of a particular place is central to understanding not only global dynamics, but regional experiences as well. Place-oriented actions and decisions often rely upon extra-local interactions which stretch spatial and organizational conceptions of place (Cox, 1998). Thus, there are multiple scales at work in shaping the character and experience of place.

In the theoretical discussion that follows, the concepts of place, scale, community and regional fields, and governance help to orient a conceptual framework for understanding extralocal place-oriented action. Thoughts are offered on how we might think about place and decision making within a regional context. An example of places engaged in regional-scale interaction and governance from the context of landscape disturbance in north central Colorado is discussed.

\section{Framing place}

As Noel Castree suggested, "Places are not what they used to be" (2003, p.165). In this statement, Castree referred to changes in how places have been conceptualized. Historically, considerable geographic attention was fixed on differentiating places from one another 
(Hartshorne, 1939). Certainly, even today, few would deny that places are unique, different, and independent in many ways (Castree, 2003; Kirby, 1989). The politics, experiences, and humanenvironment relations in Vail, Colorado are hardly the same as those in Walden, Colorado. Likewise, neither of these places are the same as two, ten, or fifty years ago ${ }^{1}$.

But despite an appreciation for uniqueness and differentiation, places are rarely conceptualized as isolated from one another and are influenced by structural processes from other scales. Indeed, appreciating the connections between places, and conceptually between place and broader scales, is essential to understanding the role of place in decision-making (Castree, 2003; Cox, 1998; Kirby, 1989). The increasing interaction and interdependence of places across landscapes suggests we need a more dynamic interpretation of place to capture the special contexts and everyday processes that shape life and interactions among people and their environments (Castree, 2003; Staeheli, 2003). As Castree (2003) suggested, people cannot put up barriers to the outside world and survive. Interconnections and linkages between places are critically important (Paasi, 2004).

To suggest that people only operate, attach, or identify with a narrow notion of place is a disempowering and oversimplified view of human activity and human-environment interactions. The concept of scale is useful for expanding an appreciation of place to match the realities of identity and action for real people.

\section{Scale as an organizing concept for connecting places}

Places don't exist in isolation, they simultaneously operate within larger spheres of activity, or scales (Howitt, 2003). Scales provide a useful way to organize connectivity from

\footnotetext{
${ }^{1}$ This example follows from Kirby (1989) who suggested that "city politics in Houston could never be confused with city politics in San Fransisco" (p. 323) and from Massey (1994) who focused on the changes in places and the conceptualization of place over time.
} 
local to global. However, scale is as much of a "troubling and even chaotic concept" (Howitt, 2003, p.138) as place (Staeheli, 2003). Though often treated as neat, discrete, bounded units or levels or as separate, concentric rings or rungs of a ladder (Howitt, 2003, p. 145), portrayals of scale as a rigid, hierarchical system are problematic. In reality, connections between places and levels of society and the environment may involve more "awkward juxtapositions and jumps" (Howitt, 2003, p. 145). In other words, interactions among multiple scales need not rely on notions of nestedness or contiguity in order for connections to occur. On a cautionary note, splitting up the world into discrete, separate parts or levels may overemphasize scale as an organizing framework and de-emphasize processes that are not scale-dependent or operate within scales (Brenner, 2001; Marston, 2000). The key to a useful conceptualization of scale is appreciating the fluidity of connections that exist between varying levels of engagement and interaction among people and between people and their environment (Brenner, 2001).

Unfortunately, disciplines often specialize in analyses at different particular scales, making integration across scales more difficult (Agnew, 1993). For example, political science typically focuses on the role of the state, psychologists tend to focus on individuals, and sociologists frequently delineate their work in terms of households or communities. Since different processes and phenomena are critical at different scales, the history of scale separation is somewhat understandable (Morse, Hall, and Kruger, 2008). However, in order to fully appreciate the interactions among processes and phenomena, the ability to transcend multiple scales is essential (Morse et al., 2008). Thus, it is all the more important for interdisciplinary work to keenly seek to understand multi-scale linkages and to eschew prioritizing one scale over all others (Swyngedouw, 2003). Further, appreciating connectivity across scales not only reduces 
uncertainty about change, but helps build capacity for holistic problem-solving and ethical inclusion of multiple interests:

(T)he scale politics of power, identity and sustainability offers dispossessed, marginalized, and disadvantaged peoples a better framework for political action across and between multiple scales (Howitt, 2003, p. 139)

How does the concept of place fit within a multi-scale perspective? Cox (1998) outlined the useful concepts of spaces of dependence and spaces of engagement for understanding the interdependence and actions of places within a broader context. Cox suggested people have dominant areas of local interest or spaces of dependence. We can think about these areas as places. Activities within these spaces of dependence shape place-based identities and everyday life. Yet, operating within narrow spaces of dependence is insufficient for the maintenance and continual shaping of places. In everyday life, people logically connect with other places and with other scales beyond their primary locality or place of residence. In order to maintain places and fulfill needs and desires, there is a need for engagement outside of narrowly conceptualized places - to larger spaces of engagement (Cox, 1998):

Local agents are participants in a much more spatially extensive set of exchange relations than those contained within the bounds of a particular place (Cox, 1998, p.4).

This broader engagement, or interaction across space, redefines places relative to others and the larger realm in which they are situated. It also stretches the notion of place as people develop affinity and meanings for broader spaces. Since places are spaces imbued with meaning, we can still think of these larger scales of interaction as places. New place-based meanings may emerge for these larger spaces - or places - of engagement. Resulting regional or larger scale 
identities may become the nexus of decision-making, in turn changing or enhancing original place-based meanings, interpretations, and actions.

It should be emphasized that this larger scale interaction by people beyond their places or spaces of dependence, while likely and common, may not always have the effect of enhancing or empowering place-based identities or meanings. While conceived largely as positive phenomena, this may not always be the case. Hall and Stern (2009) described the reluctance of a rural community in Ontario to fully engage in regional collaboration, instead seeking to maintain more direct lines of access to provincial and federal government funding. Poorer communities may not always benefit from participation in regional collaboration (Hall and Stern, 2009) as the "geometry of power" within regions may empower some localities or interests while marginalizing others (Edwards, Goodwin, Pemberton, and Woods, 2001). In their examination of rural governance in Wales, Edwards et al. (2001) found that some regional partnerships actually strengthened the position or power of the state rather than localities or communities, while others empowered local groups and community development by opening up access to resources regionally. The success or failure of regional collaboration or spaces of engagement for places is influenced by the socio-political geography within regions as vulnerabilities and capacities to benefit from regional engagement are not ubiquitous. It is useful, therefore, to think about place in the context of regional governance and decision-making.

\section{Place-oriented governance in rural regions}

The contemporary neo-liberal political context emphasizes the devolution of decisionmaking and a shift from the dominance of government, or the role of the state and directly elected officials (Painter and Goodwin, 1995), to governance, or: 
Any strategy, tactic, process, procedure, or programme for controlling, regulating, shaping, mastering, or exercising authority over others in a nation, organization or locality (Rose, 1999, p15).

This shift in decision making processes has given responsibility to lower scales - in essence, to places. This devolutionary process involves the emergence of new players and new relationships to create capacities to act in common interests. As Rose (1999) suggested, "The pattern or structure that emerges as the result of the interactions of a range of political actors - of which the state is only one" (p.16).

Johnston (1991) highlighted political actions by those with power in society - people "who use space and create places in the pursuit of their goals" (p. 68). Though the emergence of new institutions and forums for decision making at different scales sounds at first glance as an opportunity for places to assert themselves in self-determination, in places lacking capacity, it can be also be a burden (Flint and Brennan, 2006; Herbert, 2005). Particularly in rural areas, new institutional arrangements may be slow to emerge and benefits may not emerge as readily (Jones $\&$ Little, 2000). The question remains whether those without power in rural society or regions have a voice or indeed any ability to use space or create places that fit their identity and goals.

The notion of governance at the local scale and the concept of place are tightly related to the concept of community (see Theodori and Kyle chapter in this volume). Community as a concept is as contested as place (Luloff, Krannich, Theodori, Koons- Trentelman, and Williams, 2004). While many definitions of community exist, a territorial or place-based component is commonly found (Wilkinson, 1991). In an interactional interpretation of community (Flint and Luloff, 2005; Wilkinson, 1991), place plays an important, but incomplete role in the emergence of community. Community emerges through collective actions by people who share common 
interests and care about the place in which they live (Flint and Luloff, 2005; Luloff and Bridger, 2003; Wilkinson, 1991). Therefore, though place and community are not synonymous, they are strongly linked.

Place-oriented community action influences informal and formal decision-making and governance practices. The concept of a community field is helpful to understanding how people from various social interests or fields come together in the general interests of a community to take action or influence decisions about their shared place (Theodori, 2005; Wilkinson, 1991). Yet we need not isolate this field process to the scale of locality or place. Indeed, communities often come together in the general interests of a larger region to influence decision making. This process can be as the development of a regional community field (Flint, Luloff, and Theodori, 2010). There is room within a regional field concept for both generalized regional actions as well as place-oriented actions. In other words, people working together are likely to extend beyond the realms of their own spaces and places to engage others, both for broader regional interests as well as their own place-based orientations. This type of extra-local interaction is closely related to Cox’s (1998) notion of spaces of engagement.

Rural, natural resource based communities often have a legacy of dependence, powerlessness, and being subject to decisions made at higher scales. Rural places have suffered from shifting national emphasis to urban issues and sources of capital in the post-fordist economy, not to mention the preoccupation with national and international security issues (Flint and Luloff, 2005). On their own, individual rural communities may lack resources and capacities to shape and develop places on their own as they would like, or in other words, to use space to suit their collective needs and desires, much less to come together to sort out what those needs and desires might be or how to reconcile conflicting interests. But through interaction among 
places and by reaching out across landscapes and scales, they may be able to interact with others via new governance opportunities. Without meaningful dialogue, interaction, careful procedures, and acceptance of divergent interests, people and places may be powerless to influence decision making at larger scales. With interaction, however, local people may find the elements and meanings of their place that are shared with others and are worth fighting for, thus catalyzing potential for collective action and participation in the new forms of governance by operating within larger regions or spaces of engagement (Cox, 1998). The section below describes experiences in north central Colorado where interaction among people representing multiple places forged new relationships and effective forms of governance for responding to landscape disturbance.

\section{Forging New Relationships Amidst Landscape Disturbance in North Central Colorado}

In a five county region of north central Colorado ${ }^{2}$, mountain pine beetles (Dendroctonus ponderosae) are causing massive tree mortality across over 1 million acres. The outbreak continues to spread and intensify within and beyond this area. A landscape disturbance of this magnitude challenges place meanings for those who live, work, and play in and around forested areas. People interact with the changing forest environment in many ways at different levels from visitors to recreational or protected areas, permanent or second home residents in neighborhoods and communities, to interactions across broader regional landscapes (Flint, McFarlane, and Müller, 2008). There are also important links between forest-oriented communities and state and federal policies as new opportunities for and restrictions on forest management influence land use and human-environment interactions. Discussions of global

\footnotetext{
${ }^{2}$ Communities included in the study of this region are Breckenridge, Dillon, Frisco, Granby, Kremmling, Silverthorne, Steamboat Springs, Vail, and most of Jackson County. Counties are Eagle, Grand, Jackson, Routt, and Summit.
} 
climate change and impacts on forest disturbance and management strategies also show that places in Colorado also have links to global processes.

Particularly at more local scales of human-environment interaction, communities and places can be key loci for decision making. The everyday interface between people and the forest environment occurs in localities whereby place-based experiences are shared by people with multiple interests. Decision-making in the context of forest disturbance is influenced or limited by larger scale structures such as state and federal regulations, but there is also a degree of autonomy for actions to emerge locally. Individuals make decisions about what to do with their own property. Permanent or second-home residents within homeowner associations and neighborhoods collaborate (or fail to collaborate) to regulate activities within delineated areas. City governments enact regulations and restrictions on forest management, influence risk management strategies such as local fire prevention and response, and shape policies regarding local development which impact wildland-urban interface zones. County commissioners facilitate dialogue across multiple local level interests and have jurisdiction over rural issues, including land use and forest management, outside of city limits. Locally-based representatives of state and federal land management agencies interact with local interests as they seek to manage public lands around the region. In this way, these agency representatives create a bridge between local interests and state and federal scales of decision-making.

While there are opportunities for local action to emerge in response to forest disturbance, capacity for interaction and collective action is not always present in neighborhoods, communities, and other local scales. Using the language of Cox (1998), the spaces of dependence around each local community are often inadequate for dealing with the multi-scale implications of changing landscapes by forest disturbance. By linking actions among multiple 
communities and local interests across multiple places, considerable region-wide actions emerged in north central Colorado influencing state and national policies and decisions and reshaping places, place meanings, and regional identities.

Primary state and federal actors dealing with the forest disturbance and forest management issues include the US Forest Service, the US Bureau of Land Management, the US National Park Service, and the Colorado State Forest Service. As a caveat, one problem with the typical government structures for decision making in the area is the rapid turnover in local representatives of some of these agencies. When district rangers and field officers are replaced every couple of years, there is little institutional history or memory of interaction with local interests and communities.

Over the time-span of this recent mountain pine beetle outbreak in Colorado, new governance relationships were forged as local residents and representatives of different interest groups, communities, and organizations tapped into existing and emerging networks of association, or new spaces of engagement, to promote their place-oriented issues and influence decision making and action. A wide variety of new relationships developed across the five county area most heavily affected by the initial years of the current mountain pine beetle outbreak.

One compelling example of place and scale interaction influencing decision making came in the form of the Colorado Bark Beetle Cooperative ${ }^{3}$ (CBBC). Organized in 2005 and remaining active in 2009, this diverse group of participants included representatives from local county and municipality governments; the Colorado State Forest Service; the Bureau of Land Management; and the U.S. Forest Service. The Cooperative engaged in regular dialogue with private landowners, major utility companies, conservation districts, water districts, and industry leaders

\footnotetext{
${ }^{3}$ This effort was initially named the Northern Colorado Bark Beetle Cooperative (NCBBC).
} 
in open meetings and workshops. The CBBC local representatives traveled to Washington D.C. to meet with agency and congressional representatives and to lobby for funds and policies to support forest management efforts to mitigate risks associated with the mountain pine beetles in Colorado. Through this interaction, local representatives came to realize that different places in the region were coping with many of the same disturbance processes and management needs, despite variations in local perceptions and attitudes about what should be done. Through extralocal interaction, community representatives were able to collectively visualize regional and place-based strategies for promoting and locating forest industry options in more extractive resource tolerant communities, while prioritizing aesthetic and conservation strategies around higher-end amenity communities.

In addition to this larger regional organization or "new governance" initiative, place interaction occurred on a smaller, grassroots scale as well. In Summit County, local citizens formed a local task force called the Forest Health Task Force as part of a local initiative called Our Future Summit. With bi-monthly meetings, this local group provides a venue for local citizens, representing themselves, homeowner associations, or non-profit organizations from communities within and beyond Summit County to interact and learn about forest health issues and to initiate local and regional efforts to mitigate risks. In other words, this local task force provided a space of engagement for local residents to obtain information, express their views, and to interact with others to protect and defend their respective places from the impacts of landscape disturbance.

Amidst major landscape change and forest disturbance, new relationships for governance emerged in north central Colorado. Local and non-state actors took over some natural resource management functions with new and different ties to state actors. A regional identity emerged 
with new forms of interaction mobilizing political action. These new forms of governance and interaction did not come without difficulties and tension. There remain disparities and disagreements over "haves" or wealthy communities such as Vail and Breckenridge and relative "have nots" such as areas of Grand and Jackson Counties. There are still areas with lower capacities for people to work together collectively in the name of shared places and interests or weak representation at higher scales of governance. In some cases, community engagement beyond places is low because of strong government representation as seen in the case of Vail where many engagement efforts are dominated by city officials rather than broader civic participation. In other cases, conflicts of interest, tensions between newcomers and longtime residents, and poor economic conditions dominating everyday life, such as Jackson County, are perceived to block full engagement in assertive decision-making and collective action. Instability in federal agency representation at the local level continues to create problems with continuity, institutional memory and ability to facilitate collaborative processes. The Colorado situation exemplifies rural governance literature suggesting the emergent "geometries of power" (Edwards et al., 2001, p. 291) from regional collaboration may not work to, or be perceived to work to, the advantage of every community or locality within a region (Hall and Stern, 2009).

\section{Conclusion}

Concerted effort is needed to avoid contentious conflict and entrenched place-limited orientations. New forms of multi-scale engagement and connectivity among places can expand place-based identities to broader regional scales. However, such interaction may not always empower localities as the expansion of place-based decision making restructures regional "geometries of power" (Edwards et al, 2001). In general, north central Colorado regional 
collaboration and governance around forest disturbance issues empowered people in places to address their shared vulnerabilities and common goals around a new regional identity. Places can maintain their identity and meaning for residents in regional interaction while becoming more familiar with the opportunities made possible by extra-local and multi-scale interactions.

How can the benefits of extra-local or multiple place interactions be promoted and the barriers to or limitations of such interaction be reduced? Whether as researchers or as agency representatives promoting natural resource management strategies, one of the key considerations ties back to how we conceptualize place. As researchers, we do not always use the same definitions of place as the people we study (Staeheli, 2003) and may have different place meanings from those who live there. Thus, it is important to incorporate local knowledge and local meanings in our research on places, taking care not to impose our own interpretations of place onto those who live work and play in places, especially places at risk. For research as well as resource management outcomes to be locally relevant and oriented toward improving human and environmental well-being, local people should be encouraged to articulate their own place meanings as well as their engagements beyond their own localities and communities.

Just as interactions among people with diverse interests contribute to the process of community building as they uncover shared as well as different goals and interpretations of their community and place, interactions among people from multiple places within a region may foster collective interpretations of their shared landscape and regional processes. Concerted effort is needed to break down cultural, political, or logistical barriers to interaction among people from multiple places which can stymie the emergence of spaces of engagement. Successful placebased decision making may well rely on our ability to think outside the box - or place - to fully appreciate the role of place in decision-making. 


\section{References}

Agnew, J.A. \& J.S. Duncan. (1989). The power of place: Bringing together geographical and sociological imaginations. Boston: Unwin Hyman.

Brandenburg, A.M. \& M.S. Carroll. (1995). Your place or mine: The effect of place creation on environmental values and landscape meanings. Society and Natural Resources 8, 381398.

Brenner, N. (2001). The limits to scale? Methodological reflections on scalar structuration. Progress in Human Geography 25(4), 591-614.

Castree, N. (2003). Place: Connections and boundaries in an interdependent world. In S.L. Halloway, S.P. Rice \& G. Valentine (eds.) Key concepts in geography (pp. 165-185). London: Sage.

Cheng, A., L. Kruger \& S. Daniels. (2003). Place as an integrating concept in natural resource politics: Propositions for a social science research agenda. Society and Natural Resources 16(2), 87-104.

Cox, K. (1998). Spaces of dependence, spaces of engagement and the politics of scale, or: looking for local politics. Political Geography 17(1), 1-23.

Edwards, B, M. Goodwin, S. Pemberton, \& M. Woods. (2001). Partnerships, power, and scale in rural governance. Environment and Planning C: Government and Policy 19:289-310.

Flint, C.G. \& M.A. Brennan. (2006). Tapping the potential of rural Community Emergency Response Teams. Rural Realities 1(3), 1-9.

Flint, C.G. \& A.E. Luloff. (2005). Natural resource-based communities, risks, and disasters: An intersection of theories. Society and Natural Resources 18(5), 399-412.

Flint, C.G., A.E. Luloff, G. Theodori. (2010). Extending the concept of community interaction to explore regional community fields. Journal of Rural Social Science 25(1):1-13.

Flint, C.G., B. McFarlane \& M. Müller. (2009). Human Dimensions of Forest Disturbance by Insects: An International Synthesis. Environmental Management. 43(6):1174-1186.

Hall, P.V. and P. Stern. (2009). Reluctant rural regionalists. Journal of Rural Studies 25:67-76.

Hartshorne, R. (1939). The nature of geography. Lancaster, PA: Association of American Geographers.

Herbert, S. (2005). The trapdoor of community. Annals of the Association of American Geographers 95(4), 850-65. 
Howitt, R. (2003). Scale. In J. Agnew, K. Mitchell \& G. Toal (eds.) A companion to political geography (pp. 138-157). Malden, MA: Blackwell.

Johnston, R.J. (1991). A question of place. Oxford: Blackwell.

Jones, O. and J. Little. (2000). Rural challenge(s): Partnership and new rural governance. Journal of Rural Studies 16, 171-184

Kemmis, D. (1990). Community and the politics of place. Norman: University of Oklahoma Press.

Kirby, A. (1989). A sense of place. Critical Studies in Mass Communication 6(3), 322-326.

Luloff, A.E. \& J. Bridger (2003) Community agency and local development. In D. Brown \& L. Swanson (eds.) Challenges for rural America in the twenty-first century (pp. 203-213). University Park, PA: Pennsylvania State University Press.

Luloff, A.E., R.S. Krannich, G.L. Theodori, C. Koons Trentelman \& T. Williams. (2004). The use of community in natural resource management. In M.J. Manfredo, J.J. Vaske, B.L. Bruyere, D.R. Field \& P.J. Brown (eds.) Society and natural resources: A summary of knowledge (pp. 249-259). Jefferson, MO: Modern Litho.

Marston, S. (2000). The social construction of scale. Progress in Human Geography 24(2), 219242.

Massey, D. (1979). In what sense is a regional problem? Regional Studies 13, 233-43.

Massey, D. (1994). Space, place, and gender. Minneapolis, MN: University of Minnesota Press.

Morse, W.C., T.E. Hall \& L. Kruger. (2008). Improving the integration of recreation management with management of other natural resources by applying concepts of scale from ecology. Environmental Management (online first).

Paasi, A. (2004). Place and region: Looking through the prism of scale. Progress in Human Geography 28(4), 536-46.

Painter J. \& M. Goodwin. (1995). Local governance and concrete research: investigating the uneven development of regulation. Economy and Society 24, 334-56.

Pred, A. (1984). Place as historically contingent process: structuration and the time-geography of becoming places. Annals of the Association of American Geographers 72, 279-297.

Rose, N. (1999). Powers of freedom: Reframing political thought. Cambridge: Cambridge University Press. 
Staeheli, L.A. (2003). Place. In J. Agnew, K. Mitchell \& G. Toal (eds.) A companion to political geography (pp. 158-168). Malden, MA: Blackwell.

Swyngedouw, E. (1997). Neither global nor local: "Glocalization" and the politics of scale. In K. Cox (ed.) Spaces of globalization: Reasserting the power of the local (pp. 137-166). New York: Guildford.

Theodori, G. (2005). Community and community development in resource-based areas: Operation definitions rooted in an interactional perspective. Society and Natural Resources 18, 661-69.

Wilkinson, K. (1991). The community in rural america. Westport, CT: Greenwood Press.

Williams, D. \& W. Stewart. (1998). Sense of place: An elusive concept that is finding a home in ecosystem management. Journal of Forestry 96, 18-23. 


\section{Organizational cultures and place-based conservation}

Patricia A. Stokowski

Viewed by outsiders, natural resource management agencies are notable for their deep environmental values and concern for nature, sentiments expressed in a variety of symbols, from Smokey Bear, to traditional green uniforms, to the concept of wilderness. The mythic qualities of many of the landscapes and of sites managed by resource agencies are also symbolic, contributing to the shared culture of resource protection evident across the workforce of resource management agencies. These public agencies provide a sense of occupational enculturation for their members, institutionalizing a set of practices that endow meaning in the ways they "impose upon the world a particular conception of how things... are and how men (sic) are therefore obliged to act" (Geertz 1973: 316). The internal culture of a resource management agency bears directly on how, and how well, that organization accomplishes its work, and how it sees itself relative to others in the broader social environment.

What we think of as "culture" involves the personal and social practices through which people make sense of the world and their lives, and the shared symbols through which they give meaning to their actions. In the broadest sense, culture can be defined as the "historically transmitted pattern of meanings embodied in symbols, a system of inherited conceptions expressed in symbolic forms by means of which men communicate, perpetuate, and develop their knowledge about and attitudes towards life" (Geertz 1973: 89). Applied to social groups and organizations, the concept encompasses the traditions, rituals, beliefs, ideologies, stories, habits, myths, patterns of behavior, and other features of shared experience that distinguish a group and give its members a sense of uniqueness. Cultural practices provide a sense of logic, a 
set of predictable and implicit guidelines and routines, and an array of artifacts around which personal and collective identity and behavior may be organized.

Because a natural resource agency's work always involves making decisions about the management of specific locales, the idea of "place" becomes important in agency functions. Analysis of cultural aspects of agency organizing behavior can improve understanding of how agencies think about places, how they organize their work relative to ideas about place, and how they use elements of organizational culture strategically to reinforce notions about place. This paper considers how research about organizational behavior and culture might improve agency decision making about place. The central question is this: how should "place" be more fully incorporated into natural resource decision making? That is, how can organizational processes internal to resource management agencies yield both richer understandings of place as well as better agency decision making about the management of place?

\section{Conceptualizing “Place”: Foundations for Resource Agency Behavior}

The idea of "place" has always been implicit in deliberation about natural resource management and policy, and different conceptualizations about place have led to particular ways of organizing for agency action. Historically and administratively, places of concern to resource agencies and their managerial staff have been defined as objects in nature - physical sites or regions, identified by borders, and valued for utilitarian, economic, social, or sentimental reasons. Objectified places can be categorized in a variety of ways, as natural and physical sites (areas, zones, landscapes) where specific kinds of natural resources are available (wood, wildlife, recreation opportunities), where definable activities occur (timber harvesting, agriculture, management of waterways, recreation participation), and where management activities can be 
used to obtain specific kinds of outputs (measurable products such as board feet, number of animals or bushels of crops raised, clean and flowing waters, or intangible benefits such as leisure enjoyment, or scenic beauty). This concept of place - as physical site, as repository of potentially measurable resource values, and as setting for action - is constructed around the notion of place as a tangible, physical reality, as a setting managed by agency leaders who are educated in the sciences of ecology and human behavior, and authorized by their leadership roles to manage resources for the public good. Thus, a manager's knowledge of place arises from the direct experience of managing objects in nature. Benevolent in spirit, this approach to resource management is situated within the structures and functions of rational, efficient, scientificallybased organizational systems.

In contrast to the notion of place as object, places can also be seen as subjective sites of meaning and contestation, lived-in as well as imagined settings for the flourishing of sentiments, attitudes and values linked with specific geographic or physical qualities. This view aims to reinvest the physical settings and objects of place with the sentiments and meanings held by people to whom that setting matters. Places are described by their social and cultural importance, by their historical uses and transformations, and by the ways they have been appropriated by various groups (Sokolove, Fairfax and Holland 2002). Cheng and Daniels (2003: 843) say it simply: "Place meanings are expressions of how people come to know and value a biophysical setting." What we call a "sense of place" usually refers to aspects of personal, social, historic, and sociocultural meanings interlinked with physicality - a notion of place that links agency culture and external socio-cultural meanings.

Within this conception of place as center of human meaning, managerial processes oriented to analysis of multiplex, diverse meanings require data collection, analysis, and 
planning based less in top-down procedures, and more in participatory processes (see the papers in Farnum and Kruger 2008 for examples). And, because technical decision-making is often incongruent with ways of dealing with the complexity and sensitivity of emotion-laden issues, deliberative approaches are used. Deliberative approaches rely less on top-down, technical decision-making, and more on collaborative processes and locally-oriented interactions. Through dialogue and participatory practices, individual citizens, interest groups, and agency leaders share their direct and close understandings of places, striving for mutual learning and appreciation of diverse views, ultimately (ideally) opening the discussion space for consideration of alternative resource management strategies.

Few places ever come to our attention in "raw form," though, without also being accompanied by our own or others' existing impressions, prior knowledge, histories, and meanings. This is obvious for iconic sites (such as Old Faithful), but it is equally true for more common or local settings that are more generally endowed with personal or public depths of sentiment and emotion. Moreover, people who have strong feelings for specific places are not only those who use or encounter those places - this group also sometimes includes people who are not visitors to the specific sites, and also, importantly, those who also manage the meaningful places. Natural resource places are a fundamental input to managerial decision making, and how public agencies think about place generally, and how they manage places specifically, has longterm implications for natural resources as well as for people.

Places and Organizing Forms. Approaches to conceiving of and managing natural resources places can be viewed within the context of John Friedmann's (1987) analysis of the philosophical traditions of scientifically-based planning. Asking, "How do we make a good 
society?," Friedmann described four philosophical traditions that support different kinds of organizing processes and result in different approaches to societal planning.

The Social Reform perspective, grounded in scientific reasoning and focused on continual improvement of institutional processes across society, involves benevolent leaders working with experts to provide for the well-being of citizens. The work of public institutions, such as local, state and federal governments, illustrates this tradition. In counterpoint to this, the Social Mobilization tradition is centered on the actions of grassroots organizations to effect either disengagement or confrontation with prevailing forces of social order. Utopian as well as revolutionary groups both fit within this tradition. The Social Learning tradition, departing from mechanistic explanations about human behavior, invokes collaboration, trust, and learning within small groups to achieve goals; examples of this tradition can be found in non-hierarchical, matrix-like models of social collaboration. The tradition of Policy Analysis, grounded in efficiency and technology, is expert-driven and focused on achieving the best technical outcomes of planning processes; NASA is an example of this approach.

Of these four philosophies, traditional resource management (where places are conceived as natural objects awaiting technical solutions) tends to primarily apply the philosophies of bureaucratic Social Reform, sometimes incorporating expert-driven Policy Analysis approaches to rationalize and justify scientific claims. More recent collaborative approaches in resource management (where place is viewed as a context for personal and social meaning) reflect a combined Social Reform and Social Learning perspective, where deliberative processes are encouraged within standard bureaucratic decision-making models. 
The colloquialism "form follows function" is useful here. When agencies define place as the location for a set of physical objects in nature, top-down styles of management and decision making predominate, and standardized, technical solutions are needed. On the other hand, when places are viewed as centers of meaning, more diverse perspectives are required. Deliberative practices encourage managers and citizens to develop new understandings of the meaningful qualities of places and their contested nature, by incorporating more inclusive processes of shared interaction during planning and decision-making processes. These two approaches reflect a transition over time in how natural resource agencies conceive of place and incorporate place into management actions. They also require that two different types of cultures (agency, and community) come into contact and make accommodations in order to move forward with decision-making processes.

Ultimately, the two perspectives about place share a single organizing point: the agency continues to set the agenda by defining relevant questions, overseeing the process of participation, and in most cases, remaining as the final decision-maker. Since Friedmann's model gives little attention to issues beyond structural and functional aspects of organizational behavior, we still know relatively little about the very details of how decisions are made about natural places. The received wisdom is that bureaucracies make rational decisions "deliberately considering and weighing alternatives, deciding on a course of action that promises the best returns, and acting accordingly" (Fuchs 2001: 127), but that is sometimes an unreliable guide. One way to explore the issue of decision making further is to move away from structural and functional aspects of organizing, because hierarchies and learning circles may have vastly different cultural and interactional qualities. These two traditions would also seem to produce 
different kinds of organizational cultures and values. In the next section, a cultural approach to natural resource management of place is considered.

\section{Organizational Culture and Resource Management Agencies}

Much of the formal decision making related to utilization, protection, and meaning of natural resource places in America has been coordinated through federal, state, and local government agencies. Public natural resource management agencies obviously differ from one another in their missions, responsibilities, degrees of centralization, funding, staff and administrative autonomy, size, and so on, but all are also similar in some important ways. As bureaucratic organizations, they each manage multiple units across all or part of the country, hire people who feel strong commitments to lands and resources, and tend to rely on science, efficiency, and measures of accountability in doing their work. As public agencies, they can be considered to be a special kind of organization, different from corporations or small businesses or non-profits. But, they are organizations fundamentally - systems of human activity, intentionally created to achieve specific goals. As such, they have features that characterize all organizations, including predictable routines, linked roles arranged in hierarchy or other relation, internally coordinated activities, systems of rules and controls, stocks of knowledge, unique organizational cultures, and potentially permeable boundaries (Aldrich 1999).

Of these organizational characteristics, it is the culture of resource agencies that is of considerable interest in analyzing the management of place. Employees are immersed, to greater or lesser degrees, in an organization's continually evolving cultural system - but even before they become members of an organization, they are also automatically and deeply enmeshed in the broader cultures of their community and society. As Aldrich (1999: 155-6) noted, 
"Organizational cultures do not develop in isolation from the surrounding society ...

Organizations are sites for the reproduction of cultural norms and practices, but they also generate cultural norms and practices." Cultural systems operate at several levels simultaneously, then, ordering the world and giving meaning to human experience.

Organizational cultures offer comparison-potential for employees as well as outsiders, along with implicit guidelines about how to act, what to expect from oneself and others, and how to deal with change. The value of studies about organizational culture has been well-illustrated by classic studies in natural resources such as Kaufman's analysis of the functional coherence and internal control of the USDA Forest Service's operations and philosophies, examined through the daily work of its rangers (Kaufman 1960), and in Twight's (1983) study of the ways that power and values intersected to produce political decisions made by the Forest Service relative to Olympic National Park. Both of the studies show that the patterned, functional activities of the Forest Service (and, it is implied, other resource management agencies) are sustained by certain qualities of the organization's internal culture that reinforce an individual's identification with and commitment to the organization. As Twight (1983: 25) noted, "An organization's value orientation constitutes a shared frame of reference, which includes sanctioned patterns prescribing the approved way of doing things and the established goals of that body. This orientation controls an organization's perceived purpose in society and filters its perceptions of public demands."

Within natural resource professions, federal resource management agencies are seen to have strong and unique cultures. Colfer and Colfer (1978) provided an example of Forest Service culture in their study of the interactions between logging families and public agency employees in a remote Washington state town. They observed that, "Many Forest Service 
personnel and their families refer to the Forest Service as 'one big happy family"' (p. 209), and use of the family metaphor gave agency employees and their kin a sense of cohesion and connectedness within the organization, as well as an identity beyond it. Strong organizational cultures may have potentially negative consequences, though, as Kennedy (1988) points out in his analysis of "groupthink" in the US Forest Service during the 1950s and 1960s. Entrenched and isolating organizational practices result in difficulties in changing an agency's direction, goals, and response patterns. For example, the US Forest Service's dominant metaphor of forests as production “machines” (Kennedy and Quigley 1998; Fairfax 2005), and its replacement with a more "organic" and participatory model of forest ecosystem management, required shifts in both external world-view and internal organizational culture.

Ideas about "place" becomes meaningful for agency decision making processes not only because an agency's work is to manage specific places - but also because places "work" back on agencies reciprocally, to help define, challenge, contest, or give meaning to the operational practices of agencies. That is, while agencies enact managerial activities upon places from positions of political distance and power, places sometimes "respond" to the agency, often most visibly when natural changes occur, or when individuals or communities use the site in ways unintended by managers. Thus, while agencies aim to "produce" places congruent with their internal goals, places can also fail at being organized into an agency's vision. The result is that places influence and even "produce" specific kinds of agencies and organizational practices.

\section{Culture, Discourse, and Decisions about Place}

Because so much of a public agency's work is in communicating with internal and external constituents, one issue of particular interest in the study of organizational culture is that 
of discursive aspects of an agency's culture. The concept of discourse has been defined by van Dijk (1997: 3) as "talk and text in context." Hajer (1995: 44) explained that the term discourse refers to the "specific ensemble of ideas, concepts, and categorizations that are produced, reproduced and transformed in a particular set of practices and through which meaning is given to physical and social realities." Eisenberg and Goodall (1993:115) described these "language(s) of the workplace" as key to understanding "the routine and dramatic performances of managers and employees, and a wide variety of shared practices that help an organization know its own uniqueness.”

Discourses are deployed by organizations and agencies to explain and reinforce organizational values, beliefs, and behaviors. Constructed within all types of communications media (spoken language, written texts, non-verbal messages), the intentional creation and development of meaningful discourses offers an agency considerable opportunity to construct its own story about how it sees the world, then to use methods of persuasive communication to disseminate that message internally and externally. Discourses are bounded by context, and by agency intent and skill. "Discourse is social," wrote Macdonell (1986: 1), and "Possibilities for meaning are pinned down and made into definite meanings through the social and institutional position from which the discourse comes" (p. 12). This should not imply that meanings emerge fully formed and set in stone. Language and meaning are malleable, shifting across contexts, audiences, and speakers, over time. It is this fluidity that makes discourse effective in reaching different people (the same words can be interpreted in a variety of ways), but it also means that discourses are always subject to interpretation. As Fiske (1989: 170) observed, "Discourse does not reveal the "truth" about the world, it makes meanings that serve some interests better than 
others and inserts these meanings into the constant play of domination and subordination, of power and resistances, that characterizes late capitalistic societies."

Bloemmart (2005: 223) said it another way: "People speak from a place." The same is true for agencies and organizations. Organizational cultures, built from and reproducing patterns of habitual behaviors and routine ways of seeing the world, presuppose the rightness and inevitability of an agency or manager's discourses. Thus, the management of place can be seen as an arena of cultural performance drawn around particular kinds of questions and issues, and specific orientations to places, types of social interactions, decision making choices, administrative rules and responsibilities, and practical applications. Within this conceptual setting, place discourses that diverge from those produced by powerful organizations and mangers are likely to be unanticipated, challenged, treated with skepticism, or ignored within decision making processes.

\section{Illustrations}

How does analysis of organizational culture, and its manifestation in and through organizational discourses, help agencies make better decisions about place? This question has several parts. First, what can be learned about organizational culture and the cultures of other groups in society? Second, what do we need to know about how discourses work to be able to consider their effects? Third, how can agencies use what they learn about organizational culture to develop more effective strategies for managing place? The importance of discursive aspects of organizational culture is evident in a variety of natural resource-based management and decision-making contexts, and several examples are given below. 
Interpretive programming is one arena where an agency's use of specific images and language use is strategic and intentional, seeking particular kinds of effects across message recipients. Interpretive materials and presentations are "one kind of institutionalized rhetorical situation by which persuasive messages are delivered to receptive audiences" by credible agency personnel (Stokowski 1990: 47). Interpretive messages are usually intended to educate, entertain, or move audiences to action - but they also work to expose visitors to the ideals and goals of the managing agency and to its slate of meanings about specific resource places. Indeed, one might argue that building a loyal, supportive, knowledgeable constituency is one of the more important purposes of interpretive communications.

An example of cultural discourses of place can be seen in Peterson's (1988) analysis of the mythic structure of park interpretive materials at Grand Teton National Park. Her analysis revealed that the agency's preservationist interpretive messages were drawn around religious, mystical themes, effectively reducing visitors to passive observers who were expected to submit to nature's god-like processes. The textual analysis showed, however, that the agency failed to acknowledge a contradiction in the mythology it presented: if the national park is a "holy place" where nature itself is in charge, what is the role of park administrators, and how can their managerial actions be justified? Implicit in the interpretive story produced by that park is that managers can be considered to be nature's direct representatives, helping nature succeed at its work - a rationale, one might observe, that not only provides considerable latitude in making management decisions, but also elevates agency personnel to partners with nature, a status certainly above that of park visitors, the ostensible owners of the public lands.

Another context where culture-based discourses have importance for agency decision making is that of natural resource planning. The shift from thinking about places as objects to 
places as contexts for human meaning is seen in new approaches towards place-based planning "land and natural resource planning efforts that bring together diverse human values, uses, experiences, and activities tied to specific geographic locations" (Farnum and Kruger 2008: 1). Place-based planning has a cachet and appeal because it implies that decisions will be more local, more participatory, and more meaningful in outcome, without the inherent objectification of place that tends to accompany traditional managerial practice. But, the malleability and fluidity of meanings of place, and their reciprocal power to interact with other agency discourses, is often overlooked in a planning effort eager to obtain the broadest possible set of place meanings from a wide range of citizens and groups. In addition, structural changes made by agencies to accommodate new processes of deliberation may accidentally become the focus of the process, with process substituting for full context and content. The risk is that meanings of place will be seen merely as individual beliefs (or as an objectified list of independent and decontextualized meanings), not as segments of full and rich discourses associated with an array of cultural groups engaged in communication about resource places.

Structural changes to deliberative processes still may not result in changes to decision making processes if there is no accompanying cultural change. If an agency's decision making processes remain routine, then we can also presuppose a taken-for-granted, standardized view of internal and external organization environments. This raises questions about how managers might even become familiar with place meanings and understandings that are outside their agency's prevailing interpretations (or how they might include these in decision making processes). If managers seriously seek plurality in citizen participation and decision making, then cultural openness, capacity for change, and a focus on the emergent quality of multiple, diverse place discourses, is needed. 
While resource agency cultures are strong, conflicts sometimes exist between agency and public views of places and acceptable alternatives for place management. Competing cultural forces that impinge on people arise from community affiliation, occupational affiliation, personal preference, and historic ties. As Cronon observed (in Langston 1995: ix), "ecosystems are profoundly historical, meaning that they exist in time and are the products as much of their own past as of the timelessly abstract processes we think we see going on in them." Particular ways of seeing and knowing place lead to particular kinds of agencies as well as decision making processes, all reinforced and reaffirmed by the specific kinds of cultural artifacts that sustain the agency and its ideas. Recent writing about collaborative planning practices would be richer with more focused attention to relationships between cultural aspects of organizations, communities and other groups affiliated with resource places.

Another arena for exploring the importance of agency discourse for decision making is that of conservation practice generally. Conservation is imagined to be an historically welldefined philosophy and set of principles, but as Vivanco (2003: 59) pointed out, "conservation is never simply about what kind of nature people imagine or...want to preserve or restore; it is also an important arena in which they, explicitly or implicitly, project and re-imagine social relationships and cultural institutions." The need for incorporation of cross-cultural and intercultural relationships surrounding resource places is not a new idea, though most analysts have used those terms with respect to working with international visitors to resource places, or managing for different ethnic and cultural user groups at sites like campgrounds. In fact, the idea is equally necessary for working with the diversity of organizational, group, and community cultures within the same society. In this respect, discourse will take on great importance, for people speaking about the same geographic places may not be speaking at all about the same 
"place." If the places agencies manage are places created by the agency, then analysis of organizational culture and discourses can reveal, to employees as well as to external constituents, the values, symbols, structures of meanings, and points of intersection with the internal cultures of other groups engaged with specific places. The result may be new kinds of cross-cultural dialogue, sharing of ideas, experiences of new customs, possibilities of new opportunities, and a re-invigoration of alternatives for management.

Some of the needed cross-cultural changes might simply be about creating more substantive relationships between natural resource agencies and the communities which surround them. A particular example comes to mind. A resource agency directed its staff architect to work on the reconstruction of an historic but remote railroad site and tunnel. Funding was limited, though, and much of the work was done by committed volunteer groups from outside the area. In the valley below the historic site, a small town began to experience an influx of second home owners charmed by the beauty of the rural area. Both the agency and local community leaders spoke of enhancing tourism development opportunities - but neither group worked together toward that shared goal. Each had its own way of defining the problem and addressing it (that is, of making decisions about how to set goals, move forward through a series of steps, and come to agreement about what to do), and as a result, a collaborative approach to planning never emerged. The cultures of each, agency and community, remained impenetrable to the other, to the detriment of each.

\section{Propositions}

This paper makes a plea for the study of natural resource agency cultures and consideration of their roles in management of resource places. What is it exactly about "place" 
that needs to be better incorporated into natural resource decision making? And, how can a cultural view of resource agencies and their organizational behaviors improve current circumstances and lead to better agency decision making and more effective management of meaningful places? Several propositions come to mind.

First, resource management agencies use cultural symbols, languages, and artifacts in strategic ways to accomplish their management goals. An understanding of cultural aspects of organizing can lead to richer knowledge about how agencies work, how they think about places, and how they attempt to justify for their employees and for outsiders the choices they make about place management actions. Discourse-based approaches to place will likely reveal the stability (some might even say rigidity) of many agency perspectives about place. There is an organizational advantage in making patterns of work look and seem routine, because it lends a sense of predictability are certainty to life. But, critical analysis of organizational meanings about place, and the agency cultures that support these, may move agencies and citizens towards more vigorous and flexible forms of public action in natural resource management, and towards newer definitions of place.

Second, by analyzing agency cultures, we may be better positioned to ask important questions about the nature of decisions in natural resource management. Conventionally, we think of decisions as both procedural choices and outcomes of organizing behaviors, and the term is applied with reverence to "the final choice" in a completed planning process. As part of processes of decision-making about place, managers conduct resource inventories, evaluate notable ecological and social features of landscapes and sites, consider how places contribute environmental services, analyze visitor's experiences, and aim to understand the sentiments groups hold for specific places. Information gathered from such procedures and analyses is 
claimed to help in making decisions about places over time - in developing and implementing programs and plans, making financial investments, adjusting staffing, evaluating alternative strategies for resource protection and use, and formulating policy. But, often what happens is that decisions somehow become hidden behind the data.

Fuchs (2001: 128) suggests, though, that the term "decision" should be seen instead as "a schema for assigning organizational responsibility and allocating praise and blame." From this perspective, decisions are both symbols and myths, performing important work of organizational control and coordination. Analysis of organizational culture can help us see how the use of decisions in this way has cultural meaning both internal and external to organizations. From this viewpoint, decision-making can be seen to have its own internal logic and sub-culture, linked with structures of authority and power in organizations, and tightly woven with rituals, symbols, and ideologies.

Third, organizational cultures and their embedded discourses are important in the ways they are employed to achieve organizational goals. In the same ways that individuals are more than their roles and positions, agencies are more than impassive organizations conducting business in standardized form, immune from change, and unrelentingly predictable. Research about organizational behaviors should attempt to learn about how agencies use specific elements of organizational cultural strategically. Learning to "read" an organization's cultural behaviors may open up possibilities for updating conservation and preservation philosophies, and for understanding exactly what agencies are talking about when they talk about place (as suggested in this paper, they are often talking about themselves). Such research may lead to finding better ways of organizing in resource management, and more successful ways of communicating between agencies and other social groups. Perhaps one outcome of this analysis may be a new 
focus on human behavior in the outdoors that could be termed "language as a way of being in place." Recreation researchers who study place have typically thought of language as utterances about place, or as people's feelings about place - not as, in and of itself, the primary behavior of people in place. An agency's responsiveness to this type of reconceived image of place may require the application of new kinds of symbols systems and organizing processes.

Fourth, societal economic pressures affect not only citizens but also agencies. There is a pressing need to consider new ways of organizing and governing in a shared space of community and societal responsibility. Traditional patterns of behavior often cannot respond quickly to new needs, and cultural analysis of resource management agencies as well as communities and other groups and organizations may provide new tools and strategies for collaboration in the face of change. It would be worth knowing, for example, if an agency's idea of place varies from the ideas of citizens who have allegiance to various other conceptions of place. One agency response might be to more effectively design messages that seek understanding, rather than simply attempting to educate others in a top-down fashion about the agency's positions. Finally, roadblocks in traditional agency approaches may be overcome by emphasizing cultural features of agencies in collaboration with other groups or organizations, rather than simply by rearranging the agency's own organizational functions.

Mason (2008) points out that the prevailing narrative of new place-based land use planning and management initiatives is that "deeply rooted communities, thoughtfully and deliberately shaping their environmental futures" work in ways that are "democratic, inclusive, informed, mutually respectful" - but this is an ideal and not always a reality. It also seems to be a code emphasizing the virtues of local environments, small geographic scales, and deep familiarity with people and place (Kemmis 1990). Such close connectedness reflects strong ties 
between people - strong ties that are both predictable as well as limited, inhibiting new ideas and participants. Additionally, as Mason (p. 46) points out, sometimes "local problems are in no small part the product of extralocal processes," and communities may not have the resources needed to solve the problems. A role remains for government expertise, funds, and incentives to broaden and support local planning and land use management initiatives. Wondolleck and Yaffee (2000) reinforce this idea in their analysis of successful collaborative cases, in which they show that a sense of place and a sense of community can serve to foster collaborative activities. These authors write (p. 74), "Places can be powerful symbols that encourage people to reframe their identity and interact with individuals or groups that historically have been viewed as "outside" their geographic, interest-based, or perceptual boundaries."

Efforts to build cultural capacity based on shared ideas about place, creating linkages between agencies and communities, can mitigate some of the problems. McGinnis, Woolley, and Gamman (1999: 1) wrote that, "more than reliance on good scientific information, technology, and the resolution of value-based conflict...collaboration can also be achieved by recognizing and cultivating shared understandings or commonly held values and beliefs that are inherent to community-based watershed planning." These bonds often occur around places, as Manzo and Perkins (2006: 347) observed: "affective bonds to places can help inspire action because people are motivated to seek, stay in, protect, and improve places that are meaningful to them." Moreover, an agency with a strong internal culture focused on shared interactions about place and its social meanings can develop adaptive skills by building relationships to foster learning opportunities. As Armitage (2005: 706) wrote, "adaptive capacity is largely a function of social and institutional relationships and the manner in which social actors mediate among contested interests to avoid potentially negative... action outcomes," a point echoed by Berkes 
(2009). Though persons with strong organizational identities may find it difficult to adopt broader perspectives, "Establishing a common group identity may be an important step towards enhancing collaboration among stakeholders and fostering shared ways of knowing” (Cheng and Daniels 2003: 852). Social practices that build shared cultures will contribute to success.

\section{Conclusions}

Wuthnow et al. (1984: 247) wrote that, "the principle questions for cultural analysis now not only include the meaning of symbols but the conditions, patterns, and rules of use which render symbols meaningful." Organizations, as much as individuals, use culture to establish and reinforce identity. A full analysis of natural resource agency culture (together with analyses of community culture and inter-organizational relationships) would necessarily also consider how it is that place management helps support organizational identity, and what the difficulties might be in re-conceiving place from the perspective of a natural resource management agency.

The production of particular discourses of place, generated by and within natural resource agencies, is inherently linked to other processes of power and control in agency systems (Stokowski 2002). To the extent that decision-making constitutes much of what managers do in their day-to-day work, organizational culture and its relation to agency decision-making processes are areas of fruitful study. Among the many interesting topics that could be studied about the organizational cultures of natural resource agencies, there are important questions about how agency employees understand organizational cultures and participate in their reproduction, how organizational culture affects staff and leader behavior, and how an agency's culture interacts with the cultures of other groups and organizations in society to accomplish broader social and political goals. In practical terms, managers in resource agencies are 
particularly well-positioned to influence how staff members think about and act towards places (Brown and Humphreys 2006: 248), and the ways in which managers and staff incorporate symbols of place into group identity rituals can reveal much about control of place meanings in public dialogues.

This paper has been written about public natural resource agencies, but of course the ideas discussed here apply equally well to other organizations, groups, and communities that participate in natural and cultural resource management and decision making. Resource places are not only activity sites people visit, or places for the harvest of commodities, or places that capture social imagination. These are places integrated into the life histories of people living in communities and oriented to a specific geographic locale or region. As McCullough (2003: 40) observed, "our communities and landscapes are patchworks of natural and cultural resources and...changes to incidental parts can ultimately transform the whole." We cannot save the places of nature without also saving cultural places; their interdependence is also the reason that changing only the internal structures and functions of natural resource agencies addresses only part of the problem.

This paper suggests that organizational cultures intersect with different conceptions of place and different kinds of management approaches. When place is considered in objective terms, managers define, inventory, and analyze places as physical sites. This results in a style of scientific management that routinizes decision-making processes. When place is considered in terms of a complexity of personal and social meanings, managers apply more deliberative, inclusive, and varied processes of gaining place knowledge from wider ranges of constituents. This produces a place-based style of management that is contextualized, localized, and personal. Moving beyond both of these approaches would be an effort to develop a fuller understanding of 
the culture of a resource agency, in counter-point to the broader societal cultures in which it is enmeshed. Focusing on agency discourses would seem to be a very useful starting point for studying cultural aspects of place-making and their role in resource planning and management.

Recent calls for finding ways to incorporate close ties to nature into planning processes imply that the planning process is adequately able to incorporate new processes - but what if the planning process itself is problematic? Langston (1995: 303) notes that we need to work with landscapes "by forming close connections to a place but also being willing to adapt to the character of the place (in a) combination of mobility and connection." The same might be applied to our managing authorities: organizations should not be static but also "moveable" and flexible to account for new needs and concerns. This would mean that the culture of organizations must in some ways also be more flexible, informed by diversity and fluidity.

A full analysis of "agency talk" and agency culture remains to be written. But, what we might find as we begin the task is that culture is not only a feature of agencies, but indeed the agency is produced by and through its discourses. And that may mean everything for how an agency thinks about and makes decisions about place. 


\section{References}

Aldrich, H. 1999. Organizations Evolving. London, England: Sage Publications.

Armitage, D. 2005. "Adaptive capacity and community-based natural resource management." Environmental Management 35(6): 703-715.

Berkes, F. 2009. "Evolution of co-management: Role of knowledge generation, bridging organizations and social learning." Journal of Environmental Management 90: 16921702.

Blommaert, J. 2005. Discourse: A Critical Introduction. Cambridge, England: Cambridge University Press.

Brown, A.D. and M. Humphreys. 2006. "Organizational identity and place: A discursive exploration of hegemony and resistance." Journal of Management Studies 43: 231-257.

Cheng, A.S. and S.E. Daniels. 2003. "Examining the interaction between geographic scale and ways of knowing in ecosystem management: a case study of place-based collaborative planning." Forest Science 49(6): 841-954.

Colfer, C.J.P., with A.M. Colfer. 1978. "Inside Bushler Bay: Lifeways in Counterpoint.” Rural Sociology 43(2): 204-220.

Eisenberg, E.M., and H.L. Goodall, Jr. 1993. Organizational Communication: Balancing Creativity and Constraint. New York: St. Martin's Press.

Fairfax, S.K. 2005. "When an Agency Outlasts its Time: A Reflection.” Journal of Forestry (July/August): 264-267.

Farnum, J.O. and L.E. Kruger, Eds. 2008. Place-based Planning: Innovations and Applications from Four Western Forests. Portland, OR: U.S.D.A. Forest Service, Pacific Northwest Research Station, PNW-GTR-741. April.

Fiske, J. 1989. "Representations of Power: Paradigms and Politics.” Pp. 169-172, in:

Rethinking Communication, Vol. 1: Paradigm Issues. Ed. by B. Dervin, L. Grossberg, B.J. O’Keefe, and E. Wartella. Newbury Park: Sage Publications.

Friedmann, J. 1987. Planning in the Public Domain. Princeton, NJ: Princeton University Press. 
Fuchs, S. 2001. Against Essentialism: A Theory of Culture and Society. Cambridge, MA: Harvard University Press.

Geertz, C. 1973. The Interpretation of Cultures. New York: Basic Books, Inc.

Hajer, M.A. 1995. The Politics of Environmental Discourse: Ecological Modernization and the Policy Process. Oxford, England: Clarendon Press.

Kaufman, H. 1960. The Forest Ranger: A Study in Administrative Behavior. Washington, DC: Resources for the Future, Inc.

Kemmis, D. 1990. Community and the Politics of Place. Norman, OK: University of Oklahoma Press.

Kennedy, J.J. 1988. "Legislative confrontation of groupthink in US natural resource agencies." Environmental Conservation 15(2): 123-128.

Kennedy, J.J. and T.M. Quigley. 1998. "Evolution of USDA Forest Service organizational culture and adaptation issues in embracing an ecosystem management paradigm." Landscape and Urban Planning 40: 113-122.

Langston, N. 1995. Forest Dreams, Forest Nightmares: The Paradox of Old Growth in the Inland West. Seattle, WA: University of Washington Press.

Macdonell, D. 1986. Theories of Discourse: an Introduction. Oxford, England: Basil Blackwell.

Manzo, L.C. and D.D. Perkins. 2006. "Finding common ground: the importance of place attachment to community participation and planning." Journal of Planning Literature 20(4): 335-350.

Mason, R.J. 2008. Collaborative Land Use Management: The Quieter Revolution in PlaceBased Planning. Lanham, MD: Rowman \& Littlefield Publishers, Inc.

McCullough, R. 2003. "The Nature of History Preserved; or, The Trouble with Green Bridges." Pp. 33-42, in: Reconstructing Conservation: Finding Common Ground. B.A. Minteer and R.E. Manning, Eds. Washington, DC: Island Press.

McGinnis, M.V., J. Woolley, and J. Gamman. 1999. "Bioregional conflict resolution: 
rebuilding community in watershed planning and organizing." Environmental Management 24(1): 1-12.

Peterson, T.R. 1988. "The Meek Shall Inherit the Mountains: Dramatistic Criticism of Grand Teton National Park's Interpretive Program.” Central States Speech Journal 39(2): 121133.

Sokolove, J., S.K. Fairfax, and B. Holland. 2002. "Managing place and identify: The Marin Coast Miwok Experience.” The Geographical Review 92(1): 23-44.

Stokowski, P.A. 2002. "Languages of Place and Discourses of Power: Constructing New Senses of Place." Journal of Leisure Research 34(4): 368-382.

Stokowski, P.A. 1990. "The Rhetoric of Interpretation: More than a Set of Techniques." Journal of Park and Recreation Administration 8(4): 43-51.

Twight, B.W. 1983. Organizational Values and Political Power: The Forest Service Versus the Olympic National Park. University Park, PA: The Pennsylvania State University Press.

Van Dyke, T., Ed. 1997. Discourse as Structure and Process: A Multidisciplinary Approach. London, England: Sage Publications. Vol. 1.

Vivanco, L.A. 2003. "Conservation and Culture, Genuine and Spurious.” Pp. 57-73, in: Reconstructing Conservation: Finding Common Ground. B.A. Minteer and R.E. Manning, Eds. Washington, DC: Island Press.

Wondolleck, J.M. and S.L. Yaffee. 2000. Making Collaboration Work: Lessons from Innovation in Natural Resource Management. Washington, DC: Island Press. 
Community, place, and conservation

Gene L. Theodori and Gerard T. Kyle

Today, the term community is commonly invoked in natural resource, ecosystem management and decision-making literature. ${ }^{1}$ Domain-specific expressions such as "community fisheries management," "community forestry," "community watershed management," and "community wildlife management," as well as the general, overarching phrase of "community natural resource management" are commonplace in popular and scientific writings. In recent years, there has been a preponderance of papers presented and journal articles published on community-based natural resource management and decision-making issues (Luloff et al., 2004). This relatively large body of research, much of which was conducted in developing countries of southern Asia and Africa, has provided scientists, natural resource managers, policy makers, activists, and the general public with an overview of the paradigmatic shift from the overly synoptic, scientifically-based, top-down, centralized, expert-driven, rational-comprehensive management and decision-making model to one that promotes - both literally and often figuratively - the integration of "communities" into natural resource management and decisionmaking processes (Brosius, Tsing, \& Zerner, 1998; Conley \& Moote, 2003; Cortner \& Moote, 1999; Lachapelle, McCool, \& Patterson, 2003; Lee \& Field, 2005; Weber, 2000). It has also provided empirical information on a variety of community-related natural resource management and decision-making topics, spanning the gamut from implementation to evaluation (Carr \& Halvorsen, 2001; Kellert et al., 2000; Kruger and Shannon, 2000; Wittayapak \& Dearden, 1999). 
Theoretically, the core premises underlying community-based natural resource management are very appealing. Included among the principal assumptions of devolving natural resource management and decision-making activities to local communities, as noted by Brosius et al. (1998, p. 158), are the ideas "that local populations have a greater interest in the sustainable use of resources than does the state or distant corporate managers; that local communities are more cognizant of the intricacies of local ecological processes and practices; and that they are more able to effectively manage those resources through local or 'traditional' forms of access." Despite the hopeful enthusiasm, numerous questions surrounding the purported strengths and limitations of community-based natural resource management abound in the literature (cf. Bradshaw, 2003; Cortner et al., 2001; Gray, Fisher, \& Jungwirth, 2001; Webber 2000).

A basic, fundamental issue in the extant community-based natural resource management and decision-making literature is the problem of definition. Upon careful examination of both the international and domestic research, it becomes increasingly evident that no shared theoretical foundation or common use of the concept of community exists (Agrawal \& Gibson, 1999; Flint, Luloff, \& Finley, 2008; Kumar, 2005; Luloff et al. 2004). The term community has been used in a vast assortment of ways, and we believe there is no foreseeable end to the countless ways it might be used. Undoubtedly, such variations in conceptual orientations and use have led to a somewhat complex and cloudy knowledge base with respect to community - and - natural resource management and decision-making linkages. In fact, with respect to the increasing popularity and use of the phrase community-based forestry, Flint, Luloff and Finley (2008, p. 526) recently posed the following question: "Where is 'community' in community-based forestry?" 
Concomitant issues surrounding definitions and uses of the concept of community abound in the place literature (Agnew, 1987, 1989; Entrikin, 1991; Eyles, 1985). While the term community is frequently employed in the place literature, it is rarely, if ever, rooted to any theoretical perspective of social organization, much less defined. Subsequently, place researchers have tended to use a priori definitions of community in their studies, which are generally deduced from objective indicators that may have little in common with any subjective interpretations held by community members. In such investigations, community is often equated with a geopolitically-bounded territory (i.e., township, neighborhood, borough, city, county). A central theme throughout much of the place literature is the identification of settings within territories to which individuals, most often the local residents, ascribe meaning and sentiment. A vast majority of these studies are empirical examinations focused on a particular aspect of human-place bonding (e.g., place attachment, place identity, place dependence, sense of place) within a territorial setting, which is generally referenced as a community (Fried, 2002; Hidalgo \& Hernández, 2001; Low \& Altman, 1992; Speller, Lyons, \& Twigger-Ross, 2002). Virtually no attention is given to the social organization and/or processes girding community, the role of community for the manner in which residents ascribe meaning and sentiment to place, or to community theory.

For natural resource managers and/or policymakers interested in natural resource management and decision-making at a local community level, certain conceptual concerns must be addressed. Included among these concerns are (a) defining the concept of community and (b) explicating its relationship to place (see also chapter by Flint in this volume). The purpose of this paper is to present an analytical framework for examining the association of community and place, and for focusing natural resource management and decision-making issues upon aspects of 
this relationship, specifically as it pertains to our nation's public lands. In the United States, natural resource ownership patterns and management systems are quite different than the resource management regimes found in most developing countries. In many developing countries, some - and oftentimes a relatively substantial portion - of the natural resource assets in the public domain are shared as communal property and/or managed as state property through leases or other agreements between residents and the central government. Conversely, natural resources in the United States, as Flint et al. (2008, p. 528) noted, "are sometimes figuratively shared, but management decisions are made in a complex jurisdictional mosaic where private landowners maintain control over their land and resources while public land is managed in a bureaucratic, top-down approach."

Despite all of the recent rhetoric surrounding the integration of communities into natural resource management and decision-making activities, management decisions involving our nation's public resources ultimately reside with the government agencies. Policies and management decisions continue to be made by agency scientists with specific disciplinary expertise. A quotation from Lee and Field (2005, p. 291) clearly illustrates the disconnect between decision-making and communities:

Even today, policies are legitimated by chartering scientific studies and policy and management decisions by developing 'scientific-based plans.' Communities, especially territorial communities, are the recipients of 'rational' decisions made by experts - what we today often refer to as the many 'ologists': biologists, ecologists, sociologists, ornithologists, etc. Professional decision makers may solicit community 'input,' and make decisions in the interests of interested publics, including communities. Community participation is often avoided because 
it is replete with the sorts of 'messiness' that was to be supplanted by rationality and sciencebased decisions.

Much of this messiness with respect to community involvement in natural resource management and decision-making, we contend, stems from a lack of systematic theory and a misunderstanding of what a community is, how a community develops, and how community is related to place. Below we provide a conceptual framework for addressing these issues. The interactional theory of community (Kaufman, 1959, 1985; Wilkinson, 1970a, 1991), which asserts that community is a field of place-oriented social interaction, serves as the analytical foundation of our discussion. Before concluding, we highlight the potential applications of the interactional approach for public agency natural resource managers.

\section{Community and Place}

For the sake of a place to start, we begin our discussion of community with place. Place has been and remains a critical component in social scientific studies of community. In Day's (2006, p. 32) summation:

... the whole approach to community studies displays a certain circularity. Places are singled out for study because they appear to constitute viable communities, and once they are investigated and documented, the findings are read as showing precisely what a real community is like.

If, in fact, place is a logical point to begin the search for community, how does one know when he/she has found community? Let us assume that one does find community in or around a place, as is often the case; then, of what significance does that place hold for community? Concomitantly, what influence does community have on place? And, most importantly for our 
present purposes, what are the associations between place, community, and natural resource management and decision-making? Attempts at answering the latter question, theoretically, have been relatively naïve in the natural resource management and decision-making literature. The interactional theory of community advocated by Harold Kaufman $(1959,1985)$ and Kenneth Wilkinson (1970a, 1991) and further elaborated upon by their colleagues and students provides a useful framework for addressing the aforementioned questions, as well as examining the relationship of community to place and for focusing natural resource management decisionmaking upon aspects of this relationship.

Rather than quibble with semantics, allow us to clearly state up front what we are talking about with regard to the terms place and community. Our conceptualization of the former term is grounded in Gieryn's (2000) definition. According to Gieryn (2000), place has three necessary and sufficient features: geographic location, material form, and the investment with meaning and value. This definition is also consistent with other scholars' conceptualization of place (Agnew, 1987, 1989; Entrikin, 1991; Eyles, 1985; Relph, 1976; Seamon, 1982; Tuan, 1977). We conceive the concept of community to refer to that sociological unit of analysis conventionally referred to as "the community." The use of the article "the" before the word community allows us to distinguish the community - that phenomenon which occurs "in a particular kind of territorial and social environment" (Wilkinson, 1986, p. 3) - from alternative non-local uses of community (cf. Bernard, 1973; Wilkinson, 1986). As opposed to community, the community refers to "settlements ... in which locale is a basic component" (Bernard, 1973, p. 3; emphasis in original). The three major theories taking local territory as the base for community - human ecology (Hawley, 1950; Park, 1936; Quinn, 1960), social systems (Sanders, 1966; Warren, 
1978), and the interactional approach (Kaufman, 1959, 1985; Wilkinson, 1970a, 1991) emphasize and utilize the concept of place, albeit in varying degrees and at different scales.

From the interactional perspective (Kaufman, 1959, 1985; Wilkinson, 1970a, 1991), the theory of community which we draw upon throughout the remainder of this chapter, place defined as a geographic location with material form invested with meaning and value (Gieryn, 2000) - can be viewed as a necessary but not sufficient condition for the community. No local community exists nowhere; every local community exists, in fact, somewhere. Accordingly, the local community has geographic location. In and around this locality is material form, both natural and man-made. The physical locale with a compilation of material form is invested with varied meanings and sentiments by its residents and, oftentimes, non-residents alike. The meanings and values of a local community are imagined, felt and understood in varying degrees by the people who may or may not live there. These meanings and values are often expressed and perpetuated through public discourse, collective representations, and rhetorical devices, including heritage narratives and community typifications (Bridger, 1996; Maines and Bridger, 1992; Suttles, 1984).

In addition to place, which "is an essential element of community" from the interactional definition (Wilkinson 1991, p. 19), community requires two additional attributes: (1) a more or less complete local society, and (2) place-oriented collective actions. A local society refers to the social institutions and associations that cover the broad range of human interests in the shared life of a local population (e.g., economic, educational, familial, medical, political, religious, etc.). Place-oriented collective actions refer to the process of interrelated actions through which people express a shared sense of identity while working together to address the common concerns of life in the locality and local society. The latter of these - the place-oriented collective actions, also 
referred to as the "community field" - is the inherent and indispensable ingredient of community from the interactional perspective (Kaufman, 1959, 1985; Wilkinson, 1970a, 1991). The community field provides a unique framework for examining the relationship of community to place, and for focusing natural resource management and decision-making issues upon aspects of this relationship. It is to the notion of a community field that we now turn.

\section{Community Field: A Generalizing Place-Oriented Social Action Field}

As outlined by Kaufman $(1959,1985)$ and Wilkinson (1970a, 1991), local settlements are marked by the presence of several more or less distinct social fields. A social field can be defined as an unfolding, loosely bounded, constantly changing, interconnected process of social interaction displaying unity through time around an identifiable set of interests. As a process, a social field is characterized by a sequence of actions over time carried on by different actors working in or through various associations. Actions include the projects, programs, activities, and/or events in which actors and associations are engaged. Associations refer to formal organizations and informal groups. Actors consist of the leaders and other persons participating in associations and actions.

Multiple social fields comprised of both local and extra-local actors and associations exist and act in any local population. While these social fields can and often do overlap and blend into one another, each field is generally marked to a greater or lesser extent by its own identity, organization, core interactional properties, and set of specific and/or institutional interests. Common recognizable social fields found in many local settlements include those pursuing interests in education, government, faith-based services, economy, recreation, health care, social services, land use, transportation, and environmental protection. The actors and associations of 
the various social fields may share similar perspectives, or they may maintain intensely incompatible ideas. Accordance, as well as conflict, confrontation, competition, marginalization, disenfranchisement, and/or challenges for leadership are common occurrences both within and between/among the social fields in a community (Theodori, 2005).

When the actors and associations of the various social fields, likeminded or otherwise, converge and interact on place-relevant matters, the potential exists to form a community field. Following the interactional perspective, the community field is the mechanism that integrates the various social fields of action into an interactional community. Community, from the interactional perspective, arises "when the latent bond of common interest in the place - the shared investment in the common field of existential experience - draws people together and enables them to express common sentiments through joint action” (Wilkinson, 1991, p. 7). In fact, the underlying reason why a community "hangs together," according to Wilkinson (1991, p. 37 ), is because of the community field.

A community field is a place-oriented social field that is related to, yet distinguished from, other activity fields. Unlike most social fields which are typically focused on furthering their own special interests, a community field pursues the interests of the larger population. In other words, the interest that guides a community field is an interest in social structure rather than an interest solely in specific goals of the particular social fields. Like other social fields, a community field is comprised of actors, associations, and phases of action. Moreover, the actions of a community field, like those in other social fields, are also directed toward certain interests. However, unlike other social fields:

the interests [in a community field] are generalized and intrinsic; they are not specialized or instrumental. The community field cuts across organized groups and across other 
interaction fields in a local population. It abstracts and combines the locality-relevant aspects of the special interest fields, and integrates the other fields into a generalized whole. It does this by creating and maintaining linkages among fields that otherwise are directed toward more limited interests (Wilkinson, 1991, p. 36).

The central feature distinguishing a community field from other social action fields is the generalization of place-oriented actions across interest lines. Generalization gives structure to the whole of community as an interactional phenomenon by linking and coordinating the common place-relevant interests and behaviors of multiple social fields. In essence, a community field interlinks and organizes the various social action fields and binds their knowledge, experience, resources, and energy for the common good. It is extremely important to recognize, though, that: the coordinating actions undertaken in the community field do not necessarily harmonize diverse interests or completely bridge different perspectives and viewpoints. Instead, the community field brings into focus common interests in local aspects of local life. And, of equal importance, as the linkages that comprise the community field proliferate, they lead to a more inclusive decision-making process (Bridger \& Luloff, 1999, p. 384).

While the potential for a community field to emerge exists in all human territorial settlements, the extent to which such emergence occurs is highly variable. Numerous structural constraints at regional, national, and international levels, each manifested at the local level, contribute to this variability (Theodori, 2008). Factors such inequality (e.g., racial, ethnic, class, gender, etc.), poverty, ruralness, population size and dispersion, and deficits in economic and social services (Wilkinson, 1991) often impede the natural processes of local social interaction and, in turn, the emergence of a community field. It follows, then, that the community field is a variable; it is a matter of degree. The presence of the community field is what differentiates a 
community, that "natural disposition among people who interact with one another on various matters that comprise a common life" (Wilkinson, 1991,p. 7), from an aggregation of individuals who may or may not share a sense of community in and around a place with a more or less complete local society. Such variance, as will be described below, has implications for place and any natural resource management and decision-making activities that may be undertaken.

To this point, we have established that place is a necessary but not sufficient condition for the local community. We also have recognized that in addition to place, community requires a more or less complete local society and a community field. And, we have suggested that a community field is not a given. Instead, as we will argue, a community field emerges in a population and persists as long as the local citizens ensure its survival. The idea that community is an interactional phenomenon provides a unique way of thinking about how to build, strengthen, and nurture the community field. This is accomplished through the process of community development.

\section{Community Development}

The process of community development - that is, "purposive action undertaken with positive intentions at improving community structure" (Theodori, 2005, p. 666) - is what is needed for the community field to materialize and flourish in a local settlement. Community development, from the interactional approach, can be viewed as a process of building, strengthening, and maintaining the community field (Wilkinson, 1972, 1991). Concerted efforts to promote community development are needed at multiple levels (e.g., local, state, and federal) to successfully surmount the aforementioned structural impediments that restrict and/or suppress 
the emergence of the community field. Attempts at the local level without action at other levels, and vice versa, are likely to be less successful than a coordinated, multi-pronged effort (Theodori, 2008). However, it is important to keep in mind that despite the necessity for efforts at other levels, community development, as we conceive it, does not happen unless local people try to make it happen.

Four principles underlie the process of community development from the interactional perspective (Theodori, 2005; Wilkinson, 1972, 1989, 1991). First, community development is purposive. Community development is the intentional consequence of actors and associations interacting to initiate and maintain community among themselves. Second, community development is positive. The purposive intentions of the actors and associations revolve around a shared commitment to improving their community. Third, community development is structure oriented. The purposive and positive actions of actors and associations are direct attempts to establish, strengthen, and/or sustain the community as an interlinking and coordinating structure of human relationships. And fourth, community development exists in the efforts of people and not necessarily in goal achievement. The essence of community development as an interactional phenomenon resides in the doing - the working together toward a common goal - not solely in the outcome.

Viewed in this light, community development involves purposive, positive, and structureoriented actions between/among the various social fields aimed at constructing, enhancing, and/or sustaining channels of cooperation and communication across interest groups within the community. In this process, individuals, informal groups, and formal organizations, despite their differences, consciously work to increase the number and/or reinforce the strength of relationships among the various social fields, while reducing and/or circumventing the barriers to 
cooperation and communication (e.g., conflict, confrontation, competing interests, marginalization, disfranchisement, and/or challenges for leadership). With time and effort, these newly formed relationships encourage mutual understanding, cultivate trust, and, in turn, promote social well-being (Wilkinson, 1979).

At this point in our discussion, it is important to draw a distinction between two broad types of development and two broad spheres of community action. The former are commonly referred to as development in community and development of community (Summers, 1986; Theodori, 2005; Wilkinson, 1991). In brief, development in community primarily refers to improvements and infrastructural enhancements such as economic growth, modernization, improved service delivery, and business retention, expansion, and recruitment activities. In contrast, development of community, the type of development described above, is a much broader process aimed at building, strengthening, and maintaining the community field.

The broad spheres of community action are generally known as task-accomplishment and structure- building (Cartwright \& Zander, 1968; Kaufman, 1959; Theodori, 2005; Wilkinson, 1970b, 1991). Community actions that occur in the social fields containing specialized or limited interests can be viewed as having a task-accomplishment orientation. Task accomplishment refers to activities that move people toward specific goals, which are generally related to a particular project in a specific field of interest. Task accomplishment processes can be thought of as having five stages or episodes (Bales \& Strodtbeck, 1951; Wilkinson, 1970b, 1991). Wilkinson's (1970b, 1991) articulation of these included: (1) initiation and spread of interest, (2) organization of sponsorship, (3) goal setting and strategy formation, (4) recruitment, and (5) implementation. In the process of group problem-solving and decision-making, initiation and spread of interest involves recognizing and discussing a problematic issue as a potential focus for 
group action. Organization of sponsorship involves identifying an existing structure (i.e., a committee, group, organization) or establishing a new one to deal with the issue. Goal setting and strategy formation involves setting goals and developing a plan to reach those goals. Recruitment involves mobilizing resources, such as participants, facilities, and finances. And implementation involves applying resources and employing strategies to deal with the issue.

The same five stages or episodes can be used to conceptually frame the structure-building actions associated with the acts of a community field. In this case, though, initiation and spread of interest involves generating widespread consciousness of an issue among various fields of interest in a community. Organization of sponsorship involves the formation of multi-interest networks and inter-organizational linkages to coordinate and integrate actions within and across the various social fields. Goal setting and strategy formation involves developing short-term strategies and long-range goals that transcend the special interests of particular social fields. Recruitment involves encouraging participation from the various social fields. And implementation involves applying resources and employing strategies to create, reinforce, and sustain relationships and lines of communication between/among the various social fields. ${ }^{2}$

In any given community, both forms of development - development in community and development of community - and both spheres of action - task-accomplishment and structurebuilding activities - make and shape places and have direct implications for proposed natural resource management and decision-making. However, it is important to understand that the social interactions which occur in/through the processes of structure-building will construct place and affect natural resource management and decision-making actions in a qualitatively different manner than those that only occur with a task-accomplishment orientation. When actors and associations engage in task-accomplishment actions while giving attention to structure-building 
activities, the place that is made assumes a gestalt-like character. In other words, the place that is made in/through the community field is greater than the sum of its individual social field parts. And, the involvement of the community field in proposed natural resource management programs and decision-making processes will be community-based as opposed to reflecting the interest of some other unit(s) of organization.

In short, the interactional theory of community and community development described above provides a conceptual framework for understanding what a community is, how a community is related to place, and how a community develops. Our attention now turns to highlighting the potential applications of the interactional approach for natural resource managers and agency personnel.

\section{Potential Applications for Natural Resource Managers and Public Agency Personnel}

Good theory, we believe, leads to good application. While other perspectives of community (e.g., human ecology and social systems) do, in fact, exist and may be considered justifiably worthy, we believe that the interactional theory of community has much to offer natural resource managers and agency personnel as they interact with local population settlements in and around our nations' public lands. Community-based natural resource management and decision-making activities rooted in the assumptions, propositions, and concepts of the interactional approach have the potential to truly enhance the focus and effectiveness of resource management policies and practices at the community level.

Before proposing or engaging in any type of community-based natural resource management activity, public agency natural resource managers must assess the extent of community in a local population. Community, as has been maintained throughout this discussion, is not a given; it is a variable. Community has three essential elements - place, a 
more or less complete local society, and a community field. These three properties provide the criteria for assessing its extent in a local population settlement. Like conventional community studies, an assessment of the extent of community in a local settlement should begin with place. Natural resource managers and agency personnel must understand place and the significance it holds in the everyday life of a local population. With the aid of local key informants, managers must become cognizant of the size and scope of the physical locale, the natural and man-made material forms in and around the locality, and the associated meanings and values of the local population as expressed and perpetuated through public discourse, collective representations, and rhetorical devices.

In addition to understanding place, natural resource managers and agency personnel must recognize the extent and comprehensiveness of the local society. As noted above, a local society refers to the social institutions and associations that cover the broad range of human interests in the shared life of a local population (e.g., economic, educational, familial, medical, political, religious, etc.). Local societies generally vary in the quantity and quality of their respective social and economic institutions. Concerted efforts must be undertaken by natural resource managers and agency personnel to enhance their knowledge of the social institutions and associations that are and are not manifest within the local settlement. Also, natural resource managers and agency personnel must discern the horizontal and vertical patterns of relationships among the local social units that comprise the various social institutions (Warren, 1978).

Last but not least, natural resource managers and agency personnel must assess the presence and/or strength of the community field. With assistance from local key informants, public agency natural resource managers must first inventory the various social fields that exist within and/or share interest in a local settlement. The inventory should include: the principal 
actors (i.e., formal and informal leaders), the associations (i.e., formal organizations and informal groups), and the major actions (i.e., project, programs, activities or events) that have been, or are currently being, undertaken. Moreover, the inventory should differentiate between highly locality-oriented social fields and their lesser locality-oriented counterparts, and account for the use-value and exchange-value orientations of the different social fields. Unlike their counterparts, highly locality-oriented social fields are clearly identified with the locality; they tend to involve local residents as primary actors and/or leaders. As opposed to those with usevalue orientations, the actions of exchange-value oriented social fields generally revolve around maximizing economic profits through the commodification of places and resources in and around the local community. Exchange-value oriented social fields are typically directed by local and/or extra-local elites, who more or less control the local decision-making and growth machinery. Overall, attempts should be made to see that the inventory is as inclusive as possible.

Next, with the help of local key informants, natural resource managers and agency personnel must spell out any/all connections that exist, or have existed, between/among the various social fields. Even though social fields maintain unity through time around an identifiable set of interests, they are in a constant state of change as actors and associations, each with their respective actions, move into and out of contact with the process. Therefore, it is important to view these linkages temporally. Following this strategy, public agency resource managers should discover which social fields share (or have shared) similar ideas on placerelevant matters, and which social fields display (or have displayed) differences in opinions. In addition, they should uncover which social fields customarily work (or have worked) together on place-relevant matters, and which social fields are traditionally (or have been) hostile to one 
another. Such an exercise will provide an evaluation of the presence and/or strength of the community field, and it will highlight potential points of conflict to be carefully negotiated.

The presence of strong community fields representing the shared, overlapping placerelevant interests of all segments of the local population, we believe, is required to successfully integrate communities in and around our nation's public lands into natural resource management and decision-making activities. And, community development - purposive, positive, and structure-oriented actions aimed at constructing, enhancing, and/or sustaining channels of cooperation and communication between/among the various social fields - is needed for strong community fields to materialize and flourish. In addition to conventional output-based components, natural resource management plans must incorporate structure-building activities. Efforts to foster development of community at the local level must, in fact, be a key ingredient in natural resource management practices and policies. We contend that much of the messiness surrounding community participation in natural resource management and decision-making, as alluded to above, can be rectified with conscious, systematic endeavors aimed at cultivating and nurturing the community field.

Finally, as public agency natural resource managers work to increase the number and/or reinforce the strength of relationships among the various social fields, while reducing and/or circumventing the barriers to cooperation and communication, they must make a concerted effort themselves to communicate openly and honestly. Open and honest communication, including full disclosure about the potentially positive aspects and negative consequences of proposed management plans and activities, is likely to reduce the chances of inaccuracies, rumors, and future litigation. All of the efforts suggested above will surely mean investments in time and money. Failure to do so, however, may prove to be even more time-consuming and costly. 


\section{Concluding Comment}

Our purpose in this chapter was to present an analytical framework for examining the association of community and place, and for focusing natural resource management and decision-making issues upon aspects of this relationship. Our thesis was that a fundamental dilemma associated with these issues is one of definition. We contended that natural resource managers and agency personnel must enhance their understanding of community, the concept that lies at the heart of community-based natural resource management, if they plan to integrate communities into management and decision-making activities. Echoing sentiments by Flint et al. (2008, p. 535), "simply invoking community in discussions and efforts relating to access to and management of forest and other natural resources without a clear understanding of the term in frameworks, methods, and implementation endangers efforts to link natural resource management with improvements in community well-being." 


\section{References}

Agnew, J.A. (1987). Place and politics: The geographical mediation of state and society. Boston: Allen \& Unwin.

Agnew, J.A. (1989). The devaluation of place in social science. In J.A. Agnew \& J.S. Duncan (Eds.) The Power of place: Bringing together geographical and sociological imaginations (pp. 9-29). Boston: Unwin Hyman.

Agrawal, A. \& Gibson, C.C. (1999). Enchantment and disenchantment: The role of community in natural resource conservation. World Development, 27, 629-649.

Bales, R.F. \& Strodtbeck, F.L. (1951). Phases in group problem solving. The Journal of Abnormal and Social Psychology, 46, 485-495.

Bernard, J. (1973). The sociology of community. Glenview, IL: Scott, Foresman \& Co.

Bradshaw, B. (2003). Questioning the credibility and capacity of community-based resource management. The Canadian Geographer, 47, 137-150.

Bridger, J.C. (1996). Community imagery and the built environment. Sociological Quarterly, 37, 353-374.

Bridger, J.C. \& Luloff, A.E. (1999). Toward an interactional approach to sustainable community development. Journal of Rural Studies, 15, 377-387.

Brosius, J.P., Tsing, A.L., \& Zerner, C. (1998). Representing communities: Histories and politics of community-based natural resource management. Society and Natural Resources, 11, $157-168$.

Carr, D.S. \& Halvorsen, K. (2001). An evaluation of three democratic, community-based approaches to citizen participation: Surveys, conversations, with community groups, and community dinners. Society and Natural Resources, 14, 107-126.

Cartwright, D. \& Zander, A. (1968). Leadership and performance of group functions: Introduction. In D. Cartwright \& A. Zander (Eds.) Group dynamics: Research and theory (pp. 301-317). New York: Harper \& Row.

Conley, A. \& M.A. Moote. (2003). Evaluating collaborative natural resource management. Society and Natural Resources, 16, 371-386.

Cortner, H.J. \& Moote, M.A. (1999). The politics of ecosystem management. Washington, D.C.: Island Press.

Cortner, H.J., Burns, S., Clark, L.R., Sanders, W.H., Townes, G. \& Twarkins, M. (2001). Governance and institutions: Opportunities and challenges. In G.J. Gray, M.J. Enzer, \& J. 
Kusel (Eds.) Understanding community-based forest ecosystem management (pp. 65-96). New York: Food Products Press.

Day, G. 2006. Community and everyday life. New York: Routledge.

Entrikin, J.N. (1991). The betweeness of place: Towards a geography of modernity. Baltimore: The Johns Hopkins University Press.

Eyles, J. (1985). Senses of place. Cheshire, England: Silverbrook Press.

Flint, C.G., Luloff, A.E., \& Finley, J.C. (2008). Where is "community" in community-based forestry? Society and Natural Resources, 21, 526-537.

Gieryn, T.F. (2000). A space for place in sociology. Annual Review of Sociology, 26, 463-496.

Gray, G.J., Fisher, L., \& Jungwirth, L. (2001). An introduction to community-based ecosystem management. In G.J. Gray, M.J. Enzer, \& J. Kusel (Eds.) Understanding communitybased forest ecosystem management (pp. 25-34). New York: Food Products Press.

Fried, M. (2000). Continuities and discontinuities of place. Journal of Environmental Psychology, 20, 193-205.

Hawley, A.H. (1950). Human ecology: A theory of community structure. New York, NY: The Ronald Press.

Hidalgo, M. C., \& Hernández, B. (2001). Place attachment: Conceptual and empirical questions. Journal of Environmental Psychology, 21, 273-281.

Kaufman, H.F. (1959). Toward an interactional conception of community. Social Forces, 38, 817.

Kaufman, H.F. (1985). An action approach to community development. In F.A. Fear \& H.S. Schwarzeller (Eds.) Focus on community (pp. 53-65). Greenwich, CT: JAI Press.

Kellert, S.R., Mehta, J.N., Ebbin, S.A., \& Lichtenfeld, L.L. (2000). Community natural resource management: Promise, rhetoric, and reality. Society and Natural Resources, 13, 705-715.

Kruger, L.E. \& Shannon, M.A. (2000). Getting to know ourselves and our places through participation in civic social assessment. Society and Natural Resources, 13, 461-468.

Kumar, C. (2005). Revisiting 'community' in community-based natural resource management. Community Development Journal, 40, 275-285.

Lachapelle, P.R., McCool, S.F., \& Patterson, M.E. (2003). Barriers to effective natural resource planning in a "messy" world. Society and Natural Resources, 16, 473-490. 
Lee, R.G, \& Field, D.R. (Eds.). (2005). Community complexity: Postmodern challenges to forest and natural resources management. In R.G. Lee \& D.R. Field (Eds.) Communities and forests: Where people meet the land (pp. 291-303). Corvalis: Oregon State University Press.

Low, S. M., \& Altman, I. (1992). Place attachment: A conceptual inquiry. In I. Altman \& S. M. Low (Eds.) Place attachment (pp. 1-12). New York: Plenum Press.

Luloff, A.E., Krannich, R.S., Theodori, G.L., Trentelman, C.K., \& Williams, T. (2004). The use of community in natural resource management. In M.J. Manfredo, J.J. Vaske, B.L. Bruyere, D.R. Field, \& P.J. Brown (Eds.) Society and natural resources: A summary of knowledge (pp. 249-259). Jefferson, MO: Modern Litho.

Maines, D.R. \& Bridger, J.C. (1992). Narrative, community, and land use decisions. Social Science Journal, 29, 363-380.

Park, R.E. (1936). Human ecology. The American Journal of Sociology, 62, 1-15.

Quinn, J.A. (1960). Human ecology. Englewood Cliffs, NJ: Prentice-Hall, Inc.

Relph, E. (1976). Place and placelessness. London: Pion.

Sanders, I.T. (1966). The community: An introduction to a social system. New York, NY: Ronald Press.

Seamon, D. (1982). The phenomenological contribution to environmental psychology. Journal of Environmental Psychology, 2, 119-140.

Speller, G.M., Lyons, E., Twigger-Ross, C. (2002). A community in transition: the relationship between spatial change and identity processes. Social Psychological Review, 4, 3-22.

Summers, G.F. (1986). Rural community development. Annual Review of Sociology, 12, 347371.

Suttles, G.D. (1984). The cumulative texture of local urban culture. American Journal of Sociology, 90, 283-304.

Tuan, Y. F. (1977). Space and place: The perspective of experience. Minneapolis, MN: University of Minnesota Press.

Theodori, G.L. (2005). Community and community development in resource-based areas: Operational definitions rooted in an interactional perspective. Society and Natural Resources, 18, 661-669.

Theodori, G.L. (2008). Constraints to the development of community. Community Development: The Journal of the Community Development Society, 39, 91-110. 
Warren, R.L. (1978). The community in America. Chicago, IL: Rand McNally \& Co.

Webber, E.P. (2000). A new vanguard for the environment: Grass-roots ecosystem management as a new environmental movement. Society and Natural Resources, 13, 237-259.

Wilkinson, K.P. (1970a). The community as a social field. Social Forces, 48, 311-322.

Wilkinson, K.P. (1970b). Phases and roles in community action. Rural Sociology, 35, 54-68.

Wilkinson, K.P. (1972). A field-theoretical perspective for community development research. Rural Sociology, 37, 43-52.

Wilkinson, K.P. (1979). Social well-being and community. Journal of the Community Development Society, 10, 5-16.

Wilkinson, K.P. (1986). In search of the community in the changing countryside. Rural Sociology, 51, 1-17.

Wilkinson, K.P. (1989). The future for community development. In J.A. Christenson \& J.W. Robinson, Jr. (Eds.) Community development in perspective (pp. 337-354). Ames, IA: Iowa State University Press.

Wilkinson, K.P. (1991). The community in rural America. New York: Greenwood Press.

Wittayapak, C. \& Dearden, P. (1999). Decision-making arrangements in community-based watershed management in northern Thailand. Society and Natural Resources, 12, 673691. 


\section{Notes}

${ }^{1}$ Throughout the remainder of this paper, the term "ecosystem management" will be subsumed under the concept "natural resource management."

${ }^{2}$ In practice, the stages for both task accomplishment and structure building activities are rarely well sequenced. Task accomplishment activities within a specific social field and structure building activities at a multiple social field level can begin at any stage, frequently backtracking and leaping ahead. 


\section{Part Two: Individual relationships with place}

Individual relationships with environments are a beginning point to understand the concept of place for many people. We each have places in which we live, work, and have grown-up that provide senses of identity, value, and wholeness. The chapters in this section characterize such relationships and breakdown the issues that make place challenging for planners.

"Sensing value in place" by Herb Schroeder broadens the concept of value to allow a connection between place and decision-making. He views place as being grounded in personal experience and an intimate awareness of one's relationship with certain environments. Schroeder's expansion of the value umbrella to include felt dimensions of place provides needed credibility for place-based planning. In order to articulate these felt dimensions of place, Schroeder recommends experiential practices to improve communication between stakeholders and argues that decision-making should incorporate felt values of place.

"Place meanings as lived experience" by James Barkley extends Schroeder's argument for inclusion of felt dimensions of place within decision-making. Barkley indicates that traditional ways of knowing through science or mainstream environmental ideology stifle the representation of emotions and place meanings by stakeholders. He problematizes our ability to represent our relationships to places in land-use planning processes. Sharing stories of lived experiences about places holds promise to move beyond entrenched conflict and traditional points of contention. His chapter ultimately targets public memory as being critical to create new public values for places. 
Tyra Olstad's chapter entitled "Personal experience and public place creation" describes a significant challenge to connect place to practice. Written from a first-person vantage point, Olstad draws readers into her own lived experience of Wyoming's Red Desert, and clearly portrays a strong sense of place attachment. Yet the agency, in this case the Bureau of Land Management, does not show awareness of her place meanings within their land-use plans. She discovers that other people also feel as if their sense of place is being ignored. Olstad's essay takes readers on a transformation of "my Red Desert" into "our Red Desert" in which new public place meanings are created through stakeholder interaction.

Amsden, Stedman, and Kruger provide insight on a volunteer-based education and restoration program known as "Streamwatch" in Alaska's Russian River. The original purpose of the program was to educate anglers on resource-friendly fishing activities, however as the authors indicate, the campground volunteers do far more than teach campers how to fish. Amsden et al. show that volunteers carry a strong place identity, and share their sense of place with visitors and with each other. Using a photo-elicitation technique, volunteers' sense of place grows with each visitor contact and is reinforced with their own group dynamics as part of the Streamwatch program. Likewise, visitors and managers witness the volunteer restoration activities that have direct effects on the resource, and learn about place meanings through their individualized engagement with volunteers.

These chapters underscore the importance of personal senses of place, and the need to find strategies to represent these senses of place within decision-making forums. Public representation of individual relationships with place is necessary for place-based planning. There are needs to expand that-which-is-deemed-legitimate-evidence for land-use planning forums. 


\section{Sensing Value in Place}

Herbert Schroeder

The concept of value provides a natural connection between place and conservation, the two domains that are the focus of this book. On the one hand, the concept of value is implicit in the practice of conservation. We put time and effort into conservation decision-making because we believe some possible outcomes of our actions have greater value than others. In making decisions, we seek to identify which outcomes actually have the greatest value, and we choose the actions that we believe are most likely to bring about those outcomes. Without some notion of value, we would have no reason for making decisions and no basis for choosing one alternative outcome over another.

On the other hand, the idea of value is also implied in discussions of place attachment and sense of place. To say that someone has an "attachment" to a place is to say that they value the place in a certain way. In the place-studies literature, sense of place is implicitly or explicitly regarded as a quality that enhances the value of a place - a quality that we should seek to create, cherish, and protect in the places where we live, work, and recreate. Thus, the basic question addressed in this book could very well be framed as, "How can the value of place be represented in the conservation decision-making process?"

In this chapter, I will explore the concept of value as it relates to individual people's experiences of places. I will try to show that different ways of understanding the concept of value lead to different approaches to decision-making, some of which are better suited for including place in conservation decisions than others. I will argue that the individual experience of value is grounded in an implicitly felt dimension of awareness, and that this dimension must be taken into account if place-based values are to function effectively in decision-making. Finally, I will 
discuss how experiential practices for accessing the implicit dimension might help people to articulate and communicate their felt sense of place, providing a basis for a decision-making process that better reflects and includes the value of place.

\section{The concept of value}

The word "value" refers to a fundamental dimension of human existence. Issues of value pervade our experience of the world and are involved in virtually all areas of human speech and action - ranging from simple choices of what to have for dinner to basic questions about the meaning and purpose of one's life. The English word "value" comes from an Indo-European root, wal-, which means "to be strong." Related words derived from the same root include "valor," "validity," and "valence" (Morris, 1969; Ayto, 1990). In the English language, it appears that the concept of value is metaphorically linked to ideas of motivation and emotion. Both "motivate" and "emotion" come from an Indo-European word meaning "to push" or "to move" (Morris, 1969; Ayto, 1990). The etymology of these words suggests that when we say something has value, we mean that it has the strength to move us emotionally and motivate our behavior. Despite the ubiquity and importance of value in our lives, finding a precise, scientific definition for the concept of value is problematic. Different schools of philosophy and different disciplines of science have developed alternative definitions and theories for understanding what value is and how it functions in our lives. To review this entire literature would be beyond the scope of this chapter. Instead, I will take as my starting point a frequently-cited paper by Brown (1984), which examines the concept of value as it relates to natural resource allocation decisions. Brown points out several different ways in which the word value has been defined and presents a simple conceptual model for understanding how these different value concepts are related. The account of value that I present in this chapter builds on Brown's ideas and extends them in a way that I 
believe better represents the character of place-based values, providing a basis for decisionmaking practices that can more effectively include the value of place.

\section{Three realms of value}

Brown (1984) focuses on value concepts that relate directly to human preference. In a literature review of value concepts, he finds three distinct ways in which preference-related concepts of value are understood. He presents these as three "realms" of value. The conceptual realm deals with the basis of preference, the relational realm deals with the act of preferring, and the object realm deals with the result or outcome of preference. Differently defined concepts of value are associated with each of these three realms.

In the conceptual realm, Brown defines held value as "an enduring conception of the preferable which influences choice and action." (p.232). Held values are labels by which people identify basic modes of behavior, end-states, and qualities that are good or desirable - like "honesty", "freedom", "beauty", and "loyalty".

In the object realm, Brown defines assigned value as "the expressed relative importance or worth of an object to an individual or group in a given context." (p.233). Assigned values are behavioral expressions of preference for one thing in comparison to others, and can take many forms. Verbal statements of liking, purchases of goods or services, and preference ratings on numerical scales in surveys are all examples of assigned values.

When it comes to the relational realm, Brown is less direct about defining a corresponding value concept. He characterizes value in the relational realm as much in terms of what it is not as in terms of what it is.

[In the relational realm] value is neither a concept held by the subject nor something attributed to the object, but merely that which arises from the preference of a subject for an 
object in a given context. Here, value is not an intrinsic quality of anything-rather, it emerges from the interaction between a subject and an object. ... Value in the relational realm is not observable; it is only at the feeling level (Brown, 1984, p. 233).

While somewhat vague, this definition seems to characterize value in the relational realm as a feeling that arises from a person's preference for an object in a given context. Brown does not provide a distinct name for this concept of value, as he does for held value and assigned value; and he seems to downplay its importance by saying that it is "merely" that which arises from the preference of a subject for an object and "only" at the feeling level.

Brown (1984) depicts the relationship between the three realms of value in a simple diagram (Figure 1). In this diagram, the relational realm is represented by the term "preference relationships" (which apparently refers to an ordering of objects relative to each other in terms of an individual's preferences). Held values in the conceptual realm give rise to preference relations in the relational realm, which in turn give rise to assigned values in the object realm. Thus, in Brown's account, held values are the basis of preference and assigned values are the end result of preference, while the relational realm is merely an unobservable, intermediate step on the causal pathway from held to assigned value. Value in the relational realm is a sort of epiphenomenon, a mere feeling, which apparently does not merit much attention.

In a follow-up to Brown's (1984) article, Hetherington et al. (1994, p. 538) reiterate that the relational realm of value consists of "unobservable thoughts, feelings, or psychological states". They assert that the role of research on environmental values is to identify and measure the relationship between latent concepts of value (held values) and manifest expressions of value (assigned values). They do not discuss what place (if any) the relational realm has in such research. Similarly, a recent review of literature on environmental values (Dietz et al., 2005), 
discusses value mostly in terms of concepts and behaviors, the dominant question being how people's general concepts of what is good or desirable influence their overt choices and actions. The role of feeling in this process receives little if any attention. Other authors who have cited Brown's (1984) paper (e.g. More et al., 1996) also tend to focus on held value and assigned value, while ignoring value in the relational realm.

Thus, the relational realm, where the "act of preferring" (Brown, 1984, p.232) actually occurs, seems to have been left out of most research on environmental values and decisionmaking. Instead of inquiring into the function of feeling and its relationship to held and assigned values, researchers usually seem to assume that people employ (or should employ) a mathematical process to compute assigned values for specific objects based on their general held values. For example, one frequently-used model of human decision-making involves decomposing objects or decision outcomes into a set of attributes, features, or components. An importance weight is assigned to each attribute (presumably reflecting a person's or a group's held values), and then the weighted sum of all the attributes for an object is calculated to obtain the assigned value of the object. This general approach, known as multi-attribute utility theory (Keeney and Raiffa, 1993), is the basis for many decision-making models and practices, such as cost-benefit analysis and conjoint analysis.

In the application of multi-attribute utility theory to decision-making, value is treated as an abstract quantity rather than as a subjective feeling. Once the importance weights are determined, a decision can, in principle, be made simply by carrying out a numerical computation. The actual experience of liking or disliking, accepting or rejecting, is replaced by a mathematical formula for calculating assigned values. This approach, while very useful in many kinds of decision situations, may not be well-suited for decisions in which sense of place is an 
important concern. Multi-attribute utility theory assumes that a place is a bundle of attributes or components whose separate values can be added up to determine the value of the whole. Research on sense of place, however, suggests that place is a holistic, dynamic, experiential phenomenon that cannot be reduced to such a simple, additive model (Patterson et al., 1998; Bott, Cantrill, and Myers, 2003; Brooks et al., 2006). In other words, the value of a place is not just the sum of the values of its various parts. The unique, hard-to-define, gestalt qualities of places as people actually experience them tend to drop out of such an analytical decision-making process.

\section{Felt value}

To incorporate the holistic, subjective experience of place into the decision-making process, the role of value in Brown's (1984) relational realm needs to be reconsidered. To better recognize and represent the qualities inherent in people's experiences of places, the relational realm needs to be placed on an equal footing with the conceptual and object realms in our understanding of how people value places. Giving full consideration to the relational realm requires a shift from a cognitive and analytical view of the value of place to a more affective and experiential perspective, in which the process of making decisions matters as much as the end results of decisions.

In the relational realm, value is not an abstract concept about what is good or preferable, nor is it a numerical quantity that can be multiplied and added up to arrive at a measurement of worth. In the relational realm, value is an immediately felt experience of liking or disliking, approving or disapproving, accepting or rejecting. In his philosophical analysis of relational value meanings, Jessup $(1943,1949)$ argues that it is precisely this kind of experience that characterizes value as value. Unlike Brown (1984) and Hetherington et al. (1994), Jessup (1949) 
does not see value in the relational realm as consisting of unobservable feelings that are inaccessible to empirical study. Jessup argues that feeling is in fact observable and constitutes essential data for the study of values. Feeling, Jessup says, is an element of awareness just as much as is sensation. It can be attended to while it occurs and can be remembered and reflected upon later. Its occurrence and quality can be checked by repeated experience of an individual and can be compared to reports from other people of their feelings: "Felt-value or feeling is on a par with sensation. Somehow, judgments of fact come out of sensations; and equally, somehow value-judgments come out of felt-values (Jessup, 1949, p. 138)." Following Jessup, I will give the name "felt value" to value in the relational realm. I define felt value as the immediate, subjective feeling of the importance, worth, or significance that something has for an individual.

Recognizing that the relational realm is not a black box but is accessible to observation allows us to take a closer look at how the three realms of value relate to each other in the human process of valuing. Brown's (1984) scheme implies that the valuing process begins with abstract concepts about what is good or desirable (held values), and that felt value does not arise until after a preference ordering of objects has been established based on held values.

Phenomenological inquiry into the actual experience of valuing suggests, however, that feeling is involved in every aspect of the human phenomenon of value. Held values are not simply abstract concepts about what is good, but already carry with them an immediate feeling of importance or "requiredness" (Fuller, 1990), which is what gives them their motivational force. In Jessup's (1949) account, value-judgments (which correspond to Brown's held values) emerge from feltvalues and retain the felt quality characteristic of value. A concept of the preferable that is devoid of any actual feeling of liking or approval cannot, according to Jessup, function as a 
value. A purely intellectual idea of "honesty," for example, would be no more able to motivate our behavior than an abstract concept of "blueness" or "roundness."

From an experiential perspective, it may make more sense to say that held values arise from felt values, instead of vice versa. That is, held values are generalized concepts about what is desirable, which emerge over time from our feelings of liking and disliking in particular circumstances and situations. But it is also true that, once we form abstract held values, our underlying felt values may change as a result. A similar consideration applies to assigned values. In the act of expressing the worth of specific things, the felt values on which our assigned values are based may undergo change. This implies that the relationship between the three realms of value is not as linear as Brown (1984) pictured it, but is more interactive and dynamic (Figure 2). As they give rise to held values and assigned values, felt values themselves may shift and change.

\section{Implicit awareness and the felt value of place}

Within our experience, I contend, felt value underlies and is more fundamental than either held values or assigned values. But it is also true that we are able to think conceptually and reason abstractly about our values. Once we have formed concepts of the preferable, we are able to make logical inferences of what our assigned values ought to be based on those held values. We can and often do use such deductions to guide our decision-making. But sometimes it seems that the assigned values we deduce logically from our held values don't quite match up with our 'gut feelings' about the options we are choosing among. Having made a decision based on a rational analysis of the alternatives in light of our held values, we may still feel uncomfortable with and reluctant to accept the outcome. When that happens, it suggests that something at the 
feeling level has been missed or passed over by our rational thought process. Some facet of felt value is not adequately conceptualized and represented by our system of held values. In this case, no amount of conceptual thinking or logical reasoning based on abstract held values will lead to a resolution of the decision problem. The only way to resolve such a decision impasse is to work it through at the feeling level, to explore how our general concepts of the preferable relate to the intricate, felt texture of the particular situation we are facing. In the words of experiential psychologist and philosopher Eugene Gendlin, ... one hasn't really got the decision (only a general formula for it) as long as one is still unresolved in one's feelings. Feelings are not just intra-psychic entities, they are one's sense of the real situation, how one is in the situation ... . Universal principles and willed standpoints [i.e., held values] haven't really been realized at all until they are realized in terms of the living texture (Gendlin, 1971).

Gendlin's (1996a, 1997a, 1997b) seminal work on the philosophy and psychology of the implicit suggests that the relationship between felt value, held value, and assigned value need to be understood in terms of a distinction between explicit and implicit levels of awareness (Figure 3). Held value and assigned value are both at the explicit level. We can express them in words, name them, communicate them, and make logical deductions about them. Felt value, however, is at the implicit level, which means that, although we experience it and it plays a vital role in everything we do, we generally do not have it in words or explicit concepts. The implicit level of experience is like a backdrop or background of feeling that stays on the fringe of awareness and is often overlooked. More than just an affective tone that colors our experience, it is the whole felt meaning of our experience before we put that meaning into words (Gendlin, 1997a). 
Place meaning and place attachment, I contend, are phenomena that go on primarily at the implicit level. Sense of place is really a felt sense of place - an implicit, preverbal sense of the kind studied by experiential psychologists. Gendlin (1981) defines a felt sense as ... a bodily awareness of a situation or person or event. An internal aura that encompasses everything you feel and know about the given subject at a given time - encompasses it and communicates it to you all at once rather than detail by detail (Gendlin, 1981, p. 32).

Gendlin emphasizes that a felt sense is not the same thing as an emotion. It is both more subtle and more intricate than an emotion. It embodies the whole meaning or structure of a situation and implies the diverse ways in which the situation might unfold and develop. A felt sense conveys far more information than can be expressed in words and concepts at the explicit level. In particular, this means that the implicit felt sense of a place and of its value to a person is too intricate to be captured in a multi-attribute utility model. The felt value of a place is not mathematically determined by how well the place complies with a pre-specified list of held values. Instead, the felt value of a place embodies a person's whole history and experience of interacting with that place and with other places. Relevant dimensions of value emerge from a person's holistic felt sense of place and may change depending on the context. Therefore, to include sense of place in decision-making we need decision practices that do not by-pass the implicit level of experience and do not ignore or lose touch with the felt value that underlies held and assigned values. Our decision-making process needs to include some means for directly accessing and working with this implicit, felt level of experience.

\section{Experiential practice and value process}

In his research on psychotherapy, Gendlin $(1981,1996 a)$ found that when people attended to their unclear, implicit felt sense of a situation in a particular way, they could experience a shift in 
the felt sense that brought new insights and changed the way they felt about and related to the situation. Clients who were able to do this had consistently better outcomes from their therapy than those who simply talked about their issues at a conceptual level. Gendlin developed a way of teaching people how to tune into this level of awareness in order to facilitate such shifts. Gendlin's (1981) method, which he calls focusing, involves a series of six steps:

1. Clearing a space. This is a preliminary step, in which you review or inventory the issues, concerns, and problems that are most prominent in your awareness at the present moment. The purpose is to temporarily set these issues aside, creating a positive and receptive mind/body set within which the other steps can take place.

2. Getting a felt sense. In this step you select an issue or concern (or, in the context of this chapter, a place); try to sense the whole, unclear bodily feeling of it; and stay with that feeling without analyzing or coming to any conclusions about it.

3. Finding a "handle" for the felt sense. You then look for a word, a short phrase, or an image that fits the quality of the felt sense. This "handle" should come from the felt sense itself and not be imposed on it from outside.

4. Resonating. Now you check the rightness of the handle by going back and forth between the words or image and the felt sense. If the handle fits, you will feel a response or a slight change in the felt sense.

5. Asking. In this step, you ask what the felt sense is all about, and wait for an answer to come out of the felt sense. Along with the answer comes a shift in how the situation or issue feels. This shift feels like an opening or a release of tension with respect to the issue of concern. 
6. Receiving. In the final step you accept whatever came in the previous steps in a friendly way and spend a little time with it, before deciding whether to continue focusing or to stop.

Gendlin (1981) presents these steps as an aid for learning, not as a rigid process. The steps might actually occur in any order, each step may occur several times in a given session, or some may not occur at all. The whole process is done with an attitude of openness and flexibility, going along with the felt sense as it unfolds, rather than trying to force it through a predefined program. A noticeable shift in the felt sense might not occur at all, or (more commonly) there might be several small shifts in the felt sense during a given focusing session.

It is perhaps best to think of focusing not as a technique defined by a particular set of steps, but as a general style of relating to implicit, bodily awareness. Gendlin (1996b) has characterized focusing in a very broad sense as "just that uncomfortable, bodily sense that's complex and you don't know what it is yet. That's all it is. It's spending time with that body sense. As soon as somebody does that, they've got focusing." Gendlin's (1981) six-step formulation of focusing has been modified, adapted, and extended in a variety of ways based on people's experience with using it. Alternative approaches to describing and teaching it have been put forward (e.g. Cornell, 1996; Campbell and McMahon, 1997). Ultimately, anyone who uses this kind of experiential practice must discover for themselves what works and doesn't work for them. The fifth step in Gendlin's focusing practice, in which an explicit word or image brings a noticeable shift or change in the felt sense, is the crux of the process and is worth examining more closely. The felt shift comes with a sense of relief or rightness, as though it were what the felt sense was wanting all along. Gendlin uses the term carrying forward to refer to this kind of shift in a felt sense. The kinds of words, images, or events that a felt sense needs in order to carry 
forward are implied by the felt sense even before the person knows explicitly what they are. When they occur, the felt sense "recognizes" them and responds with an easing of tension and a sense of enlivenment.

The act of finding and making explicit something that is initially only implicit in the felt sense is sometimes called explication. When a felt sense is explicated, however, it does not lose its implicit character. Rather, it is carried forward into a new, different felt sense that implies something further, beyond what has already been explicated. In this way, the focusing practice proceeds through a sequence of explications by which the felt sense continues to shift and unfold in greater clarity and intricacy. In these terms, we can now say that held values and assigned values are explications of felt value. That is, held values and assigned values are words and actions that make explicit, in different ways, some of what is implicit in a felt sense of value. If accurately formulated, they will carry forward felt value in the way described above. If not, there will be a lingering feeling of uneasiness and a sense that the words do not convey what really matters in the situation.

Gendlin (1967) uses the term "value conclusions" to refer to a person's explicitly stated preferences, choices, and goals. (In the terms we are using here, this includes both held and assigned values.) He argues that an adequate understanding of values must consider not only a person's value conclusions but also the process by which the person reaches them. When a person's decision-making process is effective, its course is not determined by the general value beliefs that the person holds at a conceptual level, but by the implicit, highly specific, experiential aspects of the situation the person is dealing with.

The order in which experiential valuing occurs is the reverse of how it is often portrayed. We do not first adopt value-conclusions from some system and then apply them to choose between 
different possibilities. First we must confront and differentiate experienced meanings (felt meanings). Then we find that these now differentiated felt meanings have a significant feel of good or bad, resolved or conflicted. If the latter, we resolve them by differentiating still further and further (Gendlin, 1967).

The process of differentiating felt meanings is what Gendlin formulates and teaches in the steps of his focusing practice. When value conclusions are adopted without engaging in some such experiential process, he argues, the person will be unable to "adapt, creatively employ, explain, show in detail, [or] respond well to certain situations requiring these values." In the worst case they may experience "confusion, denial, conflict, and surrender of certain areas of enterprise" (Gendlin, 1967).

While set specifically in the context of psychotherapy, Gendlin's discussion of values and experiential practice is relevant to any area in which important and difficult decisions must be made. Experiential practices like focusing have in fact been applied to a variety of areas beyond psychotherapy, such as dream interpretation (Gendlin, 1986), creative writing (Perl, 2004), conflict resolution (McGuire, 2008), spirituality (Campbell and McMahon, 1997), environmental psychology (Schroeder, 2008), ecopsychology (Fisher, 2002), phenomenological psychology (Shapiro, 1985), qualitative research (Todres, 2007), and philosophy (Gendlin, 1997b; Hendricks, 2004). In an earlier paper (Schroeder, 1990), I have illustrated how Gendlin's focusing practice can be used to explicate the felt value in one's experience of a natural environment. By focusing on my felt sense of one of my favorite places (a forested arboretum) I was able to identify and express why I felt a sense of rightness and belonging in that place. Aspects of my experience of the place that up until then had only been implicitly felt became explicit, enabling me to articulate more clearly why I valued that place so strongly. 


\section{Application to place-based conservation}

Recently, there has been considerable interest in applying experiential practices to enhance decision-making in people's personal lives (Cornell, 2006; Afford, 2008) and in fields like business (Johnson and Barak, 2007; McGuire, 2008), medicine (Grindler-Katonah, 2003; Prado Flores, 2007), education (Doi, 2008), the arts (Crvenkovic, 2008), and environmental management (Walkerden, 2005). Anecdotal evidence suggests that working with the implicit felt sense of a complex or difficult issue may help an individual to make better decisions about the issue, find creative alternatives that they otherwise might not have thought of, and feel more confident that their final decision is a good one. Some individuals have reported that basing a decision on their felt sense of a difficult situation empowered them to resist pressure from expert authorities and to participate more proactively with professionals in deciding on a course of action (Hendricks-Gendlin, 2003; Darer, 2007).

Because experiential practices like focusing are based in the experience of the individual, their most obvious application in decision-making is to situations where one person must make a decision about which they feel ambivalent or conflicted. An example in the context of placebased management might be a landowner deciding how to manage a forested parcel that has been in their family for many years. An expert on forest ecology might urge the landowner to thin their forest and remove non-native species of trees to promote the health of the ecosystem. The landowner might feel pressured to follow this advice, since it conforms with generalized beliefs about caring for the environment and is backed by the authority of science. At the same time, complex feelings relating to family history and traditions with respect to the property might cause the landowner to feel hesitant about acting according to the expert's advice. In resolving the decision problem, the landowner would benefit from being able to explicate the intricate felt 
meanings and values that he or she has about the land. If those meanings and values are left implicit and unacknowledged, the landowner later may regret having made a decision that at the time appeared rational and reasonable.

A decision involving a property of which one is the sole owner is difficult enough, but most decisions about managing places are still more complex because they involve multiple owners or stakeholders who may have different ways of knowing and valuing the same place. In this case, individuals must not only be able to access and express their own felt sense of value for a place, but must take into account the values, meanings, and feelings of other people involved in the decision.

Experiential practices like Gendlin's focusing have an intrinsic social aspect that comes into play when they are used in a group context. The presence of another person can have a profound effect on a person's ability to carry out a practice like focusing. Being heard by a listener who is open, accepting, and non-judgmental is often found to facilitate the practice, allowing an individual to go deeper into their own felt sense of an issue or problem. On the other hand, a listener who responds with judgments and opinions or who tries to direct the other person's process according to their own agenda interferes with the process and may make it hard for the person to stay with and to carry forward their felt sense of a situation. For this reason, guidelines for facilitation and interpersonal communication have become an important part of the training in focusing and related practices (Cornell and McGavin, 2002).

Approaches to group and community decision-making and conflict resolution have been developed that incorporate this social dimension of experiential practice. For example, McGuireBouwman (2007) describes a structured group process based on Gendlin's focusing practice that was developed for collaborative, consensual decision-making in support groups. McGuire (2007) 
presents the same process in a somewhat modified form for use by teams in hierarchical organizations like business and government. Leadership roles of agenda-setting, time-keeping, process-monitoring, and recording are shared among group members. The group process is designed to provide individuals with opportunities to go into their felt sense of the topic under discussion, to speak from that felt sense without interruption, and to be assured that other group members have listened and accurately heard what they have said. In this way, group interactions serve to support and maintain the participants' awareness of their implicit, felt values and to bring them constructively into the decision process. Various alternative procedures are provided to work through conflicts and other obstacles to reaching consensus.

Applying a formal, collaborative decision-making process like McGuire's (2007) in a place-based conservation context ideally would enable individuals to stay in touch with their implicit felt sense of the values that underlie the issues and choices being debated, and to respect and support other members of the decision-making group in doing the same until a decision that respects everybody's sense of place can be found. Adapting this kind of approach to a public land-use decision-making context might be quite challenging, however, since it requires all participants to have a high degree of trust, a willingness to step back from entrenched positions, and a commitment to really listen to those with whom they may disagree. Everyone involved in the decision would have to be committed to using such an experientially-based, consensual process in coming to a decision as a group.

In situations where a formalized process like McGuire's is not feasible, there still may be opportunities for individuals (professionals or members of the public) to draw informally upon their implicit, felt sense of value while deliberating over a decision as a group, and to encourage and support others to do the same. Walkerden (2005) offers insights into how the implicit 
dimension or "felt knowing" can be brought into environmental decision-making based on his own experience working at the local community level. He argues that working from felt knowing (as opposed to relying completely on technical rationality) is central to skilful environmental practice and makes collaborating across disciplines easier. Working from felt knowing involves "slowing down in the midst of conversation, thinking, writing, experimenting and observing," and "taking in a layer of knowing that it is easy to feel in a background way without heeding" (Walkerden, 2005, p.183). Walkerden suggests several specific ways for doing this:

- Paying attention to feelings of unease, inklings, and intimations in meetings and interactions; taking time to let them unfold and become clearer so that they can be made explicit and be expressed.

- Pausing from time to time to provide space and stillness in which issues and ideas about the matter at hand are allowed to arise spontaneously.

- Feeling for "fresh edges" in situations that seem to require innovation and creative ways of moving forward.

- Asking one's felt knowing specific questions to help draw out facets of a decision that are as yet implicit and unclearly sensed - for example, "Does this make political sense?" or "How will this sit with our colleagues and managers?"

\section{Conclusion}

Brown (1984) made an important contribution to understanding the concept of value in natural resource management by identifying and distinguishing between the main ways in which this concept is used. In order to clarify the nature of economic values (one form of assigned value) he focused mainly on the object realm and (to a lesser extent) the conceptual realm of value. In this chapter, I have attempted to expand on Brown's approach and adapt it to place- 
based values by offering a fuller account of value in the relational realm (felt value) and of the relationship between the three realms of value.

The experiential decision-making practices described above — whether formalized or informal, and whether used in an individual or a group context - are all intended to give people involved in decision-making access to an implicit, felt level of meaning that holistically encompasses their awareness of all the complexities and nuances of the situation. This is the level at which felt value is lived. Rather than treating value as a numerical quantity (with or without a dollar sign) and reducing decision-making to a computational exercise, these practices aim to keep the decision-maker in constant contact with felt value so that its relevant aspects will not be left out of the decision process. When implicit values and meanings are not acknowledged and respected, the decision process is more likely to run afoul of conflict and hidden agendas, and stakeholders are less likely to be committed to carrying out the decisions that are reached.

While these considerations apply to any decision-making context, they seem especially relevant to place-based conservation. Places are complex amalgams of social, perceptual, and ecological dimensions that are experienced and lived largely at an implicit level. Unless a deliberate effort is made to explicate people's felt sense of place, the meanings and values of the place are likely to remain unspoken and unrepresented in the decision process. Generalized values and norms, scientific assessments, and economic considerations may then dominate the decision while important, context-specific facets of people's relationships to the place are ignored. When implicit meanings are acknowledged and people are supported in speaking about them, the decision process can stay grounded in people's genuine felt senses of the value of a place. At the same time, the act of explicating felt value into verbal expressions of held value and assigned value may carry forward an initially vague sense of value into a clearer and more 
differentiated experience of how and why a particular place is important to a person. In this way, experiential practices for working with felt value may enable people not only to make better decisions about places, but also to unfold and deepen their appreciation of the places about which they are making decisions.

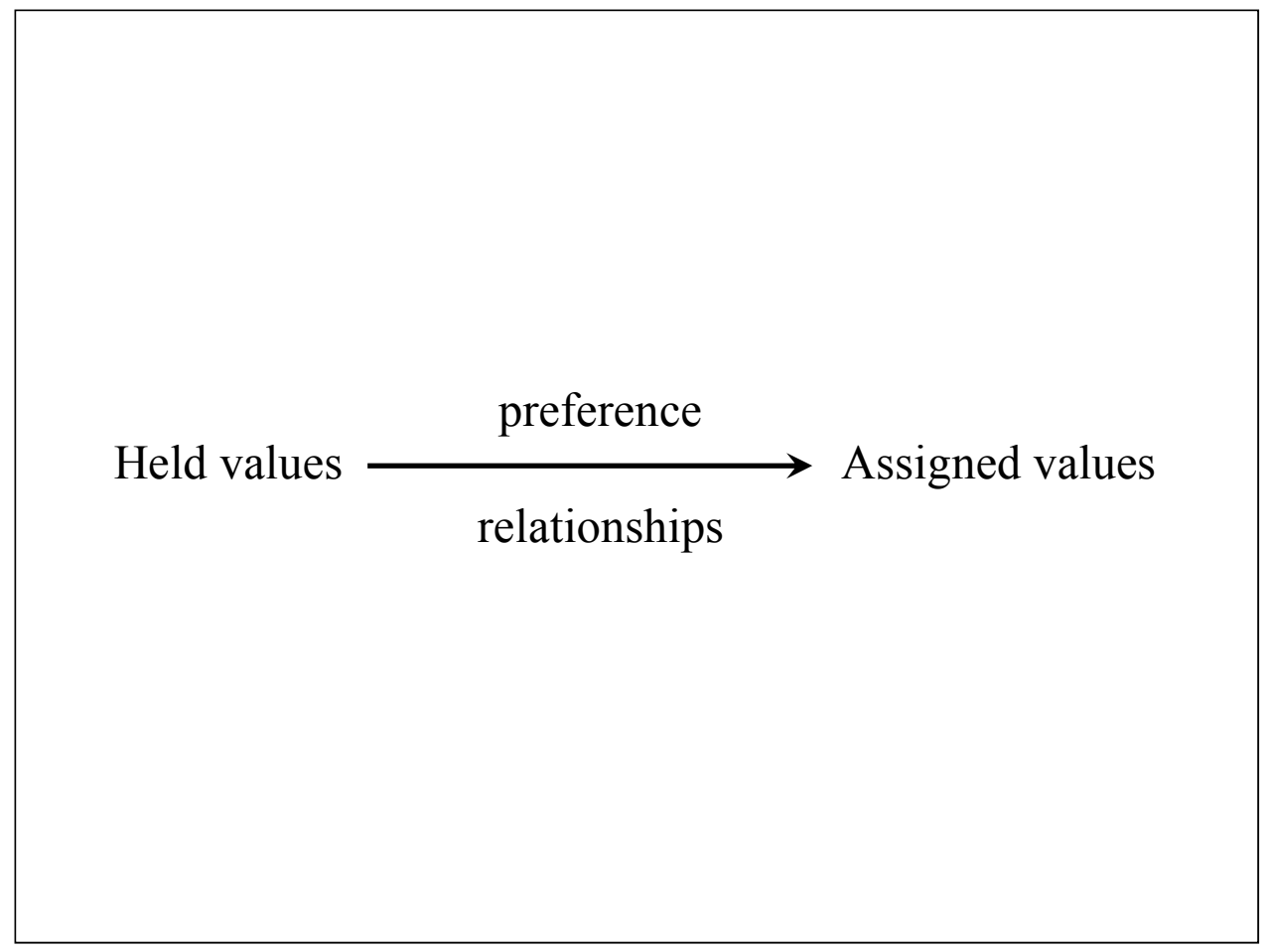

Figure 1. Brown's (1984, p.234) depiction of the relationship between the three realms of value. 


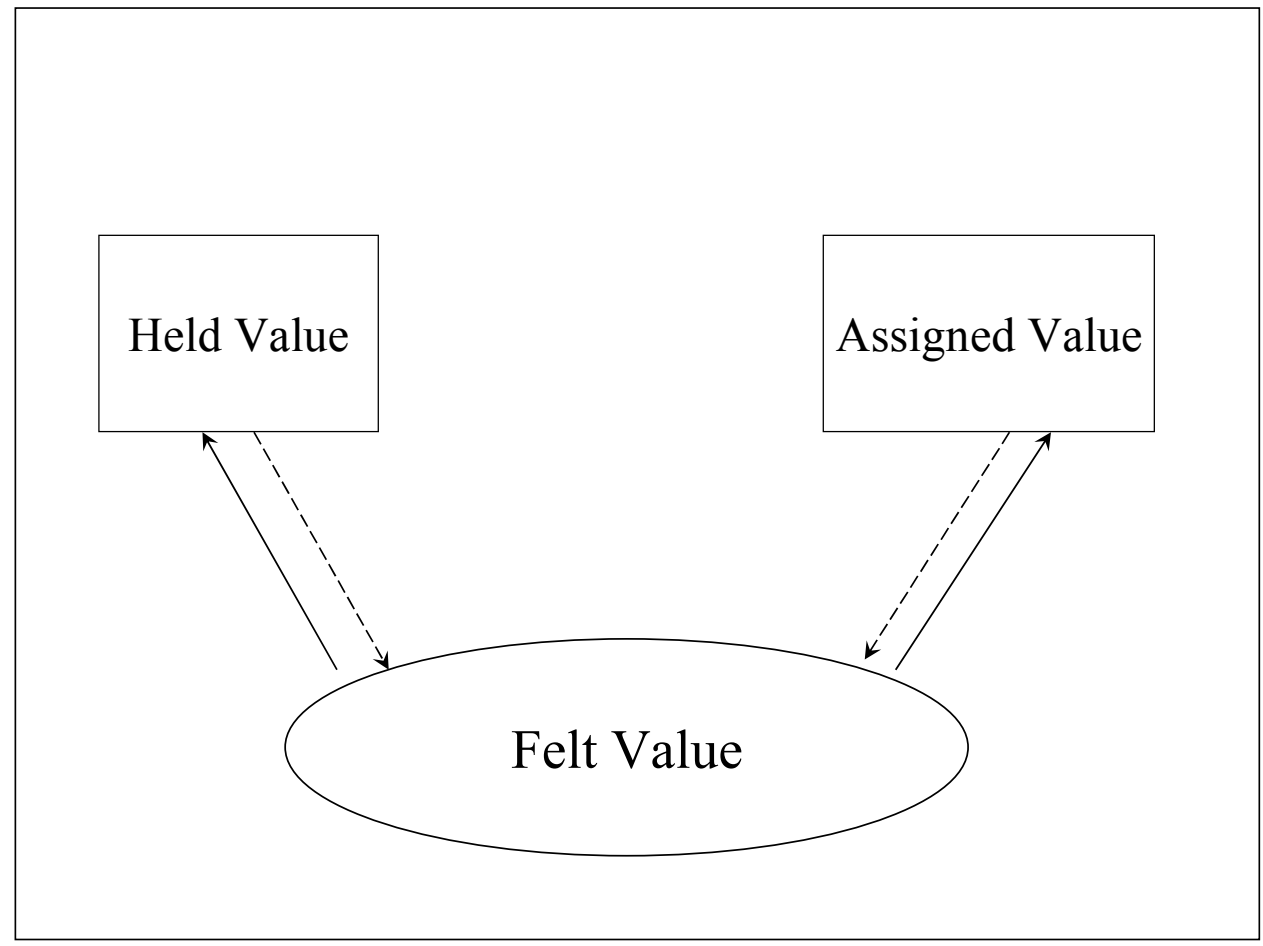

Figure 2. An experiential view of the relationship between the three realms of value. 


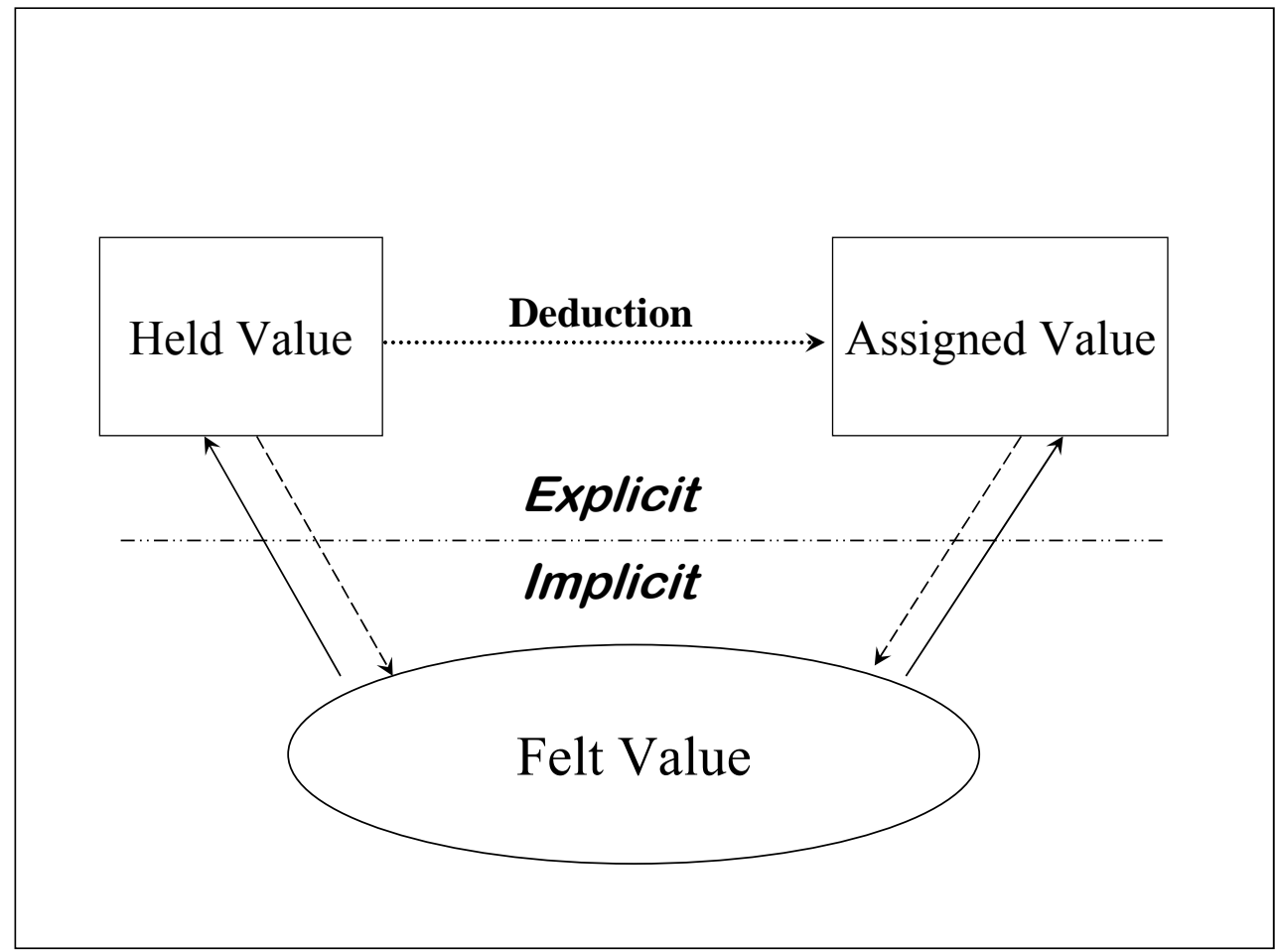

Figure 3. Explicit and implicit levels of awareness in relation to the three realms of value. 


\section{References}

Afford, P. (2008). Focusing \& listening: Decision making. Retrieved January 6, 2009, from http://www.focusing.co.uk/decision.html.

Ayto, J. 1990. Dictionary of Word Origins. New York: Arcade.

Bott, S., Cantrill, J. G., and Myers, O. E., Jr. (2003). Place and the promise of conservation psychology. Human Ecology Review, 10, 100-112.

Brooks, J. J., Wallace, G. N., and Williams, D. R. (2006). Place as relationship partner: An alternative metaphor for understanding the quality of visitor experience in a backcountry setting. Leisure Sciences, 28, 331-349.

Brown, T. C. (1984). The concept of value in resource allocation. Land Economics. 60, 231-246.

Campbell, P. A. and McMahon, E. M. (1997). BioSpirituality: Focusing as a way to grow. Chicago: Loyola Press.

Cornell, A. W. (1996). The power of focusing. Oakland: New Harbinger Publications.

Cornell, A. W. (2006). Focusing with decisions. Audio recording. Retrieved September 5, 2008 from http://www.focusingresources.com/downloads/focusing_and decisions.mp3.

Cornell, A. W. and McGavin, B. (2002). The focusing student's and companion's manual, parts one and two. Berkeley, CA: Calluna Press.

Crvenkovic, T. (2008). Focusing and writing about doing the dance. The Folio, 21, 156-165.

Darer, M. (2007). Focusing leads to a new stress test. Staying in Focus: The Focusing Institute Newsletter. 7(2), 3-4.

Dietz, T., Fitzgerald, A., and Shwom, R. (2005). Environmental values. Annual Review of Environment and Resources. 30, 335-372.

Doi, A. (2008). Let the felt sense speak in English: Experiential learning and teaching of English as a second language. The Folio, 21, 206-212.

Fisher, A. (2002). Radical ecopsychology: Psychology in the service of life. Albany: State University of New York Press.

Fuller, A. R. (1990). Insight into value: An exploration of the premises of a phenomenological psychology. Albany: State University of New York Press.

Gendlin, E. T. (1967). Values and the process of experiencing. In A. Mahrer (Ed.), The goals of psychotherapy, pp. 181-205. New York: Appleton-Century. 
Gendlin, E. T. (1971). On decision making. In B. Marshall (Ed.), Experiences in being, pp. 6574. Belmont, CA: Brooks/Cole.

Gendlin, E. T. (1981). Focusing. New York: Bantam Books.

Gendlin, E. T. (1986). Let your body interpret your dreams. Wilmette, IL: Chiron.

Gendlin, E.T. (1996a). Focusing-oriented psychotherapy: A manual of the experiential method. New York: Guilford Press.

Gendlin, E. T. (1996b). Making concepts from experience. Presentation at the 1996 International Focusing Conference, Gloucester, MA. Retrieved January 12, 2009, from http://www.focusing.org/think96.html.

Gendlin, E.T. (1997a). Experiencing and the creation of meaning : A philosophical and psychological approach to the subjective. Evanston, IL: Northwestern University Press.

Gendlin, E.T. (1997b). A process model. Spring Valley, NY: The Focusing Institute.

Grindler-Katonah, D. (2003). Medical decision-making. Presentation at the 6th International Congress on Cancer, Hong Kong University, Hong Kong, Nov. 1999. Retrieved January 12, 2009, from http://www.focusing.org/doralee_med_decision-making.htm.

Hendricks-Gendlin, M. (2003). Focusing as a force for peace: The revolutionary pause. Retrieved January 12, 2009, from http://www.focusing.org/social_issues/hendricks_peace.html.

Hendricks, M. N. (Ed.). (2004). Thinking at the Edge: A new philosophical practice [Special issue]. The Folio, 19(1).

Hetherington, J., Daniel, T. C., and Brown, T. C. (1994). Anything goes means everything stays: The perils of uncritical pluralism in the study of ecosystem values. Society and Natural Resources, 7, 535-546.

Jessup, B. E. (1943). Relational value meanings. Eugene: University of Oregon Monographs.

Jessup, B. E. (1949). On value. In Lepley, R. (ed.), Value: A cooperative inquiry. New York: Columbia University Press.

Johnson, C. and Barak, M. (2007). Managers can benefit from an overlooked resource: the gut. Retrieved January 12, 2009, from http://www.focusing.org/business/gut.htm.

Keeney, R. L. and Raiffa, H. (1993). Decisions with multiple objectives: Preferences and value tradeoffs. New York: Cambridge University Press.

McGuire-Bouwman, K. (2007). Focusing in community: How to start a listening and focusing 
support group. Retrieved January 12, 2009, from http://www.cefocusing.com/pdf/ FOCUSING_IN_COMMUNITY_Introduction.pdf.

McGuire, K. (2007). Collaborative Edge Decision Making. Retrieved January 12, 2009, from http://www.cefocusing.com/freedownloads/CollaborativeEdgearticleFinal.pdf.

McGuire, K. (2008). Creative edge organizations: Businesses and organizations as a "kind" of focusing community. The Folio, 21, 256-267.

More, T. A., Averill, J. R., and Stevens T. H. (1996). Values and economics in environmental management: A perspective and critique. Journal of Environmental Management, 48, 397-409.

Morris, W. (ed.) (1969). The American Heritage dictionary of the English language. Boston: Houghton Mifflin.

Patterson, M. E., Watson, A. E., Williams, D. R., and Roggenbuck, J. W. (1998). An hermeneutic approach to studying the nature of wilderness experiences. Journal of Leisure Research, 30, 423-452.

Perl, S. (2004). Felt sense: Writing with the body. Portsmouth, NH: Boynton/Cook.

Prado Flores, J. B. (2007). Focusing in a medical practice. Staying in Focus: The Focusing Institute Newsletter. 7(2), 1-2, 4.

Schroeder, H.W. (1990). The felt sense of natural environments. In Selby, R. I., et al. (eds.), Coming of Age: Proceedings of the Twenty-First Annual Conference of the Environmental Design Research Association (p. 192-195). Oklahoma City: EDRA, Inc.

Schroeder, H. W. (2008). The felt sense of natural environments. The Folio, 21, 63-72.

Shapiro, K. J. (1985). Bodily reflective modes: A phenomenological method for psychology. Durham, NC: Duke University Press.

Todres, L. (2007). Embodied enquiry: Phenomenological touchstones for research, psychotherapy and spirituality. Hampshire \& New York: Palgrave Macmillan.

Walkerden, G. (2005). Felt knowing: A foundation for local government practice. In Keen, M., Brown, V. A., and Dyball, R. (eds.), Social learning in environmental management: Towards a sustainable future (pp. 170-187). London: Earthscan. 


\section{Place meanings as lived experience}

James Barkley

The emotion that drives political participation and defines stakeholder's important places needs to find an avenue for productive integration into park and natural resource planning. How we experience the environment and how we remember it are emotional processes that define our important places and largely influences our preferred planning outcomes. Stakeholder representation in planning dialogue historically mutes emotional and imaginative place meanings in favor of ideological positioning supported by [techno] rational argument. While this sort of debate is valuable and necessary, it would be well served by foundational dialogue that addresses how stakeholders feel about the area of focus for planning efforts. From a lived experience perspective, this chapter discusses the role of memory and emotion in support of a theoretical platform for improving stakeholder representation in park and natural resource planning.

Political scientist Martin Nie (2003) describes most political arenas that focus on park and wild land management as being stilted by historically embattled ideologies. Driving and reinforcing this ideological embattlement are "wicked problems that characterize most public policy and planning issues" (Nie, 2003, p. 309). These wicked, or complex, problems are social controversies that lack technical solutions and are generally managed (not solved) in a process of political judgments, adaptive management regimes, and/or fragmented planning forums (Allen \& Gould, 1986). Nie (2003) identifies a lack of effective communication and the crisis orientation among interest groups as roadblocks to expanding dialogue. As stakeholders continually draw upon their entrenched ideological moorings when entering into dialogue and negotiations a 
stalemate to progress is triggered by the inability of representation to move beyond simplistic, adversarial, and deeply ingrained rhetoric.

Issues of representation in democratic land management are often the product of an expert-public gap that can exacerbate historic ideological conflict. The expert-public gap is the result of two conditions: experts dismissing citizen views as less-informed, and the difficulty of the citizenry in finding a political foothold for their perspectives (Yankelovich, 1991, p. 4). The result of this trend is a diminishing capacity of the public to represent itself in expert-based decision-making forums. Put succinctly:

"It is sometimes difficult to believe that the public and policy-making experts in the U.S. share the same language and culture” (Yankelovich, 1991, p. 3).

Without access to representation in park planning, the potential for self-governance is eroded and stakeholders to the process become frustrated. This political landscape has defined American democratic process in land management and has served to alienate a concerned public.

As a result of ideological rifts compounded by the cultural codification of knowledge within a traditional scientific perspective (Bell, 1962, p. 25), emotionally volatile stakeholder engagement is common in park and natural resource management. In the book, Wisdom of the Spotted Owl, Yaffee (1994) refers to behavioral biases of human actors and organizations as contributing to a poor policymaking environment surrounding spotted owl habitat protection in the forests of the Pacific Northwest. Tension and conflict were prevalent as emotions ran high in what was, and still is, an ideological battleground of iconic significance. Further, the conflict over habitat protection for the spotted owl continues to be defined by scientific debate that addresses policy mandates set forth in the Endangered Species Act. This theme of emotionally- 
fueled rhetoric centered on conflict and scientific expertise is recurrent. Be it emboldened protest of offshore drilling on the Pacific coast (Freudenburg \& Gramling, 1994), local resident's meltdowns over confined animal feeding operations in the Midwest (Johnsen, 2003), or cultural conflict over fishing rights on the Atlantic coast (Lynch, 1993) stakeholder's engagement in natural resource planning typically takes the form of conflict and crises with scientific expertise positioned as the ultimate form of representation (see Williams, this volume for a critique of the prevailing and historically exclusive techno-rational approach to land use planning).

While a great deal of warranted attention is given to technical issues in land-use decisionmaking, there are other forms of knowledge that are useful in their own right and context. The need for stakeholder dialogue to extend beyond historically strained rhetoric that grants superiority to a traditional scientific perspective is taken up here with a characteristic focus on the role of emotion. Emotion is at the center of place meaning and political activity. In recognizing the transformative power of emotion, it is suggested here that an increased focus on shared place meanings among politically active stakeholders can improve dialogue surrounding park and natural resource planning.

\section{Stakeholders and democratic representation}

American democracy in the second half of the twentieth century focused largely on ethical concerns that were, and still are, taken up by special interest groups. Issues surrounding land use planning are brought to bear politically through communication of organized interests. This type of identity politics in American democracy centers on negotiation, contestation, and representation of multiple perspectives (Benhabib, 1996). In the case of park and natural resource management, conservation-based ecological concerns are a clear example of a political 
movement within this type of identity politics. Political representation for these concerns is taken up by such groups as The Wilderness Society, American Wildlife Foundation, Sierra Club, and Earth First; each group with a unique identity and political ideology. Moreover, political representation is embodied in those individual representatives from special interest groups who are part of planning dialogue surrounding America's parks and natural resources. Often these individuals live in or around the areas of concern. This peculiar subset of individuals are referred to here as localized representative stakeholders and are viewed as vital sources of experiential, emotional knowledge that is key to expanding dialogue surrounding park and natural resource planning.

Our democratic processes need to be equipped to make sense of the emotional energy that catalyzes politicized ideology and shapes place meaning. The basic theoretical underpinning of sense of place or place meaning, as referenced interchangeably here, is the notion that space becomes place as a result of an emotional transformation (Relph 1976, Tuan, 1972). To understand place meanings is to understand emotional transformations of physical space to human place. Like place meanings, political ideology is the result of emotional transformation (Lerner, 1947). As political scientist Daniel Bell points out:

“... What gives ideology its force is its passion. ... One might say, in fact that the most important, latent, function of ideology is to tap emotion. Other than religion (and war and nationalism), there have been few forms of channelizing emotional energy. ... Ideology fuses these energies and channels them into politics" (Bell, 1962, p. 400).

Ideology, catalyzed by emotion, takes a representative turn through human enactment. With strong feelings for the places of interest and how they should be managed, politically active 
stakeholders that have a personal history with the area are positioned at the emotional nexus of place and political ideology. These stakeholders have the capacity to enhance democratic representation in park and natural resource planning by sharing their experiential, emotional knowledge of place.

Localized representative stakeholders have two basic characteristics that make them an appropriate focus for efforts at incorporating emotional knowledge into planning and policymaking processes. First they have a clearly defined political ideology evidenced by their subscription to the mission of a larger organization. In addition, they typically have first hand experiential knowledge of the area(s) at the center of planning and policymaking efforts. As members of organized interest groups, and as frequent visitors to the area of interest, individual stakeholders who are member-representatives of larger organized groups are seen as important and relevant participants in researching place meanings. As these representatives discuss their lived experiences in their important places the door is open for productive entrée of emotional knowledge in stakeholder dialogue.

\section{Emotion}

With emotions playing a crucial role in expanding stakeholder dialogue it is important to further conceptualize them so we may explore representational strategies that move beyond politically and scientifically simplified meanings of place. The sociology of emotion identified here as particularly relevant focuses on two modes of lived emotion: feelings of the lived experience, and feelings while telling about them (see Denzin, 1985, who referred to these as the "lived body" and "intentional value feelings," respectively). These feelings immediately associate the individual with their environment in ways that are accessible to a broader audience. 
Denzin (1985) describes feelings of the lived experience and their ability to foster a shared understanding, as an:

... orientation to the interactional world of experience, they are accessible to others and they can furnish the foundations for socially shared feelings..... Others are able to vicariously share in the subject's feelings. ... The subject can communicate and 'give' these feelings to others, thereby allowing them to enter into a field of emotional experience with him. (p. 230).

These feelings give meaning to places and are told in stories of the lived experience. Further, these types of feelings are commonly understood, as we all have lived experiences. Feelings associated with the telling of lived experience, "are felt reflections, cognitive and emotional, about feelings" (Denzin, 1985, p. 230). This second mode of emotions is the result of reflecting on our experiences and telling about them selectively according to a given political context and associated ideological framework. Framing emotion in this way provides an interpretive mechanism for understanding stakeholders emotions associated with their experiences and in the telling of those experiences.

With a focus on value-theory, Schroeder (this volume) provides another way of labeling and thinking about the two modes of emotion described here. With 'felt value' underlying both 'held' and 'assigned' values, the process of value determination is one of experiencing and feeling (i.e., felt values) that is made explicit in the form of 'held' or 'assigned' values. Schroeder further describes a relationship whereby the formation of abstract 'held' and 'assigned' values can transform the foundational 'felt values.' In this cyclical framework of value determination, the lived experience is accounted for according to a developing framework of [explicit] 'held' and 'assigned' values that are both informed by, and serve to inform, 
[implicit] 'felt values.' In these terms, feelings of lived experience include implicit, felt values and the feelings while telling about the lived experience shape our explicit, held and assigned values.

Using the terms, "personal," and, "shared," Olstad (this volume) provides an example of how the two modes of emotion associated with lived experience may be encountered. In this case the author invites the reader to feel the experience of being in the Red and Painted deserts. Through the use of first-person descriptive prose, Olstad invites the reader to 'enter into a field of emotional experience with her' (ex. feelings of the lived experience) while carrying an overarching reflection on, and implications for, the [shared] telling of those experiences (ex. feelings while telling about the lived experience). The author describes the feelings of the lived experience in ways that include, " a labyrinth of vibrant clay hills, stretching beyond the horizon, rolling large as the sky..." (Olstad, this volume) In turn, Olstad reflects on her feelings in the telling of her lived experience by situating herself as a social theorist in concluding that there is a need for both scientifically based information and experiential knowledge. In each case, Schroeder and Olstad highlight the centrality of lived experience in understanding place values and place meanings. Each of these authors delineates differences between an internal, personal understanding of one's lived experience and the external, shared representation of this knowledge. In each case the role of emotion changes from the personal experience, or "felt sense," to the public representation of this knowledge that can take the form of held and assigned values.

To seek and interpret emotions as characterized by feelings of the lived experience and feelings while telling about the lived experience provides a means of interpreting stakeholders emotional place meanings in ways that concurrently build trust and understanding. By giving a 
basic form to emotional representation, this two-pronged description of emotional engagement is one that does not seek causality and so it is a positive framework for building trust. This basic framework of emotion focuses on understanding how people feel about their important places and not why they feel that way. People are more likely to share freely if they can trust that they are not being personally scrutinized for how they feel about their important places. Trust and understanding is further bolstered by drawing on stories of lived experience as a common source of knowledge. We all have lived experiences and so we have an empathetic charge toward that of others. We can understand how people feel and how they express themselves when they are talking about something with which we are familiar. By centering stakeholder dialogue on lived experience we increase the capacity for what environmental historian Keith Basso (1996) has described as 'place making'. In describing the process of place making, Basso writes: “... place-making is a way of constructing history itself, of inventing it, of fashioning novel versions of 'what happened here.' For every developed place-world manifests itself as a possible state of affairs, and whenever these constructions are accepted by other people as credible and convincing - or plausible and provocative, or arresting and intriguing - they enrich the common stock on which everyone can draw to muse on past events, interpret their significance, and imagine them anew." (Basso, 1996 p. 6)

Place making - through shared stories of lived experience - presents an avenue for creating shared meaning and appreciation for multiple stakeholder interests. An exemplary place-making forum is described by Stewart, Glover and Barkley (this volume). The authors describe how 'learning circles' - supported by photo-elicitation techniques - are promising to access feelings of the lived experience and for understanding feelings while telling about them. By their account 
of the learning circle format, implemented in three different land use scenarios, the authors describe the creation of shared emotional space among stakeholders that fostered empathy and shared understanding.

Place meanings shared among politically active stakeholders to park and natural resources management are a way that managers-as-stakeholders can come to understand the emotions that typically ride high in park and natural resource planning and policymaking. Further, without access to these types of place meanings managers retain a limited perspective on the importance of the area to its localized stakeholder constituency. In a technical report entitled Understanding Concepts of Place in Recreation Research Management (Kruger, Hall \& Stiefel, 2008), Stokowski (2008, pp. 31-60) describes a history of research and theory on place that points to place meanings as both emotional and constantly in flux. Accordingly, Stokowski extends Tuan's (1972) emotional transformation of space to place in necessitating the communicative precipitation of place. In championing the sharing of experiential knowledge in place-making processes Stokowski extends a charge to managers-as-stakeholders:

“A manager's imperative then, should be to understand the emergent qualities of place-making and place meanings in order to respond to patterns of discourse shaped by structured communicators linked across social networks. In this effort managers should err on the side of variety rather than constraint in allowing resource settings to be as open as possible to social and cultural behaviors through which place meanings may be expressed." (Stokowski, 2008, p. 54) 
In this vein, place-making exercises like Stewart, Glover and Barkley’s (this volume) learning circles should be embraced and encouraged by park and natural resource managers.

The creation of shared place meanings is manifest in shared memories. As we tell stories of our experiences and what it's like to be in a place we are constructing memories and sharing them in some fashion. The relationship between memory and the lived experience is at the center of knowledge production in coming to understand people's important places. To understand how stakeholders important places are represented through the sharing of experiential knowledge, the term lived experience needs to be defined and the subsequent role of memory and processes of remembering need further articulation.

\section{Remembering the lived experience}

As the subject of investigation into emotion, lived experience requires definition so that the subsequent implications for memory and place making are made explicit. Lived experience refers to a series of temporal, spatial organizations that in its most basic form involves our immediate consciousness of life prior to reflection (Dilthey, 1985; Sartre, 1957). Lived experience - so defined - exists only in its representation and does not exist outside of memory (Denzin, 1992). Where Schroeder's (this volume) implicit, felt value is pre-verbal, the definition of lived experience offered here is pre-reflective. That is, once the individual has formed an idea of their lived experience, they have only done so by remembering an ever passing lived experience. Where Olstad (this volume) juxtaposes personal place meanings with shared or public place meanings, lived experience and the associated process of remembering as it is described here are at the root of both private and public representations of place. The only way we can come to know and understand our lived experience is through acts of remembering and 
sharing those memories. Stewart, Glover, and Barkley (this volume) embrace the idea of requisite remembering in coming to understand lived experience in their use of learning circle exercises. In this case the authors used photographs to prompt memories and stories of lived experience among stakeholders to land use planning processes.

It is through the implicit role of memory according to the definition of lived experience offered here that emotion finds entrée into stakeholder dialogue surrounding land use planning. The process of memory construction is imaginative and emotional (Denzin, 2001) as the act of remembering is something that happens in the present but is referencing an absent past (Huyssen, 2003). Recollection is not merely reduplicative, but socially influenced (Bartlett, 1932/1967; Durkheim, 1924/1974; Halbwachs, 1941/1992). We engage in memory-making processes in which the people and places of our experiences shape our memories and our stories. Condensation, elaboration and invention are common characteristics of ordinary remembering (Bartlett, 1932, p. 205). Further, the ways that we streamline our memories and stories are constantly in flux. It is through social interaction (Schwartz, 1989) that place meanings derived from memories of the lived experience - are represented to a broader audience.

Memory is an active process, and not something that is passively received by the individual. We choose to remember and account for our experiences according to our individual relationship with social processes. Anthropologist James Wertsch (2001) describes the functional relationship between the individual and society using 'mediated action' (Wertsch, 1998; Vygotsky, 1987) as a theoretical foundation. The theoretical framework of mediated action holds that the cultural tools made available to the individual by society mediate all human action. While cultural tools are made available by society, they are actively consumed and usually transformed through use patterns introduced by the individual (Wertsch, 1998). We are 
not simply bystanders whose memories are bestowed upon us by socio-cultural forces beyond our command.

We choose what we remember and how we represent those memories. The ways we choose to remember and retell our stories is a social and emotional process. The individual sentiment is transformed in association with the collective sentiment (Durkheim, 1924). Like individual sentiment, individual memory is constructed within a group perspective (i.e., the collective) while the collective memory is realized through the memory of the individual (Halbwachs, 1941). In this sense the group can't express itself separately from its individuals (Bartlett, 1967). This suggests that the individual memory is constructed by the individual based on the influence of the collective memory, and in turn, contributes to the collective memory of the group to which the individual belongs. Understood as such, the construction of memory is an ongoing process of reception and appropriation (Bartlett, 1932; Halbwachs, 1941; Wertsch, 1998) through which individuals serve to represent collective, or group sentiment. Historian John Bodnar discusses this process in terms of 'public memory' (Bodnar, 1992). Public memory is something that is continually created while at the same time drawn upon, to bring the past, present, and future together in ways that are relevant. Bodnar writes: "Public memory is produced from a political discussion that involves not so much specific economic or moral problems but rather fundamental issues about the entire existence of a society: its organization, structure of power, and the very meaning of its past and present... Its function is to mediate the competing restatements of reality these antinomies express. Because it takes the form of an ideological system with special language, beliefs, symbols, and stories, people can use it as a cognitive device to mediate competing interpretations and privilege some explanations over others. " (Bodnar, 1992, pp. 14) 
This description of public memory speaks to the poignancy of the concept while alluding to major limitations in strategically garnering collective remembrance. While bringing stakeholders together to share stories of their lived experience (e.g., learning circles) can refocus dialogue from a traditional scientific perspective and offers a way of mediating multiple perspectives, the concept of public memory sheds light on two primary limitations of the theoretical approach described here. First, as a strategy of deliverance from ideologically entrenched dialogue, [re]creating public memory is problematic in that public memory itself takes the form of ideology. While it may be thought of as a newly-shared ideology and a way to ‘channelize emotional energy' (Bell, 1962, p. 400), public memory is nonetheless ideological and is vulnerable to becoming yet another layer of entrenchment in an already adversarial political arena. Perhaps more serious than the ideological implication of public memory is the privilege afforded to it's [re]creators. In the case posited here, where localized representative stakeholders serve in the construction of public memory, the privilege of determining memorable and meaningful aspects of place is enjoyed by a select group. For public memory to serve as a foundational concept in promoting a more informed and productive planning dialogue these limitations need to be addressed.

An important first step in addressing the above limitations is to properly locate the resultant knowledge of place and memory making processes within the broader scope of planning. The type of knowledge described here - garnered through place making processes and the creation of public memory - is most aptly addressed during pre-planning phases. Stewart, Glover, \& Barkley (this volume) are quick to point out that this type of knowledge and learning is most appropriate as a precursor to formal planning. This important caveat appropriately 
situates [imaginative and emotional] experiential knowledge as a means of improving planning dialogue; not as a direct referent for the types of decision making scenarios taken up by formal planning procedures. The privilege that is afforded to those that take part in selective place making processes is further addressed through the characteristic focus on localized representative stakeholders. These individuals are appropriate for these types of pre-planning efforts according to their capacity for experiential knowledge (i.e., as frequent visitors to relevant sites) and ability to represent special interests (i.e., as member-representatives of larger affiliate interest groups) within an identity politic.

In addressing the limitation of public memory as a form of ideology, the primary concern is to avoid having shared meaning relegated to overly-simplistic points of debate. To address this limitation is to keep tabs on public memory and facilitate opportunities for further [re]creation. While public memory is a form of ideology, repeated place making forums are a way to provide aeration so that these shared memories and meanings do not become static ideological representations prone to inappropriate application to park and natural resource planning processes.

\section{Conclusion}

Place, political ideology, and the emotion enmeshed in both are identifiable through sharing stories of lived experience. Told through stories of lived experience, place meanings present a promising communicative concept in seeking the productive inclusion of emotional knowledge in park and natural resource planning. Creating memories and places by sharing stories of lived experience is a way to address a history of stagnant dialogue in natural resource planning that is consistently relegated to historically embattled stakeholder ideologies. This 
scenario is compounded by the exclusiveness of expert-based planning that prefers the technorationality of traditional science. A lived experience perspective offers an alternative form of representation that has the capacity to build shared place meanings, memories, and visions for the future.

Lived experience, as a philosophical orientation toward knowledge and knowing reality, holds central the idea that through the actual experience of something its essence may be felt and understood as reality (Fals-Borda \& Rahman, 1991). As a series of temporal, spatial organizations that in its most basic form involves our immediate consciousness of life prior to reflection (Dilthey, 1985; Sartre, 1957), it is through our memories and stories of the lived experience that the places of our experience are imbued with meaning. When the management areas of interest serve as a setting through which the individual has passed previously, memories and stories of their experience provide insight into what those important places mean. When these stories are shared among stakeholders in place making processes - as exemplified by 'learning circles' (Stewart, Glover, \& Barkley, this volume) - it is a form of social learning by which emotional knowledge may be addressed to the advantage of stakeholder dialogue by creating shared memories and place meanings.

The power of a lived experience perspective is realized in a democracy defined by identity politics, where place meanings may serve to critically nuance communication among individuals speaking for their affiliate interest groups. Place making processes among localized representative stakeholders - undergirded by a lived experience perspective - are a way to build trust by facilitating the representation of emotion in seeking to understand what people are feeling; not why they feel that way. Localized representative stakeholders are individuals who live in the region and stand in at local and/or regional meetings to carry the message of organized 
interest groups. Sitting at the crossroads of place meaning and political ideology, these stakeholders should be afforded an opportunity to share their experiential knowledge of the area. This is in keeping with the imperative of a manager-as-stakeholder to, "understand the emergent qualities of place-making and place meanings in order to respond to patterns of discourse shaped by structured communicators linked across social networks" (Stokowski, 2008, p. 54). By sharing these stories, a public memory may be forged that can present new possibilities for future planning efforts by creating shared place meanings that focus on the emotional source that drives stakeholder engagement.

Born of a hopeful vision for land-use decision-making processes in America's public parks and other natural resource areas, place making is conceptualized here as an avenue by which agreement may be reached, or perhaps conflict more fully understood among political actors. Discussing lived experience and creating public memories is a way to 'enrich the common stock' (Basso, 1996, p.6) among representative stakeholders while keeping tabs on emotional place meanings that, along with our memories, change over time. As these representatives discuss their lived experiences in their important places the door is open for important emotional knowledge to further become a part of public memory. In other words, place making among stakeholders can [re]shape a public memory that frames emotional knowledge - that which catalyzes political ideology and defines sense of place - as a source of shared meaning and not of a priori conflict. This public memory, resulting from place making activity as a precursor to formal planning, can expand stakeholder dialogue through the productive inclusion of emotional knowledge by sharing and understanding place meanings from a lived experience perspective. 


\section{References}

Bartlett, F.C. (1932/1967). A theory of remembering. In F.C. Barton, Remembering: A study in experimental and social psychology (pp. 197-214). New York, NY: Cambridge University Press.

Basso, K. Quoting the ancestors. In Wisdom Sits in Places: Landscape and Language Among the Western Apache, Ch. 1

Bell, D. (1962). The end of ideology: on the exhaustion of political ideas in the fifties. New York: Free Press.

Benhabib, S. (1996) 'Toward a deliberative model of democratic legitimacy', in S. Benhabib (ed.), Democracy and Difference: Contesting the Boundaries of the Political. Princeton, Princeton University Press, pp. 67-94.

Bodnar, J. (1992). Remaking America: public memory, commemoration, and patriotism in the twentieth century. Princeton, NJ: Princeton University Press.

Brown, T. C. (1984). The concept of value in resource allocation. Land Economics. 60, 231-246.

Denzin, N.K. (1985). Emotion as lived experience. Symbolic Interaction, 8, 2, 223-240.

Denzin, N.K. (1992). The many faces of emotionality. In Ellis and Flaherty (eds) Investigating Subjectivity, pp. 17-30, Sage: Newbury Park California.

Denzin, N. (2001). Interpretive Interactionism, Second Edition. Thousand Oaks, CA: Sage.

Dilthey, W. (1985). Poetry and experience. Princeton, NJ: Princeton University Press.

Douglas, K.B. (1998). Impressions: African American first-year students' perceptions of a predominately white university. Journal of Negro Education, 67, 4, 416-431.

Dovi, S. (2007). The Good Representative. Malden, MA: Blackwell.

Durkheim, E. (1924/1974). Individual and collective representations and The determination of moral facts. In E. Durkheim, Sociology and philosophy (pp. 1-35). New York, NY: The Free Press.

Eisenberg, A.I. (1995). Reconstructing political pluralism. Albany: SUNY Press

Fals-Borda, O., \& Rahman, M.A. (Eds.). (1991). Action and knowledge: Breaking the monopoly with participatory action research. New York: Intermediate Technology/Apex.

Freudenburg, W. \& Gramling, R. (1994). Oil in Troubled Waters: Perception, politics, and the battle over offshore drilling. Albany, NY: State University of New York Press. 
Gutmann, A. \& Thompson, D. (2004). Why deliberative democracy? Princeton, NJ: Princeton University Press.

Habermas, J. (1996). Three Normative Models of Democracy. In Seyla Benhabib (ed.) Democracy and Difference: Contesting the Boundaries of the Political, pp. 21-30. Princeton: Princeton University Press.

Halbwachs, M. (1941/1992). On collective memory (L.A. Coser, Ed. \& Trans.). Chicago: University of Chicago Press. (Original work published 1941).

Hammitt, W.E.; Backlund, E.A.; Bixler, R.D. (2004). Experience use history, place bonding and resource substitution of trout anglers during recreation engagements. Journal of Leisure Research, 36, 3, 356-378.

Harper, D. (2000). Reimagining Visual Methods: Galileo to Neuromancer. Denzin, Norman and Yvonna Lincoln, eds. Handbook of Qualitative Research, second edition. Thousand Oaks, CA: Sage Publications, 717-732.

Hemingway, J.L. (1999). Leisure, social capital, and democratic citizenship. Journal of Leisure Research, 31, 2, 150-165.

Huyssen, A. (2003). Present pasts: Urban palimpsest and the politics of memory. Stanford: Stanford University Press.

Johnsen, C. (2003). Raising a Stink: The Struggle over Factory Hog Farms in Nebraska. University of Nebraska Press

Klitzing, S.W. (2004). Women living in a homeless shelter: Stress, coping and leisure. Journal of Leisure Research, 36, 4, 483-512.

Kuchler, S. (1999). The place of memory. Adrian Forty and Susanne Kuchler, eds. The Art of Forgetting. Oxford: Berg.

Kyle, G.T.; Absher, J.D.; Graefe, A.R. (2003). The moderating role of place attachment on the relationships between attitudes toward fees and spending preferences. Leisure Sciences, $25,1,33-50$.

Lerner, M (1939). Ideas as weapons; the history and uses of ideas. New York: Viking Press.

Lynch, B. 1993. The Garden and the Sea: U.S. Latino Environmental Discourse. Social Problems, pp. 108-124.

Nie, M. (2003). Drivers of natural resource-based political conflict. Policy Sciences, 36(3/4), 307-341.

Peterson, T.R., Peterson, M.N., Peterson, M.J., Allison, S.A. \& Gore, D. (2006). To play the 
fool: can environmental conservation and democracy survive social capital? Communication and Critical/Cultural Studies, 3, 2, pp. 116-140.

Putnam, R.D. (1995). Bowling Alone: America's Declining Social Capital. Journal of Democracy 6, 1, 65-78.

Relph, E. (1976). Place and placelessness. London: Pion Limited.

Sartre, J.P. (1985) Existentialism and human emotions. New York: Citadel Press. (Original work published 1957)

Schwartz, D. (1989). Visual ethnography: Using photography in qualitative research. Qualitative Sociology, 12, 2, 119-153.

Stedman, R., Beckley, T., Wallace, S., \& Ambard, M. (2004). A picture and 1000 words: using resident-employed photography to understand attachment to high amenity places. Journal of Leisure Research, 36, 4, 580-606.

Stewart, W. P., Barkley, J., Kerins, A., Gladdys, K., \& Glover, T. D. (2007). Park development on the urban-agricultural fringe. Journal of Park and Recreation Administration, 25 (4).

Stewart, W., Liebert, D., \& Larkin, K. (2004). Community identities as visions for landscape change. Landscape and Urban Planning, 69, 315-334.

Stokowski, P.A. (2008). Creating social senses of place: new directions for sense of place research in natural resource management. In Understanding Concepts of Place in Recreation Research and Management. Kruger, L.E., Hall, T.E., \& Stiefel, M.C. (eds.). USDA Forest Service General Technical Report PNW-GTR-744, pp. 31-60.

Tuan, Y.F. (1972). Space and place: The perspective of experience. Minneapolis, MN: University of Minnesota Press.

Vygotsky, L. (1987). The collected works of L.S. Vygotsky, vol 1. problems of general psychology (N. Minick, Ed. \& Trans.). New York: Plenum.

Warren, M. (2002). Deliberative Democracy. In A. Carter and G. Stokes eds. Democratic Theory Today, pp. 173-202. Cambridge: Polity Press.

Warzecha, C. \& Lime, D. (2001). Place attachment in Canyonlands National Park. Journal of Park and Recreation Administration, 19 (1), 59-78.

Wertsch, J.V. (1998) Mind as action. New York: Oxford University Press.

Wertsch, J.V. (2001). Narratives as cultural tools in sociocultural analysis: Official history in soviet and post-soviet Russia. Ethos, 28, 4, 511-533. 
Yankelovich, D. (1991). Coming to public judgment: Making democracy work in a complex world. Syracuse, NY: Syracuse University Press..

Young, I.M. (1996). Communication and the Other: Beyond Deliberative Democracy. In Seyla Benhabib (ed.) Democracy and Difference: Contesting the Boundaries of the Political, pp. 120-135. Princeton: Princeton University Press. 


\section{Personal experience and public place creation \\ Tyra Olstad}

"This is the most beautiful place on earth. There are many such places." (Abbey 1968, p. 1)

There is a place called the Red Desert. The landscape there doesn't look particularly red, but yawning expanses of dusty greasewood easily appear deserted. The "miles and miles of nothing but miles" add up to an overwhelming sense of space - featureless, limitless, meaningless space.

But the Red Desert is a place. Land and sky, sagebrush and antelope, fences and roads it has material characteristics; it exists. I've seen it. You can see it too, just by driving across Wyoming on Interstate 80. Better yet, you can pause somewhere between Rawlins and Rock Springs to see, smell, hear, feel, literally sense the place. As your mind filters and favors certain sensations, you might feel pleased by the wildness of the uninterrupted vistas or hear desolation howling in the incessant winds. Either way, you'll take memories from and layer meaning upon the landscape.

If you don't have time to actually go to the Red Desert, you can look at photographs of it and read descriptions about it. Many people have shared their own experiences and perceptions of the place, hoping to show you that it's not just meaningless space. They want you to care about it - they need you to care about it - because you own it. The Red Desert is mostly public land, owned by citizens who have myriad conceptions of economic and sociocultural "value."

The Rock Springs, Rawlins, and Lander offices of the Bureau of Land Management (BLM) have the difficult duty of reconciling different perceptions for and valuation of the Red Desert. Decisions that regulate land use - even "multiple use" - recognize and preference 
particular physical, cultural, and aesthetic "resources" over others. This can easily lead to controversy. When the BLM issued Draft Environmental Impact Statements that proposed expanding oil and gas development in parts of the Red Desert, officials were astounded by the volume and vehemence of the response; dozens of organizations and thousands of individuals contacted the agency to express deep concern. Abstract references to "beauty" and "wildness" swirled through the public sphere, but personal pronouns grounded the debate. People shared their own experiences and their own opinions, giving voice to their deeply-held and valued senses of their Red Desert.

Land management officials have grown increasingly aware of the need to integrate peoples' senses of place into policies and procedures (Mitchell et al. 1993; Williams and Stewart 1998; Davenport and Anderson 2005). What, though, is a "sense of place"? How is it created and how is it used? As researchers seek to understand the process of public place-creation, they often focus on the material characteristics of meaningless "space," the sociocultural values layered on this space, and the political processes that regulate appropriate use (Cheng et al. 2003; Eisenhauer et al. 2000; Greider and Garkovich 1994). While these are all important factors, they discount personal elements of place-creation. Phenomenological and psychological research, meanwhile, explores the meaning and significance of individuals' interaction with their environments (Brown and Toadvine 2003, Stedman 2002, Casey 2001 and 1996, Proshansky et al. 1983, Shumaker and Taylor 1983). To link these concepts, practitioners need to consider how the social and political processes and decisions that govern management and determine use of public lands arise from and negotiate visceral sensations, perceptions, and values - how personal experience affects public place-creation. 
That is why, in exploring the conflict over the Red Desert, I cannot help but discuss the Painted Desert. The Painted Desert is a million-acre swath of colorful badlands that arcs across northeastern Arizona. It shares many ecological and cultural characteristics with the Red Desert (Bailey 1983; McNab and Avers 1994; Petrified Forest 2009), but has a very different feel. In part, the Painted Desert feels different because 53,000 acres are preserved as Wilderness within Petrified Forest National Park; different political designations and policies create and are created by different senses of place. But also the Painted Desert feels different to me because I see it not as lines on a map or lists of attributes; it is my experiences, my memory of land and sky. It is my desert.

I invite you to come with me on an intellectual tour of the Red Desert then on to experience the Painted Desert. In comparing and contrasting levels of understanding and attachment, we will explore concepts of public and personal place-creation and discuss the implications for phenomenological research and land management policy.

\section{My Red Desert}

I had never heard of the Red Desert until controversy over energy development began to infiltrate local and national media. People's expressions of attachment to a seemingly empty place intrigued me, so I paid attention to journal articles, radio reports, travel guides, websites, and letters-to-the-editor. The more I heard, the more I wanted to know. How did people perceive the desert? What sort of relationships had they developed with the place? How did they communicate their feelings and positions?

To answer these questions, I reviewed academic literature, analyzed management documents, and interviewed a variety of interested stakeholders (who were encouraged to discuss personal opinions, not representative positions). After months of formal, structured research, I 
thought I had developed a well-informed sense of the controversy. It was simple enough to understand: "place + people $=$ politics. In the American West, the simplicity becomes complicated very quickly as abstractions of philosophy and rhetoric turn into ground scrimmages" (Tempest Williams 2002, p. 3; Kemmis 1990). In order to understand the people and the place, all I had to do was separate the philosophy and rhetoric from the real world; all I had to do was experience the place first-hand.

So I found myself driving across south-central Wyoming late one April afternoon. I had already been warned that "the face of the Red Desert that people see driving through on the interstate does not reflect the richest wildlife habitats or the prettiest landscapes or the areas indeed that are pristine and untouched. You [will] notice, driving through, oil and gas development, strip mines - you name it, - pipelines, powerline corridors everywhere" (Interview with Biodiversity Conservation Alliance employee, 6 September 2006). Verily, I didn't see anything aside from dusty sagebrush, cracked pavement, and a few wispy clouds. In years' worth of exploring, I'd seen similar scenes all over the West and hadn't bothered to learn the names of locations and meanings of stock memories of pretty landscapes. This afternoon, though, I was in The Red Desert. I had a vested interest in - and thus a deeper appreciation for the view out my window. Somewhere in that expanse, I thought to myself, there are herds of wild horses! And habitat for sage grouse! Petroglyphs and ruts from wagon trails, fossils and fossil fuels, all sorts of secret delights.

Knowing too that the Red Desert "is a land that gives up its secrets grudgingly" (Friends of the Red Desert 2008), I was armed with lots of water, sturdy hiking boots, maps of dirt roads, and a long list of destinations and directions. I hoped to spend days hunting out people's favorite places - Adobe Town! Desolation Flats! Jack Morrow Hills! I would experience it all! 
But sometime during the night, a cold front moved through. I woke to a landscape of featureless whiteness buried under a shadowless grey sky. I stubbornly tried maneuvering the "Wild Horse Loop," but when my car rebelled against the mix of clay and ice I returned to the main road and headed northeast away from Rock Springs. At some point, I passed the most photogenic features - Killpecker Dunes and Boars Tusk - but I don't know when or where; I couldn't see through the storm. Turning vaguely eastward, I stopped to read a historic marker, but the winds were so fierce that I didn't get out of the car. A Visitor Center in Lander was closed, so on southeast to Rawlins, where I merged back on to Interstate 80 and found myself again crossing the heart of the Red Desert.

So much for experience. Friends of the Red Desert insist that their place "has a way of drawing you in, inviting you to explore its mysteries (Friends of the Red Desert 2006), but it was telling me to go away. I was cold. And tired. I didn't connect with the land at all, didn't create personal meaning, let my conception of the place remain a flat map containing names and boundaries to which I attach no memories.

Well, one memory. Of the rush of delight I felt when I turned off the highway, parked on some little dirt lane near a gas well pad, pulled out the Utah and Arizona maps, and, with the snow swirling dryly across my windshield, planned my route south. To the Painted Desert. To my place.

\section{My Painted Desert}

When I had first paused to consider the "Welcome to Petrified Forest National Park" sign one grey November morning many years before, I had no idea what to expect; I had barely taken the time to confirm that the place was, indeed, in Arizona, and that yes, I could work there instead of spending another long winter in New Hampshire. After stopping at the Visitor Center 
to glance at the displays and watch an interpretive film - Chinle Formation? Ancestral Puebloan? Short-grass prairie?, - I got back in the car, drove through a half-mile or so of scrubby scenery, pulled into the first designated overlook, and felt the bottom drop out of my sense of space. The Painted Desert. A labyrinth of vibrant clay hills, stretching beyond the horizon, rolling large as the sky, bigger and grander than anything I'd ever know. A legal and literal wilderness.

The sky was raw, the landscape forbidding, but I felt compelled to switchback down the access trail. I said farewell to a final juniper, dropped into a dry wash, slipped tentatively around the nose of a cliff, and whoosh! Cold dry wind burst straight through to my lungs. The Painted Desert. I was standing in it, breathing it in. No bootprints or cairns or other such comforts to cling to, just the earth and clouds and me.

I spent the rest of the winter cultivating a relationship between self and place, seeking a sense of belonging - an existential insideness (Relph 1976). I learned to locate myself according to the bends in the Lithodendron Wash, the lonely verticals on the horizon, the layers of stone and time. I explored Angels Garden and the Black Forest, discovered the petrified stump field and petroglyph panels. I found pottery sherds and fossil bones, blazing paintbrush and bobcat prints. Once I even tripped over a geologic marker - thousands of acres of sandstone and bentonite and sagebrush undulating in 30-foot waves and there it was, a 3-inch piece of metal hammered into the ground. I became infatuated with everything and everywhere Painted Desert.

After one season -- spent filling countless letters with descriptions of my adventures, countless sketchbooks with depictions of my impressions, countless hours with contemplation of the landscape - I felt I had barely scratched the surface. As Yi-Fu Tuan writes, "[a]bstract knowledge about a place can be acquired in short order. But the 'feel' of a place takes longer to acquire. It is made up of experiences, mostly fleeting and undramatic, repeated day after day and 
over the span of years" (1977, pp. 183-184). So I returned, a year and a half later, then again, and again, learning to slow down and savor experiences. I traced centuries' of swirls in sandstone, thought like a lizard basking in the sun, swam in the scent of monsoon rains. I stopped using a tent on my weekend backpacking expeditions -- just stretched out under the Milky Way or basked in the full moon. I lived for the sunrises and sunsets - walked out every morning, every evening, 5 miles then 10, attuning myself to the rhythms of time and space.

With all of these experiences fermenting in my mind, I couldn't understand why others did not appreciate the desert - the "stillness, solitude, and space; an unobstructed view every day and every night of sun, sky, stars, clouds, mountains, moon, cliffrock and canyons; a sense of time enough to let thought and feeling range from here to the end of the world and back" (Abbey 1968, p. 39). When a new roommate arrived one summer and immediately packed up again, wanting to leave because she couldn't stand the dryness and desolation, I implored, "Please just give it time. Stay. You'll love it," thinking, "how can anyone not?" It took her a few weeks, but she slowly developed an interest in the place's history, then the night sky, then found herself rhapsodizing about the beautiful landscape.

When I was hired as a ranger, my job was to share the Painted Desert - to provide visitors with the information they wanted to know about their National Park, but also to encourage them to pause and feel a deeper, personal connection to the place. I gave hundreds of talks and chatted with thousands of visitors about the geology the archaeology the ecology of the region, but so few - too few -would linger to ask questions. I wrote articles for the park newsletter and made paintings for school programs and drew wildflowers for bulletins and photographed bones for scientific publications, but my art hardly did the attributes justice. Visitors would come, stop and snap a photograph of a geologic or topologic wonder before 
continuing on their way to the Grand Canyon or Sedona. "Photographs won't do it justice," I wanted to shake them, "it's a sense, it's a feel, it's a place, not just a scenic drive or green splotch on the map."

The first time I read Edward Abbey's Desert Solitaire, I hadn't really understood his exhortation, "In the first place you can't see anything from a car; you've got to get out of the goddamned contraption and walk, better yet crawl, on hands and knees, over the sandstone and through the thornbush and cactus. When traces of blood begin to mark your trail you'll see something, maybe" (1968, p. xiv). But the more time I took to experience the sandstone and cactus of the Painted Desert -- leaving my fair share of blood,-- the more I understood how passionately a person can care for a place, how deeply it can become part of them, how desperately they will want to both share and protect it.

Although I felt a fierce desire to get people to experience the Painted Desert - to value the place as something more than pretty scenery, -- I did not have to take drastic measures to protect it. A Wilderness Area within a National Park is already afforded the highest level of protection possible for federal land management. No plans threaten to immediately and permanently alter the material characteristics of the place, my place. My memories of the land -as well as my desires for future experiences -- remain safely intact.

But that is not the case for the Red Desert, where changing management priorities and plans have created a sense of insecurity and mistrust as well as a heightened awareness of and appreciation for the place. It warrants another visit.

\section{Our Red Desert}


When the BLM issued a Draft Environmental Impact Statement that would allow more roads and gas wells in the Red Desert, they launched "an ideological battle...among those who value what is here. Some value what lies on the surface; some value what lies beneath" (Clifford 2002). It is not quite that simple, though. The breadth and depth of the battle suggests a complex interaction between "two types of attachment: attachment to the specific area itself and attachment to the type of area it represents" (Williams et al. 1992, p. 19).

Attachment to a place-type - pristine wilderness or desolate wasteland or rich mineral repository - powers public place-creation. In launching a campaign to promote the region as a beautiful, ecologically-rich "Wild Heart of the West," non-governmental organizations such as Friends of the Red Desert (FRD), Biodiversity Conservation Alliance (BCA), and even the Sierra Club acknowledge that they have been working locally and nationally to "educat[e] the public and show them what's out there, so that we can burst this myth that it's just this empty void that's just waiting for drilling rigs and bulldozers to make dollars out of it" (BCA employee, interview, 6 Sept 2006). Several interviewees echoed the "myth" of "an empty void," referring to people who believed "'It's just the desert. If you gotta wreck someplace, it oughta be this place"” (BLM employee, paraphrasing comment letters, interview, 5 May 2006) and that "there's so much open space out there, so much undeveloped space that we can afford to just carve it up willy-nilly" (Artist, also paraphrasing others, interview, 4 Feb 2007). "When you let roads develop willy-nilly," they countered, "there is a loss of solitude" (Bill Crump, quoted in Clifford 2002). "Desert," "space," and "solitude" are powerful symbols- ones that have caught the public's imagination and "generate[d] a response from people, even among people who have never even been to the place in dispute" (Cheng et al. 2003, p. 97). 
People who have never been to the Red Desert can develop a sense of the place via the BCA and FRD's articles and brochures, slide-shows and websites. These materials, which use specific locations as symbols for abstract ideals, are filled with facts and figures that promote a political position -- namely a Red Desert Citizens' Alternative that relies on the representative type of place attachment to advocate establishment of a National Conservation Area (NCA).

Maps of the proposed NCA place it outside of what some consider the Red Desert, however. Beyond the debate over what the place means or how it should be managed, people can't agree on where it actually is; perceptions of the location and extent range from a halfmillion-acre patch of rusty soil north of the Interstate - sometimes referred to as the "Red Strip," and "Red Desert Basin" - to a six-million-acre expanse that stretches all the way from Lander to the border of Colorado and encompasses much of the physiologically diverse Great Divide Basin. This makes it difficult to discuss policies, especially because controversial areas such as Adobe Town Wilderness Study Area and Desolation Flats Project Area are outside the geographic scope of several management documents. Officials express surprise and in some cases dismay to see "how [the Red Desert] has grown" in others" eyes (BLM employee, interview, 4 May 2006).

Although the Red Desert exists as a geographically ambiguous idea of "space" and "solitude," it evokes powerful memories of and attachment to very specific places. Much of the strength of the campaign to "Save the Red Desert" can be attributed not to societal valuation but to wise recognition for and use of personal experiences. Rather than simply advocate certain uses for the Red Desert, non-governmental organizations have encouraged individuals to share their stories in the public sphere - to share their photos and paintings at galleries; to write articles reminiscing the time they "sat in camp one spring morning" (Wyoming Wilderness Association 
2006) or recounting the day they "first drove off the pavement into the Red Desert..." (Jones 2005); to contact their governmental representatives not to spout out rhetorical positions, but to "[t]alk about personal experiences and what you enjoy doing in the Red Desert" (Friends of the Red Desert 2006).

Groups have also focused much effort on getting people out on the land to experience it for themselves - to learn first-hand that “[p]hotos don't even do it justice. You can have great photos, but you really don't get the same sense of space and grandeur and scale" (BCA employee, interview, 6 Sept 2006). Tourism brochures detail "Scenic Drives" and BLM handouts provide directions to particularly popular spots and websites offer suggestions for hiking destinations. Insisting that "[e]very Wyoming outdoors person must take a trip soon to the Red Desert and experience the thrill and enchantment of hiking through the maze of Honeycomb Buttes without another person or sound but that of the wind" (Wyoming Wilderness Association 2006), BCA offers a number of guided driving and backpacking expeditions. As a member of the organization describes the strategy:

"The best way for people to feel investment in these landscapes and to understand the need to protect them is not to send them a ten-page diatribe or talk on the radio or be in the newspaper - that doesn't convey it. All you have to do is set people in front of this landscape, and without saying anything to them at all, they get it.” (BCA employee, interview, 6 Sept 2006)

What is 'it'? According to scholars, it's a "construction" or "perception" or "interpretation" or "endowment of value" (Williams and Stewart 1998, Cheng et al. 2003, Davenport and Anderson 2005 and Stedman 2003, and Tuan 1977, respectively.

According to those who have experienced the Red Desert, it's "a sense of the space, the sound of the grass, the smell of the wind" (Lillegraven 2007). It's a personal appreciation for a public place. 


\section{Our Deserts}

You may not realize that the Painted Desert is your National Park and/or that the Red Desert is your public land. You may disapprove of boundary expansions and/or acknowledge the value of oil and gas. You don't need to backpack through the Wilderness Area or drive across Wyoming to understand that some people love these places, know them as their own but recognize that they're shared.

The difficulty lies in weaving personal experiences and values and places into a web of support for public land management practices. Thirty years ago, Tuan noted that "[w]e are in the habit of denying or forgetting the real nature of our experiences in favor of the cliché of public speech" (1977, p. 204). His observation still rings true today, especially in relation to public land management. It's far too easy for individuals to abandon their own stories in the public sphere and instead attempt to assert political positions: "Well I have a personal opinion," admitted one interviewee, "and I have a professional opinion" (BCA employee, 6 Sept 2006). Even citizens who are not speaking for and/or employed by any agency or group may find themselves reciting stock lines such "I urge you to adopt the Western Heritage Alternative for a revised Great Divide Plan that will balance industrial uses of my public lands with the needs of public recreation, clean air and water, and desert wildlife" (BCA letter template, 2008, emphasis added).

The sociopolitical sphere undervalues personal perceptions and beliefs, relying on cold, hard use of the term "our public lands" instead of intimate, passionate appeals for personal places. Yet individual experience and attachment is often what grounds and fuels debate over land management policies and procedures. "Our relation to the natural world takes place in a place," Gary Snyder reminds us, "and it must be grounded in information and experience” (1990, p. 39). I have learned as much as I can about the Red Desert but because I haven't truly seen, 
smelled, felt the landscape, I haven't attached to it as other people have. I can, though, empathize: when I see a photographer's images of Boars Tusk, I think of my Pilot Rock; when people tell of watching day break over the hills of Adobe Town, I hear echoes of my sunrise strolls toward Chine Mesa; when I read about the impacts of road construction in Wyoming, I recall tiptoeing across cryptobiotic soils in Arizona. When I talk to ranchers, scientists, managers, visitors, citizens about their Red Desert, I also tell them about my Painted Desert. It's an exchange, an inclusion, a deepening of understanding and respect.

The theorist in me says that if you want to understand the conflict over the Red Desert, you need to ground yourself with both information and experience, to recognize it as a place. Read official management documents; peruse opinion pieces and personal testimonies; look at photographs and listen to stories; think about it as you would a place you love. Then, even if you think you understand the depth of people's attachment to the place, above all, go to the Red Desert. Stop somewhere, get out of the car, explore, feel the ground, smell the sky, go. I'm going soon, this August. On my way to the Painted Desert. 


\section{References}

Abbey, E. 1968 (1990). Desert Solitaire. New York, NY: Simon \& Schuster Inc.

Bailey, R. G. 1983. Delineation of Ecosystem Regions. Environmental Management 7(4):365373.

Biodiversity Conservation Alliance. http://www.voiceforthewild.org. Accessed November 17, 2008.

Brandenburg, A. M. and M. S. Carroll. 1995. Your place or mine: The effect of place creation on environmental values and landscape meanings. Society and Natural Resources. 8:381398.

Brown, C. and T. Toadvine. 2003. Eco-Phenomenology: Back to the Earth Itself. Albany, NY: State University of New York Press.

Bureau of Land Management. 1972. Red Desert Study: Final Draft.

Bureau of Land Management, Rawlins Field Office. 1996. Green River Resource Area Resource Management Plan and Final Environmental Impact Statement.

Bureau of Land Management, Rock Springs Field Office. 2004. Environmental Impact Statement for the Jack Morrow Hills Coordinated Activity Plan/Proposed Green River Resource Management Plan Amendment.

Bureau of Land Management: Rawlins http://www.wy.blm.gov/rfo

Rock Springs http://www.wy.blm.gov/rsfo/

Accessed November 17, 2008.

Casey, E. S. 2001. Between geography and philosophy: What does it mean to be in the placeworld? Annals of the Association of American Geographers. 91 (4): 683-693.

----. 1996. How to get from space to place in a fairly short stretch of time: Phenomenological prolegomena. In Senses of Place, eds. S. Feld and K. Basso, pp. 13-52. Santa Fe, NM: School of American Research Press.

Casper Star-Tribune Editorial. July 25, 2006. Some public land should get special protection.

Cheng, A. S., L. E. Kruger, and S. E. Daniels. 2003. "Place" as an integrating concept in natural resource politics: Propositions for a social science research agenda. Society and Natural Resources. 16:87-104.

Clifford, H. 2002. The last lonesome place. OnEarth Fall 2002. http://www.nrdc.org/onearth/02fal/desert1.asp 
Davenport, M. A. and D. H. Anderson. 2005. Getting from sense of place to place-based management: An interpretive investigation of place meanings and perceptions of landscape change. Society and Natural Resources. 18:625-641.

Doane, M. February 28, 2005. Wyo wants it done right. Casper Star-Tribune opinion piece.

Eisenhauer, B. W., R. S. Krannich, and D. J. Blahna. 2000. Attachments to special places on public lands : An analysis of activities, reason for attachments, and community connections. Society and Natural Resources 13:421-441.

Friends of the Red Desert. 2006. Wyoming's Red Desert: A balanced solution.

-----. http://www.reddesert.org/ Accessed November 17, 2008.

Gearino, J. November 14, 2006. Labor's love of outdoors. Casper Star-Tribune.

Greider, T. and L. Garkovich. 1994. Landscapes: The social construction of nature and the environment. Rural Sociology. 59 (1) : 1-24.

Jones, D. October 24, 2005. Don't sacrifice the Northern Red Desert for one use. Casper StarTribue opinion piece.

-----. July 23, 2005. A place worth protecting. Casper Star-Tribue opinion piece.

Kemmis, D. 1990. Community and the Politics of Place. Norman, OK: University of Oklahoma Press.

Lillegraven, L. Artist Statements. Provided in personal communication, February 4, 2007.

McNab, W. H. and P. E. Avers. 1994. Ecological Subregions of the United States. USDA Forest Service WO-WSA-5. Online link: http://www.fs.fed.us/land/pubs/ecoregions (Accessed 20 November 2009)

Mitchell, M. Y., J.E. Force, M.S. Carroll, and W.J. McLaughlin. 1993. Forest places of the heart: Incorporating special places into public management. Journal of Forestry 91(4):32-47.

Petrified Forest National Park. 2009. National Park Service, Department of the Interior. Online link: http://www.nps.gov/pefo/ (Accessed 11 October 2009).

Proshansky, H. M., A. K. Fabian, and R. Kaminof. 1983. Place identity: Physical world socialization of the self. Journal of Environmental Psychology 3: 57-83.

Relph, E.C. 1976. Place and Placelessness. London: Pion Books.

Shumaker, S. A. and R. B. Taylor. 1983. Toward a classification of people-place relationships: A model of attachment to place. In Environmental Psychology: Directions and

Perspectives, eds. N. R. Feimer and E. S. Geller, pp. 219-256. New York, NY: Praeger.

Snyder, G. 1990. The Practice of the Wild: Essays. San Francisco, CA: North Point Press. 
Stedman, R. C. 2002. Toward a social psychology of place: predicting behavior from placebased cognitions, attitude, and identity. Environment and Behavior 34(5): 405-425.

----. 2003. Is it really just a social construction? The contribution of the physical environment to a sense of place. Society and Natural Resources 16:671-685.

Tempest Williams, T. 2002. Red: Passion and Patience in the Desert. New York, NY: Vintage Books.

Trimble, Stephen. 1996. Our gardens, our canyons. In Testimony: Writers of the West Speak on Behalf of Utah Wilderness, eds. S. Trimble and T. Tempest Williams, pp. 19-22. Minneapolis, MN: Milkweed Editions.

Tuan, Y. F. 1977. Space and Place: The Perspective of Experience. Minneapolis, MN: University of Minnesota Press.

Williams, D. R., M. E. Patterson, J. W. Roggenbuck, and A. E. Watson. 1992. Beyond the commodity metaphor: Examining emotional and symbolic attachment to place. Leisure Sciences 14: 29-46.

Williams, D. R. and S. I. Stewart. 1998. Sense of place: An elusive concept that is finding a home in ecosystem management. Journal of Forestry May 1998:18-23.

Wyoming State Office of Travel and Tourism. Wyoming Vacation Guide, 2005.

Wyoming Wilderness Association.Wyoming Wilderness Roundup. Summer/Fall 2006. 


\section{Part Three: Producers of place and place-makers}

Humans are place makers. It is hard to imagine living in a house or working in an office without doing something to personalize one's space and endow it with meaning that otherwise would not be there. There are countless agencies and organizations whose mission includes place making, and otherwise positioning an environment for a set of place meanings. Some of these organizations are self-aware of their place making. Others are not, and take for granted the place meaning as "out there" and obvious to all who encounter the site. The chapters of this section share stories of organizations who produce place meanings in intentional ways. They tell of place meanings as being actively created and evolving based upon social interaction of stakeholders and the discourse of their own making.

Amsden, Stedman, and Kruger provide insight on a volunteer-based education and restoration program known as "Streamwatch" in Alaska's Russian River. The original purpose of the program was to educate anglers on resource-friendly fishing activities, however as the authors indicate, the campground volunteers do far more than teach campers how to fish. Amsden et al. show that volunteers carry a strong place identity, and share their sense of place with visitors and with each other. Using a photo-elicitation technique, volunteers' sense of place grows with each visitor contact and is reinforced with their own group dynamics as part of the Streamwatch program. Likewise, visitors and managers witness the volunteer restoration activities that have direct effects on the resource, and learn about place meanings through their engagement with volunteers.

Hurley examines residential development purposely directed at creating a compelling sense of place. He examines regional and local processes that function to re-territorialize the meaning housing developments in Central Oregon. Zoning restrictions vary by county regarding 
minimum lot size, which has implications to the place meanings of resultant homesites.

Developers controlled amount of open space with a subdivision, their emphasis on planting native flora, and to some extent, the size and clustering of lots. In addition, in-migrants became active in conservation activities that further distinguish various environmental amenities of the subdivisions, and in doing so, influenced the senses of place. Websites, brochures, and word of mouth were instrumental as place making tools, and assisted in distinguishing various subdivision themes, such as the Old West, the ranching lifestyle of Oregon, agricultural or pastoral Oregon, and living in harmony with the land, to name a few. It is clear from Hurley's chapter that place making is something that involves everyone who lives in a locale whether they know it or not.

Stickney's chapter is written from a watershed manager's vantage point. She characterizes the strong place identities of villages in Northern Vermont, Upstate New York, and Southern Quebec who are part of the Lake Champlain watershed. Through a strong network of citizen-based action committees who work closely with their local and regional governments, Stickney portrays a way in which micro-level senses of place lead to a strong regional place identity. It is important that Stickney recognizes the worked landscape of which she writes; she knows the levels of pollution and degradation of the watershed across her management area. This is a landscape in which the place identities are hopefully progressive, and motivated to make Lake Champlain get healthier. Stickney details development of agreements and memorandums of understanding across the various units of the watershed. Nothing is binding, nothing regulated, yet the place-based management works. It is an inspiring depiction about an engaged group of citizens and committed set of local governments to produce its sense of place. 
Place-based management is about place making. Place meanings are authored by the people and organizations who live, work, and are affiliated with the place. Because place meanings evolve and are in a constant state of flux, the core of place-based management is an engaged group of stakeholders. The chapters of this section illustrate various contexts for placebased management, and provide windows into their style of engagement. 


\section{Volunteer meanings in the making of place}

Ben Amsden, Rich Stedman, and Linda Kruger

\section{A special place in need of volunteers}

Cooper Landing, a town of roughly 400 year-round residents, is tucked deep inside the heart of Alaska's beautiful and rugged Kenai Peninsula. For many visitors to Alaska, Cooper Landing is a prized destination because of the Russian River, a twelve mile span connecting the Upper Russian Lake with the Kenai River. The point of confluence of the Russian and Kenai rivers is one of the most popular fishing areas in Alaska, due to both its proximity to Anchorage and its abundance of trout, Coho salmon, and red salmon, all of which run the river in numbers averaging over 60,000 fish per year (AK Dept of Fish \& Game, 2007). During the height of the season, which runs from April to August, over 1,000 fishermen can be found fishing the river at the same time, oftentimes standing shoulder to shoulder along the banks of the river. These fishermen harvest nearly one-half of the salmon run, a total often averaging over 30,000 fish (AK Dept of Fish \& Game, 2007).

Because of the popularity of the Russian River and the sheer volume of fishermen, several issues threaten the area. Trampled vegetation and the resulting erosion threaten the fish by eliminating shade, warming the water temperature, and increasing the current (AK Dept of Fish \& Game, 2007). What's more, the byproducts of this and other recreation activities (such as fish-cleaning waste, human waste, dogs and litter) attract large numbers of bears and seagulls. To combat these issues, a volunteer-based education and restoration program known as "Streamwatch" was established to serve and protect the banks of the river. This volunteer program was implemented in 1994 by the US Forest Service, placing volunteers at the Russian 
River Campground to educate fishermen in the ways of resource-friendly fishing practices. By 2005, the program included 39 total volunteers, most of whom worked one day shifts, for periods of up to two weeks at a time.

Why are management programs like Streamwatch, and the volunteers who staff them, important to discussions of place and decision making? The answer lies in the impact that volunteers have upon the places and landscapes in which they work. Clearly, the economic importance of volunteers is obvious - without the (nearly) free workforce that volunteers represent, many programs could not survive. Less obvious is the idea that volunteers, in effect, are "making" place. To do this, volunteers create meanings that emerge from the place, the activities in which they are engaged, and the institutions they represent. From a management perspective, the landscape in which a volunteer program operates will thus be re-made or reinterpreted through the lenses of these meanings. This chapter explores the concept of "making" place, situating it within sense of place theory and a recent qualitative study of ten Streamwatch volunteers that described the place-making process as it emerged along the Russian River.

\section{Sense of place, volunteer meanings, and the place-making process}

People often maintain a deep connection to the places in which they live, work, and play. This sense of place is built upon the meanings people create as they directly experience and interact with the multiple settings and activities that define their day-to-day lives (Relph 1976). These settings and activities can be directly experienced, such as a walk on a hiking trail or a crowded city street, or they can be symbolic, such a memory of visiting a far-away place that represents past experiences or shared values. The settings and activities that drive sense of place often work in tandem - in many cases place meanings merge a setting (workplace, home, public 
beach) with a specific corresponding activity (earning a living, raising a family, or engaging in leisure).

Volunteering is a perfect example — and one that is little studied--of an activity that, in combination with an important setting, creates place-based meanings. Interacting with a special place informs how people view themselves in terms of the environment around them (Proshansky, 1978; Stedman et al., 2004). This is akin to the creation of place-based identity (Gooch 2003), which gives volunteers a sense of what they're doing and why (Glynn, 2000). For instance, while activities like boating, hiking, and hunting in a national forest may help a young person develop an identity as an "outdoorsperson," a weekend spent maintaining trail or serving as a summit steward in that same forest may lead to an identity as a "helper" or "protector." This relationship between place meaning and identity creation is in keeping with the socialpsychological literature on volunteering (Penner et al., 2005; Glynn, 2000; Piliavin \& Callero 1991).

Volunteering also creates place meanings that are embedded in both social and personal contexts, oftentimes simultaneously. These contexts help people use their volunteer activity to realize personal goals and strengthen social ties. Much of this depends on whether the volunteer is working alone, or in a group. When working alone, volunteers participate in activities that closely reflect their personal history and sense of self (Hustinx and Lammertin 2003). On the other hand, when volunteers are acting in a group context (such as a group of co-workers volunteering together one Saturday on the trail), they may focus more on the development of social ties and the organizational structure of the activities in which they engage (Wilson, 2000). Furthermore, meanings and identities may be social in the sense of the participant viewing him or herself as a member of a group, including the institution or agency that one represents. 
Ultimately, place meanings influence the processes and outcomes of "making place" through volunteer work. When volunteering, people create and contribute to the settings and landscapes of their lives and communities either directly (through work activities such as building a bridge, or painting a home) or indirectly (teaching their children, or helping a neighbor in need). For example, imagine a group of volunteers who come together once a month to perform maintenance on a long-distance hiking trail that runs through their home state. As they work, they make place directly by removing blowdowns, cleaning waterbars, and trimming brush. In addition, over the course of the day they also make place indirectly, by sharing skills and ideas with each other and sharing their insights with passing hikers. The meanings which have arisen from the volunteer activity itself (e.g developing an identity as an "outdoorsperson," finding a new social network, or developing advanced skills) have influenced the place-making process by giving the volunteer a foundation from which they engage in their work and interact with (and in some cases teach) others.

The example of volunteers on the trail also reveals why the place making process and the meanings that inform it should interest managers. First, the feelings that volunteers hold towards the place in which they work can influence how visitors or other users feel about that same place. For instance, the perceived importance of a historic landmark can be created, enhanced, or diluted when a volunteer tells a visitor how they "ought" to perceive a certain feature of that landmark. Additionally, meanings come into play when visitors to a national park encounter interpretative, volunteer-delivered programming telling them what is "important" about that particular place. These social interactions, especially when they occur between people with different backgrounds, perspectives, or levels or training (as often exists between volunteers and 
the visiting public), can make a substantial contribution to visitor perceptions (Williams \& Patterson, 1999). Managers thus can use volunteers to spread their message.

Understanding the place-making process requires the deciphering of a complex recipe that includes the volunteer setting, volunteer activities, and volunteer meanings. The specific questions at hand are: what are the place meanings that emerge from the Russian River and the

Streamwatch program? How do they inform the place-making process? What does the making of place by volunteers mean to resource managers?

\section{Studying the Streamwatch volunteers}

To learn more about the Streamwatch volunteers' place meanings, data collection was modeled after the approach of Stedman and Beckley, who employed a simultaneous qualitative analysis of both photographic images and interview text (Stedman et al. 2004; Beckley et al., 2007). Ten volunteers were chosen using a purposive sampling technique established in conjunction with the Forest Service manager who was serving as the Streamwatch liaison. Purposeful sampling is a technique "in which particular settings, persons, or events are deliberately selected for the important information they can provide that cannot be gotten as well from other choices" (Maxwell, 1998, p.126). Participants were issued single-use cameras and asked to capture elements of their daily lives and their volunteer work that provide the most meaning, that represented why they volunteer, or demonstrated what they most would miss if they ceased volunteering. Once the cameras were collected from both the residents and the volunteers, follow-up interviews were conducted in order to review the photos and retrieve the personal story behind each one. Interviews lasted between forty-five minutes and three hours. Discussion of each photo centered on getting the respondent to "describe the content of the 
picture, what they were attempting to represent, and why they took it" (Stedman et al., 2004, p.588). During the interview all participants were free to explore tangents, tell stories, bring in other people (several respondents chose to include their spouses in the project), or provide additional materials (usually in the form of notes or additional photographs). By conveying their place meanings both visually and verbally, the participating Streamwatch volunteers were able to show, instead of just tell, specific details of the places that were important to them. Volunteers could also use their photographs to capture multiple details about each important place or to remind themselves of what (or who) they felt were important. The photos and interviews collected from the Streamwatch volunteers were then analyzed using a qualitative process known as categorical aggregation. This technique requires the researcher to create a series of labels, codes, and categories to organize data (Dewalt \& Dewalt, 2002; Henderson, 1991; Spradley, 1980). Once the photos and interviews were coded, the data were reorganized to identify emergent place meanings, which were then distilled into four place-based themes.

\section{Volunteer meanings and the making of place}

Each of the four themes connects place and activity, linking the important places in and around the Russian River with the meanings that emerged from participating in the Streamwatch program. In addition, these four themes show how meanings contribute to the making of place. The first two themes, The Russian River: How it is "supposed" to be and The campground as a place to teach and give back demonstrate how volunteers use their meanings to create place both directly, through hands-on activity; and indirectly, through interpretation and teaching. The second two themes, The campground as a social space: Interacting with like-minded volunteers 
and Recreation at the Russian River and in Cooper Landing have additional implications for volunteer theory, as they reflect both new avenues for public participation as a form of volunteering and new perspectives on the leisure motives that drive volunteer activity.

The Russian River: How it is "supposed" to be. The Russian River as a setting for the Streamwatch program was very important to the volunteers as both an actual setting and a symbolic meaning. As a setting, it embodied a wide range of both past and present experiences, both volunteer-related and not. As a meaning, it symbolized the importance the volunteers placed on the immediate preservation of the natural resources of Alaska. To Martin ${ }^{4}$, a retired volunteer from Anchorage, this preservation meant working to restore the landscape to the way it was before human impact. In a photo of a little-used hiking trail leading into the wilderness, Martin pointed out the advancing growth of the forest and how it had overcome a nearby power line. He suggested that the trail was important because it represented how the landscape might have appeared in the past. By participating in Streamwatch, Martin could express this vision by helping to restore the natural area. A similar example was provided by Dave, a five-year volunteer who provided a photo of a "keep off" sign that was almost overgrown by the vegetation it was designed to protect. He described how that sign had once been put up on a patch of bare ground, and how it represented the fact that his actions and the actions of his fellow Streamwatch volunteers could create a dramatic improvement in the landscape over time.

This idea of Streamwatch as a vehicle for preserving the landscape also shed light on why certain volunteers participate. For example, some of the volunteers engaged in the restoration of the river because of their enduring love for it. Sarah, a 66 year old retiree who had been with Streamwatch for five years, provided a photo of a stretch of river bank known as "Cottonwood

\footnotetext{
${ }^{4}$ Names have been changed to preserve anonymity.
} 
Corner," and suggested that her love for the river was a primary reason why she participated in Streamwatch. In fact, the idea of "love" for the Russian River area was articulated by several participants. Dave provided one of the more interesting examples, a photo of a place he loved so much that he wanted his ashes spread there. He explained that his love for the area is the primary reason he volunteers, so that he can convince other visitors to "stop and look at these things, and appreciate them more."

In addition to describing place meanings involving the protection of the natural landscapes around the Russian River, the participants described a connection to the area's wildlife. Interestingly, their photos did not necessarily have to include an actual image of an animal in order to contain a wildlife meaning. Multiple participants showed photos of places where they had once encountered an animal, and one photo in particular showed a group of people viewing a bear who was off in the distance. The emergence of wildlife-based meanings suggests two things - that the animals themselves are important personal components of the volunteers' sense of place, and that their presence conveys why the volunteers feel their work with Streamwatch is important. Charlotte, a 62 year old resident of Moose Pass who was in her ninth year with the Streamwatch program, described how the increase in the bear population in and around the campground had added an additional element to her work as a Streamwatch volunteer. She felt that warning visitors about bears and other wildlife is one of the primary responsibilities of the Streamwatch program, and was therefore a chief ingredient of how volunteers and the public related to the landscape.

The campground as a place to teach and give back. Another place meaning described by the Streamwatch volunteers involved their ability to construct and maintain the role of "teacher." One of the major requirements of the Streamwatch program was to educate fishermen in 
resource-friendly fishing practices, and help visitors avoid the attentions of the many bears that populate the area. To this end, volunteers would patrol the boardwalk, observing behaviors, engaging in interpretation, answering questions, providing assistance, and offering advice. This opportunity to "be an expert" about the facilities, the agency, and the Streamwatch mission was of great importance to volunteers. In some cases, this was symbolized by the campground itself, including signage and facilities. In other cases, it was symbolized by the process of volunteering. Megan, a middle-aged resident of the nearby town of Moose Pass, indicated the importance of teaching fishermen about bears. She suggested that while some fishermen were resistant to the information, most (she estimated about 75 percent) were responsive to the larger message, mainly because most visitors "are in awe of the place."

The Streamwatch volunteers also described meanings centered on the importance of protecting the actual facilities that people (including the volunteers themselves) frequently use. This was often couched in terms of "giving back," or working towards the upkeep of facilities through which they themselves had created place meanings in the past. Many volunteers saw facilities built by the Forest Service along the river as a public good, and felt a strong connection to their role as maintainers. In one photograph, Martin provided an example of just such a facility, with a photo of a staircase that was built to ease the erosion of a steep trail leading from the parking lot to the river. Martin felt that facilities such as these complimented his landscapebased meanings that focused on the restoration of the shoreline. At another point in his interview, he conveyed pride in his role in the upkeep of the facilities, in part because he felt he had contributed to the overuse of the Russian River in the past. By participating in the Streamwatch program, and helping to build and maintain the boardwalk and the staircase, he could give back to the place that once upon a time had given to him. 
The meanings surrounding the act of teaching and giving back also manifested themselves in the volunteers' perceptions that they were an important part of something official. The volunteers were given official-looking uniforms and materials, so that many members of the public could not easily distinguish between the volunteers and full-time rangers. According to one of the Forest Service managers overseeing the project, this was done on purpose, to provide a sense of authority and expertise that make the volunteers more convincing to the general public. It is important to note, however, that despite this look of authority, the volunteers continued to see their interactions with the public as those of a teacher, not an enforcer.

A number of photos and interviews showed that the volunteers took pride in the Forest Service's establishment of Streamwatch as an "official" program. The installation of the preprinted, professional-looking signage captured in a number of her photos allowed Megan to describe her good feelings about her role as a volunteer, and the commitment of the Forest Service to the program: "Official signage helps get our point across, and the Forest Service has done a good job with the signage. They change the signs to reflect evolving needs and things get updated. As a result, people are taking time to read the signs."

Sarah also provided a picture of a pre-printed sign, but her connection to it was different. While the previous signs were important to volunteers because they were current and officiallooking, this sign was also important for what it said. According to Sarah, the sign "shows what's happening. It contains a picture of the 'before,' so you can compare it to what you see in front of you." Later in her interview, Sarah indicated that in addition to its content, this sign also made her feel "official" because it offered her a chance to participate in interpretation - an activity which she felt was usually reserved for paid Forest Service staff. She was proud of her expertise, and happy to share it in an official capacity. 
The campground as a social space: Interacting with like-minded volunteers. The third important theme describing the meanings held by Streamwatch volunteers involves the importance of friendships and relationships cultivated during the volunteer experience. Representing fun, solidarity, and purpose, the act of creating and maintaining friendships was revealed to be one of the highlights of volunteering in the Streamwatch program. Many participants suggested that seeing familiar people was one of the main reasons they returned to the Streamwatch program each year. Marissa, a volunteer in her mid forties, used a photo of two other volunteers staying at a nearby campsite to describe her enjoyment of socializing: "Tom and Elaine are friends who camp with us. We like the social aspect of meeting other volunteers. When we started, we already knew some folks, but we have met many more."

In addition to maintaining friendships, the "teamwork" that took place among the fellow Streamwatch volunteers was an important social meaning among many of the participants. Charlotte gathered several Streamwatch members for a group photo, and stated during her interview that "relationships are the reason you come back." The most important person in this group photo was Alicia, the Streamwatch Coordinator and liaison between the volunteers and the Forest Service. Alicia was held in high esteem by the Streamwatch volunteers, as evidenced by the substantial numbers of photographs containing her image. Alicia was important to the Streamwatch volunteers for three reasons. First, they saw her as a reliable and expert presence upon whom they could rely for advice, instruction, and resources. Second, they felt she did a great job training and recruiting volunteers, mainly because of her ability to account for differences among people and accommodate their various needs. Third, and most importantly, many of the volunteers considered her to be a close friend. Ultimately, Alicia was one of the reasons the volunteers returned to Streamwatch each season. To the dismay of many of the 
volunteers, Alicia was due to retire at the conclusion of the summer in which the research was conducted, and nearly every volunteer indicated that she would be missed.

The volunteers also suggested that socially-oriented meanings emerged from how the group was rewarded and recognized by the Forest Service. Meredith, a 60 year old resident of Cooper Landing, and Dave, the 56 year old retiree, both provided photos of the covered pavilion at the campground, which was the site of the annual volunteer picnic. This event, held to thank the volunteers and recognize their participation in the Streamwatch program, was an important reward for the volunteers for two reasons. First, it allowed them to catch up with other volunteers who they might only otherwise see occasionally throughout the summer. Second, the picnic served as an official "thank you" from the Forest Service and the Kenai River Sportfishing Association. Nearly all the volunteers reported that this recognition was an important inspiration towards the continuation of their efforts.

The meanings involving socializing with like-minded people were occasionally political in nature, and served to connect the volunteers to local citizen interests. Carter, a 47 year-old resident of Cooper Landing who had been with Streamwatch for five years, provided a photo of a gated roadway. He had spearheaded an effort to persuade the Forest Service to unlock the gate, allowing passage to local residents. The political relationships that he nurtured during the course of this project were important contributors to his sense of place, as was his pride in his fellow volunteers - many of whom were not involved with Streamwatch. In this case, it was volunteering in general, and not necessarily Streamwatch, that helped him create meanings of comradeship and accomplishment. 
Recreation at the Russian River and in Cooper Landing. In the final theme, several of the Streamwatch volunteers saw their efforts as a form of recreation. This was evidenced by the recurrence of images depicting the complimentary campsites provided to those Streamwatch workers who lived outside the local area. A number of photos showed the RV spots available for free to Streamwatch volunteers at the Russian River Campground itself. In fact, one participant indicated that "amenities like this allow us to volunteer. We couldn't afford it otherwise."

The free campsite was important to the Streamwatch volunteers for three reasons. First, they felt that receiving use of the site made their volunteer efforts seem less like work, and more like recreation. After their shifts, they could return to the campsite and engage in the same recreation activities as everyone else. Second, receiving the site for free helped many of them afford to participate in the project, since a normal two-week reservation at the campground cost in excess of two hundred dollars. Third, it fostered connections with other volunteers. In many instances, volunteer shifts would overlap, and as a result other volunteers would share the site. This resulted in the strengthening of old friendships and the development of new ones.

In the case of the campsite, the recreation was concurrent with the volunteer activity. That was not always the case. In some instances, the volunteers did their work, and felt that they were then were rewarded with an opportunity to recreate. Dave provided a photo of he and his wife "fishing for reds," and suggested that "one of the reasons that we volunteer is to keep fishing." This suggests that while in some cases recreation may be concurrent to the volunteer activity, in other cases the act of volunteering is actually peripheral to the recreation. Either way, nearly all the volunteers say Streamwatch as a desirable opportunity to both do some good and participate in a favorite activity at the same time 


\section{The Implications of the Place Making Process}

The four themes that describe the place meanings held by the Streamwatch volunteers (preservation/restoration, teaching, socializing, and recreating) emerged jointly from the nature of the experience (participation in the Streamwatch program) and the setting (the Russian River) where those experiences occurred. In addition, volunteering in the Streamwatch program helped volunteers' legitimate important identities as "teachers" or "protectors" within a specific setting. The variety of experiences shared by the participants reveal that the volunteers chose the Streamwatch program in part because it allowed them to combine an important place with a specific activity allowing them to create or express important place-based identities. The volunteer participants also saw Streamwatch as a way to combine their love for the Russian River with their need for social connection, using the program as an outlet to search for new opportunities for social growth. This growth came about through the creation of new, teamwork based relationships with fellow volunteers, which helped the volunteers feel as though they were an important factor contributing to a greater, place-based good. Volunteering is a form of fun, much like the fun that people have in other areas of their lives. In fact, volunteer activity, in this case, is almost a means to a recreational end (i.e. participating in Streamwatch in order to camp or fish). However, not all volunteers saw their work in that way - some saw their work as a combination of both recreation and fulfillment.

These findings reveal how the volunteers use their involvement in the Streamwatch program to "make place" in two main ways. First, they directly change the landscape by engaging in restoration work: they give their time and skills back to a resource that they felt had given much to them. The meanings and experiences surrounding the natural landscape in and around the Russian River involved both protection of the land itself and protection (through 
successful coexistence) of the wildlife that inhabit the area. This idea that volunteers are working to ensure that things stay as they are "supposed to be" is a very direct form of participatory volunteering. Some volunteers change the place through indirect activities such as attending meetings or advocating for management change. In this case, the Streamwatch volunteers are engaging in a direct form of public participation for the preservation of the Russian River landscape. It also represents a hands-on, direct approach. By building boardwalks, installing fence, and removing trash, volunteers are (re)creating the Russian River in ways that are important to them - clean, neat, the way its "supposed to be." This is both accomplished and taught through volunteer work.

Second, the volunteers communicate and interpret place, thus re-creating the landscape by teaching others. The volunteers shared the common meanings of trying to be teachers tasked with spreading the Forest Service message. This shared identity, based on the Streamwatch mission of resource conservation and shoreline protection, is dissimilar to other place meanings because is centered more on the activity — and the pride associated with it--than on the specific place. However, the Forest Service created the Streamwatch program to protect a specific place. This suggests that the roles played by both the agency and the volunteer are more than just managers of a resource - they are place makers that use the meanings derived from their teaching (and the experiences and behaviors that inform them) to influence how a place is perceived by others.

\section{Lessons for Management and Policy}

The Streamwatch program has been successful because of the hard work, dedication, and enthusiasm of the volunteers. This photographic approach to the study of their meanings and 
their role in making place provides a useful starting point for natural resource managers and decision-makers, giving them a perspective from which they can better reach out to the volunteers who are becoming more important to the future of important places like the Russian River.

What can managers learn from the place-making process? First and foremost, the Streamwatch volunteers who participated in this research see the act of volunteering in Streamwatch as recreation, reflected by the numerous pictures of the campsite where they stayed and the repeated referrals to the "fun" of the program, the enjoyment of seeing wildlife, and the act of socializing with others. Their image of place is one of fun, so managers should focus on opportunities or programs that continue to establish the volunteer site as a "fun" place to volunteer. Additionally, the volunteers' identities as experts and professionals (established by the uniforms and training) mean that managers should continue to provide opportunities for volunteers to emphasize the "official" nature of the work.

Managers themselves could employ a written handbook for recruitment that uses place meanings as a tool for volunteer recruitment, possibly in the form of detailed place descriptions to entice potential volunteers. The handbook could include a training manual, with a section on developing and sharing place-based information in a "teaching" style. Managers could also make use of a manual of best practices aimed at the long-term retention of volunteers in specific places. In the long term, observing how these materials work will also help managers gain a comprehensive understanding of how activities, place meanings, and social relationships inform the place-making process in which their volunteers engage. 
Finally, it is crucial for managers to consider the sources of their volunteers' place meanings, and the degree to which they are free to express them. Volunteers are socialized into their activity and the institution they represent. As such, the meanings they hold for the landscape and the act of volunteering are not exactly created from a blank slate: the position of the management agencies (such as the USFS) are reflected in their actions, as their volunteering activity is shaped by official requirements. Thus, although meanings may be created from experience, these experiences are structurally influenced. In this sense, volunteers - and the meanings they make — may further manifest agency goals and visions. Their identities as "teachers", rather than "enforcers" may foster public receptiveness to their efforts.

Sense of place can be a useful way to reach out to the volunteers who are becoming more important to the future of important places such as the Russian River. As budgets shrink and services decline, it makes sense to implement place-based approaches to understanding those who donate time and energy to support recreation spaces and their management. While an elucidation of sense of place has direct implications for management, it can also help the volunteers themselves better understand what they do, providing them with a means toward the realization of repeated, satisfying and fulfilling volunteer experiences. 


\section{References}

Alaska Dept. of Fish and Game. (2007). The Russian River - Kenai Peninsula Recreational Fishing Series .Southcentral Region Division of Sport Fish.

Dewalt, K., \& Dewalt, B. (2002). Participant Observation: A Guide for Fieldworkers. Walnut Creek: Altamira Press.

Glynn, M.A. (2000). When cymbals become symbols: Conflict over organizational identity within a symphony orchestra. Organization Science, 11(3), 285-298.

Gooch, M. (2003). A sense of place: Ecological identity as a driver for catchment volunteering. Austrailian Journal on Volunteering, 35(2).

Henderson, K. A. (1991). Dimensions of Choice: A Qualitative Approach to Recreation, Parks, and Leisure Research. State College, PA: Venture Publishing, Inc.

Hustinx, L., \& Lammertyn, F. (2003). Collective and reflective styles of volunteering: A sociological modernization perspective. Voluntas: The International Journal of Voluntary and Nonprofit Organizations, 14(2), 167-187.

Penner, LA, Finkelstein, MA, \& Brannick M. (2005) Motive, role identity, and prosocial personality as predictors of volunteer activity.Social Behavior and Personality: An International Journal.33(4).

Piliavin JA, \& Callero PL. (1991). Giving Blood: The Development of an Altruistic Identity. Baltimore, MD: Johns Hopkins Univ. Press

Proshansky, H. (1978). The city and self-identity. Environment and Behavior, 10, 147-169.

Relph, E. (1976). Place and Placelessness. London: Pion, Ltd.

Spradley, J. (1980). Participant Observation. Orlando: Harcourt Brace Jovanovich.

Stebbins, R. (1992). Amatuers, Professionals, and Serious Leisure. McGill-Queen's University Press.

Stedman, R., Beckley, T., Wallace, S., \& Ambard, M. (2004). A picture and 1000 words: Using resident-employed photography to understand attachment to high amenity places. Journal of Leisure Research, 36(4), 580-606.

Wilson, J. (2000). Volunteering. The Annual Review of Sociology, 26, 215-240.

Williams, D., \& Patterson, M. (1999). Environmental psychology: mapping landscape meanings for ecosystem management. In H. Cordell \& J. Bergstron (Eds.), Integrating social sciences with ecosystem management: Human dimensions in assessment, policy, and management (pp. 141-160). Champaign, IL: Sagamore Publishing. 


\section{Part 3: Group relationships with Place}

Humans are place makers. It is hard to imagine living in a house or working in an office without doing something to personalize one's space and endow it with meaning that otherwise would not be there. There are countless agencies and organizations whose mission includes place making, and otherwise positioning an environment for a set of place meanings. Some of these organizations are self-aware of their place making. Others are not, and take for granted the place meaning as "out there" and obvious to all who encounter the site.

Place meanings are not easy to represent. We all have place meanings, yet they are not given to top-of-mind reporting. Although we grow-up knowing our preferences for food and clothes and other everyday things, we do not grow-up knowing our place meanings. Because place meanings are more than simple statements of preference, their representation becomes a conscious process of building a frame for them to be understood. In other words, place meanings need a context of someone's life or a group's narrative before their representation is fully comprehended. The chapters of this section breakdown the problems in the representation of place meanings, and identify processes in which they become public and potentially integrated within planning processes. This section describes organizations, communities, and groups of people who have produced place meanings in intentional ways. They tell of place meanings as being actively created and evolving based upon social interaction of stakeholders and the discourse of their own making.

Hall and colleagues depicted places as being bounded by communication. They portray land-use conflicts as struggles for control over the interpretive framing of the landscape. Because land managers can not control the ways in which groups represent place, they need to understand relationships between representations of place and communication practices of everyday life. 
The way places are named and labeled has implications for the type of activities done there as well as activities not done. They explore place representations of stakeholders of Wyoming's Yellowstone River, and discover the meanings of everyday life represent their place meanings: hobbies, occupations, education, chores, and so forth. Recognizing the dynamic nature of place, the identify roles for land managers to represent place and actively participate in legitimizing knowledge about place.

Stewart, Glover, and Barkley extend the work by Hall and colleagues by arguing that social learning is at the center of place-based planning. They argue that emotions about place need to come to the surface of stakeholder dialogue, and done in ways that lead to appreciative accounts of place and people. Stating the social learning should occur prior to any formal stage of planning in order to being public dialogue at a point that appreciates landscapes and builds a positive base to grow relationships among stakeholders. Recognizing an outcome of communication is the construction of something new, Stewart and colleagues provide insight to conditions that would foster social learning within stakeholder forums. Their chapter develops "learning circles" as a strategy for stakeholders to feel safe sharing place meanings, to represent emotional attachments to place, and to create new public values for place.

Van Auken and Golding discuss the relationships of collective action to place meanings of rural property. They view the process of place making in rural areas as being affected by inmigrants pulled by amenities of living in the country. Van Auken and Golding argue and provide evidence of two rural towns facing similar pressure to develop a brand image. They develop a model that integrates community, commodity, and place interests as having implications to collective action. Their chapter details the behavior of local organizations to 
reaffirm or resist various place meanings, and the purposeful communication used to frame the community by asserting place meanings.

Hurley examines residential development purposely directed at creating a compelling sense of place. He examines regional and local processes that function to re-territorialize the meaning housing developments in Central Oregon. Zoning restrictions vary by county regarding minimum lot size, which has implications to the place meanings of resultant homesites. Developers controlled amount of open space with a subdivision, their emphasis on planting native flora, and to some extent, the size and clustering of lots. In addition, in-migrants became active in conservation activities that further distinguish various environmental amenities of the subdivisions, and in doing so, influenced the senses of place. Websites, brochures, and word of mouth were instrumental as place making tools, and assisted in distinguishing various subdivision themes, such as the Old West, the ranching lifestyle of Oregon, agricultural or pastoral Oregon, and living in harmony with the land, to name a few. It is clear from Hurley's chapter that place making is something that involves everyone who lives in a locale whether they know it or not.

This section is concerned with the seemingly simple act of representation of place meanings. Although they exist in the everyday lives of people and communities, place meanings are not always recognized as such in planning forums. Place meanings are authored by the people and organizations who live, work, and are affiliated with the place. Because place meanings evolve and are in a constant state of flux, the core of place-based conservation is an engaged group of stakeholders. Place-based conservation starts with the representation of place meanings and translation of them into public values. 
Integrating divergent representations of place into decision contexts

Damon M. Hall, Susan J. Gilbertz, Cristi C. Horton, and Tarla Rai Peterson

Environmental conflict arises when divergent representations of a shared resource clash. Representations of place — as containers for group identities and interests - become sites of struggle for control over the interpretive frames that direct land use and planning. A shared vocabulary helps groups of people work together (Burke 1959; Peterson 1997), and agreement on a shared set of terms for representing a place endows decisions about how to manage that place with legitimacy. Because managers cannot fully control the social dynamics of how groups represent place, they need to understand how place representation connects meaning and language to culture via practices of everyday life and the practical consequences of those practices. An awareness of this social compact is useful for framing decisions that emerge seamlessly from representations of place offered by local stakeholders. Place meanings can be used as rich demographic data, and observed in their politically-engaged form as representations that contribute to the struggles over legitimacy in decision making. This chapter focuses on place representations, as they emerge through people's taken-for-granted communication. We offer the cultural inventory as a tool to enable managers to understand how people connect symbolic and material resources as part of their representation of place. In response to natural resource management (NRM) needs for the Yellowstone River, we designed and conducted a cultural inventory to discover and document dominant representations of that place. The cultural inventory began as any inventory, with identification of available resources (in this case human resources), and then moved to production of a data base describing how these resources function to represent place. After identifying major groups of resource users, we conducted informant- 
directed interviews with landowners, recreationalists, civic leaders, and agriculturalists that live along the river. We then analyzed the interview transcripts attending to how these residents individually and collectively represented their place. Our analysis suggests how attention to localized cultural discourses provides NRM advisors, planners and other decision makers with a conceptual framework that may help them integrate divergent place representations into decision contexts, leading to more effective management in and of place.

In this chapter, we contextualize the cultural inventory by beginning with a broad discussion of how processes of place representation contribute to place meaning. We then examine the functions and forms of place representation. Using Edward Casey's (2002) framing of the practices of place representation, we examine resource users' flattened and deepened representations of the Yellowstone River, including how discourse has integrated the river with local and cultural meanings, political strategies implicit in the discourse, and unexpected consequences. After describing the results of the cultural inventory, we end with suggestions for how decision makers can encourage place representation frames that enable diverse resource users to creatively negotiate their identities and interests in the resource.

\section{Place Meanings and Place Representation}

People connect to place in significant and lasting ways that influence their identities, sense of belonging, and rootedness. Natural resource scholars have examined the expression of individual place meanings to account for their significance within planning by discerning landscape valuation in terms beyond but not mutually exclusive from economics (Williams et al. 1992). Resource users' affective valuations of place meaning — expressed through metrics of 
attachment, sense of place, place identification, and others (Patterson and Williams 2005) - are described as indicators of use-value and behavior.

Although identifying the psychometrics of place meaning is useful, it has limited value for increasing our understanding of communication processes that contribute to meaning, and the political contexts wherein that meaning operates. Our interest concerns how group practices of representing a meaningful place pose challenges that impact management. This chapter focuses on understanding the communicative process of making meaning for a place, or representing place. We argue that understanding how place representation functions in the political realm can improve the ability of decision-makers to negotiate between diverse resource users, who have developed apparently irreconcilable place meanings.

\section{The Work of Place Representation}

How we speak and write about place and the words we assign to it constitutes much of how we think and act in place. Several scholars have examined connections between communication and place: from language and place making (cf. Meinig 1979; Lefebvre 1991; Tuan 1991; Greider and Garkovich 1994; Herndl and Brown 1996; Spirn 1998) to discourse and management (cf. Berdoulay 1989; Myerson and Rydin 1994; Dryzek 1997; Stokowski 2002; Norton 2005; Wolf and Klein 2007). They argue that representations of place in public discourse make sense of complexity, unite disparate persons, anchor collective memory, and give authority to subscribers.

Representation of any sort connects meaning and language to culture via everyday practices. We define representation as the production of meaning through language or a link between concepts and language that enables us to refer to both the material world of objects, people or events, and to imaginary objects, people and events (Hall 1997, p. 17). Such 
representations live through communicative practices like storytelling that function as sources of explanation, comprehension, thought, meaning, and beyond (Entrikin 1991; Stegner 1992;

Gilbertz 2002; Carbaugh and Rudnik 2006). Stories representing place include mostly cogent logics, a structural and temporal order, and implied values. Because discourse simultaneously structures and expresses understanding of the experienced world (Burke 1969; Lakoff and Johnson 2003), identifying certain places through the naming and labeling of space simultaneously constructs and communicates what behaviors are allowed and which practices are appropriate in that space (Burke 1969; Cronon 1992; de Certeau 1984). Henri Lefebvre (1991) likens representations of space to street signs that are intended to guide, direct, command, and orchestrate behavior. By naming and framing normative practices appropriate for particular sites, place representation reinforces some management options while excluding others. The representation of place, then, is a cultural practice whereby people use various modes of communication to construct and adjust legitimate uses of space (Rose 1994).

Because people depend on communication to enable cooperation in the face of division, they seek a common language to conceptualize, discuss, and manage the natural systems required to sustain life (Burke 1959; Peterson 1997). Each community (e.g. governing agency, industry, stakeholder group, etc.) develops a vocabulary of terms that guides decision making by framing and positioning relations between humans and the natural world. As such, "language reveals much about a profession, about its preoccupations, about the social, political, economic, and scientific forces that bear down upon it, and also about its readiness to confront those forces effectively" (Guttenberg 1993, p. 1). The discourse of NRM, for example, has relied upon technical knowledge to understand and manage the natural environment within institutional, 
legal, and bureaucratic capacitates and frameworks. This discursive frame may have created unwarranted limitations for NRM decision possibilities.

When people represent a place, they bound, order, and define it by communication (Sack 2001). This process has both constitutive and instrumental functions. Representing place legitimizes certain cognitive schemes toward reality and excludes others. It produces what we know about a particular landscape, what actions are proper and improper within its boundaries, and how we come to value it. How we represent place not only delineates (points to) a place by highlighting its borders but also makes a statement about its character, utility, past, future, and how it should be managed.

\section{Place representation by flattening vs. deepening}

Edward Casey (2002) argues that representations of place slice up space into pictures that flatten and/or deepen space. Representations that flatten space make sense of complexity by translating landscape's idiosyncrasies into gridlines, contours, and other classifications with the aim of accurate orientation, definition, and utilization. Flattened space is the bounded site where place is displayed as generalizable, accessible, calculable, and isometric. This flattened space is the realm of abstract space or space as object (Lefebvre 1991). Space in this form is represented in Euclidian geometry and is often conceptualized without the potentially confounding presence of human subjects, which could threaten its objective representation. An alternative way of representing place is by deepening it to explore the subjective experience, often through artistic or poetic accounts. Where flattened representation of place removes the subject from place to ensure accurate replication of reality, deepened representation of place is more interested in active participation of the experiencing subject in place than in creating a replicable account. 
Deep representations of place situate the human subject in place, as opposed to flattened accounts that situate the human subject above place.

Both deep and flat representations of place are social practices that unite disparate persons, anchor collective memory, and give authority to subscriber. Conflict arises when groups must reconcile a site's, sometimes highly divergent, deepened and flattened representations. Therefore this seemingly benign social act of representing plays a critical role in the potential failure and success of managerial efforts.

\section{The Yellowstone River Cultural Inventory}

The U.S. Army Corps of Engineers (Corps) regulates riparian corridor activities under the authority of Section 10 of the Rivers and Harbors Act and Section 404 of the Clean Water Act (CWA). Since assuming CWA permitting duties in the mid 1970s, the Corps has processed a total of 156 bank stabilization-related permit actions for the upper Yellowstone River (Park County, MT). Over two-thirds of the permit actions occurred during or after two consecutive 100-year floods in 1996 and 1997 (Auble et al. 2004). The high volume of permit requests for bank stabilization projects prompted a grassroots call for a cumulative impact study of the potential environmental and ecological consequences of this channel modification.

The cumulative effects study focused on physical features, biological inventories and historical floodplain mapping of the Yellowstone River. When the Corps decided to include social and cultural dimensions as part of the cumulative effects study, we suggested a cultural inventory that would be analogous to the biological inventories.

\section{Historical context}


In 1806, on a canoe made from a cottonwood tree Captain William Clark traveled down the Yellowstone River to meet Meriwether Lewis at its confluence with the Missouri for the return trip to Washington D.C. (DeVoto 1953). The objective of their journey was to map and describe the newly purchased lands of the Louisiana Purchase for purposes of delineating the riverine highways of the coveted Northwest Trade Passage between the east and west coasts of North America. Lewis and Clark characterized the landscape with maps from survey measurements and described the natural resources via journal accounts of their subjective experiences. Lewis and Clark presented the landscape in maps that used mathematics and geometry to flatten the landscape to paper and journal descriptions that deepened it by chronicling the plants and wildlife, the aboriginal peoples and practices, the weather and the topography they experienced. Their report was the first Euro-American documentation of the Yellowstone River.

The Yellowstone River remains much as it was when Clark traveled its length - the longest undammed river in the United States. This characteristic affords scenic and recreational amenities which attract visitors and residents. At the same time, much about this place has changed. The river's seasonal flooding, for example, is problematic for riverfront homes and farmland. In a single flood event, hundreds of acres of bordering land may be lost or gained by the movement of the river channel. We conducted a cultural inventory 200 years after Lewis and Clark's now famous expedition. We spoke with 313 riverfront landowners and users along its entire length, from the point where it leaves federal jurisdiction in Yellowstone National Park to its confluence with the Missouri River (Gilbertz et al. 2007). To ensure appropriate distribution of stakeholder interests and account for geographic differences we divided the river into five geographic reaches. As a complement to the interviews, we gathered related documents, engaged in participant-observation, and performed thematic analysis of all texts (Peterson et al. 1994). We 
analyzed and organized these comments into a report of the cross-sectional themes that ensured the inclusion of each unique perspective using 1700 quotes from participants to illustrate and provide evidence for our findings (Gilbertz et al. 2007). Representations were identified based on the frequency of appearance, the connectedness between common comments, and the magnitude of importance within individual interviews and across river-length segments.

\section{Inventory of place representations}

Those who live with the Yellowstone River project a hyper-complex assortment of representations of both deep and flat elements onto the river. Meaningful aspects of people's lives contribute directly to the spectrum of representations they give the river: occupations, hobbies, relations with the land, loves and fears, education, expertise, daily practices, river uses, family legacy, etc.

Among the local vernacular that heaps meaning, value, and purpose onto this resource, three representations consistently stood out. Most people represented the river as: the lifeblood of the valley, a great playground, and/or a national treasure. We briefly summarize these prevalent constructions, and then provide more detailed description of one case to illustrate how place representations enter the political sphere and may incur unexpected consequences upon the natural resource.

\section{1. "The Lifeblood of the Valley"}

"It's the lifeblood of the Yellowstone Valley, that's all there is to it."-Agriculturalist Perhaps the most dominant image of the Yellowstone River among agriculturalists, recreationalists, civic leaders, and other long-time residents is that of the river as "the lifeblood of 
the valley," or an essential element in the creation and maintenance of valley life. One civic leader explained, "the Yellowstone River is the lifeblood as far as Ag and recreation goes. It is what draws people here. It is the main artery." Representing the river as "lifeblood" flattens and objectifies it into economic and legal structures that include food crops and other commodities, businesses, and services. One informant noted that the "vast majority of the economy is within the boundaries of that river." The river supplies irrigation water for crops, livestock, and drinking water for humans. As a driving force for development of towns, goods, and services, the river offers communities a "lifeline" by making water available in the semi-arid landscape: The river as lifeblood evokes flat descriptions of biophysical forces. Residents understand that the valley's "productive agricultural lands" relate to the river's dynamic forces of historic seasonal flooding. The "June rise" ensures the fertility of the fields and the regeneration of the bottomland cottonwood forests. The river also provides habitat and nutrients for fish and wildlife while maintaining humidity throughout the seasons in this arid landscape. Another informant summed it up: "[the river] is the most important thing. It provides water for drinking, flood irrigation, and recreation. It is the lifeblood of our community."

Descriptions of the Yellowstone as the lifeblood of the valley also include deep subjective representations. One agriculturalist, for example, told us the river "is like having an artery in your body. It is a vital part of this valley. It is the lifeblood of the valley." Nonlinguistic images and practices also play an important role in deep representations of the place. Everyday operations raising sugar beets, spring wheat, and others irrigated crops are passed down from grandparents and parents to children. The rhythms of flood irrigation practices are represented as part of the lifeblood. Resource users talked of opening and closing the ditch gates, monitoring the furrows to ensure optimum flow, and pulling their irrigation boots off and on. They pointed 
out everyday sights such as ditch hoes and other machinery in the fields, all operating in rhythm with the river. These felt practices and vocabularies are ingrained in the foundation of community values, and they represent the river as a provider. From this perspective, resource users expressed an ethic of protecting the river, which included preserving access rights to the water, whether for irrigation or for recreation.

\section{2. "A Great Playground"}

"There is a lot of river there. . .. It is a great playground." -Residentialist A second dominant representation of the Yellowstone resonates with, at the same time it contrasts against, the lifeblood metaphor. This is the representation of the river as "playground," or a place to play and relax. Informants represented the river as a place that provides a refuge from the stresses of everyday life. The playground representation builds on sharing a name with Yellowstone National Park. A civic leader explained that, "people have a picture of what Yellowstone Park is even if they have never been there. I describe it [Yellowstone River] as an extension of Yellowstone [National Park]. You attach things like the fishing culture, the hiking, the outdoor mountain recreation."

Playground images typically begin with a deep account of the ideal recreational experience: An experience of solitude, wildlife, peace, rest, natural beauty, or encountering the wild.

I've always gravitated towards it because it's always relaxed me ....The fog comes up off the water....The sun pops up and your line is singing out there and you look down and see the little crystals on it, then I see a herd of elk crossing a couple hundred yards from $m e$ (Recreationalist). 
Many see river recreation as a way to regain their sense of well-being whether through flyfishing the cold waters or bait fishing the warm waters; hunting deer, waterfowl, pheasants, wild asparagus, mushrooms, or agates; hiking, bird-watching, boat floating, inner tubing, or swimming; or just sitting and watching the water. Although recreationists frequently used the playground metaphor, so did informants representing other user groups.

The deep representation of felt experience when fly-fishing, hunting, boating, etc., is thoroughly intertwined with flattening representation, as the place becomes an object of business and a legal matter of recreational permitting and licensing, bag limits, designations of special waterfowl habitat refuges, and Montana's stream access law. Flattened representations depict the river as a producer of revenue for outfitters, guides, private landowners, and fishing shops, hotels and restaurants. These representations allow calculable financial valuations of the river's recreational assets at specific points along its length. The salience of the playground metaphor drives riverfront development and the local real estate industry. The gridlines and contours that flatten this place include motor boat restrictions, development of public river access points, state investments in the management of fisheries, and map making for boating and angling.

The economic motif of the playground metaphor is most visible among residents and other resource users of the western cold-water stretches of the river, near the northern entrance of Yellowstone National Park. Post cards, calendars, brochures, and varied tourist kitsch depicting the Yellowstone as a sublimely wild river are sold throughout that stretch of the river. Because resource users explicitly affiliate the river with Yellowstone National Park, texts centered on the Park as a tourist destination are available to reinforce the playground place representation for the Yellowstone. 
The deep representation of the river as a place of play was reinforced by Norman Maclean's book (1976) and movie (1992) A River Runs Though It. Although the story was about the Big Blackfoot River, the movie was filmed in Paradise Valley on the Yellowstone River. One result of what some locals disdainfully call "The Movie," was that fly fishers flocked to the Yellowstone River in hordes. Leighton (1998) describes this phenomenon as a "battalion of outfitters, guides, and other full- and part-time trout bums" eager to exploit the region's resources in the "final Gold Rush," (p. 46). Partly in response to public enthusiasm generated via the movie, the playground representation has influenced home site preferences and property values.

\section{3. "A National Treasure"}

"I would like to keep the Yellowstone a free-flowing river. It is a national treasure." -Recreationalist

The Yellowstone River is the longest undammed river in the United States. The exclusivity associated with this material condition contributes to its representation as a national treasure, and to the frequent inclusion of the word "wild" in descriptions of the river. Informants articulated this special characteristic of the river as a rarity that enhances the quality of experience for users and quality of life for residents. The National Geographic Magazine labeled the Yellowstone River as "the last best river" (Chapple 1997) borrowing from a Montana state tourism campaign that promoted the state as the "last best place." Local residents from across the political spectrum are especially protective of "their" river, dating at least to the proposed Allen Spur Dam in 1958, which locals viewed as threatening to both natural amenities and private property rights. Many of our informants used the idea of the river as a unique national treasure to explain why most 
attempts to control the river were inappropriate. As one recreationist said, “you don't want to dam this river. This is one of the-THE_-last wild river in Montana, and it may be the last wild river in the nation. There is no dam on the Yellowstone, and we really don't want a dam on the Yellowstone."

As with any national treasure, the Yellowstone River is often represented as needing protection. One resident articulated his obligation this way, I guess living next to the Yellowstone; you get such a loyalty to it. It is something that has to be protected and you can't give it away...It just got into a real almost a spiritual thing - when you live next door to it, it becomes something bigger than property rights and that sort of thing.

Many informants similarly expressed their sense of "responsibility," or "duty," to safeguard the river. "To alter [the river] or to change that in any way would be a national loss, a national tragedy...this is our national heritage" (Recreationalist). By representing the river as a national treasure, our informants elevated the importance of protecting it as a rare remnant of the truly wild in nature. Residents often spoke about how "lucky" and "privileged" they felt to live along the river. "You know, every other river in the country is dammed, and it is nice to have something that's wild in your backyard" (Recreationalist).

These deepening representations of place interact across stakeholder categories, uniting streamside residents, agriculturalists, and recreationalists in appreciation for this place. Some comments demonstrated an experienced awareness of the interconnections between themselves and the natural world fostered by the river: 
It is a national treasure. It is at the river that I best understand my role as a human being on this planet. I am part of nature too, as you are and we all are. When you stand by the river you have a tendency to realize that (Recreationalist).

The national treasure metaphor also allows flattening representations. In this case, the discussion swirls around cost-benefit assessments of water storage, flood protection, and electrical power generation potential. The river's (relatively) free-flowing status also makes it always vulnerable to flattened images that de-value many of the felt experiences described above. Subjective descriptions of the river's "spirituality" for example, are of little use if the river's value is predicated solely on the dollar value of its use for irrigation or the dollar cost for prevention of flooding. Whether described as the lifeblood of the valley, an incredible playground, or a national treasure, the Yellowstone River emerged as a place with distinctive deepened and flattened characteristics that offer clues for NRM.

\section{Conflicting place representations in the public realm}

Different representative images of the same place can clash. The battleground is in public conversation where each seeks to reframe the place to create 'proper' ways of thinking about access rights, quality and quantity of the resource, management authority, and what is considered legitimate use of the resource. Competing representations of place are "meeting points of tremendous pressures coming from rival word-users, each of whom would like to appropriate the word for his [sic] own purposes" (Guttenberg 1993, p. 6). Competing perspectives of a shared site and the coordination of competing interests is often dubbed the politics of place (cf. Jackson 1987; Kemmis 1990; Norton and Hannon 1997; Yung et al. 2003; Cheng et al. 2005; Norton 2005) where vested and vetted socially-constructed representations clash. 
Past management initiatives for the Yellowstone River illustrate this clash, and resonate in contemporary accounts of river users. In 1958, a state delegation prompted by U.S. Senator James E. Murray (Montana) and the U.S. Bureau of Reclamation (Bureau) offered a strategy for using the Yellowstone River to provide water and energy security by proposing the construction of a water-retention dam at a narrow point in Paradise Valley (Nolt 2007). Based on the Bureau's flattened representation of the place, the valley was ideally shaped for a dam (Wheelwright 1978). The 380-foot tall Allen Spur Dam was to house a 250 MW power plant and a 30-mile reservoir covering 20,000 acres (Nolt 2007). A grassroots campaign soon developed to provide an alternative deep representation of the river as a site of meaningful experiences important to Montanans. By 1963, Park County Commissioners, the Rod and Gun Club, and Farm Bureau united their efforts to oppose the dam, citing concerns over the loss of farmland and fish and wildlife habitat (Nolt 2007). In the face of organized local opposition, interest in the proposed dam subsided until the energy crisis of the 1970s, when it resurfaced as potential support for development of the nearby Fort Union coalfields.

Recreationalists opposed the second attempt to dam the river, because it would have flooded the Yellowstone's best trout fishery, the source of several nutrient rich spring creeks where trout spawn including the endangered Yellowstone cutthroat trout (Oncorhynchus clarki bouvieri). They resisted the proposed dam by publicly representing the Yellowstone River as a blue-ribbon fly-fishing destination and an ideal location for riverfront vacation homes. Their expressed intention was to interrupt the proposed dam by attracting wealthy fly-fishing enthusiasts to move to the valley. Filling the valley with expensive vacation homes would discourage the Bureau from siting the dam on the Yellowstone by skewing the cost-benefitanalysis calculations when the federal government considered the costs of necessary regulatory 
takings. The fly-fishing community of Paradise Valley, multiple Greater Yellowstone advocacy organizations, other recreational users and agriculturalists harnessed the symbolic prowess of "Yellowstone" to save the river and its natural amenities. In addition to grassroots organizing, dam opponents used the media to cover the controversy and brought visitors to Paradise Valley, the bed of the proposed reservoir. A 1978 Life article titled "Great River in Crisis" told the story of the proposed dam as a demand for a "30-mile long storage tank" and described the threats to this undammed wonderland alongside full-page aerial color photos of the river's mountain scenery and quotes from a "ruddy-faced Montana cowboy with tears in his eyes" (Wheelwright 1978). The campaign worked. During initial stages of the Bureau's planning, regional and national outcry combined with a proliferation of riverfront second homes and recreation-oriented homeowners' values to prevent the construction of the dam. Twenty-five years later the high numbers of vacation homes in the valley continue to suppress re-visitations of the Allen Spur Dam conversation yet the fly fishing experience has changed. Some participants describe fishing that stretch of the Yellowstone River as "floating through a subdivision." Others no longer fish that stretch of the river because of the loss of wild attributes. Furthermore, annual flooding and the close proximity of new residents' homes have led to the installation of large boulders (riprap) which affect the flow characteristics of the riparian corridor. One of the original framers of the strategy to prevent the construction of the Allen spur Dam told us that although he was happy to have saved the river, the success of the campaign has now backfired. As he and other participants in the original advocacy campaign explained, their representation of place has contributed to "loving the river to death," and is damaging the ecological amenities that preservationist advocates sought to protect. 
As in this example, representations of place regularly "intervene in" and "modify spatial textures" according to a truth-teller's interests (Lefebvre 1991, p. 42). Participants in the advocacy campaign in opposition to the dam recognized that controlling the dominant representations of place was one means of influencing decision making. By representing Paradise Valley in a certain way, advocates influenced agency behavior, interpretive frames, and decision making. Their successful struggle to shape acceptable uses and norms so as to exclude the dam had the unforeseen consequence of spurring momentum for riverfront development.

\section{Enhancing NRM Decisions by Reconcile Competing Representations of Place}

Like bank stabilization practices along a wild and moving river, words and images armor the boundaries of place. Different interest groups advance representations of place that privilege certain knowledge they believe will stabilize or further their advantage over other interests (Kemmis 1990; Cheng et al. 2005). Any representation, for example, deflects opposing worldviews to protect the preferred image of a place. As riverfront landowners and agriculturalists on the undammed Yellowstone River know; all bank stabilization efforts are temporary, and require frequent repairs, and even redesign. Likewise decision makers must frequently revise management approaches in light of shifting place representations.

As we followed the Yellowstone River speaking with its residents, listening to their stories, experiencing their practices, and participating in their events, a kaleidoscope emerged. The images and descriptions were strikingly diverse and yet threaded together by the materiality of the natural system, the legal status of the river as a shared resource, and by vernacular phrases that resonated throughout the community. When we asked participants to describe their place along the river, each informant articulated a unique image based on their lived experiences of the 
river. Responses displayed how participants: (1) perceived the riparian areas, (2) formed their views on flooding and bank stabilization and (3) articulated their interests and desires for future management. Using names ranging from "Monster," to "Prom Queen," our informants represented the Yellowstone River as (1) the lifeblood of the valley, (2) a playground, and (3) a national treasure.

Although we organized our data collection around interest groups and geographic segments of the river, many of the place representations that emerged cut across both locations and stakeholder categories. This is one strength of analyzing how place enters everyday discourse via representation that is potentially useful for decision makers. We chose to emphasize the conceptual representations of place rather than the classification or categorization of individual informants. Emphasis on the conceptual constructions of place rather than on speaker classification enables us to reflect more of the complexity in how people conceive, experience, and reconcile place filtered by multiple overlapping representations. Focusing on the multiplicity of truths told about the place rather than on the truth-teller may enable NRM decision makers to de-emphasize entrenched positions and identity based politics.

By shifting attention from personalized meanings of place to how discourse actively represents place, the cultural inventory offers a way to identify the shared meanings expressed by interest groups, communities, and institutions via representations of place. This redirection towards the representation of place as both deepened and flattened space suggests opportunities for NRM advisors, planners and decision makers to explicitly incorporate multiple meanings, effects, and outcomes into their decision calculus. By taking a dynamic view of place representation, decision makers may become more conscious of the potential impacts of seemingly benign acts of place representation and strategic reframing. Awareness of the 
dynamism of place representation may enhance opportunities for managers and publics to cooperatively participate in the production of legitimate knowledge about shared places via shared vocabularies.

Managing natural resources necessarily involves the management of symbolic resources. A particularly precarious and daunting task that decision makers must perform within the politics of place is the coordination and management of legitimate information. That place is classified, named, and labeled is necessary for planning and management. This representational practice is complicated because shared places are discussed and constructed multivocally. Each carries with it diverse perspectives including disciplined scientific lenses, bureaucratic organizational perspectives, multi-generation lived experiences and other stakeholder interests. The problem that decision makers must overcome is rhetorical insofar as they must reconcile divergent conceptualizations of landscapes housed in place representation in order to get things done.

Just as managers attend to the consequences of physical actions on managed landscapes, so must they attend to concomitant symbolic actions. Managing natural resource sites requires them to gather and disaggregate deep representations of place to be integrated into flattened managerial frameworks and administrative policies. Managers cannot completely control representations of place, but they can study these representations to understand their role in decision making and knowledge formation by asking: What are the dominant representations of this managed place? What are the origins and assumptions of each? How do shared place meanings enter decision making? Which representations clash? What effects do place representations have upon planning scenarios? Why? What are the potential consequences of various representations being publicly approved or rejected? How can representations of place 
be reconciled in a way that leverages perspectives of place to inform the common management objectives for a site?

Careful reflection regarding representation of place will help managers understand stakeholders' beliefs and their argumentation strategies. Analysis of representations of place may reveal unintended consequences of certain frames. Mangers may become aware of power dynamics, bring consciousness to stakeholders, actors, and agencies so that they may guard against ideological concoctions, and call attention to strategies of oversimplification, expertise, obscurity, identification, and estrangement. Discursive frames for discussing place representation within decision making vocabularies should be respectful of and accessible to local vernaculars. Members of the local community are valuable allies for implementing resource decisions. Understanding and explicitly including the interests of those involved, and then communicating to landowners and residents within these terminologies may mitigate the off-putting scientific jargon.

In order for decision makers to effectively incorporate place representation into their decision calculus, they must understand it as a participatory construction that both flattens and deepens that space. Place representation includes a (relatively) accurate flattened representation of the abiotic, biotic and social factors coordinating multiple areas of expertise. At the same time, they must integrate this understanding with awareness of an imagined deep representation that accounts for desired futures for that place and its communities of users. The challenge lies in getting the proportions right; and that effort remains always problematic. Flat representations must not oversimplify and be so removed that it disregards the realities of politics or neglects resource health. Deepened representations of place cannot be so personalized that they are limited to the needs of powerful interest groups or mask ecosystem processes. 
With these cautions in mind, an analysis of place representation can inform decision making efforts in NRM choices when representing these places. Place representation also offers NRM professionals an inventive or liberating dimension. Because place is socially constructed, it can be socially reconstructed. From this perspective, planning and decision making become sets of practices for creating legitimate discourses that guide place users. While the practices of place representation may entrench polar positions, forcing a choosing of sides, decision makers must remind all participants that there is only one material place to be shared: a single common ground. Managers can use existing representations of place to invent amicable constructions that bridge multiple interest groups and promote new ways of seeing place and NRM practices. 


\section{References}

Auble, G. T., Z. H. Bowen, K. D. Bovee, A. H. Farmer, N. R. Sexton, and T. J. Waddle. 2004. Summary of studies supporting cumulative effects analysis of upper Yellowstone River channel modifications: U.S. Geological Survey, Biological Resources Discipline, Open File Report 2004-1442, 60 p.

Berdoulay, V. 1989. Place, meaning, and discourse in French language geography. In Agnew, J. A. and J. S. Duncan, editors. The power of place. London: Unwin Hyman, 124-139.

Burke, K. 1959. Attitudes toward history. Los Altos, CA: Hermes Publications.

Burke, K. 1969. A rhetoric of motives. Berkeley: University of California Press.

Carbaugh, D. and L. Rudnik. 2006. Which place, what story? Cultural discourse at the border of the Blackfeet Reservation and Glacier National Park. Great Plains Quarterly, 26:167184.

Casey, E. S. 2002. Representing place: Landscape painting \& maps. Minneapolis: University of Minnesota Press.

Chapple, S. 1997. The Yellowstone: The last best river. National Geographic, 194: 56-77.

Cheng, A., L. E. Kruger, and S. E. Daniels. 2005. "Place" as an integrating concept in natural resource politics: Propositions for a social science research agenda. Society and Natural Resources, 16: 87-104.

Cronon, W. 1992. A place for stories: Nature, history, and narrative. Journal of American History, 78:1347-1376.

de Certeau, M. 1984. The practice of everyday life. Steve Rendall Trans. Berkeley, CA: University of California Press.

DeVoto, B. (ed.). 1953. The journals of Lewis and Clark. Boston: Houghton Mifflin Company.

Dryzek, J. S. 1997. The politics of the earth. New York: Oxford University Press.

Entrikin, J. N. 1991. The betweenness of place: Toward a geography of modernity. Baltimore: Johns Hopkins University Press.

Gilbertz, S. J. 2002. A qualitative study of place: local understandings of the social and physical geographies of San Antonio Bay. Dissertation Texas A\&M University.

Gilbertz, S. J., C. C. Horton, and D. M. Hall. 2007. Yellowstone River Cultural Inventory2006. Sponsored by the Yellowstone River Conservation District Council. Funded by the 
US Army Corps of Engineers.

http://dnrc.mt.gov/cardd/yellowstonerivercouncil/2006culturalinventory.asp.

Greider, T. and L. Garkovich. 1994. Landscapes: the social construction of nature and the environment. Rural Sociology, 59: 1-24.

Guttenberg, A. Z. 1993. The language of planning: Essays on the origins and ends of American planning thought. Urbana, IL: University of Illinois Press.

Hall, S. 1997. The work of representation. In S. Hall, editor. Representation: Cultural representations and signifying practices: Culture, media and identity. Thousand Oaks, CA: Sage, 17-64.

Herndl, C.G. and S. C. Brown. 1996. Green culture: Environmental rhetoric in contemporary America. Madison, WI: University of Wisconsin Press.

Jackson, P. 1987. Social geography: Politics and place. Progress in Human Geography, 11: 286292.

Kemmis, D. 1990. Community and the politics of place. Norman, OK: University of Oklahoma Press.

Lakoff, G. and M. Johnson. 2003. Metaphors we live by. Chicago: University of Chicago Press.

Lefebvre, H. 1991. The production of space. Trans: Donald Nicholson-Smith. Oxford: Blackwell.

Leighton, K. 1998. Great American Rivers: Seasons of the Yellowstone an angler's year. Minocqua, WI: Willow Creek Press.

Maclean, N. 1976. A river runs through it. Chicago, IL: University of Chicago Press.

Meinig, D. W. (ed.) 1979. The interpretation of ordinary landscapes: Geographical essays. Oxford: Oxford University Press.

Myerson, G. and Y. Rydin.1994. 'Environment' and planning: A tale of the mundane and the sublime. Environment and Planning D: Society and Space, 12: 437-452.

Nolt, D. 2007. Free river: How the Yellowstone River kept its course. New West, April 7, http://newwest.net.

Norton, B. G. 2005. Sustainability: A philosophy of adaptive ecosystem management. Chicago: University of Chicago Press.

Norton, B. G. and B. Hannon. 1997. Environmental values: A place-based theory. Environmental Ethics, 19: 227-245. 
Patterson, M. E. and D. R. Williams. 2005. Maintaining research traditions on place: Diversity of thought and scientific progress. Journal of Environmental Psychology, 25: 361-380.

Peterson, T. R., K. Witte, E. Enkerlin-Hoeflich, L. Espericueta, N. Flora, J. Florey, T. Loughran, and R. Stuart. 1994. Using informant directed interviews to discover risk orientation: How formative evaluations based in interpretive analysis can improve persuasive safety campaigns. Journal of Applied Communication Research, 22: 199-215.

Peterson, T. R. 1997. Sharing the Earth: The rhetoric of sustainable development. Columbia, SC: University of South Carolina Press.

Rose, G. 1994. The cultural politics of place: local representation and oppositional discourse in two films. Transactions of the Institute of British Geographers: New Series, 19: 46-60.

Sack, R. 2001. Place, power and the good. In Adams, P. C., S. Hoelscher, and K. E. Till. (eds) Textures of place: Exploring humanist geographies. Minneapolis: University of Minnesota Press, 232-245.

Spirn, A. W. 1998. The language of landscape. New Haven, CT: Yale University Press.

Stegner, W. 1992. A Sense of place. New York: Random House.

Stokowski, P. 2002. Languages of place and discourses of power: Constructing new senses of place. Journal of Leisure Research, 34: 368-382.

Tuan, Y. 1991. Language and the making of place: A narrative-descriptive approach. Annals of the Association of American Geographers, 81: 684-696.

Wheelwright, J. 1978. Great river in crisis: There is too much demand for the Yellowstone's water. Life, 1(3): 94-104.

Williams, D. R., M. E. Patterson, J. W. Roggenbuck, and A. E. Watson. 1992. Beyond the commodity metaphor: Examining emotional and symbolic attachment to place. Leisure Sciences, 14: 29-46.

Wolf, S. A. and J. A. Klein. 2007. Enter the working forest: Discourse analysis in the Northern Forest. Geoforum, 38: 985-998.

Yung, L., W. A. Freimund, and J. M. Belsky. 2003. The politics of place: Understanding meaning, common ground, and political difference on the Rocky Mountain Front. Forest Science, 49: 855-866. 


\title{
Sharing stories of place to foster social learning
}

\author{
William Stewart, Troy Glover, and James Barkley
}

Place research underscores a need for social learning. Place research recognizes complexity in place meanings (Manzo, 2005), the potential for conflict amongst stakeholders (Measham \& Baker, 2005), and need to create new public values for places (Kruger \& Shannon, 2000; Schusler, Decker, \& Pfeffer, 2003). The implications of place research often point to dialogic planning processes that allow place meanings, values, and emotions to be shared amongst stakeholders.

Over the past few decades, trends in land-use planning have moved in the direction of processes that sustain dialogue among various kinds of stakeholders (Daniels \& Walker, 2001). However, not all land-use planning forums are conducive to social learning. Some are counterproductive to building constructive dialogue (Parson \& Clark, 1995; Sarewitz, 2004). Many are framed as public involvement or participatory planning events during which agencies garner viewpoints from stakeholders (Germain, Floyd, \& Stehman, 2001). Rather than embedding decisions in a learning process, many public involvement strategies are one-way in their communication flow and result in stakeholders reaffirming their understandings of the issues and reinforcing stereotypes of each other (Blahna \& Yonts-Shepard, 1989; Gramling \& Freudenburg, 1994; Keen, Brown, \& Dyball, 2005). Although several strategies for social learning have been explored, there are still needs to continue these efforts and directly link learning objectives to shared meanings and emotions of place (Friedman, 1984; Stokowski, 2008).

The practical relevancy of this chapter is directed at a preparatory phase prior to initiating a formal planning process. Social learning about place is appropriate in a pre-planning phase and has modest aims: (1) to begin public dialogue at a point that appreciates landscapes, and (2) to 
build a positive base to grow relationships among stakeholders. Planning often begins in negative ways by directing attention to problem identification, scoping, inviting reaction to a preferred alternative, or some other point of alarmed discovery (Germain et al., 2001). These are conflict-ridden points to begin a planning process, and encourage stakeholders to formulate their positions and create boundaries amongst each other.

Social learning should be considered in cases where multiple values and place meanings may appear incompatible, and where agency staff want to build relationships with (and among) stakeholders (Schusler et al., 2003). Social learning involves simple acts of publicly representing one's sense of place and listening to others (Parson \& Clark, 1995). Through these acts of representation, a dialogue is developed that creates new public values and ways to understand the issues at hand - this is the crux of social learning (Keen, Brown, \& Dyball, 2005). The social learning that comes from sharing stories about place is not about reaching consensus nor resolving differences; rather it is about understanding place meanings of oneself and others, and opening opportunities for new meanings to emerge. Creating dialogic relationships amongst stakeholders with potential for new public values has not been a traditional function of planning yet is vital for effective implementation (Blahna \& Yonts-Shepard, 1989).

Stories about place are narratives that connect people to their environments. The sense of time developed in narratives is critical to understand relationships between people and places (Cronon, 1992), and such relationships are best represented through stories of one's lived experience (Stewart, 2008). Several researchers have argued that story-telling is a natural way for people to organize their experiences, emotions, and values into meaningful wholes, and suggest that landscape planning processes could be facilitated through strategies that invite people to share stories about place (Kruger \& Shannon, 2000; Fine, 2002; Richardson, 1990). 
This chapter characterizes social learning as essential for place-based planning. The recognition of environments as places to which people form emotional attachments is at the center of place-based planning (Introduction to this volume; Williams, this volume). The first half of this chapter identifies some major challenges that must be addressed in place-based planning. The last half of this chapter addresses these challenges by exploring a strategy for social learning applied in three different contexts.

\section{Emotions about place}

A goal of sharing stories about place is to provide a positive starting point for planning. The sharing of stories of place allows emotions to come to become known. Emotions and the knowledge that goes with them, although sometimes discussed as an important part of land-use decisions (Kennedy \& Vining, 2007), are rarely given a forum for expression. Planning processes generally try to avoid inclusion of emotional representation, and in doing so, neglect knowledge that comes from their public expression. Emotions are often cast as irrational, unscientific, hard to understand, and ultimately irrelevant to land-use decision-making (Davidson-Hunt \& O'Flaherty, 2007). As a consequence, emotions emerging in public decisionmaking contexts are not formally anticipated, often perceived as negative (e.g., anger, frustration, sadness), viewed as counter-productive to dialogue, and being such, usually work to alienate stakeholders from each other. Social learning through the sharing of place meanings is a strategy designed to introduce emotions as important knowledge for planning. Sharing stories about place uniquely explains a person or community and their relationships to an environment (Patterson, Grenny, McMillan, \& Switzler, 2002, pp. 98-101). 
Sense of place is about people and relationships with their environments. Such relationships usually are connected with various emotions and feelings, often referred to as place attachment (Kyle, et al., 2004). There has been an impressive accumulation of research directed at place attachment, and invariably it has assessed the strength of the attachment rather than the emotion behind the attachment (Bricker \& Kerstetter, 2000; Stedman, 2003). Social learning about place recognizes the importance of emotions in our relationships with places, and allows a face-to-face representation of place attachment in ways that other methods are unable to facilitate. Without representation of emotions, a critical part of our relationships to place is missing.

Emotions are best understood when they are shown rather than told. A telling of emotions is a summary or some abstracted representation of emotions. Social scientists, and others in positions to represent a third party, often tell about emotions felt by participants in their studies (Denzin, 1985). People who tell of emotions are in roles of being "objective" or "neutral" to the emotions. Audiences of a telling receive the information but are not changed by the telling. A showing of emotions is a living of the emotions at the moment of representation. Audiences of a showing feel the impact of the emotions - people are changed by a showing of emotions (Denzin, 2001). Roles for social scientists traditionally are to represent, provide summary statistics, and otherwise objectively characterize people who have been studied. Such studies reflect a telling of emotions. Although there are some exceptions, most social scientists do not facilitate a showing of emotions as part of their research, nor are they comfortable in roles where they participate and become emotionally influenced by those whom they study. Sharing stories about place requires social scientists and planners to expand their traditional roles to facilitate stakeholders showing emotions about place (Barkley, this volume; Olstad, this volume). 
The flipside of showing emotions is to feel the impact of emotions when they are represented. Witnessing emotions usually results in immediate changes in one's experience, and aligns with Walkerden's (2005) discussion of "felt knowing." He argues that western traditions have privileged logical reasoning at the expense of other senses of feeling, intuition, and personal experience. Walkerden characterizes felt knowledge as originating from felt meaning and essential to work through complex situations requiring collaboration and innovation (pp. 175180; see also Gendlin, 1997; Schroeder, this volume). In his work on social learning, Walkerden (2005) indicates that felt meaning is about "making sense together - embracing learning within a social context, and specifically embracing dialogue" (p. 179). He claims that when we de-center ourselves from disciplinary and professional ways of knowing - effectively detaching ourselves from anything deemed logically fundamental - we open to new ways of referencing knowledge and exploring felt meanings with one another (Schroeder, this volume). For Walkerden, felt meaning within contexts of public dialogue needs to claim space within planning processes that historically have been debilitated by technical rationality. Place-based conservation frames feelings and emotions in terms of wisdom.

\section{Public Dialogue about Place}

A dialogue is a special form of communication. It is not just people talking to one another and informing each of their own perspective. It is a way of communicating between people as meaningfully as possible and results in the creation of something new together (Bohm, 1996, pp. 2-3). The back-and-forth of dialogue is where people articulate their thoughts and respond in attempts to clarify, challenge, empathize, or embrace the ideas growing among participants in the dialogue. There are often differences between intentions of representation and 
that which gets represented; there are also differences between the listeners who receive the information and the intentions of the speaker. In a dialogue, differences between that which was said, intended, and received becomes reconciled, and participants invariably see something new that connects the viewpoints of the dialogue. A dialogue is not simply representing one's view to make known information already known to the person. A dialogue is about two or more people making something new together - something they share in common.

Unlike traditional forums for public involvement that are framed in adversarial ways, a dialogue is about representation of one's viewpoint. Creating dialogue forums about place provides a promising starting point for planning. Fisher and Ury (1981, pp. 41-57) have argued that public dialogue should focus on interests of stakeholders in which they represent their motives and values, in contrast to promoting their political positions. In advocating the need for new strategies of public involvement, Ison (1995) claims that a dialogue is about thinking together. Unlike a debate, a dialogue is where participants represent their perspectives and jointly create new meanings (Bohm, 1996; see also Bitzer, 1968; Stokowski, 2002).

By viewing dialogue as a "free flow of meaning" among people, Patterson et al. (2002) developed strategies to create new public meanings (in their words, to expand the pool of shared meanings, pp. 21-25). They indicate that people enter a dialogue with their own set of thoughts that comprise personal meanings. During dialogue, thoughts are expressed, and meaning becomes shared by those in the dialogue. Meaning moves from being personal to being shared. As the pool of shared meaning grows, so too does a group's synergy and ability to make decisions for themselves. Patterson et al. (2002) recognize the difficulties of building group synergy (in their words, a group's IQ), and claim that a key element of doing so is "to develop the tools that make it safe for us to .... come to a shared pool of meaning" (p. 25). They 
understand that successful public dialogue requires conditions that allow participants to share stories in ways that freely express thoughts, meanings, and emotions.

To improve the creativity of organizations, Gratton and Ghoshal (2002) argue that the quality of dialogue is at the heart of any strategy for improving the dynamics of working together. They recognize the "denial" of emotions in workplace discourse and the privileged position of technical rationality in traditional planning (p. 214). They found organizations that enable explicit representation of emotions within decision-making contexts are the most successful in their functioning. Gratton and Ghoshal (2002) indicate that people are more creative when emotions are freely expressed, and form stronger relationships through dialogue that brings-out emotions. Their recommendations are to build conditions that encourage emotional expression within working relationships to enhance the capacity to make good decisions.

\section{Social Learning about Place}

Social learning engages people to share their perspectives, to develop a common framework, and to value their collective experience as a basis for action (Keen, Brown, \& Dyball, 2005; Korten, 1981). Daniels and Walker (2001, pp. 4-8) assert that land managers are in positions to lead processes for social learning. They argue persuasively that social learning is essential to the formation of new public values to address the increasing complexity of environmental decision-making (Reich, 1985; Yankelovich, 1991). Social learning about place is a first step in any planning process for people to see environments as places (Measham \& Baker, 2005; Williams \& Stewart, 1998). 
It seems like a platitude to assert that environments are places. We take for granted the places of our lives, and most people understand that environments are connected with senses of place. However there are some powerful forces that run counter to such a claim and often prevent planning processes from treating environments as places. Firstly, the long-standing privilege of science in environmental decision-making is already well-known as a force that searches for generalizable knowledge and universal truths (Allen \& Gould, 1986; Fisher, 2000; Irwin, 1995; Yaffee, 1994). If one views an environment as an exemplar of some scientific principle, its uniqueness is seen in comparison with other environments that embody a similar set of scientific facts. Sarewitz (2004) argues that scientific knowledge has traditionally held a central role in environmental controversies because of a "shared view of science as a disinterested force that could guide political decision making by providing appropriate facts - so long as it was kept separate from politics" (p. 388). He observes that scientific facts are not detached from human values, even though people on all sides of controversies validate their value preferences based upon an alleged body of facts (p. 397). Sarewitz (2004) suggests that environmental controversies are overly "scientized" because environmental values and place meanings are concealed by most planning processes. In an ironic twist, he claims that scientific narratives have become the primary means in which values surface within environmental controversies.

Secondly, land management agencies each have a culture and history of policy-making that influence decisions in systematic ways. From mission statements to agency policy to onthe-ground implementation, agency forces understandably push for consistency and alignment with precedence rather than uniqueness of locale or exception to a rule (Twight, 1983; Vining \& Ebreo, 1991). The significance of agency cultural bias has spawned a literature stream exploring 
the impacts of professional bias on decision-making (Clarke \& McCool, 1996; Foresta, 1984; Jasanoff, 1990; Priscoli \& Wolf, 2009). Agency culture and professional bias may work against recognizing environments as places, and instead frame issues as challenges to agency policy.

Thirdly, agencies and their environments have a history of decision-making involving various stakeholders. To gain favorable outcomes of decisions, stakeholders learn to work the system in their best interests (Yaffee, 1994). In varying degrees, interest groups and stakeholders use scientific expertise and agency policy precedence to argue their positions and frame their cases (Sarewitz, 2004). It is not unusual for stakeholders to adopt the language of scientists and agency staff, and in doing so, treat environments as battlegrounds for national ideological conflicts while neglecting the representation of their own place meanings (Barkley, this volume; Gottleib, 1993; Nie, 2003).

In short, there are forces that influence the major players in environmental decisionmaking - experts, agency staff, and stakeholders - that do not recognize environments as places. The result is that a significant portion of stakeholders have learned to work together in ways that avoid seeing environments as places. No doubt it is easy to claim environments are places, but in the practice of decision-making, there is unwitting resistance to this claim.

When environments are viewed as places, people and communities become part of the place. Sharing stories of place necessarily involves stories of people and communities. Although a story of place is ostensibly directed at a specific environment, it is as much about the person whose story is being shared. Western society generally views aboriginal people as being intimately tied to their land and as holding deep-seated place meanings. Measham and Baker (2005) counter this point by arguing that all cultures believe "wisdom sits in places" whether they know it or not (a reference to Basso's work with Apache Indians, 1996). They urge 
planners to prioritize the representation of place meanings as central to environmental decisionmaking (Measham \& Baker, 2005, pp. 96-101). At the crux of place-based conservation is a dialogue process that engages stakeholders to learn about each other's place meanings (Keen, Brown, \& Dyball, 2005, pp. 6-18).

The ideas in the above discussion translate to challenges for the practice of land-use planning. They indicate the need for strategies to foster social learning, which in itself is not a new observation to make. However the above ideas provide sensitivity to some of the conditions for social learning, and further suggest that stakeholder forums need to address the following three challenges: (1) To be structured in ways that allow participants to feel safe and comfortable sharing stories about place; (2) To value emotional expression; and (3) To recognize that sharing place meanings creates new public values for a landscape. Fortunately strategies for environmental decision-making have expanded in the past few decades, and there are planning frameworks that hold promise to address the above challenges (Davidson-Hunt \& O'Flaherty, 2007; Ison, 2005; Schusler, Decker, \& Pfeffer, 2003; Walkerden, 2005).

The second part of this chapter draws on examples from three sites in which stakeholders shared stories of place. The studies explored photo elicitation as a technique to engage stakeholders in a two phase process starting with their self-reflection and personal sense of place, and a second phase as a stakeholder forum for sharing stories of place (referred to as a learning circle). This strategy has been developed and applied in the following three land-use planning contexts of Midewin National Tallgrass Prairie (a USDA administered site near Chicago, Illinois), Grand Canyon National Park (a world heritage site administered by the NPS in northwestern Arizona), and Urbana Park District (a municipal park district in a mid-size urban area of central Illinois). The purpose of introducing this strategy is to illustrate the above three 
challenges and provide examples of a way in which they could be addressed. An overview of the methods is presented here (for further background see Glover, Stewart, \& Gladdys, 2008; Stewart, Larkin \& Leibert, 2004; Stewart, Barkley, Kerins, Gladdys, \& Glover, 2007).

\section{A Strategy to Share Stories of Place}

\section{Eliciting Stories about Place}

All three sites were either in their initial stage of planning or had not yet formally embarked on a planning process. Stakeholders were recruited as study participants, and identified through their participation in previous land-use planning processes or were accessed onsite at agency-based public events. Agency personnel were also recruited to be study participants. Resulting groups of study participants were a mixture of citizen-stakeholders, representatives from various interest groups, and agency personnel. The number of participants varied from 15 to 25 across the three locations. Disposable cameras were distributed to participants. They were asked to take pictures of special places around the study sites important to their life.

The use of participants' photographs was instrumental in facilitating conversations that elicited place meanings and landscape values through the telling of lived experiences. The first phase of the process coupled participant photography with conversations focused on photographs, referred to as an autodriven photo elicitation conversation (APEC). The APEC is particularly suited for research that requires a telling of deep-seated personal experience due to its capacity to equalize power between researcher and participant. The APEC is centered on the life experiences of participants; they choose places to photograph, and they co-construct meanings for these places during conversations with researchers. During the conversation, the 
researcher is in a listening mode albeit prompting participants to discuss the significance of places they photographed. The capacity of APEC to center itself on the life experiences of participants is a virtue of the method and contrasts with traditional social science techniques.

The photographs provided conversational structure during the APEC. As such, meaning was situated in the text of the conversation and not in the photograph itself. Photographs served as a site for the embodiment of memory and were the means by which their experiences in places were narrated. Conversation about the photograph served as an interaction through which meaning of the lived experience was constructed. During the telling of their lived experiences, stakeholders came to some understanding of their place meanings. From the APEC and the follow-up with researchers regarding review of transcripts and modifications to their narratives about places, stakeholders deliberated with their own set of place meanings. They were invited to the next phase that functioned like a group APEC, referred to as a "learning circle."

\section{Learning Circles}

In preparation for the second phase, stakeholders were asked to identify two or three photographs from which they could share their place meanings with others. Their photographs were projected onto a screen during their presentation. Discussions were tape-recorded and transcribed to allow for a review of the dialogue. As a final task, stakeholders were asked to reflect on the discussion. They wrote their thoughts and reactions on a notepad at the learning circles. The discussion of these examples explores a strategy to foster social learning about place.

Feeling safe sharing stories about place. The learning circles, coupled with use of stakeholders' photographs, focused attention on landscapes not people. Stakeholders viewed 
each other's pictures and considered place meanings, rather than thought critically about the stakeholder doing the talking. When individuals talked about their places, attention was directed at the place rather than at the person doing the talking. Stated differently, we are each experts on our lived experiences in the places of our lives. To enable people to share these lived experiences with others, the structure of the dialogue forum needs to shift the "spotlight" away from the person and towards the environment. With such a shift, people are likely to feel safe and comfortable sharing their stories of place.

As an indicator of this focus of attention on places, stakeholders often introduced themselves in reference to their place meanings. For example, several stakeholders began their discussion by explaining reasons for living where they do, or visiting certain places; these reasons were directly related to their place meanings. Others introduced themselves with details on their personal environmental history that gave comparison points to understand their place meanings. These meanings often connected with deeply held values about their family history including appreciation for their parents and grandparents, their sense of national identity and cultural pride, or their personal or family-based land ethic.

With a focus on place, attention was deflected away from the speaker and quite literally toward an image of the place as projected onto a screen. Stakeholders' stories supported concepts of "place identity" and "topophilia," which generally assert that people construct deep personal relationships with environments (Williams, this volume). The stories of stakeholders described their personal relationships for the places they had come to know. The discussions were seemingly not about themselves or their ideological beliefs but about the places of their lives. Because of the perception that this discussion was about places and not about themselves as individuals, the conversations about place meanings unfolded with ease. 
As part of deflecting attention away from individuals to places, the truth-claims of stories were not given to debate or questioning. Because each stakeholder had undergone the same process of taking photographs and having conversations about the importance of their places, the stories and visual images were received as genuine, and the sharing of stories had become a familiar task that was easy to produce. For example in a final reflection, one stakeholder wrote "I really don't like public speaking, but talking about something I know about and love helps me to become a better speaker." Another wrote "Sharing memories of places is as good as any ice breaker." From both the transcripts of the learning circles and the final reflections written on the notepads, the findings suggest stakeholders felt safe and comfortable sharing their stories of place. There were not any questions about the accuracy of the stories, the credibility of the speakers, or the genuineness of emotions.

Building contexts to represent emotional attachment to place. Describing special places was often told as a personal history, and it fostered a re-living of the experience in a place. With all eyes focused on a visual image of the place, a showing of emotions came naturally to most stakeholders. Sharing personal histories were important contexts for emotional attachments to be known and understood, and as a consequence, were deeply felt. The use of photographs was essential to reflect on place meanings, and to build a social context to show emotional attachments to place.

The use of photographs was instrumental in creating a shared memory that fostered empathy for speakers. In sharing their stories, stakeholders were re-living their experiences in the place (Denzin, 1985). The visual image became emotionally laden due to the emotions that surfaced in the story. The visual image became a shared symbol that brought the group into the same emotional sphere as the speaker (Harper, 2000), and led to recognition of joint caring- 
even though there were implicit differences in political agendas across participants in the circle. In each of the learning circles there were moments of silence as speakers and participants held back tears or choked-up, there were flashes of spontaneous smiles, and there were examples of collective curiosity as place histories were constructed. The emotions that surfaced, particularly those that led to eyes welling-up with tears, were generally associated with family connections to place and the potential for their disruption. When memories of one's ancestors or expectations for one's children were shared, the emotional attachments were palpable.

Stakeholders did not plan to show emotions or become involved with each other as part of their anticipation for the learning circles. The emotions were authentic and the collective empathy that emerged was sincere. The shared emotions created an intimacy among stakeholders that could not have been replicated through traditional planning processes, and established a basis for trust. As written on the notepad by one stakeholder, "[I] learned we all have the same values...[even though] a lot of the pictures were different but it seemed to bring us together as a group."

Creating new public values for place. Several of the stories of place explained current conditions by characterizing a place history. The intentions of such stories were often to enhance the ability of others to interpret the landscape. Several stakeholders' addressed questions about "Why has a place become the way it is?" In essence, they were telling others about their way to read the landscape. By telling place histories to others, stakeholders shared rationales for ways in which a place came into being. Conversations often led to additional layers of meaning to explain current conditions, and a more complex place history was created compared to the initial story told. The spirit of such discussions was framed as teaching, with intentions to enlighten others about reading, and possibly appreciating, the landscape. Additional layers of meanings of 
place history were invariably received as adding value, and there were no examples in which the dialogue became competitive or adversarial about expanding a single truth into a more complicated and multi-layered place history.

Stakeholders' comments on their notepads indicated that new meanings were created for several places. One stakeholder wrote "It was neat to hear about other people's perceptions and histories. This has helped me to see some of the places differently." Another wrote "The next time I go to [a specific wooded area], I will think of Frances [pseudonym] and her sisters collecting walnuts with her grandmother. I didn't even know there were walnut trees growing there." The personalized contexts of the stories were easily understood by participants to the point where several participants changed their place meanings, or will "see some of the places differently."

With the inclusion of agency personnel as stakeholders in the learning circles, it was clear that agency staff members hold a diverse set of stories and do not embrace a singular sense of place. Public perceptions during traditional planning processes may simplify agencies and their staff into a uniform mould (i.e., the Park Service or the Forest Service) and fail to understand the complexity of agency decision-making and staff orientation to the landscape (Freudenburg \& Gramling, 1994). For example, stakeholders from the Grand Canyon staff spoke about the toils of constructing trails, appreciation for sublime nature, teaching student groups about natural history, and patriotic meanings of a landscape. Viewing agency staff as fellow stakeholders and understanding their collective diversity is a first step toward redefining a territory. Likewise, learning the place meanings of other stakeholders led to seeing them in a different light (Schusler, Decker, \& Pfeffer, 2003). An important part of creating new public values for a place is to see decision-makers and other stakeholders from a new perspective. 
During the learning circles, differences between place meanings were generally nonthreatening and easy to understand. Dialogue about commonalities and differences among stakeholders in the learning circles appeared smooth and progressed without the anxiety and tension reflective of traditional forums of public involvement - such as public hearings or planning workshops. The written comments on the notepad from one stakeholder stated "I learned that I am more of preservationist than I ever realized I am. I also learned that thinking about the future as well as the past is very important to me." As an example of understanding differences, and its potential for social learning, some staff of Midewin learned about differences in various goals for ecological restoration. Where agency directives were generally focused on restoring an historic prairie landscape devoid of any signs of human development, stakeholders appreciated place meanings of a contemporary prairie that included vestiges of the various eras of humanity that had passed through the Midewin landscape. By opening-up the vision for ecological restoration of Midewin, participants shared and took ownership in the nuance to a new public value for the prairie (Stewart, Larkin \& Leibert, 2004; Stewart et al., 2007). By comparing their place meanings, the dialogue allowed stakeholders to discover both themselves and others, with the discoveries leading to the creation of shared values for places.

\section{Conclusions}

The effectiveness of the learning circles is their capacity to frame environments as places. All stakeholders in the learning circles became more aware of their own place meanings during the research process. A first step in place-based planning is to recognize that people need assistance in knowing their own place meanings. Western culture does not encourage individuals to reflect on their own sense of place, nor does it support collective deliberation 
about a community's sense of place. The photo elicitation technique legitimized environments as places. In the learning circles, stakeholders became comfortable sharing their place meanings and learning about others. The start of place-based planning is to have built groundwork that centers dialogue on place meanings.

The learning circles shifted dialogue from stakeholder-planner to stakeholder-stakeholder relationships, where agency staff members were part of the mix of stakeholders. The shift has many consequences that hold promise for innovative discussion to support new pubic values for place, including creating a safe and comfortable space for sharing stories and emotional attachments of place. The dialogue of the learning circles was about sharing with fellow stakeholders not about speaking to authority. Because the format of the learning circles felt safe, emotions emerged and participants were open to learning about place meanings.

Public speaking was noticeably easy for participants, in part, because they were talking about their places, not about themselves. Because of this, differences were viewed not between people but between various ways to care about a place. Tension that could align with interpersonal differences was neutralized. Values for landscapes were expressed as part of one's lived experience of place, including the teaching of landscape history, and were not abstracted in some ideological or adversarial relationship. The learning circles underscored the extent to which all stakeholders cared deeply about their places. The widespread feeling of caring for environments left a collective sense of appreciation for multiple ways to value them, and was reflected in the openness of the conversations to find compatibility across place histories.

Learning circles function to create a positive dialogue among stakeholders prior to beginning the formal steps of a planning process. Germain et al. (2001) indicate that stakeholders should be engaged early in any planning process in order to have a stake in the 
outcome rather than being reactive to some proposed action. They recommend the development of a "pre-NEPA" public involvement strategy that allows stakeholders to be proactive in planning. Although Germain et al. (2001) are focused on procedural issues, they suggest that a structured stakeholder dialogue will alleviate conflict and lead to improved outcomes. This chapter asserts place meanings as being the focus for a public involvement strategy prior to the start of formal planning, and characterizes learning circles as providing a foundation for stakeholders to build upon in subsequent planning processes.

Learning circles not only facilitated stakeholders to represent themselves in nonadversarial contexts, they also functioned as a forum for stakeholders to learn about each other. In their argument for a civic science, Kruger and Shannon (2000) championed the need to explore strategies that allowed people to express their lived experiences to others in ways that led to social learning. An important consequence of such learning was the inception of new public values for the places being discussed. This does not say that the "old" landscape values or past place meanings were forgotten or replaced. The claim is that learning circles humanized stakeholders to each other and opened opportunities to learn about their various relationships with the land. As a result, the learning circles fostered a climate of compatibility for additional layers of place meanings, and complicated traditional landscape values in ways that departed from entrenched ideology.

Photo elicitation and learning circles are not meant for every land-use planning process. The nature of the strategy requires intimacy and commitment for individuals to endure the process. The study contexts were limited to 25 stakeholders, which for many land-use decision processes would exclude some interested parties. There are several points of contact necessary to facilitate the distribution of cameras, the interview, the transcripts and their revisions, and 
coordination of a learning circle. Some stakeholders may view it as burdensome. If the number of participants is greater than 25 , there could be a loss of intimacy in the learning circles. This strategy for social learning is best framed as applicable to a defined set of stakeholders rather than one for general public involvement.

There are many other strategies for dialogue in which stakeholders would feel safe and comfortable sharing their stories about place. Photo elicitation coupled with learning circles is characterized as one such strategy. The primary factor to evaluate any strategy is that they need to foster discussion about place meanings in order for place-based planning to take root. Coordinating a discussion about place does not come naturally for many agency staff, experts, and stakeholders. Simpler to say than do, any strategy for place-based planning needs to structure stakeholder dialogue to focus on environments as places. 


\section{References}

Allen, G., \& Gould, E. (1986). Complexity, wickedness, and public forests. Journal of Forestry, $84,4,20-24$.

Basso, K. (1996). Wisdom sits in places: Landscape and language among the western apache. Tucson: University of Arizona Press.

Bitzer, L. (1968). The rhetorical situation. Philosophy \& Rhetoric, 1, 1-14.

Blahna, D., \& Yonts-Shepard, S. (1989). Public involvement in resource planning: Toward bridging the gap between policy and implementation. Society and Natural Resources, 2, 209-227.

Bohm, D. (1996). On Dialogue. NY: Routledge.

Bricker, K. \& Kerstetter, D. (2000). Level of specialization and place attachment: An exploratory study of whitewater recreationists. Leisure Sciences, 22, 233-257.

Clarke, J. \& McCool, D. (1996). Staking Out the Terrain: Power and Performance Among Natural Resource Agencies, Second Edition. Albany, NY: SUNY Press.

Cronon, W. (1992). A place for stories: Nature, history, and narrative. Journal of American History, 1347-1376.

Daniels, S. \& Walker, G. (1996). Collaborative learning: Improving public deliberation in ecosystem-based management. Environmental Impact Assessment Review, 16, 71-102.

Daniels, S. \& Walker, G. (2001). Working Through Environmental Conflict: The collaborative learning approach. Westport, CT: Praeger.

Davidson-Hunt, I. \& O'Flaherty, R. (2007). Researchers, indigenous peoples, and place-based learning communities. Society and Natural Resources, 20, 291-305.

Denzin, N. (1985). Emotion as lived experience. Symbolic Interaction, 8, 2, 223-240.

Denzin, N. (2001). Interpretive Interactionism, Second Edition. Thousand Oaks, CA: Sage.

Fine, G. A. (2002). The storied group: Social movements as 'bundles of narratives.' In J. E. Davis (ed.), Stories of change: Narratives and social movements (pp. 229-246). Albany, NY: State University of New York Press.

Fischer, F. (2000). Citizens, Experts, and the Environment: The politics of local knowledge. Durham, NC: Duke University Press. 
Fisher, R. \& Ury, W. (1981). Getting to YES: Negotiating agreement without giving in. Boston: Houghton Mifflin.

Foresta, R. (1984). America's National Parks and Their Keepers. Washington, D.C.: Resources for the Future.

Freudenburg, W. \& Gramling, R. (1994). Oil in Troubled Waters. Albany, NY: State University of New York Press.

Friedman, J. (1984). Planning as social learning. In D. Korten and R. Klauss (eds.), People Centered Development (pp. 210-222). West Hartford, CT: Kumarian Press.

Gendlin, E. (1997). Experiencing and the Creation of Meaning: A philosophical and psychological approach to the subjective. Evanston, IL: Northwestern University Press.

Germain, R. , Floyd, D., \& Stehman, S. (2001). Public perceptions of the USDA Forest Service public participation process. Forest Policy and Economics, 3, 113-124.

Glover, T., Stewart, W., \& Gladdys, K. (2008). Social ethics of landscape change: Toward a community-based model of land-use planning. Qualitative Inquiry, 14 (3), 384-401.

Gottlieb, R. (1993). Forcing the Spring: The transformation of the American environmental movement. Washington, D.C.: Island Press.

Gramling, R. \& Freudenburg, W. (1994). Oil in Troubled Waters: Perception, politics, and the battle over offshore drilling. Albany, NY: State University of New York Press.

Gratton, L. \& Ghoshal, S. (2002). Improving the quality of conversations. Organizational Dynamics, 31, 209-223.

Harper, D. (2000). Reimagining visual methods: Galileo to Neuromancer. In N. Denzin \& Y. Lincoln (Eds.) Handbook of Qualitative Research, Second Edition (pp. 717-732). Thousand Oaks, CA: Sage.

Irwin, A. (1995). Citizen Science: A study of people, expertise, and sustainable development. New York: Routledge.

Ison, R. (2005). Traditions of understanding: Language, dialogue and experience. In M. Keen, V. Brown, and R. Dyball (eds.), Social Learning in Environmental Management (pp. 2240). London: Earthscan.

Jasanoff, S. (1990). The Fifth Branch: Science Advisors as Policymakers. Cambridge, MA: Harvard University Press. 
Keen, M., Brown, V., \& Dyball, R. (2005). Social learning: A new approach to environmental management. In M. Keen, V. Brown, and R. Dyball (eds.), Social Learning in Environmental Management (pp. 3-21). London: Earthscan.

Kennedy, J. \& Vining, J. (2007). Natural resource conflicts: Why do emotions matter? Journal of Sustainable Forestry, 24, 23-50.

Korten, D. (1981). The management of social transformation. Public Administration Review, 609-618.

Kruger, L. E., \& Shannon, M. A. (2000). Getting to know ourselves and our places through participation in civic science assessment. Society \& Natural Resources, 13, 461-478.

Manzo, L. (2005). For better or worse: Exploring multiple dimensions of place meaning. Journal of Environmental Psychology, 25(1), 67-86.

Measham, T. \& Baker, R. (2005). Combining people, place, and learning. In M. Keen, V. Brown, and R. Dyball (eds.), Social Learning in Environmental Management (pp. 91103). London: Earthscan.

Nie, M. (2003). Drivers of natural resource-based political conflict. Policy Sciences, 36, 3/4, 307-341.

Parson, E. \& Clark, W. (1995). Sustainable development as social learning: Theoretical perspectives and practical challenges for the design of a research program. In L. Gunderson, C. Holling, \& S. Light (Eds.) Barriers and Bridges to the Renewal of Ecosystems and Institutions (pp. 428-460). New York: Columbia University Press.

Patterson, K., Grenny, J., McMillan, R., \& Switzler, A. (2002). Crucial Conversations: Tools for talking when stakes are high. NY: McGraw-Hill.

Priscoli, J. \& Wolf, D. (2009). Managing and Transforming Water Conflicts. NY: Cambridge University Press.

Reich, R. (1985). Public administration and public deliberation: An interpretive essay. Yale Law Journal, 94, 1617-1641.

Richardson, L. (1990). Narrative and sociology. Journal of Contemporary Ethnography, 19, 116135.

Sarewitz, D. (2004). How science makes environmental controversies worse. Environmental Science and Policy, 7, 385-403.

Schusler, T., Decker, D., \& Pfeffer, M. (2003). Social learning for collaborative natural resource management. Society and Natural Resources, 15, 309-326. 
Stedman, R. (2003). Is it really just a social construction? The contribution of the physical environment to sense of place. Society and Natural Resources, 16, 671-685.

Stewart, W., Barkley, J., Kerins, A., Gladdys, \& Glover, T. (2007). Park development on the urban-agricultural fringe. Journal of Recreation and Park Administration, 25, 117-138.

Stewart, W., Liebert, D., \& Larkin, K. (2003). Community identities as visions for landscape change. Landscape and Urban Planning, 69, 315-334.

Stewart, W. (2008). Place meanings in stories of lived experience. In L. Kruger, T. Hall, and M. Stiefel (eds.) Understanding Concepts of Place in Recreation Research and Management (pp. 83-108). Gen. Tech. Rep. PNW-GTR-744. Portland, OR: USDA Forest Service.

Stokowski, P. (2002). Languages of place and discourses of power: Constructing new senses of place. Journal of Leisure Research, 34(4), 368-382.

Stokowski, P. (2008). Creating social senses of place: New directions for sense of place research in natural resource management. In L. Kruger, T. Hall, and M. Stiefel (eds.) Understanding Concepts of Place in Recreation Research and Management (pp. 31-60). Gen. Tech. Rep. PNW-GTR-744. Portland, OR: USDA Forest Service.

Twight, B. (1983). Organizational values and political power: The Forest Service versus the Olympic National Park. State College, PA: Pennsylvania State University Press.

Vining, J., \& Ebreo, A. (1991). Are you thinking what I think you are? A study of actual and estimated goal priorities and decisions of resource managers, environmentalists, and the public. Society and Natural Resources, 4, 177-196.

Walkerden, G. (2005). Felt knowing: A foundation for local government practice. In M. Keen, V. Brown, and R. Dyball (eds.), Social Learning in Environmental Management (pp. 170-187). London: Earthscan.

Williams, D., \& Stewart, S. (1998). Sense of place: An elusive concept that is finding a home in ecosystem management. Journal of Forestry, 18-23.

Yaffee, S. (1994). The Wisdom of the Spotted Owl: Policy lessons for a new century. Covelo, CA: Island Press.

Yankelovich, D. 1991. Coming to Public Judgment: Making democracy work in a complex world. Syracuse, NY: Syracuse University Press. 


\section{Rural property, collective action, and place-based conservation \\ Paul Van Auken and Shaun Golding}

Truly democratic decision-making invites the collision of multiple interests. When communities make decisions about land use, divergent relationships to property give way to competing rhetoric, culminating in a discordant clamor of individual interests. In rural amenity areas, where connections to place are simultaneously influenced by prominent desires for both economic growth and preservation of land, planning incites particularly fervent debate. Individuals organize around property interests and mobilize civil society to maximize their influence in the public dialogue.

In this chapter we examine how private place orientations become public as they are absorbed into planning processes and civil society. We base it upon the American component of comparative research conducted from summer 2005 to summer 2007, in two rural regions facing similar challenges. As part of a collaborative study of amenity-driven community change, ninety stakeholders were interviewed in Norway and the U.S. Participants were first asked to photograph scenes of personal importance from their community. These photos were then used to initiate conversations, a format that helped to facilitate particularly deep interviews - as participants were encouraged to preemptively reflect upon their surroundings' meaningful characteristics when selecting scenes to photograph - and effectively capture place attachment. To add important context, additional interviews were completed with key informants, participant observation was employed at land-use meetings and community activities, and events and discourse were followed via local newspapers. We then performed iterative qualitative analysis, applying extended case method, which prescribes a detailed comparison of in situ observations to 
an established theoretical framework (Burawoy, 1991). The goal is to understand how a specific context may instruct a refinement of existing theory.

Contemporary land use theory has tended to focus on urban environments (cf. Logan \& Molotch, 1987; McCann, 2002; Perkins, Thorns, \& Newton, 2008), but our research suggests that rural settings warrant specific attention, particularly where planning initiatives are being met with unexpected dissent. We propose that a political economy of rural land engenders collective action around property. Lacking a contemporary theory of rural land politics, we contrast our observations with Davis's (1991) theory of collective action around urban property. Like Davis, we find that local stakeholders adopting a particular political position about land use may, in fact, maintain multiple personal interests. However, our rural informants evinced a pervasive group of interests related to common interpretations of place, and these property interests proved to be a crucial factor in dividing local stakeholders in the politics of land use. Thus, we argue that the process of place-making is profoundly impacted by many distinct but overlapping property orientations that are unique to certain rural scenarios.

This research may help to direct needed innovations in rural planning and decisionmaking. Though amenity communities and the place concept have begun to appear on the radar of rural planning practitioners (Spain, 1993; Manzo \& Perkins, 2006), rural land use planning continues to spur conflict, even among those who seem to share place meanings (Golding, 2006; Van Auken, 2007). We concur with Jensen and Field (2005), who argue that rural planning "necessarily must include the individual, and often divergent, interests of the landowners and residents" (p. 259). In fact, our research suggests that prior to proceeding with local land use planning, how and why groups organize around property must be understood. We find that although collective action may evoke opposition to planning processes based on defense or 
pursuit of particular property interests, it also engenders the democratic ideals that planning increasingly tries to emulate.

\section{Contested ground: Urban theory tested in a rural setting}

Since rural areas have not been the focus of contemporary land development theorists, we turned to urban sociology to better understand the political economic process through which development proceeds. In Contested Ground, John E. Davis (1991) advances a framework for the analysis of collective action in urban neighborhoods that provides a useful starting point. Davis argues that while important factors such as class, race, gender, and religion often produce conflict, locality-based cleavages generally develop along the lines of domestic property interests (those related to housing). People engage in collective action - latent interests become manifest - in response to threats to their domestic property interests or to pursue opportunities to enhance them.

There are two primary property interests, accommodation and accumulation, which are based on the use or exchange value of the property. Conflict develops between people and groups who attempt to make money from residential real estate and those who see intrinsic value in the use of a home. Davis further divides the two primary interests into six "relational advantages" of domestic property. Accommodative interests are characterized by security (stability of tenure and physical safety), amenity (quantity and quality of one's living space), and autonomy. Accumulative interests, on the other hand, are distinguished by equity (unencumbered value in land and buildings), liquidity (income potential), and, legacy (inheritability). These interests are material, in that they originate in relations surrounding a physical unit - land and property used for shelter. Further, they "are objective in the sense that 
one's position in relation to domestic property carries a probability of particular benefits, a susceptibility to particular costs, and a propensity to act in certain ways that inhere in the position itself" (ibid., p. 56, emphasis in original). A key point is that people have certain inherent interests, whether or not they consciously realize it or act upon them. These interests "are a latent relational bond, existing among similarly situated individuals, which may become the basis for solidarity and collective action among persons who are otherwise isolated and very different" (ibid., p. 57).

Davis argues that in general, cleavages develop between people and groups with fundamentally divergent domestic property interests. Those with community interests are most concerned with the social amenity of neighborhoods, the "communal living space" characterized by trust, support, and friendship. Capitalists, on the other hand, may utilize the rhetoric of community, but do so to enhance commodity, engaging in "colonization of urban land as a means of accumulation" (Cox, 1981, as cited in Davis, 1991, p. 297). But Davis notes that while these are useful ideal types, the reality is often less clear-cut. For example, threats to home equity can turn community-minded homeowners into (perhaps reluctant) defenders of the status quo. Alternatively, the homeplace may be the site of resistance to capitalist relations, because accommodative and accumulative interests are so distinct. Finally, and most importantly, Davis notes that this complex property interest mosaic can compel individuals to act collaboratively when their interests align.

\section{Application of framework to our U.S. case}

Bayfield County, Wisconsin, lies on the northern periphery of the American Midwest, bordering Lake Superior. It encompasses several hundred thousand acres of public forest as well 
as the Apostle Islands National Lakeshore. Bayfield County has transitioned away from dependence on extractive industries, and amenities now sustain a highly seasonal service-based economy. The county attracts roughly $\$ 130$ million in annual tourism revenue, much of it in historic Bayfield (pop. 570), due to its bucolic charm and proximity to the Apostle Islands. New housing is increasingly built on hillsides with lake views and adjacent to public lands, which is consistent with national trends (Davenport \& Anderson, 2005). Such development is slowly extending into rural townships and working class communities like Washburn, and it has led to concerns about erosion and water quality, forest fragmentation, and habitat loss. These issues fall under the official jurisdiction of the county's twenty-nine small municipal and tribal governments.

In recent years, land use conflict in Bayfield County has been the most visible in Washburn, where a new group known as Washburn Alive supported pro-“smart growth” candidates in the local election of 2004. Their efforts helped to elect a relative newcomer and strong champion of comprehensive planning as mayor, along with two new city councilors. Together they formed a new regime in local politics driven by concern about development and sustainability. With their leadership, Washburn became the first eco-municipality in the U.S, meaning that the local government pledged to make the environment a key consideration in all decisions. This distinction and the results of the 2004 election were noteworthy for Washburn, a former DuPont company town.

Support for Washburn Alive flourished in response to the city's proposed sale of lakefront property to a private developer who seemed out of touch with community interests. The developer proposed a 60 -unit condominium facility near a popular walking trail. He argued that its elderly occupants would not “cost the community anything, because they don't need 
anything. Their kids are all grown up; they don't need the schools" (O'Brien, 2004). These remarks were an affront to some members of the community, especially in light of its declining school enrollment and recent investments in local infrastructure. Further, ${ }^{\mathrm{re}}$ sidents of new condominiums in a nearby township had previously objected to contributing to Washburn's infrastructure upgrades, setting a worrisome precedent for long-time residents. Washburn Alive circulated anti-development petitions, and others pushed for the property to be designated as a natural area.

Still, others welcomed the proposed development. It complied with an existing land-use plan and was supported by the previous administration and other stakeholders. A local realtor argued that Washburn's waterfront is its "biggest jewel" and "one of the only things we have to bring income into" the community (ibid.). In a spring 2004 ballot referendum the proposal was defeated by a count of 638 to 163 votes. But in the pendulum of local opinion, this victory proved to be short-lived.

The momentum toward sustainability in Washburn was thwarted in part by changes in state and local politics. As in many rural areas of the state, Wisconsin's Comprehensive Planning Act of 1999 divided the community. The "smart growth law" required all municipalities to draft a detailed and standardized comprehensive plan by 2010 , or lose their planning autonomy and funding. Some credit the law with helping to curb sprawl and protect natural resources. Others, however, assert that the state uses it to appropriate power over local land-use decisions (Jacobsen, 2004). We observed that mandated planning draws starker contrasts between property interests without necessarily offering a venue for resolving the clashes that result.

Following the momentous election of 2004, local stakeholders began working on Washburn's smart growth plan. It was approved in the spring of 2007, narrowly passing after 
significant contestation. Some local stakeholders perceived that the plan's emphasis on sustainability came at the expense of needed economic development. One of them, Washburn's former city administrator, subsequently won a bid for city council, spurring a return to a prodevelopment governing body. Among his first actions upon joining the council was to move that the new plan be rescinded (Hollish, 2007).

Davis's framework for collective action can be fruitfully extended to the Bayfield County case. The primary actors are represented, including tenants and developers, stakeholders in social property, and both household homeowners (interested in equity, but primarily in accommodation) and acquisitive homeowners (primarily interested in liquidity). The community and commodity interest clusters are clearly important in Bayfield County as well, as elaborated upon below.

Community Interests: Regardless of length of tenure or ownership status, members of this cluster have a defining interest in security - that is, being secure in their housing tenure and use status. They may also have a strong interest in autonomy, equity, legacy, and amenity stemming from their domestic property. First-and-foremost, though, members of this cluster wish to be able to afford to live in a community in which they have long-standing ties or have found gainful employment. They believe in the "right to stay put" (Hartman, 1984).

Community interests are exemplified by the Bayfield Housing Trust (BHT). One of only a handful of such trusts in Wisconsin, the BHT is designed to provide affordable housing by selling homes at below-market prices to qualified low-to-moderate income individuals. The land is retained in trust for the community, to provide affordable housing in perpetuity (Town of Bayfield, n.d.). The BHT embodies the community interest cluster because it is dedicated to 
producing what Davis (1991) terms "social property." As discussed below, the BHT has receded in prominence over the years.

Commodity Interests: According to Logan \& Molotch (1987), “All capitalist places are the creation of activists who push hard to alter how markets function, how prices are set, and how lives are affected" (p. 3). Realtors, developers, and acquisitive homeowners are the primary commodity interest actors in Bayfield County. According to a year-round resident of Washburn, “in the last 10 years there's been a huge influx of people coming from somewhere else to cash in

on what's here." A year-round resident of rural Bayfield indicated,

You go down this road to the golf course, most of those homes are second homes... and for many years, there were one or two real estate brokers in town. Now, I bet there's 8 or 10... and the real estate market or brokers are really driving prices up. And, um, that, I think, is a real negative to our community.

Those with commodity interests may support (in action or rhetoric) efforts to maintain a "living community," but their defining interest is in facilitating liquidity from the sale of houses, rental of property, and development of the landscape. Therefore, the interests of these "place makers" inherently and antagonistically conflict with community interests. One local realtor who was heavily involved in local smart growth planning indicated that this tension is felt at a very personal level: "trying to balance preservation and development is always a big dilemma for me as realtor."

\section{Extending the framework to include place interests}


To understand the events unfolding in Bayfield County we modify Davis's framework to account for a major difference between rural and urban contexts. Davis illuminates the diverse interests involved in development and accentuates the central role played by material relations to property. Like much of the writing on place-making he emphasizes that either use or exchange value shape settlement patterns. In this literature, place attachment is interpreted as a subset of a property stakeholder's use value, and communal visions of place are relatively inconsequential (Logan \& Molotch, 1987; Davis, 1991). Our rural cases, on the other hand, are defined by struggles over place itself.

Strong place orientations have emerged through responses to change in Bayfield County, and particularly in the city of Bayfield. As an increasingly popular destination, it projects a strong place identity, or what might even be called a place "brand." Such brands are used to harness impending development by inviting change that is deemed appropriate. For example, while Bayfield has been a destination since the nineteenth century, its brand started to develop after the Apostle Islands National Lakeshore was created and a comprehensive plan was written in the 1970s. The mayor at the time of our fieldwork explained how this initial land use plan helped establish a place identity that persists.

The plan said, 'Bayfield is a great place.' It looked at all the past times, the good and the bad, and 'here's all the things that we need to do to keep it nice.' And they went and put in place architectural standards, the world's toughest sign ordinance, and created an historic district. These things were a hard sell in place like this, but thirty years later they are reasonably well accepted.

According to him, the biggest challenge facing the community is "just trying to keep Bayfield as Bayfield - the same thing they were dealing with thirty years ago - and having the 
fortitude to stick with it." His primary reason for optimism is also the same as it has been for decades: that "Bayfield still looks like Bayfield. We still have the Apostle Islands, hundreds of thousands of forest acres, and Lake Superior."

Down the road, Washburn faces a similar imperative to develop a brand, as spending by seasonal residents and tourists has become vital to its modern economy. Authenticity is part of its public image and developing brand. The former mayor asserted that, "what everybody likes about (Washburn) is that it's a residential community, and they like the amenities that are here, so as far as amenity development for me, it's quality of life. That's the only thing we've got here." She and other informants argued that a focus on authenticity and small-town quality of life would not only serve current residents' interests but also attract certain visitors and newcomers as well.

In light of this pervasive and resonant stake in place, we suggest that place interests can be reified to the extent that they comprise a third cluster in an interest mosaic for rural amenity areas (See Figure 1). There is overlap between the three categories - community interests, commodity interests, and place interests - but each has a defining interest inherently at odds with the others. Davis gives relatively little attention to the community versus commodity interest divide because his focus is upon tenurial categories (e.g. tenant versus homeowner), which clearly have important ramifications for locality-based collective action. We believe, however, that in our rural cases the interest clusters are more relevant. Having already discussed the first two, we present our ideal type of the third cluster below.

Place Interests: While this interest cluster is comprised primarily of educated, middleclass homeowners, it may also include renters. The key is that the person's interest is rooted in the quality of their living space, both the bricks and mortar of their homes and the landscape in 
which their homes are situated. Like those defined by community interests, incumbents to the place cluster are concerned with security, autonomy, equity, and legacy. Their education and income, however, have allowed them to select a specific community for seasonal or year-round living based on the presence of amenities like forests, public lands, coastal landscapes, and recreational areas. Such place-based amenities are their defining interest, which they will work hard to protect.

The commitment to preservation by people with place interests may be tolerated or even welcomed by those with commodity interests (who may realize increased property values near protected places) and community interests (who may also value amenities). But their defining interest inherently clashes with the pursuit of liquidity, since an overarching goal of the place interest cluster is to restrict development. Further, the preservation of land and historical buildings may help to "produce a thoroughly gentrified, affluent neighborhood that is eventually devoid of all who are different than themselves" (Davis, 1991, p. 246). In other words, the defense of amenity by those with primarily place interests can jeopardize the security of those with community interests, placing them at odds with this cluster as well.

The Bayfield Regional Conservancy (BRC) is a relatively longstanding place-based group that preserves land through acquisition, conservation easements, and partnerships. By removing priority landscape features from the free market and creating public access to private space, BRC engages in "radical" action (Davis, 1991). Founded in 1996, the BRC has a fulltime director and one of the few farmland preservation programs in the Midwest, credited with preserving 200 prime fruit-growing acres. The $\mathrm{BRC}$ now has more than 1,100 acres in conservation, successfully filling the void between the market and the state in this arena, and generally without direct connection to local planning efforts. It has over 400 member households 
and twenty active volunteers. According to one of the group's leaders, "half (our members) have been there 20-25 years - these people started it. The other half came up in the last ten years for the natural beauty and want to see it preserved." There are no "old-timers" on the board, because as she explains it, "they see it as their entitlement to make money on selling the land." According to her, “They love the land, but in a (hardscrabble) way...we don't have a real conflict with them - it's people coming in from the outside with money that antagonize them."

Those with community interests may, particularly in backstage discussions, decry the influence of "treehuggers," or the "kayak crowd." But they seem less likely to implicate those with place interests as threatening their security as they would the more visible developers or investors from the commodity interest cluster. The BRC board promotes the perpetuation of a "living community" and there may, in fact, be issues of common interest amongst all three clusters. The BRC's primary interest, however, is in preserving the landscape, which attracts most members - including amenity migrants. A seasonal resident from Minneapolis, for example, recently renovated a former fisherman's home in Bayfield after she and her husband "fell in love with the lake." She indicated that they have not yet made relationships with local people, but hope to be more involved and join the BRC in the future.

The Bayfield Housing Trust, devoted to affordable housing, was created in the same era as the BRC but faded from the local scene as the importance of place and commodity interests ascended. The trust acquired only one property, located in the city of Bayfield; while this home has been recycled multiple times, in contrast to the vitality of the BRC, the organization is basically dormant at this time, according to one of its founders. This supports the notion that residents primarily interested in place and landscape preservation on the one hand and 
commodity and property development on the other have reshaped the local political and civic arenas.

\section{Place-based conflict and collective action}

Our research demonstrates that "to have an interest in a parcel of domestic property, within a specific territorial space is to become enmeshed in a complex web of local and extralocal relations...that 'orient' one's behavior in a particular way” (Davis, 1991, p. 59). Land use planning forces the issues of future development and landscape preservation onto the civic stage, compelling stakeholders to make decisions as if there were a convoy of bulldozers en route to the places they love. Though use and exchange values are important considerations for stakeholders in our study areas, we observed that place-related considerations indirectly shaped planning processes by establishing who was present to participate in them, while also leading directly to organization and collective action. Relative newcomers with place interests have carried out the most prominent collective action occurring in recent years. Historic preservation is an important consideration for some, particularly in the city of Bayfield, but most that belong in this cluster are primarily interested in scenic and recreational values. This aspect of amenity has been under increasing threat.

Washburn Alive objected to the local government facilitating private liquidity (by the condominium developer) and expressed other concerns with the proposed development. Its primary motivation, however, was the preservation of amenity - the lakeshore walking trail and relatively "wild" lakefront, the development of which was encouraged by the government's land use plan. Condominium advocates included those seeking liquidity in land development and others who perceived that such a project would enhance their interests by improving the overall 
economy. Community, commodity, and place interests inevitably clashed, and the local government became the target of and arena for collective action. Davis (ibid.) argues that while governmental entities are "part of the encapsulating social structure" (p. 259) in which local groups act, they do not fit neatly into the framework. We observed, however, that government intervention in local land-use decisions may indeed be oriented toward particular property interests. In the case of the City of Washburn, its decision on but one relatively small parcel was of major consequence, highlighting the pivotal role played by governmental actors in the rural property interest mosaic.

The $\mathrm{BRC}$ has also taken significant action throughout the region to preserve amenity. It has mobilized in response to action by those looking to develop land for liquidity or personal consumption and equity, interests that threaten the amenity of others and are in direct conflict with those of its members. Further, while the BRC may not have experienced opposition from area "oldtimers," its perception that these stakeholders "are not too interested in what we do" may actually point to inherent conflict that has simply not crystallized into action. As noted by Davis (1991), "People may find themselves antagonistically related, even if they neither recognize nor want such enmity, simply because of a different and conflicting stake in domestic property" (p. 59). The efforts of Bayfield County place defenders, such as historic preservationists and the $\mathrm{BRC}$, have been very tangible and are supported by many. However, they could have detrimental impact on community interests by contributing to gentrification, or the loss of year-round businesses due to the increased seasonality of the local population and economy, which their efforts inadvertently encourage. In fact, the direct interpersonal conflict in our research was between seasonal residents, based upon, for example, the size and placement of a large, new seasonal home clashing with neighboring place interests. Thus, we argue that more 
important than categories such as insider versus outsider or newcomer and oldtimer are domestic property interests, which can actually place people from all of these categories into the same cluster.

Further, our research suggests that some collective action may be stifled by place-based development. In Bayfield County, gentrification has led to rural neighborhood stratification and an exodus of working class households. A number of former residents and current local workers - who would likely fall into the community interest cluster - have moved to more affordable homes in Washburn, the nearby Red Cliff reservation, or out of the area. Their defining interest in security may be objectively and antagonistically related to the defining interests of the place and commodity clusters, but the potential for collective consciousness - recognition of common interests, the first step towards collective action ${ }^{-}$is hampered by their diminishing numbers. While Bayfield's proportion of seasonal housing units doubled in the 1990s, the year-round population dropped by ten percent and has decreased by an additional seven percent since 2000 (USBC, 2008), with the mayor indicating that many people were displaced by higher taxes and rents, and loss of year-round jobs. Historical and cultural factors - such as an independent North Woods mentality in the region and a company town legacy in Washburn - may also be salient, but in any case, it appears that inherent conflict has not produced effective collective action by members of this cluster.

Finally, the conflicting tendencies of class stratification were pervasive. Although Davis (1991) stresses that conflict is between interest groups and not classes, we consistently observed a natural convergence between the two. For example, according to Bayfield's mayor, the creation of local architectural guidelines was a battle. Two people appointed to the committee were opposed to any governmental action around historic preservation, which turned a "six-month 
project into an eighteen-month one." One of them was an acquisitive homeowner who profited from "flipping" local houses, while the other was a wealthy woman and relatively recent migrant. Said the mayor, "some of us were concerned about how our guidelines might limit the options for lower-income people, new teachers, and so forth, and the woman...said, 'those people don't belong here." Further, it was suggested by some in our research that more urbanites with place interests were needed to help save amenity areas from themselves, while others argue that landscapes and buildings are indeed being preserved, but year-round communities are not.

\section{Discussion and conclusion}

We hope that our chapter will make three primary contributions. Planning's effective failure in some of our most threatened natural places has puzzled many. Thus, for planners, we first offer a more nuanced perspective on who stakeholders are and how they organize. Residents of our communities seem to unanimously cherish the landscape and pace of life that are characteristic of minimal development. Yet, when presented with an opportunity to curtail future development through planning, communities are unable to reach consensus. Though it is convenient to blame partisan politics for this stalemate, it is a cursory and ineffectual explanation.

The rural property interest mosaic provides appropriate focus to the complex array of interests influencing rural land use politics. Specifically, this perspective recognizes that one stakeholder can embody multiple conflicting interests, but consciousness and organization in the public realm are likely to result directly from defining interests in rural property. Stakeholders are often classified by planners under a single land use interest, such as development, 
conservation, preservation, speculation, or gentrification. While convenient, this labeling strengthens the prevalence of political stereotypes and disenfranchises stakeholders from the very interests that must be tapped in order to reach compromises around land use. Even as planning becomes increasingly participatory, it often overlooks the interests in property that underlie divisions in planning perspectives. This supports the need for decision-making processes that emerge independent of polarizing land use policies, and for conservation measures that recognize the complex diversity in personal attachments to land.

Second, this work should challenge scholars of planning, politics, and the social sciences to draw connections between the similar place themes evolving in our respective fields. Place is widely understood as space imbued with human meanings, which has been demonstrated at multiple social scales (cf. Tuan, 1977; Kaltenborn \& Williams, 2002; Hanna, Dale, \& Ling, 2009). Place meaning can be born from and maintained by individuals or it can be agreed upon and maintained by groups (cf. Davenport \& Anderson, 2005; Perkins, Thorns, \& Newton, 2008). In addition, place is invoked as a socially nuanced substitute for geographic location. Placemaking, for example, often refers to the political economy of growth and development in a specific locality. However, we have established that as commitments to spatial and economic patterns of development, land use plans are an important link between place meanings and the capitalist process of place-making. We feel this chapter charts a conceptual terrain between place concepts and literatures that is in need of further exploration as place becomes an increasingly jargonized term.

Finally, for scholars and practitioners alike, we hope this framework for understanding rural land use sheds light on the importance of using community-oriented benchmarks for measuring success. Incorporation of place values into planning seems to be viewed by some as 
the salve that will bring harmony and rootedness to bureaucratic and ineffectual processes. However, the success of group decision-making is reflected not in economic growth, or even in political unity. As we observed, successful place-making often translates into heightened inequality, and thus, the politics of planning, conservation, and development will shift inevitably and interminably. As Wilkinson (1991) proposes, it is the "free flow of authentic interaction among people whose lives are interconnected in a local society" (p. 104) that defines successful community. Accordingly, we maintain that land use conflicts such as those we have described actually represent instances of authentic, collective interaction that has the potential to build community, which is critical to social and ecological well-being (ibid.; Beatley, 2004).

We observed that while place meanings are often perceived as individualistic, subjective, and benign, they are, in fact, collective, objective, and conflictual. Though recent planning efforts and the reactions to them failed to unite residents around areas of common interests, they inspired community-based collective action. Stakeholders from competing interest groups were forced to interact and publicly debate issues of local import. As noted by one informant, it is not the debate but silence that is truly "scary."

In conclusion, place-based conflict can yield fruitful public discussion that may prove to be a first step toward democratic community-based decision-making. Planning and decisionmaking are complex and divisive, not because place is absent from these processes, but because planning is not engineered to recognize its complexity. A locally-informed understanding of the rural property interest mosaic may help to harness the inherent potential in strong but diverse interests in place. 
Figure 1. Rural Amenity Area Property Interest Mosaic

[Accommodative Interests] [Accumulative Interests]

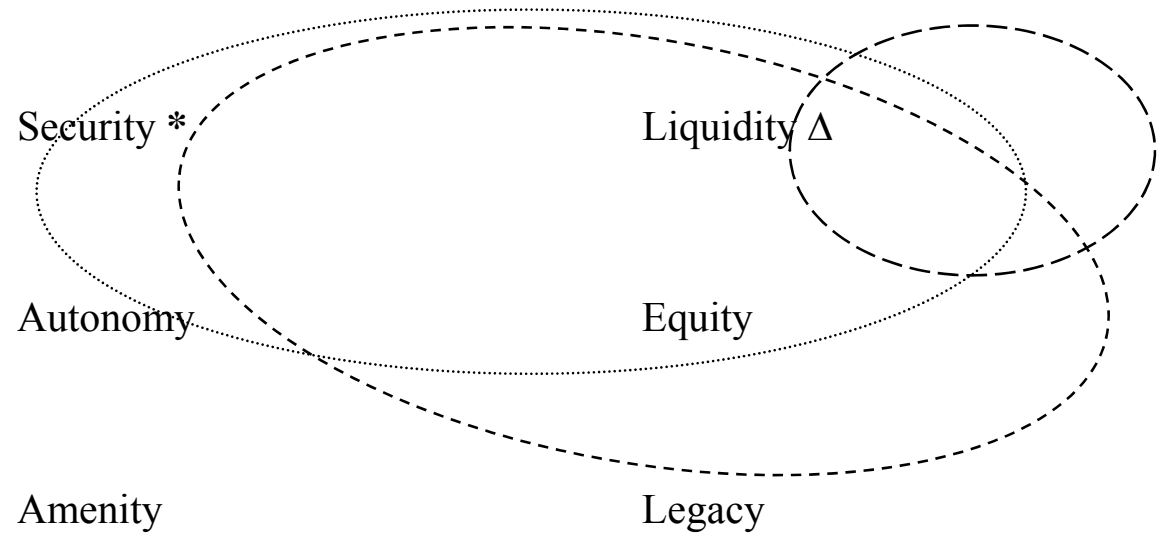

Quantity of Living Space

Quality of Living Space $\triangle$

...... Community Interests; $*$ defining interest
- - - - Place Interests;
$\triangle=$ defining interest
_ $-\ldots$ Commodity Interests; $\Delta=$ defining interest 


\section{References}

Beatley, T. 2004. Native to nowhere: Sustaining home and community in a global age. Washington, D.C.: Island Press.

Burawoy, M. (1991). Introduction. In M. Burawoy, A. Burton, A.A. Ferguson, K.J. Fox, J.

Gamson, N. Gartrell, L. Hurst, C. Hurzman, L. Salzinger, J. Schiffman, \& S. Ui (Eds.), Ethnography unbound: Power and resistance in the modern metropolis (pp. 1-27). Berkeley, CA: University of California Press.

Cox, K.R. (1981). Capitalism and conflict around the communal living space. In M. Dear \& A.J. Scott (Eds.), Urbanization and urban planning in capitalist society (pp. 94-108). New York: Methuen.

Davis, J.E. (1991). Contested ground: Collective action and the urban neighborhood. Ithaca, NY: Cornell University Press.

Golding, S. (2006). Rural fortunes: Place value and planning in an amenity area. A thesis submitted in partial fulfillment of the requirements for the Degree of Master of Science (Sociology) at the University of Wisconsin-Madison.

Hanna, K.S., Dale, A., \& Ling, C. (2009). Social capital and quality of place: Reflections on growth and change in a small town. Local Environment, 14, 31-44.

Hartman, C. (1984). The right to stay put. In C.Geisler \& F. Popper (Eds.), Land Reform, American Style, (pp. 302-318). Totowa, NJ: Rowman \& Allanheld.

Hollish, K. (2007, May 15). Mann presents Washburn council with to-do list. The Daily Press [Ashland, Wisconsin] online. Retrieved May 15, 2007 from http://www.ashlandwi.com/sharedcontent/search/index.php? search $=$ go\&o $=0 \& q=$ mann + presents $\& \mathrm{~d} 1=05-15-2007 \& \mathrm{~d} 2=05-$ $15-2007 \& s=$ relevance $\& r=$ Subject $\% 2$ CAuthor $\% 2$ CContent $\& 1=20$

Jacobson, D. (2004, May 31). Washburn controversy shows promise, peril of 'smart growth.' Business North online. Retrieved on May 4, 2005 from http://www.businessnorth.com/viewarticle.asp?articleid=848.

Jensen, D.A. \& Field, D.R. (2005). Managing growth and development in a natural-amenity-rich landscape: Landowner attitudes toward planning in northwestern Wisconsin. In G.P. Green, S.C. Deller, \& D.W. Marcouiller (Eds.), Amenities and rural development: Theory, methods, and public policy (pp. 259-281). Northhampton, MA: Edward Elgar Publishing.

Kaltenborn, B. \& Williams, D. (2002). The meaning of place: Attachments to Femundsmarka National Park, Norway, among tourists and locals. Norwegian Journal of Geography 56, 
189-198.

Logan, J.R., \& Molotch, H. (1987). Urban fortunes: The political economy of place. Berkeley, CA: University of California Press.

Manzo, L.C. \& Perkins, D.D. (2006). Finding common ground: The importance of place attachment to community participation and planning. Journal of Planning Literature $20,335-350$.

McCann, E. (2002). The cultural politics of local economic development: Meaning-making, place-making, and the urban policy process. Geoforum 33, 385-398.

O'Brien, K. (2004, April 1). Washburn condominium development plan laid out. The County Journal [Washburn, Wisconsin] online. Retrieved May 5, 2005 from http://www.washburnwi.com/sharedcontent/search/index.php?search $=$ go \&o $=0 \& q=$ Washburn + condominium $\& d 1=04-01-$ $2004 \& \mathrm{~d} 2=04-01-2004 \& \mathrm{~s}=$ relevance $\& \mathrm{r}=$ Subject $\% 2 \mathrm{CAuthor} \% 2 \mathrm{CContent} \& \mathrm{l}=20$.

Perkins, H.C., Thorns, D.C., \& Newton, B.M. (2008). Real estate advertising and intraurban place meaning: Real estate sales consultants at work. Environment \& Planning A, 40, 2061-2079.

Spain, D. (1993). Been-heres versus come-heres: Negotiating conflicting community identities. Journal of the American Planning Association, 59, 156-171.

Town of Bayfield (n.d.) Vision and comprehensive plan (Housing). Retrieved on June 7, 2010 from http://www.townofbayfield.com/files/archive/compplan/index.html.

Tuan, Y.F. (1977). Space and place: The perspective of experience. Minneapolis: University of Minnesota Press.

United States Census Bureau (USCB) (2008). 2008 Population Estimates, Census 2000, 1990 Census. Retrieved June 7, 2010 from

http://factfinder.census.gov/servlet/SAFFPopulation?_event=ChangeGeoContext\&geo_id $=16000$ US5505350\& geoContext $=\& \_$street $=\&$ county $=$ bayfield $\&$ cityTown $=$ bayfield $\&$ _state $=04000$ US55\&_zip $=\& \_l$ lang $=$ en\&_sse $=$ on $\&$ ActiveGeoDiv $=\& \_u s e E V=\& p c t x t=$ fph \&pgsl $=010 \& \_$submenuId $=$population_0\&ds_name $=$null\&_ci_nbr $=$null $\& q r \_n a m e=$ null\&r eg $=$ null\%3Anull\&_keyword $=\& \_$industry $=$.

Van Auken, P.M. (2007). Nature, community, and commodity: Shifting landscapes and social relations in rural amenity areas of Wisconsin and Norway. Dissertation, University of Wisconsin-Madison Department of Sociology.

Wisconsin Department of Tourism (2007). Research. Retrieved January 5, 2009 from http://agency.travelwisconsin.com/Research/research.shtm. 


\section{Rural property, collective action, and place-based conservation \\ Patrick T. Hurley}

Much attention has been paid to exurbanization within the United States in recent years, particularly the impact of sprawl (unplanned low-density commercial and residential growth) on rural landscapes in areas that have experienced rapid in-migration. Concerns about the myriad ways that residential development reconfigures local ecologies include habitat loss, fragmentation, and alteration (DeStefano and DeGraaf, 2003; Johnson and Klemens, 2005; Theobald, 2004), declines in the species associated with these altered habitats ((DeStefano and DeGraaf, 2003), and traditional livelihood uses (Hurley et al., 2008). Likewise, critics have bemoaned sprawl's role in creating a "placelessness" (e.g., (Duany et al., 2000) that contributes to a loss of natural resource production. In response to these ecological, aesthetic, and resource concerns, several new development approaches have emerged, such as "new urbanism" (McCann, 1995; Till, 2001; Zimmerman, 2001), which feature specific design features intended to minimize environmental impacts while creating residential spaces that better fit in with their rural surroundings and maintain some forms of agricultural production (Arendt et al., 1996; Bjelland et al., 2006).

But what role do amenity migrants and their sense of place play in efforts to create alternative developments in the American West? Drawing on the political ecology literature, I focus on the relationship among amenity migration, trends in environmental management in the urbanization process, and the role that the sense of place of individual developers plays in the construction of natural amenities in residential developments that are intended as exurban "alternatives" (see Bjelland et al., 2006). The chapter examines projects in Central Oregon that highlight the intersection of regional social-economic processes with specific developers' sense 
of place to produce development alternatives that (re)commodify landscapes in very particular ways. In doing so, I highlight the need for sense of place researchers to engage with and examine processes of migration and residential development that produce (or potentially contest) diverse place meanings within urbanizing regions.

\section{Amenity Migration and Exurban Development in the American West}

Economic restructuring in the American West has been a key feature of many natural resource-dependent communities in recent decades (Jackson and Kuhlken, 2006; Nelson, 2001; Travis, 2007). Economies built on extraction, have been replaced with economies of real estate (e.g, Brogden and Greenberg, 2003; Ghose, 2004; Walker and Fortmann, 2003). Amenity migration has become an important factor in explaining population growth, particularly differences in growth among counties (Nelson, 2006). High amenity counties have experienced higher rates of growth than low amenity counties, with non-metropolitan areas characterized by much lower-density growth than in nearby metropolitan areas (Nelson, 2006; Vias and Carruthers, 2005). In Idaho, amenity-related residential development has led to uneven development among non-metropolitan areas that were formerly characterized by natural resource production (Smutny, 2002). Population growth in counties with the presence of public lands is often higher than local averages, with growth rates differing among counties with particular federal lands agencies as a function of amenities and not management priorities (Frentz et al., 2004). These results suggest that high amenity areas are not characterized by substantial patterns of high-density land development, but rather by lower-density parcelization characteristic of exurbanization.

Meanwhile, research on amenity-migration has highlighted key differences in land management within counties, within communities, and on individual parcels. Residential 
development and social change leads to the creation of communities within communities. For example work by Halseth ((1998)) in rural British Columbia, highlights the emergence of distinctive social communities associated with proximity to particular amenities (e.g., lakeshores). Changes in landownership, including absentee landowners, often results in more diverse land management that focuses on amenity or conservation values joining, and sometimes replacing, traditional production values (Gosnell et al., 2006). In many instances, changes in environmental management at the county, community, and parcel level have led to land-use conflicts over environmental management priorities (Shumway and Otterstrom, 2001).

Walker and Fortmann (2003) locate the source of these land-use conflicts in the American West in the cultural and economic changes that accompany amenity in-migration and that result from the competing rural capitalisms that result from these changes. Importantly, Walker and Fortmann argue that one set of rural capitalism emphasizes protecting the quality of natural landscapes through planning and development-related decisions, precisely because these positively impact real estate values. Brogden and Greenberg (2003) empirically demonstrate the importance that amenity migration and changing place meanings have in reassigning resource access away from agricultural users and to environmental users. This process of reassignment occurs through property markets and new environmental management schemes.

\section{A Political Ecology of Sense of Place and Amenity Development}

Political ecology examines "linkages between social systems and ecological systems" (Berkes, 2004: 624), by combining "the concerns of ecology with a broadly defined political economy" (Blaikie and Brookfield, 1987: 17). Political ecologists see biophysical systems as being produced through politics that "are related in various ways to social relations of production and decision-making about resource use... [T] hese are exercised in diverse arenas, on multiple 
scales, and infused with cultural knowledge and value." From this perspective, individual land manager decisions are conditioned responses to broader scalar processes that range from local to global dynamics.

In explicating the politics — or logics that produce particular forms of appropriateenvironmental management (e.g., Robbins, 2004) - political ecologists have pointed to the fact that contemporary global environmental management is characterized by a proliferation of new "nature-society" hybrids. These schemes use land-use zones and associated rules to "contain in space" specific human practices (e.g., hunting, farming, housing), thereby minimizing biophysical impacts on the environment, while also expanding markets (Zimmerer, 2000, 2006). While Zimmerer's research focuses on biodiversity conservation in the developing world, these insights apply to emerging environmental management practices in human-dominated landscapes. As such, these "nature-society hybrids" are the products of processes of privatization-commodification, which rest on particular constructions of environmental scarcity and sensitivity that encourage private enterprise to value ecological resources appropriately.

However, there has been little comparative study of the diversity of "nature-society hybrids" that emerge in particular regions. A notable exception is Reed's (2007) examination of two biosphere reserves in rural western Canada, in which Reed reveals the importance that regional processes play in shaping the "formal and informal institutional arrangements" that characterize emergent (and uneven) environmental management regimes. These processes include property exchanges associated with changing regional economies and demographics, the ways these changes influence the valuation of land (i.e. differing forms of commodification and ways of marketing nature), the rules and norms that govern formal planning and land-use 
decision making, and reterritorialization or the social process through which rules are established that govern natural resource access, use, and production.

In comparing reserve formation, Reed (2007) highlights the role that diverse social actors play in constructing both particular environments as worthy of protection and particular forms of management as appropriate. While forestry management goals in her British Columbia case are reworked by a broad array of activists, scientists, First Nation groups, and governmental officials, lake and wildlife management in her Alberta case is dominated by land trusts. Reed's work demonstrates the emergence of different environmental management configurations that result from tensions between civic society and private entities. These cases demonstrate links between privatization-commodification and processes of globalization-nationalization (Zimmerer 2000). This research also raises questions about the role that "sense of place" plays in reconfiguring environmental management.

\section{"Sense of Place" and Environmental Management}

"Sense of place" research has often sought to better understand the meanings and attachment people place on their environments, including satisfaction with where they live and perceptions about environmental quality/degradation (Kaltenborn, 1999; Williams and Stewart, 1998). Scholars have demonstrated the role that both biophysical environments and political contestation play in changing these meanings and perceptions (Johnson et al., 2009; Larsen et al., 2007; Stedman, 2003), including recognition of the importance that sense of place plays in land use decision-making (Stewart, 2008). These place meanings are multi-layered and complex, with different meanings for the same location open to efforts by individuals or groups "to manipulate and market" their own set (Cheng et al., 2003). 
Power and access to capital play a key role in creating particular place meanings for communities that inhabit particular locations (e.g., Harner, 2001). This finding resonates with political ecology research of environmental management, because it makes explicit the relationship between power and flows of capital that change social dynamics which produce new ideas about what counts as appropriate uses of the environment (Robbins 2004). For example, Johnson and coauthors (2009) demonstrate that marginalized communities may strategically embrace new ideas of ecological integrity and global conservation, thereby forging new place meanings among long-term residents. But their findings suggest that efforts to protect particular natures by specific groups associated with different sides of in-migration and urbanization processes, and the actions of individuals and groups collectively, can lead to the formation of new place meanings. Yet, neither of these literatures specifically engages with changing urban land development practices.

New (Ex)urbanism? Landowners' "Quest for Authentic Place”

Over the past decade, numerous changes in urban land development have taken place, including the rise of "new urbanism," a design approach that seeks to create more responsible, aesthetically pleasing forms of compact residential (and often mixed-use) development (Bjelland et al., 2006). A key dimension of this approach lies in intentional use of design features to create a distinctive "sense of place". Among the features associated with what Bjelland and coauthors (2006) call new urbanism's “quest for authentic place" are a number of conservation principles. Besides limiting lot sizes to maximize open space, developers often alter lot layouts to avoid areas deemed to have conservation (e.g., sensitive environmental resources), natural resources (e.g., agricultural land), or recreational values (Arendt et al., 1996). Clustering lots together increases the size and contiguity of open space, while future development is prohibited in these 
common areas through deed restrictions or conservation easements (e.g., held by local government or a land trust). Finally, homeowner bylaws generally encourage ecologically appropriate interactions by residents, both within conserved areas and on their own property (Arendt et al., 1996). These design features not only address diverse environmental management issues, but reflect place meanings attached to specific landscape features.

Several scholars have been critical of new urbanist "innovations" in residential development, dissecting the ways that political economic changes are leading developers to recast social and biophysical environments as spaces in need of protection while producing housing developments for elites. In the Puget Sound region, broader social and economic conditions enabled new environmental designs to take advantage of niche markets (Veninga, 2004). In Minnesota, local developers play an important role in making new "niche products" that conserve nature a reality in the Minneapolis St. Paul region (Bjelland et al., 2006). In Illinois's "Prairie Crossing," nature is mobilized in defense of the suburban dream, representing both a nostalgic defense of the Midwestern frontier and a poor model of sustainability (Zimmerman, 2001). New urbanist projects discursively and materially produce nature in ways that play on "Edenic myths" and rural idylls in a new form of "green politics" (Till, 2001). Taken together, these observations suggest this new "green politics" is actively producing "naturesociety" hybrids through "sense of place" design features.

Against this backdrop, however, urban ecologists point out that lifestyle factors and worldviews increasingly influence the environmental management of urban land covers on individual parcels, with landscape and aesthetic concerns often trumping ecological concerns (Larson et al., 2009). In the process, though, developers have the potential to both create spaces that are managed for environmental benefits and that meet desires for individual recreation 
(Larsen and Harlan, 2006). Indeed, as Nassauer and coauthors (2009) suggest, developer led initiatives may provide the best way to bridge this gap.

\section{Natural Amenity and Land-Use Change in Central Oregon}

This study focuses Deschutes and Wasco (Figure 1) counties in Central Oregon, on the eastern slopes of the Cascade Mountains. The region is home to the Deschutes River, a significant tributary to the Columbia River, which is renowned for its fly-fishing. While both counties share many natural amenities associated with communities experiencing rapid growth elsewhere, the two counties' experiences with development are quite different. The County seat, Bend, has been Oregon's fastest growing metropolitan area since 2000 and one of the fastest growing metropolitan areas in the U.S. (U.S. Census Bureau, 2009a). Bend is close to the Mt. Bachelor ski area ${ }^{5}$ and has an abundance of sunny days (McGranahan, 1999), while Wasco County has considerably fewer sunny days. Thus, Deschutes has experienced higher growth rates. Wasco County's major metropolitan area, The Dalles and its outlying rural exception areas, largely have been overshadowed by rapid amenity-related growth in, and around, the towns of Hood River and White Salmon (across the Columbia River in Washington State), that are revered windsurfing sites. Thus, the county has seen much lower population growth (U.S. Census Bureau, 2009b) and a smaller influx of retirees and second home buyers.

Land-use change histories in Deschutes and Wasco counties share important similarities, even if the scope of these changes is quite different. The emergence of Oregon's unique land-use planning system was, in part, a specific response to the rapid partitioning of rural parcels in the southwestern portion of Deschutes County. By the time the state had created the planning system, a large degree of rural subdivision had occurred in the region. In the years it would take Deschutes County to finalize a planning document, five-acre parcelization was widespread in

\footnotetext{
${ }^{5}$ Interview A, Deschutes County 6-12-2006
} 
many parts of the county. Similarly, portions of northern Wasco County experienced pre-1973 parcelization and land speculation, albeit to a much lesser extent than in Deschutes. These densities largely set development entitlements for future projects.

Concern over growth in both counties has focused on environmental agricultural impacts from this parcelization. In Deschutes County, conservation groups, such as the Deschutes Basin Land Trust and the Deschutes River Conservancy, pursued efforts to protect critical wildlife and natural habitat characteristic of high desert terrestrial habitats (e.g., sagebrush steppe, native grasslands, and Ponderosa pine forests); increase instream flows for fish in the Deschutes River and its tributaries; and to retain working forests and farms. In Wasco County, land trusts have been active in protecting the county's limited-range Oregon white oak-Ponderosa pine woodland habitats and tremendous wildflower diversity. Some residents also worry about sprawl destroying the county's cherry orchards.

To examine the intersection of amenity migration and land development in the two counties, I reviewed development projects, their design features, relationship to local development trends, and their role in addressing area conservation issues. I analyzed proposal documents, county planning documents, marketing materials (i.e. real estate brochures and websites), and governance documents (i.e. Contracts, Covenants, and Restrictions; Design Guidelines). Using design and governance documents, I evaluated conservation goals and environmental management rules. During two visits to the area (May 2006 and May 2007), I conducted interviews with county land-use planners, representatives from land trusts and other conservation organizations, project investors/developers, and residents or landowners in the communities.

\section{Whose sense of place? Developing Amenity in Central Oregon}


We call this a preservation ranch... we're preserving the ranch by putting occasional residents on ranch, non-farm properties... ${ }^{6}$

While the use of conservation design principles is not widespread in the case study areas, a range of specific elements, often in combination, is common. Only three communities - two in Deschutes and one in Wasco — employed all features. Still, interesting patterns associated with the use of conservation design are apparent. While Deschutes County has a greater number of projects, the use of open space preservation, clustering, and new forms of environmental governance is more predominant in Wasco County. Design elements are most commonly related to place meanings that value native species and biodiversity protection, such as restrictions on or guidelines about planting practices, including in projects that neither cluster houses, nor reduce lot sizes. Indeed, one Wasco County project features large-lots, but its bylaws emphasize the protection of native flora and fauna. In Deschutes, a project places strict review procedures on plantings. Despite these similarities, there are important differences in the pathways, namely through the developer, that marry particular senses of place with environmental management forms.

\section{Whose development?}

We wouldn't need land-use planners if every developer lived in the developments they $\mathrm{did}^{7}$

Residential projects in Deschutes and Wasco counties challenge attempts to paint developers in broad-brushed strokes. For example, only one of the ten projects was undertaken by a large developer—a former timber company—whose project's bylaws provide strict guidance on appropriate land management activities, including native species plantings. Indeed, a recurrent theme among the projects in both counties was the active role that amenity in-

\footnotetext{
${ }^{6}$ Interview R, Phone Interview, 2-27-2007

${ }^{7}$ Interview B, Wasco County 5-31-2006
} 
migrants - not development companies - played in creating these alternative residential projects. Six of the eleven projects are associated with in-migrants who participated in the land purchase, helped design the project layout and features, and oversaw project implementation. Of these, two were built by individuals with extensive development experience elsewhere. Four projects are home to those in-migrants today: another was until the individual became too old to live unassisted. One of the in-migrant developers was responsible for two projects. Another project is home to the "developer," but this project features parcelization of family land to create second homes for friends and other potential buyers.

In the Wasco County, a reluctant local environmentalist entered the picture to act as developer and produce a different landscape outcome. Having learned the lesson that "developers are the enemy" at an early age, this individual purchased the property by leveraging his life savings. In creating a new project, complete with a strict set of ecological bylaws, this developer ensured that a special part of northern Wasco County's oak-pine woodlands would not be "destroyed" by the 21 home sites and equestrian-oriented project approach that had been proposed twice for this part of the County. Despite declaring his intentions to create a conservation-oriented project, the project faced opposition from local conservation groups. This story as well as the trends from the two counties paints a picture of individual developers that are literally creating their ideal community in which to live (or retire), drawing important links to amenity-related in-migration that extends beyond potential buyers.

By paying attention to local environmental contexts, amenity developers create projects that are imbued with specific place meaning and distinguish their developments in key ways. A former county planner suggested that when a "landowner comes in and creates the community that they're going to retire in, they're already looking to do all the things that we try to do by 
ordinance and they wind up doing it through the HOA, covenants, lease back options, all these other tools that we can't really regulate very readily..." Interestingly, however, land trusts were hesitant initially to get involved with a few projects, precisely because they did not want to be seen as facilitating the development of landscapes with important ecological and conservation values. Once the projects were approved by county officials, however, they saw their participation as important to ensuring the protection of ecological meanings associated with these places.

\section{Which rural amenity?}

We didn't create a little Hollywood set, you know. This [ranch] is the real deal. And people recognize that and appreciate... looking across green pastures, [seeing] cows in the field. ${ }^{, 8}$

Marketing materials for the projects are quite diverse, but vividly depict the sense of place constructions behind individual projects, with panoramic pictures that highlight the rugged Central Oregon landscape and majestic mountain views. They feature various types of recreation and describe the area's wildlife, plants, and to differing degrees, dimensions of ecological stewardship or conservation. One site includes a rustic storybook theme and features both photos and site maps that play on iconic imagery of the "Old West," including individuals on horseback wearing cowboy hats, and invites potential buyers to surround themselves with "a real Central Oregon ranch.”

Residential development has taken place overwhelmingly on lands historically used for agricultural or extractive uses. In each case, the surrounding landscape, including spectacular views of geologic features and characteristic vegetation of the local area, is a key dimension in the marketing of ownership opportunities. In Wasco County, historic land uses generally

\footnotetext{
${ }^{8}$ Interview O, Deschutes County 6-9-2006
} 
featured ranching. Four of the five developments are located in areas that were once home to roaming herds of cattle. These projects are situated in a narrow band of Oregon white oakdominated woodlands, near to the area's cherry orchards, and contain lots dotted with smallscale rock escarpments and intermittent views of Mt. Hood in Oregon, Mt. Adams in Washington, or the Columbia River. By contrast, Deschutes County projects are primarily found on former timber and ranching lands, with all of the projects within the transition zone between Ponderosa pine forest and Central Oregon's characteristic high desert shrub.

These projects represent more than discursive reconfigurations of the landscape. In Wasco County, residential development has resulted in new land-uses. Where cattle once roamed, residents and wildlife now wander the hillsides. Barbed wire that used to demarcate grazing lands has been transformed into place-based art. By contrast, there is continuity with past place meanings in Deschutes County but subtle changes in management. In part, this continuity results from the institutional imposition of strict agricultural zoning limits by Deschutes County and the state. Still, developers have used these constraints to market place meanings that both commodify the landscapes in new ways and generate environmental benefits. Using historic water rights, two projects include agricultural activities on portions of the conserved open space. In one, cattle graze on irrigated lands, while hay grows in irrigated fields in another. In both cases communities have invested in new irrigation measures that allow them to conserve water and supplement instream flows for salmonids through water rights transfers to a local conservation group. Despite its proximity to premier fly fishing rivers, one project installed a constructed trout stream, complete with meanders, a pool-riffle configuration, and native riparian vegetation. All of the communities feature walking trails, although there is generally no access for the public. One project includes horse trails that link to several thousand areas of land owned 
by the Bureau of Land Management. Indeed, adjacency or close proximity to protected lands is a common feature of these developments, including significant areas of land managed by the U.S. Forest Service and The Nature Conservancy.

\section{Whose Environmental Management?}

Projects in the study area feature diverse environmental management regimes, including involvement by local governments, regional land trusts, and the U.S. Forest Service to protect and manage common areas. All of the Wasco projects include open space or commons that are protected from future development and which contain walking trails. In one, a conservation easement held by a regional land trust, protects riparian forest habitats. Land trust activities have included riparian habitat improvements, while a local government developed trails through another property that allowed community access to an adjacent park. But more often than not, the common areas of a project are owned and managed by Homeowners Associations. At least one homeowner's association organizes regular land stewardship work parties, including using funds from the State of Oregon to help with improving wildlife habitat and minimizing fire danger. In others, landowners must abide by strict landscaping and planting guidelines that include "careful restoration of plants and rocks" in disturbed construction sites. Landscaping in areas surrounding the home is limited to a list of approved native plants.

Interviews with residents revealed the importance that biophysical environments and developer commitments to environmental protection played in their purchase. While dramatic views of the region's natural features clearly helped bolster their decisions, residents spoke about the environmental management features within their respective communities as a strong influence in their decisions. Residents in non-agriculturally oriented projects valued the respect for native vegetation found in community bylaws, emphasizing that native vegetation reduces the 
consumption of water and provides habitat for local wildlife. These residents spoke of wildlife in their yards and the sense that their communities tread lightly on the landscape. Meanwhile, those residents in agriculture projects enjoy their "oases in the desert" and appreciate that they help maintain rural traditions.

At the same time, landowner activities may or may not match the "sense of place" and management established by the developer. In one Wasco project, a new resident negotiated with the developer to install a new fruit orchard, while in Deschutes a resident planted a small apple orchard. In both cases, uses are consistent with the meanings developers place on a cultural landscape that is tied to the regional agricultural history. But in a Wasco County project noted for its strict ecological covenants and habitat focus, efforts to change the rules by a few residents to allow horses were contested and ultimately turned back by other residents. Despite the land's ranching history, a majority of residents saw horses as inappropriate, given the ecology-oriented meanings they associated with the area's oak woodlands. This situation points to the ways that the meanings associated with a particular place in a specific project may come into conflict with divergent place meanings among residents. More often, however, this mismatch is tied to consistent place meanings but a desire among some residents for stronger commitments to environmental protection within their communities. In one case, residents complained about the emphasis placed on housing aesthetics in their community's bylaws and the barrier this presented to the installation of solar panels. In another case, a resident was frustrated by the lack of awareness among neighbors and the developer-resident about oak management and invasive species. This resident organized regular work parties to remove exotics, but discussions about improving oak habitat through active thinning were resisted by the developer-resident, reflecting differing place meanings associated with forests, forest change, and untouched nature. 


\section{Discussion and Conclusions}

Using a political ecology framework to examine the relationship of "sense of place" to amenity migration and evolving environmental management practice in residential developments in Central Oregon reveals a number of key dimensions. Differing ideas about landscape qualities, place meanings, and environmental management play out within the wider context of regional changes and among competing rural capitalisms. Access to capital, both by developers and residents, are key to fusing sense of place and management in particular places. But the distinction between developers and residents is not as clear as is often assumed in the literature. In Central Oregon, these may be the same people. Indeed, many of the developers interviewed here are in-migrants whose presence is directly tied to the process of amenity migration. These individuals comprise what might be best described as amenity developers, owing both to their links to the social and economic changes that drew them to these locations and to their active role in producing specific amenities that reinforce this process. For these resident amenitydevelopers, capital is critical in realizing their place meanings through forms of environmental management that ultimately create natural amenities that are marketed to potential buyers. Environmental management in this sense is not just about creating a product, but also about ensuring that these landscapes are controlled in a way that conforms to their personal place meanings.

For non-developer residents, the proliferation of residential projects that manage environments in particular ways based on acceptable place meanings means that those with sufficient money have greater choice within the real estate market. Buyers can both consume the amenities that result from the resulting place meanings and purchase a set of management practices that ostensibly will protect their own place meaning. I do not want to argue that this 
process is not without social or ecological consequences, nor do I want to argue that access to housing opportunities in these projects is not marked by social and economic exclusion. Still, while some landowners came from other parts of Oregon and the American West, not all projects represent unaffordable housing choices for those living in their respective counties.

In the process, these actors discursively and materially reconfigure landscapes and alter resource uses through new design features and associated environmental management practices. These practices contain particular uses, such as agriculture or habitat, within specific spaces, thereby creating a set of place meanings that produce amenities and (re)commodify landscapes. Here, it is instructive to note the motivations of individual developers and their attempts to create alternatives to wider practices in their communities. But amenity developers see different place meanings and act based on diverse motivations. For one amenity developer, the project was the last resort to make things right on the landscape, seeking to prevent what would have been for him the materialization of inappropriate and inauthentic place meanings. So, too, at least one of the projects represents an opportunity for a long-time developer to do things differently. This perspective illuminates the creation of idealized places for individuals affiliated with (and likely distrustful of) the "typical" development process. For others, the discourse of conservation design may represent the path of least resistance, providing the niche product that allows a project to "pencil out" in economically rewarding ways or that minimizes the institutional barriers created by county planning.

Environmental management features in areas experiencing amenity-related urbanization remain uneven. While planning creates some constraints on the types of place meanings that can be built, land trusts are important to the creation of place meanings that blend agriculture and conservation. Providing an agricultural amenity maintains continuity with the history of these 
places, while providing legitimacy to the ecological protection features associated with the aesthetic and recreational amenities of flowing rivers. Remembering that place connections are often diverse, nuanced, and multi-layered (Cheng et al., 2003), this study suggests a need to tease apart the ways that place meanings are produced by developers and the amenity migrants who purchase properties in their developments. Although developers rely on particular place meanings to attract amenity buyers, these residents may contest those meanings and challenge the management practices that maintain sense of place. This is an area warranting further study. A similar focus on sense of place might reveal important distinctions among environmental management strategies by landowners in conventional residential developments. 


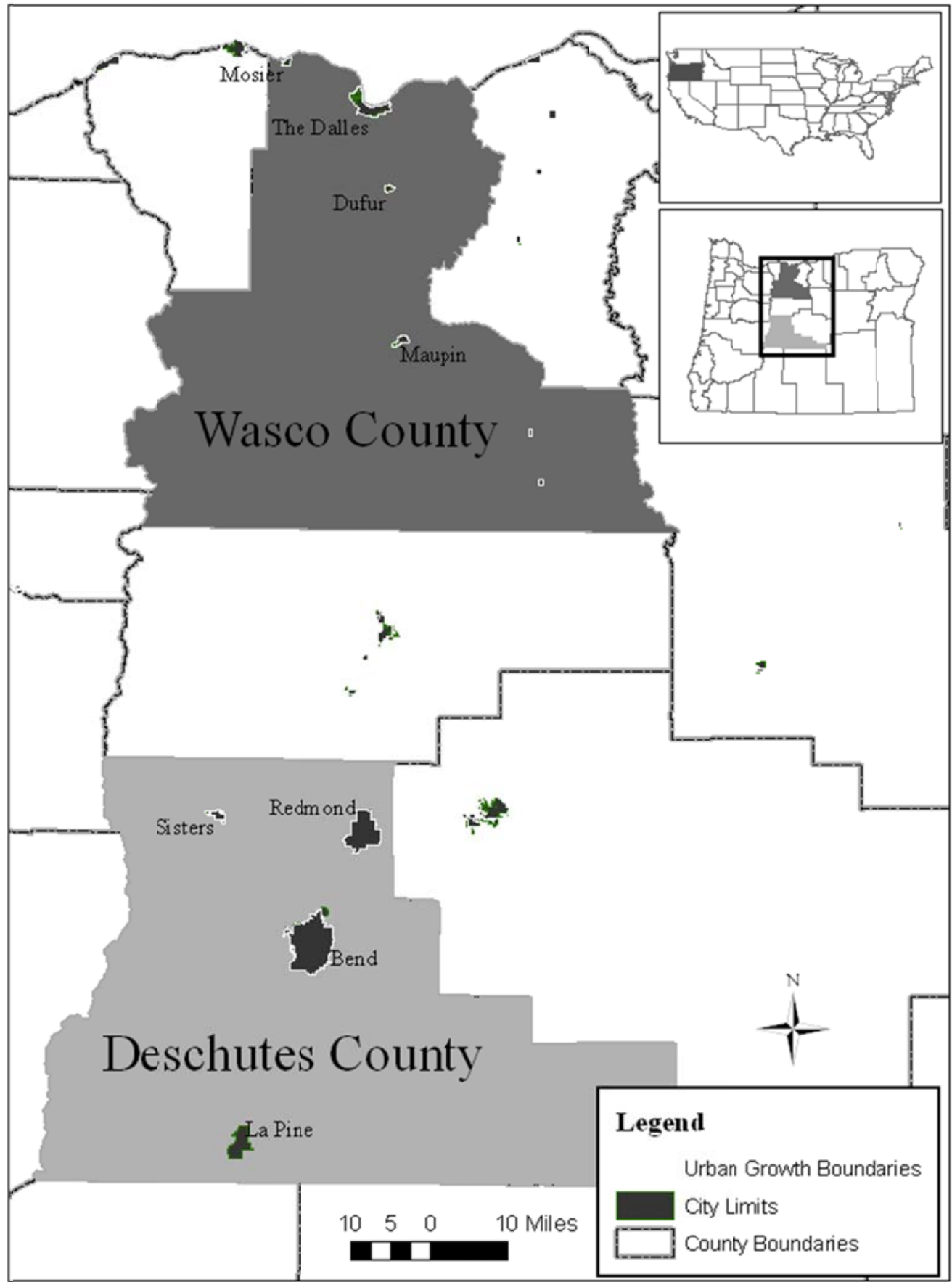

Figure 1. Map of study area, highlighting Deschutes and Wasco counties, in Central Oregon. Source: Oregon Geospatial Data Clearinghouse (2009). 


\section{References}

Arendt, R., Harper, H., Natural Lands, T., American Planning, A. and American Society of Landscape, A. 1996: Conservation design for subdivisions : a practical guide to creating open space networks. Washington, D.C.: Island Press.

Berkes, F. 2004: Rethinking Community-Based Conservation. Conservation Biology 18, 621630.

Bjelland, M.D., Maley, M., Cowger, L. and Barajas, L. 2006: The quest for authentic place: The production of suburban alternatives in Minnesota's St. Croix Valley. Urban Geography 27, 253-270.

Blaikie, P.M. and Brookfield, H.C. 1987: Land degradation and society. London; New York: Methuen.

Brogden, M.J. and Greenberg, J.B. 2003: The Fight for the West: A Political Ecology of Land Use Conflicts in Arizona. Human organization : journal of the Society for Applied Anthropology. 62, 289.

Bureau, U.S.C. 2009a: Population finder: Deschutes County, Oregon. U.S. Census Bureau.

Bureau, U.S.C. 2009b: Population finder: Wasco County, Oregon. U.S. Census Bureau.

Cheng, A.S., Kruger, L.E. and Daniels, S.E. 2003: "Place" as an Integrating Concept in Natural Resource Politics: Propositions for a Social Science Research Agenda. Society \& Natural Resources 16, 87-104.

DeStefano, S. and DeGraaf, R.M. 2003: Exploring the ecology of suburban wildlife. Frontiers in Ecology and the Environment 1, 95-101.

Duany, A., Plater-Zyberk, E. and Speck, J. 2000: Suburban nation : the rise of sprawl and the decline of the American Dream. New York: North Point Press.

Frentz, I.C., Farmer, F.L., Guldin, J.M. and Smith, K.G. 2004: Public Lands and Population Growth. SOCIETY AND NATURAL RESOURCES 17, 57-68.

Ghose, R. 2004: Big sky or big sprawl? Rural gentrification and the changing cultural landscape of Missoula, Montana. Urban Geography 25, 528-549.

Gosnell, H., Haggerty, J.H. and Travis, W.R. 2006: Ranchland Ownership Change in the Greater Yellowstone Ecosystem, 1990-2001: Implications for Conservation. Society \& Natural Resources 19, 743-758.

Halseth, G. 1998: Cottage country in transition : a social geography of change and contention in the rural-recreational countryside. Montreal; Ithaca: McGill-Queen's University Press. 
Harner, J. 2001: Place Identity and Copper Mining in Sonora, Mexico. Annals of the Association of American Geographers 91, 660-680.

Hurley, P.T., Halfacre, A.C., Levine, N.S. and Burke, M.K. 2008: Finding a "Disappearing" Nontimber Forest Resource: Using Grounded Visualization to Explore Urbanization Impacts on Sweetgrass Basketmaking in Greater Mt. Pleasant, South Carolina. Professional Geographer 60, 556-578.

Jackson, P.L. and Kuhlken, R. 2006: A rediscovered frontier : land use and resource issues in the new West. Lanham, Md.: Rowman \& Littlefield Publishers.

Johnson, C.Y., Halfacre, A.C. and Hurley, P.T. 2009: Resistant place identities in rural Charleston County, South Carolina: Cultural, environmental, and racial politics in the Sewee to Santee area. Hum. Ecol. Rev. Human Ecology Review 16, 1-16.

Johnson, E.A. and Klemens, M.W. Nature in fragments : the legacy of sprawl. New York: Columbia University Press.

Kaltenborn, B.P. 1999: Effects of sense of place on responses to environmental impacts: a study among residents in Svalbard in the Norwegian high Arctic. Sage Urban Studies Abstracts 27.

Larsen, L. and Harlan, S.L. 2006: Desert dreamscapes: Residential landscape preference and behavior. LANDSCAPE AND URBAN PLANNING 78, 85-100.

Larsen, S.C., Sorenson, C., McDermott, D., Long, J. and Post, C. 2007: Place perception and social interaction on an exurban landscape in central colorado. Professional Geographer $59,421-433$.

Larson, K.L., Harlan, S.L. and Yabiku, S.T. 2009: Residents' Yard Choices and Rationales in a Desert City: Social Priorities, Ecological Impacts, and Decision Tradeoffs. Environmental Management 44, 921-937.

McCann, E.J. 1995: Neotraditional Developments: The Anatomy of a New Urban Form. Urban geography. 16, 210.

McGranahan, D.A. 1999: Natural amenities drive rural population change. Washington, DC: U.S. Dept. of Agriculture, ERS.

Nassauer, J.I., Wang, Z. and Dayrell, E. 2009: What will the neighbors think? Cultural norms and ecological design. LANDSCAPE AND URBAN PLANNING 92, 282-292.

Nelson, P. 2006: Geographic perspectives on amenity migration across the USA: national-, regional-, and local-scale analysis. In Moss, L.A.G., editor, The amenity migrants: Seeking and sustaining mountains and their cultures, Cambridge, MA: CABI, 55-72 
Nelson, P.B. 2001: Rural restructuring in the American West: land use, family and class discourses. Journal of rural studies. 17, 395-407.

Reed, M. 2007: Uneven Environmental Management: A Canadian Perspective. Environmental Management 39, 30-49.

Robbins, P. 2004: Political ecology : a critical introduction. Malden, MA: Blackwell Pub.

Shumway, J.M. and Otterstrom, S.M. 2001: Spatial Patterns of Migration and Income Change in the Mountain West: The Dominance of Service-Based, Amenity-Rich Counties.

Professional Geographer 53, 492-502.

Smutny, G. 2002: Patterns of Growth and Change: Depicting the Impacts of Restructuring in Idaho. Professional Geographer 54, 438-453.

Stedman, R.C. 2003: Is It Really Just a Social Construction?: The Contribution of the Physical Environment to Sense of Place. Society \& Natural Resources 16, 671-685.

Stewart, W. 2008: Place Meanings in Stories of Lived Experience. UNITED STATES DEPARTMENT OF AGRICULTURE FOREST SERVICE GENERAL TECHNICAL REPORT PNW, 83-108.

Theobald, D.M. 2004: Placing Exurban Land-Use Change in a Human Modification Framework. Frontiers in Ecology and the Environment 2, 139-144.

Till, K.E. 2001: New Urbanism and Nature: Green Marketing and the Neotraditional Community. Urban geography. 22, 220.

Travis, W.R. 2007: New geographies of the American West : land use and the changing patterns of place. Washington, DC: Island Press.

Veninga, C. 2004: Spatial Prescriptions and Social Realities: New Urbanism and the Production of Northwest Landing. Urban geography. 25, 458.

Vias, A.C. and Carruthers, J.I. 2005: Regional Development and Land Use Change in the Rocky Mountain West, 1982-1997. Growth and Change 36, 244-272.

Walker, P. and Fortmann, L. 2003: Whose landscape? A political ecology of the 'exurban' Sierra. Cultural Geographies 10, 469-491.

Williams, D.R. and Stewart, S.I. 1998: Sense of Place: An Elusive Concept That Is Finding a Home in Ecosystem Management. Journal of forestry. 96, 18.

Zimmerer, K.S. 2000: The Reworking of Conservation Geographies: Nonequilibrium Landscapes and Nature-Society Hybrids. Annals of the Association of American Geographers 90, 356-369. 
Zimmerer, K.S. 2006: Globalization \& new geographies of conservation. Chicago: University of Chicago Press.

Zimmerman, J. 2001: The "Nature" of Urbanism on the New Urbanist Frontier: Sustainable Development, or Defense of the Suburban Dream? Urban geography. 22, 249. 


\section{Part Four: Techniques for Place-based Conservation}

Place-based planning does not necessarily imply the need for new techniques or revamping strategies for public involvement. Whereas some researchers start with the concept of place and derive planning process from the concept, others start with the traditional tools of landuse planners and fit the concept to adaptations of the tools. Such is the case with chapters of this section. These chapters recognize that maps are an essential element to ground land-use plans in the physical world, and because they are recognized as such, they form a common basis for dialogue amongst stakeholders. Geographic Information Systems (GIS) allow spatial information to be digitized and mapped for various kinds of analysis. Although the concept of place is embedded in frameworks of social construction, felt senses, and lived experiences, there are geographic groundings of place that emerge in the following chapters. Each chapter portrays a distinct technique and unique set of outcomes associated with the various adaptations of GIS to place-based planning.

Cacciapaglia and Yung adapted a participatory mapping technique to understand place meanings and their relationships to fire and fuel planning. Their technique involved individual conversations with stakeholders coupled with computer-based mapping exercises. When discussing their special places, stakeholders referred to specific sites and particular place meanings. However when questions were asked regarding fire planning, stakeholders' geographic scale of reference moved from site to landscape level place meanings. Private landowners could not divorce the place meaning of their property from the entire landscape, and addressed them as if they were one and the same.

McIntyre, Lesueur, and Moore elicit place meanings from local stakeholders in northwestern Ontario through coordination of focus groups and mapping. The second phase of 
their research employed a broad-based survey that resulted in mapping of the place meanings from the first phase in conjunction with a mapping of forest-based recreation activity. Their study recognizes some distinct qualities of managing Crown Lands in Canada, including the potential for disconnections between the policy-oriented federal Canadian Forest Service and the planning and operations handled by provincial governments. In particular, federal directives to manage for wilderness values were relegated to lower priority in some areas due to the provincial priorities that privilege place values related to harvesting timber. Their approach to participatory mapping elicited public dialogue on some of these disconnections, with implications for management to address the disconnections.

Using a relational marketing framework, Watson and colleagues also characterize a participatory mapping technique. Their technique emphasizes the development of long-term relations and trust building with stakeholders. Their study is conducted with stakeholders from the Flathead Indian Reservation in Western Montana, and recognizes the need to address the heavy accumulation of fuel build-up due to decades of fire suppression on tribal forests. Interviews coupled with the mapping exercises led to further clarification of the impacts of logging on places, the impacts of fire events on places, and the trade-offs between these two kinds of impacts as evaluated by tribal members. However maintaining trust between the land management agencies, the tribal council, and other tribal organizations was a significant outcome of the participatory mapping technique.

Although not employing a GIS technique per se, the community-based segmentation study conducted by Christensen and Burchfield is compatible with mapping analyses in that it promotes public dialogue about place and seeks compatibility amongst the place bonding of stakeholders. Christensen and Burchfield recommend their human / place bond procedures for 
employment in the early phases of land-use planning in order to breakdown stakeholder stereotypes, assess spatial arrangement of human / place bonds, and serve as basis for stakeholder dialogue about place attachment. The application of their study takes a seemingly polarized issue of off-road vehicle use on federal lands, and reveals multiple community segments. Although at first-blush appearing as dichotomous, the analysis portrayed a nuanced view of community from which to start collaborative efforts.

There is not any one strategy to fit place-based planning to traditional mapping or community segmentation techniques. Rather there are multiple paths that allow customization to the context of the site. They share in common a basis to foster public dialogue about place, to strengthen relationships amongst stakeholders due to the participatory exercises and depth of interaction, and hold promise to address multiple geographic scales for land-use management. 


\section{Participatory place mapping in fire planning}

\section{Michael Cacciapaglia and Laurie Yung}

The question of how to manage fire and fuels in ways that accomplish ecological and social goals is of growing importance. In many western forests, fuels have accumulated as a result of decades of fire suppression. Higher fuel loads can increase the risk of catastrophic or stand replacing fire. Climate change may increase both the frequency and intensity of fires in the west. At the same time, rural residential development within forested landscapes has expanded and forest landowners living in the wildland urban interface (WUI) are disproportionately impacted by fire and fuel treatment. Forest fires and fuel management can affect the economic resources, scenic views, and private property. As local communities are brought into the conversation about the management of nearby forests, it is particularly important to understand the views of forest landowners on the management of fire and fuels. Place may provide an important window into landowner views on environmental change and proposed management actions as they relate to fire and fuels.

In this chapter, we explore the potential of participatory mapping to link place to decision-making. We describe a study on the Kootenai National Forest in northwest Montana which utilized in-depth interviews and a computer-based participatory mapping exercise to understand landowner place meanings, and the relationship between these meanings and views on fire and fuel management. We hoped to demonstrate that management preferences were different for places that landowners identified as particularly important. While we found important connections between place and management preferences, these connections were in many ways contrary to prior research on place. Below we examine the implications of these 
findings for decision-makers interested in using place research in planning and management, and for researchers or decision-makers using participatory mapping exercises.

\section{From Place Research to Participatory Mapping}

As described earlier in this book, the building blocks of people's relationship with place are place meanings. However, such meanings are not necessarily shared or agreed upon. Even in small, rural communities, there are multiple and sometimes competing views (Belsky 2002; DuPruis \& Vandergeest 1996). Thus, place meanings are part of a broader sociopolitical landscape characterized by agreement and difference, shared and contested ideas, and, in the case of fire and fuel management in the west, conflict over natural resource management.

To the extent that decisions about fire and fuels are site specific (e.g. the decision to thin a specific stand of trees or to conduct prescribed burning on a hillside), understanding site specific place meanings or special places may be critical. Schroeder (2002) described special places:

When people have highly valued aesthetic and emotional experiences in specific places...these places...take on particular importance for them and become "special places." People become attached to such places.

In 2004, Schroeder suggested that understanding special places could help managers protect the qualities that people valued in particular locations on the landscape.

Despite extensive research and improved understanding of place meanings and special places, place research typically does not examine how people's relationships to place are related to specific management actions. Thus researchers often cannot draw direct conclusions about how documented place meanings relate to different management options. Far too often, researchers and decision-makers make "logical," but unfounded assumptions about the 
relationship between place meanings and proposed management actions. They assume that particular place meanings are threatened by particular management actions (or that the place meanings themselves influence views on particular management actions). But many questions remain. If a particular campsite is important to local residents, should it be protected from catastrophic fire through thinning? If a beautiful scenic view is important to tourists, should managers attempt to maintain that landscape in its current condition? We need to better understand if, how, and under what conditions place meanings are related to views on a range of management actions, from forest thinning to ski resort development.

Participatory mapping provides a method to link people's views on place with their ideas about specific management proposals, and to specifically examine how they relate spatially. Mapping has become increasingly important in place research because it provides a window into the spatial nature of place meanings and a way to represent such meanings visually. Geospatial data, usually in the form of geographic information systems (GIS) maps, has become a critical component of natural resource decision-making. However, to date, social scientists have struggled to capture complex and nuanced social data in such formats. Furthermore, because of the technical expertise it demands, GIS is oftentimes an inaccessible technology and is thus difficult to utilize to engage the public. But, if social data, such as place meanings, can be adequately represented in a visual format, such data might be more accessible to a range of interested parties. Specifically, participatory GIS exercises could be incorporated into NEPAmandated public involvement processes. Alternatively, collaborative groups could employ participatory mapping as they actively negotiate how they envision proposed projects actually happening on the ground. Oftentimes a visual aid such as a map will elicit different reactions and clarify important ambiguities present in abstract group discussion of inherently concrete 
phenomena. Some place researchers have suggested that such interactions can contribute to mutual learning, trust building, and much more (Carver 2003, Williams 1995, Gunderson et al. 2004).

In the past two decades, mapping tools have been used to understand the spatial components of public views, to study public opinion about the placement of nuclear waste (Evans et al, 2004), preferences for conservation and tourism development (Raymond and Brown, 2007), manager views of ecosystem services (Raymond et al, 2009), and support for legislation on national scenic byways (Brown, 2003). Early efforts involved working with pencils or markers and paper maps (see Gunderson and Watson 2007) or placing stickers-dots on maps to represent various environmental values (see Brown 2006). Gradually, these methods have given way to digital mapping techniques. Brown (2006) continues to advance the landscape values/sticker-dot methods, now in digital form, while McIntyre and others (Yuan et al. 2004) have developed a mapping process using GIS points and polygons. Carver and collaborators have developed computer-based programs that allow participants to paint locations with a spray can tool and describe their importance (see Carver et al, 2009). As transdisciplinary work becomes more common and GIS technology becomes more accessible, efforts to map supposedly qualitative data in quantitative ways will no doubt continue.

The research described herein was the third iteration of a larger research program focused on mapping place meanings to better understand local views on fire, fuels, and wilderness. An initial study was conducted by Gunderson and Watson (2007) and focused on paper and pencil mapping to understand residents' relationship with the Selway-Bitterroot Wilderness in Montana. In the second iteration of this study, described in the next chapter, Watson and collaborators investigated place meanings and the threats to these meanings by fire and fuel 
reductions on the Flathead Reservation in western Montana utilizing an adaptation of Carver's computer-based mapping method (described in more detail below).

\section{Fire and Fuel Management on the Kootenai National Forest}

Fuel build-up and the expansion of rural residential development, combined with prolonged drought and the risk of high intensity, stand-replacing fires have pushed the issue of fire to the forefront in Western rural communities. The 2000 National Fire Plan suggests that federal agencies and local governments "respond to...severe fires, reduce the impacts of these wildland fires on rural communities, [and] reduce immediate hazards to communities in the wildland-urban interface" (USDA/USDI 2000: 1). The plan included two mandates directly aimed at increasing local participation: 1) Invest in Projects to Reduce Fire Risk, and 2) Work Directly with Communities. These mandates emphasize achieving community protection through hazardous fuel reductions and collaboration between managers and stakeholders.

Volumes of research have been produced concerning the economic and ecological aspects of fire (Agee 1993; Arno \& Allison-Bunnell 2002). By comparison much less research has focused on the social and cultural aspects of wildland fire. But, according to Daniel et. al. (2003) "support for fuel reduction strategies hinges on public perception and evaluation of a complex set of tradeoffs among uncertain and potentially conflicting values" (36), including "fire safety and aesthetic/amenity values" (42).

Much of the fire social science research has focused on the aesthetic values of forest landowners. Previous literature has established that WUI landowners often preference their landscape aesthetics over fire hazard reduction on their own property (Daniel et al. 2003; Winter et al. 2000). Nelson et. al. (2005) found that homeowners in Minnesota and Florida managed trade-offs between a wide array of values including "naturalness, aesthetics, wildlife 
considerations, recreation and privacy" (178) when making decisions about managing their own property for fire safety. Many landowners who favored thinning on public lands did not favor thinning on their own property because of specific aesthetic ideals. This seeming contradiction is well documented in the literature (Daniel et al. 2003; Vogt 2003; Winter \& Fried 2000).

Beyond aesthetics, previous research has linked community-landscape relationships, including place concepts, and perspectives on fire and fuels. Gunderson et. al (2004) found that that local people held functional and emotional attachments for forest places, and that community place attachments were at risk from fire and fuels treatments that alter the landscape. Watson et al (2008) indicated that a wide range of social and ecological factors contribute to individual and community place meanings, and that some these meanings were threatened by certain types of fire.

The study described here was conducted in the rural, forested community of Libby, Montana, which lies within the Kootenai National Forest (KNF). The Cabinet Mountains Wilderness (CMW) rises sharply at the KNF's southern end. Within miles of Libby, the Cabinet Range descends steeply into heavily forested foothills. The Cabinet landscape includes wilderness and roadless areas as well as areas managed for multiple uses, including some timber production. National Forest lands gradually phase into clusters of rural residential development and some isolated homes completely ensconced by the National Forest lands. The WUI lies here, where these private parcels adjoin and intersperse public and private forest lands.

Like many rural communities across the West, the economy of Libby was historically based on extraction of natural resources. Namely, the industries of mining and logging dominated in the past. Now the region is transitioning to a more diverse economy where extractive natural resource industries play a smaller role. Service industries, such as tourism and 
outdoor recreation, are being endorsed by some residents and organizations within the Libby community. However, this vision does not represent the views of many residents who still rely on and champion the traditional livelihoods based on timber and ore. Because of these competing views on natural resource use and public lands management, local views on fire and fuel management in the WUI vary considerably, and land managers have the difficult job of negotiating the interests and needs of different groups. Conflict over management of public lands has figured prominently in local politics. If decision-makers can better understand the residents' relationships with place, they may be able to work through such conflict and achieve more desirable management results for all stakeholders.

\section{Integrating Participatory Mapping into Qualitative Interviews}

To better understand the meanings and views of local landowners, the first author conducted in-depth, semi-structured interviews during the summer of 2007. The qualitative method of extended interviews was chosen to gain insight into complex place meanings and views on fire and fuel management, and connections between the two. This study focused on the population of forest landowners living in the WUI near Libby. A forest landowner was defined as an individual or family who own a parcel of forested land adjacent to or within close proximity ( $<1$ mile) of the Kootenai National Forest. In total, 29 interviews were conducted with 37 participants. Seven married couples were interviewed together, as were one landowner and his property manager. A diverse sample was achieved by using nonprobability, purposive sampling that included landowners who varied in length of residence, gender, age, political affiliation, ethnicity, and occupation. An interview guide ensured that interviews were systematic and that data was relevant and comparable across interviews, while also allowing for 
unanticipated topics to emerge. Interview questions focused on landowner relationships with specific sites and with the landscape as a whole. Landowners were also asked about wildland fire and hazardous fuel management.

After detailed discussion of place meanings and views on fire and fuels, landowners completed a computer-based mapping exercise. This mapping exercise was adapted from the Tagger mapping program developed by Carver et al (2002) and described in more detail in the following chapter by Watson et al. This mapping program aims to capture "fuzzy" boundaries, rather than the points, lines, and polygons commonly employed in GIS-based mapping, by using a "spray can" tool which allows participants to mark locations on the map by "painting" them with bright colors. Participants can create marks that vary in size and shape. In the mapping exercise employed for this project, participants could mark specific locations on a large map that included topographic features, landownership, and human developments, or utilize a small inset map to efficiently "paint" the entire landscape (see Figure 1).

The mapping exercise first required landowners to mark important places on a map and describe why those places were important. Landowners could mark specific locations or identify the entire landscape as important. Landowners could make multiple maps, identifying locations important for different reasons. Landowners made from one to eight maps, with an average of 3.25 maps. Participants were able to select for "intensity" as indicated by the very important, important, and somewhat important options, but almost universally selected very important for the duration of the mapping exercise.

After mapping important places, landowners were asked to mark locations where three different fire and fuel management options were unacceptable. The three management options were 1) wildland fire use, 2) prescribed fire, and 3) mechanical thinning. Participants were 
provided with descriptions of each of these options using lay terminology and standard Forest Service definitions. Landowners then created three maps related to fire and fuels, identifying those locations where each of the three management options was unacceptable. Because this mapping exercise was embedded in an in-person interview, landowners verbally described why specific places were important or why specific fuel treatments were unacceptable in particular locations (unlike the mapping exercise described by Watson et al in the next chapter which required participants to describe or "tag" locations on the map by writing text in a box on the computer).

This mapping exercise allowed researchers to better understand the spatial dimensions of landowners' place meanings and their preferences for fire and fuel management. The exercise also served as an elicitation tool, deepening the dialogue between the first author and participating landowners by allowing them to visually represent and spatially delineate their place meanings and management preferences. We hoped, at the outset of the project, that maps would also demonstrate a spatial relationship between special places (or site specific meanings) and views on fire and fuels. In other words, we set out to provide evidence for the hypothesis that understanding special places would help managers understand which management actions might be supported or opposed. We also wanted to assess the ability of the mapping exercise to meaningfully represent the social data in a visual format. We wanted to know if people's place meanings could be represented spatially in a way that captured the complexity of such meanings and provided accessible GIS data to managers. Because the mapping exercise was embedded in a qualitative interview, we could evaluate what we learned from the conventional portion of the interview versus the mapping exercise versus the two combined. 
Figure 1. Computer-Based Mapping Exercise

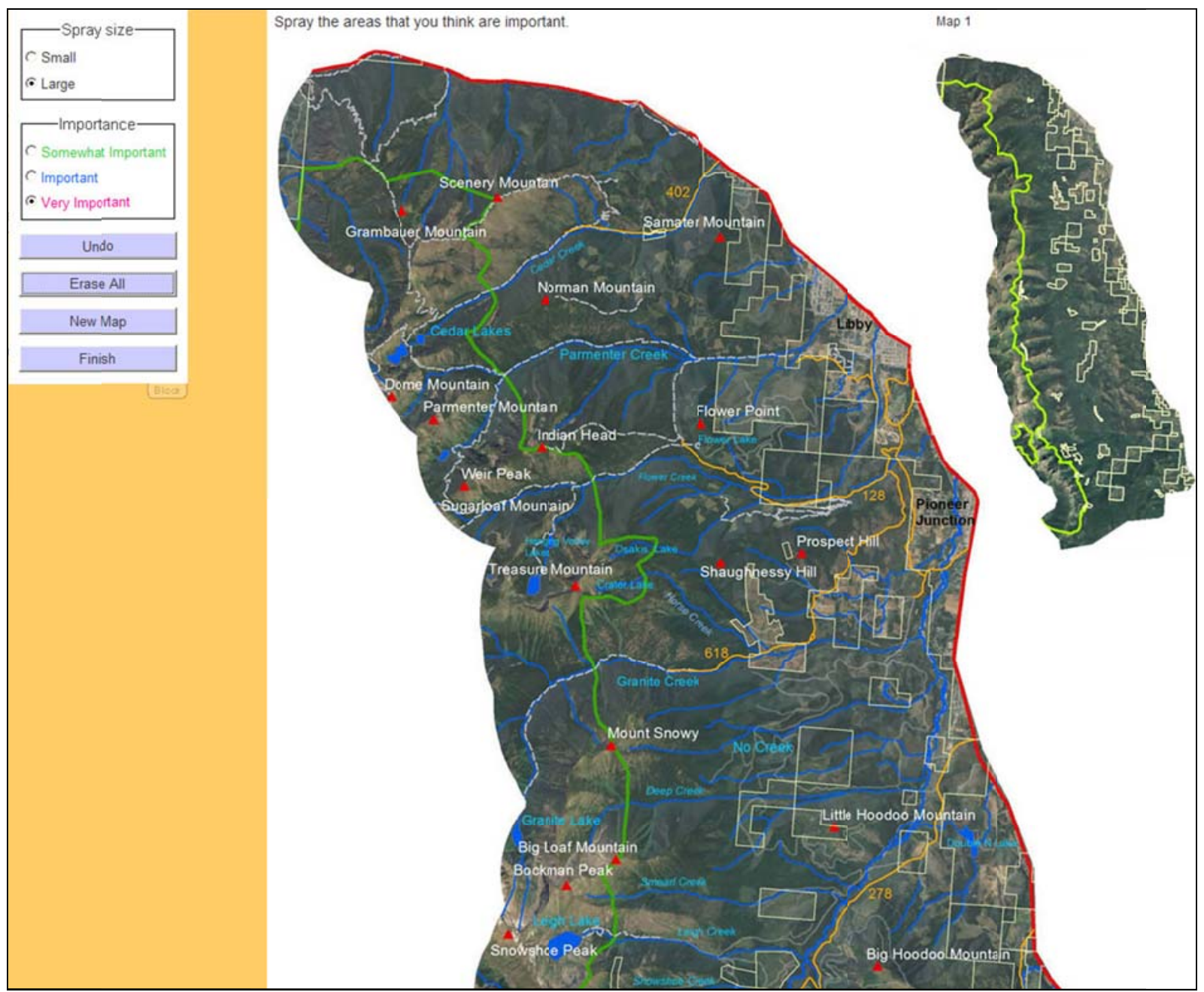

\section{Connecting Place Meanings and Fire and Fuels Preferences: Why Scale Matters}

As described above, we expected that understanding site specific place meanings (special places) would enable us to better understand site specific fire and fuel management preferences. In other words, we imagined that place meanings and management preferences would be linked spatially, and that mapping data would therefore provide managers with insights into how to use place research in decisions about fire and fuels. We did, in fact, find that place meanings and 
views fire and fuel management were connected, but not necessarily at the scale suggested by previous research. Research results indicated that landowner place meanings operated on different scales ranging from site-specific "special places" to the entire landscape, but that landowner views on fire and fuel management were almost exclusively situated at the landscape scale. Furthermore, management preferences were not connected to special places. Rather, landowner preferences for fire and fuel management were related to landscape-scale place meanings. These findings, described in more detail below, have important implications for how place research can be applied to decision-making.

\section{Special Places: Their Importance and Unimportance}

Landowners in this study described and mapped special places, often in great detail, but ultimately argued that the entire landscape was more important than specific sites. Landowners described place meanings at multiple scales, from the very discreet, such as a particular stand of blue spruce trees, to the very broad, such as the entire Cabinet Mountains range. Landowners marked their special places on the map, sometimes meticulously, and discussed them in great detail, often relating very personal stories, experiences, and memories. While a range of special places were described, these special places fit into four general categories: 1) personal home and land, 2) recreational areas, 3) scenic views, and 4) hunting and gathering areas. For example, one landowner described his huckleberry gathering activities in great detail, as this activity was both an annual rite and part of "living traditionally." He says:

Well, it's all important to me. But up in the Scenery Mountain country, this is all really important, because at one time this used to be really good huckleberrying right in here. And in Cedar Lakes it still is... My family is old-time huckleberries. I probably know more about huckleberries than most people in the world. (L31) 
These places and the activities he associates with them hold great significance through memories, stories, and subsistence as huckleberry harvesting was something that he did all throughout his life with his family. He went on to discuss how the gathering ritual connected him to both his cultural heritage and the land. Through gathering huckleberries he came to know the land quite well, which is reflected in the incredible detail he has provided by marking so many individual locations. This level of detail in mapping and describing special places was very common among landowners.

Landowners attached multiple meanings to specific areas, as these special places were the sites of annual getaways, family events, important memories, subsistence resources, and environmental values. Previous research on special places suggests that people's attachments to particular locations are connected to their preferences for management actions in those locations (Gunderson at al 2004, Moore and Scott 2003, Schroeder 2002). It follows that a special place, as a bounded physical unit, might be a tangible factor which could be easily accounted for in a land management strategy. However, in this study that did not turn out to be the case.

While small scale special places were important, landowners repeatedly cautioned the interviewer against overemphasizing specific sites. When the landowner above began to describe his special huckleberry spots, he said: "Well, it's all important to me." Before that landowner would talk about the specific importance of huckleberries, he had to state that the whole landscape was important to him. This sentiment was echoed in by most landowners. In other words, landowners were willing to create individual maps of special places but would always remind the interviewer that "the whole thing" was tantamount. To bring this point home, many landowners created maps to demonstrate the importance of the entire Cabinet Mountains and 
their broad attachment to this landscape. When asked how her special places influenced her ideas about management, this landowner said:

Well, it is [all important], because everything is part of the whole. You can't look at it... I mean, you can. Of course you can analyze different areas. But everything is related to everything else. And it all has to be important. We can't just have this microbe focus on one, little area without taking everything into consideration.

Some landowners actually resisted identifying specific spatial locations as any more or less important than the entire landscape. Instead, they asserted that an expanded focus on the whole landscape was required even though they could identify specific special places if prompted to do so. They concluded that, while their favorite locations were important to them, management agencies must take a broader view of the whole landscape.

This landowner, new to the area, admitted that, while she enjoyed occasional recreational outings, she placed emphasis on the importance of just living in the forest rather than knowing it all directly. When probed about her special places, she responded:

You can't single out a specific area in my mind that's better than another. It's all part of the package...It's all really important. I don't want to give it a lesser degree and say, well my place is more important and just, you know, 20 miles around is important. No, it's all important. It's all home...I can't say that I only want to take care of my spot, I don't care what happens to the rest. That's just so irresponsible to me.

Landowners overwhelmingly related to the Cabinet Mountains as a whole landscape, despite their willingness to describe and map special places.

\section{Fire and Fuels Preferences and Landscape Scale Place Meanings}

In the preceding section we showed that while landowners related to the landscape at a number of geophysical scales from the bounded to the broad and could readily map and describe site specific special places in detail, they repeatedly suggested that the entire landscape was the 
important scale to consider. Similarly, nearly all landowners situated their preferences regarding fire and fuel management at the landscape-level, rather than describing preferences for particular locations. Many landowners talked about not holding spatially specific preferences, and did not map in any level of detail. For example, when asked to map the locations where he thinks mechanical fuel reduction (thinning) is unacceptable, this long-term resident said:

I don't think that I could say this mile wide band on my [property] perimeter is more important than what's up adjacent to the dam. It's not any more important than the whole thing. When I talk about that they need to be managing "it", "it" is all of it. They need to start managing the whole thing [the whole National Forest]. And this piece [indicating his private property] isn't any more important to me than beyond that.

This landowner could not conceive of divorcing his private property from the entire Cabinet landscape in his thinking about fire and fuel management. The notion that one person would expect management to accommodate his personal special place seemed offensive to him and his ideas of community responsibility and stewardship. He instead described the need for management that accounts for the whole landscape. This response was common among landowners in this study.

To explain their management preferences, landowners drew on complex sets of meanings, values, interests, and ideologies. Ideas about aesthetics, appropriate use of resources, the meaning of stewardship, and the human role in nature intermingled in two distinct narratives about the Cabinet landscapes, one which emphasized a working forest and resource use, and another which focused on natural processes and non-commodity values. Landowners who describe the Cabinets as a working landscape privileged economic interests and resource use. They argued that human are stewards who have dominion over the forest and a responsibility to actively manage and benefit from natural resources. Allowing wildland fire or prescribed fires to burn was seen as a violation of these responsibilities. In the following excerpts, landowners 
explain the maps that depict their opposition to prescribed fire and wildland fire use (opposition depicted at the landscape scale).

I think that's poor management. We're stewards of the land. If we weren't going to be stewards of the land, then we shouldn't be here, and we should just let nature take its course. But we are. We live here, and we have a responsibility. (L5)

But I think [not thinning and allowing trees to burn] is wasting resources. And in wasting the resources, you also allow the ground fuels to accumulate and so when you do have the fires, they're just that much worse. It needs to be harvested rather than wasted. (L4)

The working forest narrative emphasized the notion that resource extraction is the most appropriate use of the forest, the aesthetic appeal of "park-like" stands with widely-spaced, and that idea that fire is generally "bad." Thinning was mapped and described as the most acceptable avenue for fuel reductions because it provides "jobs in the woods," useable timber products, and fire protection.

By contrast, a smaller but significant portion of landowners described the Cabinets landscape as a natural forest. Although many newcomers subscribed to this narrative, it was also described by some long-time landowners. These landowners described the forest as a landscape with its own intrinsic value, emphasizing wildlife and other ecological values. Appropriate use of the forest by humans was most often confined to recreational and aesthetic enjoyment, rather than commercial extraction of resources. Fire was described as generally "good," "natural," and "part of the ecosystem." Below, landowners connect their views on fire and fuel management to notions of the Cabinets as a natural landscape.

I have a really hard time with thinning by machine in that I have little faith in the system. I wonder what that really means to the animals and to the rest of the terrain when they go in and thin. The idea of it is probably nice. But I wonder what the reality of it is. I'd say it's unacceptable. Just as a general thing. I don't have specific places. (L29) 
I have no problem with burning as a practice. That's necessary. It's natural, and it needs to be utilized...I think that's appropriate because fire is a natural part of the ecological cycle so I have no problem with it at all. (L18)

These landowners also emphasized stewardship, but envisioned appropriate stewardship as generally "hands-off," suggesting that humans should not interfere in ecological systems. For

these landowners, thinning was seen as intrusive, and controlled burning and/or wildland fire use were preferred for their "regenerative" effect and because they "restore the balance of nature." Natural landscape landowners preferred a "natural" or "pristine" look to the forest (i.e. unmanaged) without overt signs of human activity.

Landowners drew on fundamental ideas about how humans interact with nature to explain what types of human management of fire and fuels were acceptable to them. In doing so, they described two competing narratives, the natural and working landscapes, which wove together meanings, values, interests, and ideologies to explain management preferences. Thus, these landscape narratives are much more than descriptions of a place; they are both embedded in and contain ideas about what is proper use and management of the forest and its resources. Although special places play a role in landowners' relationship with the Cabinet Mountains landscape, these site-specific places were not invoked when landowners described their fire and fuel management preferences. Instead, landowners connected management preferences to landscape-scale narratives of place.

\section{Improving Connections between Place Research and Decision-Making}

\section{Resident Adaptability: Rethinking Special Places}

We often assume that relationships with special places are of paramount concern when people consider proposed management actions. In describing the relationship between special 
places and forest management, Schroeder (2002) stated that "When a person's "special place" is lost or altered by a human action such as a timber harvest... or by a sudden natural change such as a fire... the person may experience intense emotions such as grief and anger" (p. 12).

Similarly, a Forest Service employee interviewed for this project suggested that local support for fuel reduction would be dramatically impacted by people's passion for special places. According to her, large scale fuel reductions would be necessary to protect landowners and the community of Libby from large, intense fires. But, she argued that "The likelihood of that ever happening is pretty low because you're getting into that very special area that people are pretty passionate about." Both researchers and managers imagine a strong and direct link between special places and responses to management actions and environmental change.

In this study, we found that relationships with special places, while important to landowners, had little bearing on landowner preferences for fire and fuel management. Very few landowners felt strongly about proposed alterations to their special places. Instead, most were very willing to accept change in their special places, acknowledging with equanimity that such change is an inevitable and integral part of the forest landscape. Several landowners maintained that their places will remain special even in the face of dramatic ecological and aesthetic change (such as fire) or significant management intervention (such as fuel reduction). Others said that they would find new special places if fire destroyed the old ones, indicating that, in certain situations, special places may actually be substitutable. Rarely did a forest landowner in this study conclude that their special places should be accommodated by a fire management decision.

Differences between residents and visitors might explain why this study's conclusions contradict much of the literature on special places. Previous studies on special places have focused largely on recreationists, who might have different kinds of attachments to specific 
geographic locations. The relationships that recreationists have with special places may be more salient because, at least some cases, recreationists only experience the landscape in a limited set of locations. Thus, those locations may be particularly important repositories of meaning and memory. Residents, in contrast, experience many different locations on the landscape and they have multiple relationships with these locations, including, but not limited to recreation relationships. Thus, for residents, place meanings may be connected to larger number of geographic sites and these meanings may be more diverse, drawing from recreational use during different seasons, from views on community history and agency management, and from livelihood needs. Furthermore, landowners who reside in the WUI are directly affected by National Forest management and experience such management on a daily basis, suggesting another factor that might influence relationships with place. Finally, because fire and fuel management is such an important local issue, landowners may simply prioritize such management actions over personal needs associated with special places.

The lesson here is that the relationship between place and management decisions may be highly contextualized. The population of interest might differ, as we suggested for recreationists and residents. The management issue, such fire, water quality, or wildlife habitat, might change the way place meanings interact with management preferences.

\section{It Could be the Forest, Not the Trees: Avoiding a Scalar Mismatch}

We often assume that a variety of social phenomena operate at the same scale, including place meanings and public views on management actions. As described above, past research has suggested that understanding how people view special places on the landscape will help managers understand which management actions will be acceptable in which locations. Because 
place situates social phenomenon in geographical space, the place concept demands that we think more carefully about the role of scale and how different scales interact.

In this study, landowner preferences for fire and fuel management were situated almost exclusively at the landscape scale and were not related to special places. Instead, management preferences were connected to meanings that landowners explicitly situated at the landscape scale. In other words, the stories that landowners told about the Cabinets landscape as a whole and about their relationship with this landscape, which together revealed the meanings, values, and interests associated with the area, were closely connected to views on fire and fuels.

There existed, in this study, a mismatch in scale between special places and management preferences, which was revealed in large part through the mapping exercise. Getting scale "right" is critically important to management, especially for public lands managers engaged in project planning at multiple scales, from site specific treatments to landscape level restoration. In certain situations, if decision-makers are not alert to a potential mismatch, they might rely on information about special places to guide decision-making, thus missing the social phenomena most relevant to management preferences. In the Cabinet Mountains area, a hazardous fuel management decision based on accommodating special places would have overlooked the values and interests that were actually linked to landowner preferences for fuel treatments. This sort of scalar mismatch would have resulted in inaccurate conclusions about public views of different fire and fuel management options. Instead of effectively integrating local views into decisionmaking, getting the scale wrong might have increased local conflict or public opposition to National Forest management efforts.

Decision-makers and researchers need to be attentive to place meanings that operate at different scales, and choose the appropriate scale to lend insight into the management issue of 
interest. We also need to recognize that not all management preferences will be tied to specific locations on the forest; some management preferences are instead tied to broad values and interests that people apply to the entire landscape, ideas about proper forest management and resource use, local economies and decision-making, and the meaning of stewardship.

\section{Using Participatory Mapping to Understand Local Views}

Social mapping, or the spatial representation of values, views, and interests on GIS-based maps for inclusion in decision-making, is increasingly popular. As federal, state, and local agencies work towards greater civic participation and democratization, tools such as participatory mapping of social data may become an important part of planning. If social data, such as data on relationships to place, can be adequately represented on GIS maps, then decisionmakers might be able to integrate such data with biophysical data.

In this study, participatory mapping provided additional insights beyond traditional interviews. First, the mapping exercise provided an important elicitation tool, deepening the discussions of place and fire and fuels. Second, the mapping exercise was critical in understanding the issues of scale described just above. The scalar mismatch between site specific special places and the "location" of management preferences could easily be overlooked by a mapping process that privileged site-specific phenomena such as special places. Thus, in order to capture the social phenomena most relevant to the decision at hand, it is important that mapping exercises allow participants to identify locations at a variety of scales.

Because this mapping exercise was part of a qualitative interview and because participants were able to comment directly on the mapping exercise, suggesting the ways in which it did or did not effectively capture their views, we were able to assess the effectiveness of 
mapping in capturing the complexity of social views. While the maps added to the interview, the maps alone did not adequately capture or represent the rich detail of place meanings or the complexity of views on fire and fuels. Thus, mapping cannot be seen as a substitute for other types of social research; it is not a quick method for obtaining the same information in a handy GIS format. Maps of special places may only capture certain components of individuals' and communities' complex relationships with places. By attempting to get place research into planning via mapping, decision-makers may paradoxically run the risk of reducing the complexity of local relationships, the complexity that makes these relationships so important in the first place. Decision-makers need to include more than just maps of social data to truly understand public views on proposed management actions.

\section{Conclusion}

Participatory mapping provides an important mechanism for linking place to decisionmaking. However, to realize the potential of participatory mapping, researchers must be attentive to issues of scale and how place meanings fit into the larger sociopolitical landscape. To fully integrate the lived experiences, stories, values, and interests of stakeholders, mapping should be combined with other methods of gathering social data, and mapping results must be understood within the context of a broader program of social research.

\section{Acknowledgements}

We would like to thank all of the landowners in Libby, Montana who generously donated their time for this project. This research was funded by the USDA Forest Service Rocky Mountain Research Station, the Aldo Leopold Wilderness Research Institute, and the National Fire Plan. 


\section{References}

Agee, J. K. (1993). Fire Ecology of Pacific Northwest Forests. Washington, D.C.: Island Press.

Arno, S. F., \& Allison-Bunnell, S. (2002). Flames in Our Forest: Disaster or Renewal? Washington, D.C.: Island Press.

Belsky, J. M. (2002). Beyond the natural resource and environmental sociology divide: Insights from a transdisciplinary perspective. Society \& Natural Resources, 15(3), 269-280.

Brown, G. (2006). Mapping Landscape Values and Development Preferences: a Method for Tourism and Residential Planning. International Journal of Tourism Research, 8, 101113.

Brown, G. 2003. A method for assessing highway qualities to integrate values in highway planning. Journal of Transport Geography 11(4):271-283.

Carver, S., Evans, A., and S. Fritz. 2002. Wilderness attribute mapping in the United Kingdom. International Journal of Wilderness 8(1):24-29.

Carver, S. 2003. The future of participatory approaches using geographic information: Developing a research agenda for the 21st Century. URISA Journal 15(1):61-71.

Carver, S., Watson, A., Waters, T., Matt, R., Gunderson, K. and B. Davis. 2009. Developing computer-based participatory approaches to mapping landscape values for landscape and resource management. In Planning support systems best practice and new methods, eds. S. Geertman and J.C.H. Stillwell, pp. 431-448. GeoJournal Library, Vol. 95. Springer.

Daniel, T. C., Weidemann, E., \& Hines, D. (2003). Assessing public tradeoffs between fire hazard and scenic beauty in the wildland-urban interface. Bloomington, IN: North Central Research Station, USFS.

DuPruis, E. M., \& Vandergeest, P. (1996). Introduction. In P. Vandergeest \& E. M. DuPruis (Eds.), Creating the Countryside: The Politics of Rural and Environmental Discourse (pp. 1-25). Philadelphia: Temple University Press.

Evans, A.J., Kingston, R. and S. Carver. 2004. Democratic input into the nuclear waste disposal problem: The influence of geographical data on decision making examined through a Web-based GIS. Journal of Geographic Systems 6:117-132.

Gunderson, K., and A. Watson. 2007. Understanding place meanings on the Bitterroot National Forest. Society \& Natural Resources 20:705-721.

Gunderson, K., Watson, A., Nelson, A., \& Titre, J. (2004). Mapping place meanings on the Bitterroot National Forest - A landscape-level assessment of personal and community values as input to fuel hazard reduction treatments. BEMRP Research Project Summary, 
on file with the Bitterroot Ecosystem Management Research Project, USDA FOrest Service, Rocky Mountain Research Station.

Moore, R. L., and D. Scott. 2003. Place attachment and context: Comparing a park and a trail within. Forest Science 49(6):877-884.

Nelson, K. C., Monroe, M. C., \& Johnson, J. F. (2005). The Look of the Land: Homeowner Landscape Management and Wildfire Preparedness in Minnesota and Florida. Society \& Natural Resources, 18(4), 321-336.

Raymond, C. and G. Brown. 2007. A spatial method for assessing resident and visitor attitudes towards tourism growth and development. Journal of Sustainable Tourism 5:122.

Raymond, C.M., Bryan, B.A., MacDonald, D.H., Cast, A., Starthearn, S., Grandgirard, A., and T. Kavilas. 2009. Mapping community values for natural capital and ecosystem services. Ecological Economics 68:1301-1315.

Schroeder, H.W. 2002. Experiencing nature in special places: Surveys in the North-Central Region. Journal of Forestry 100(5):8-14.

USDA/USDI. (2000). Managing the impact of wildfires on communities and the environment: A report to the President in response to the wildfires of 2000 (National Fire Plan). . Washington, D.C.

Vogt, C. (2003). Seasonal and Permanent Home Owner's Past Experiences and Approval of Fuels Reduction. Bloomington, IN: North Central Research Station, USFS.

Watson, A., Matt, R., Waters, T., Gunderson, K., Carver, S., and B. Davis. 2008. Mapping tradeoffs in values at risk in the interface between wilderness and non-wilderness lands. PSW-GTR-19x.

Williams, D. R. 1995. Mapping place meanings for ecosystem management. Walla Walla, WA: U.S. Department of Agriculture, Forest Service, Interior Columbia River Basin Ecosystem Management Project.

Winter, G., \& Fried, J. S. (2000). Homeowner Perspectives on Fire Hazard, Responsibility, and Management Strategies at the Wildland-Urban Interface. Society \& Natural Resources, 13(1), 33-49.

Winter, G. F., Vogt, C., \& Fried, J. S. (2000). Fuel Treatments at the Wildland-Urban Interface: Common Concerns in Diverse Regions. Journal of Forestry, 100(1), 15-21.

Yuan, M., McIntyre, N., Payne, R. J., \& Moore, J. (2004). Development of a spatial values-based recreation planning framework for Canadian Crown Lands. In Working papers of the Finnish Forest Research Institute 2 (pp. 93-99) (pp. 93-99). Helsinki, Finland: Finnish Forest Research Institute. 


\section{Participatory mapping of place values in northwestern Ontario}

Norman McIntyre, Perrine Lesueur \& Jeff Moore

Some researchers (e.g., Farnum \& Kruger, 2008) have argued that place-based planning approaches to natural resource management have become more popular in recent years In part, this has arisen as a result of increased involvement of planners and managers in communitybased collaborative partnerships which has encouraged a move away from traditional "one-suitfit-all" planning models (McIntyre, Moore, \& Yuan, 2008). Place-based planning approaches are focused on specific planning contexts and are collaborative in that, they recognise that people form strong bonds to places and want to be involved in influencing the future direction of change in such places.

Maps and mapping have traditionally been a major means of representing resource inventories in natural resources planning, most particularly in the case of biophysical and recreational use characteristics (e.g., forest types, topography, recreation sites). The rapid growth in availability and reduced cost of Geographic Information Systems (GIS) technologies have enabled the extension of spatial representation to a broad range of contexts beyond the traditional areas of geography and demographics (Steinberg \& Steinberg, 2006). Most recently, the development of internet-based GIS has further extended the scope and possibilities for various publics to be involved in community-based planning (Carver, et al., 2001) or what has come to be called "public participation GIS" (PPGIS). These new technologies have enabled experimentation with various web-based approaches to eliciting and mapping a wide variety of social data from neighbourhood regeneration (Kingston, 2007) to environmental issues (Evans, Kingston, \& Carver, 2004). 
Despite these technological developments, major impediments persist to the integration of social data into natural resource planning notably, the reluctance of social scientists to collect and represent such data spatially (McIntyre, et al., 2008; Williams, 2008) and attitudinal and legislative constraints to recognising the legitimate contribution of such 'soft' data to enhancing public input (Farnum \& Reed, 2008). Beyond this, a number of broader theoretical and practical challenges are involved in eliciting and spatially representing place values to better represent in decision-making the "emotional ties and feelings of connectedness that people have for places" Farnum \& Kruger, 2008: 2). These issues can be summarised in the following four questions: a) how are place values conceptualised; b) how are place values elicited; c) how are place values represented spatially; and d) how are place values incorporated into decision-making? This chapter focuses on our approach to these issues in the context of a study of the values residents attach to the boreal forest landscape of north-western Ontario, Canada. How are place values conceptualised?

The work of Brown (1984) on values has provided a basis for a common understanding of the concept in natural resource management (More, Averill, \& Stevens, 1996). He focused on a preference-related view of values which is useful in natural resource contexts in that much of the contestation surrounding recreational use centres on one value (e.g., economic) being 'better' or more preferred than another (e.g., recreation). Brown distinguished two major value realms: held and assigned. The former he defined as 'an enduring concept of the preferable which influences choice and action' (p.232) and the latter as 'the expressed relative importance or worth of an object to an individual or group in a given context' (Brown, 1984: 233).

The concept of 'held' forest values has been applied to study forests and forest ecosystems in the USA and elsewhere (e.g., Brown \& Reed, 2000; Manning, Valliere, \& 
Minteer, 1999; Xu \& Bengston, 1997). While such values may be appropriately applied to a particular forest (Manning et al., 1999: Green Mountains National Forest, Vermont) or forest system (Bengston \& Xu, 1995: US National Forests), they would seem less suitable to examining values at the site or locality level. Assigned values, however, which encompass judgments on the relative valuation of objects, would seem particularly appropriate to mapping forest values, as this process involves making choices among particular sites or localities within a forest and attaching values to them (McIntyre, et al, 2004).

\section{How are place values elicited from users of natural resource areas?}

Kuentzel, Tritton, Dennis, \& Wang (1997) argued that the main difficulties with incorporating values into public participation processes are a lack of recognition of philosophical and theoretical differences about how people form values. In clarifying this situation, these authors suggested that three dominant perspectives could be distinguished: social utility (Driver, Brown, Stankey, \& Gregoire, 1987; Bengston, 1994); social cohesiveness (Parsons, 1951); and social discourse or constructivist (Giddens, 1984)

In conceptualising forest values, we adopted a discursive approach recognizing that place values are "constructed through the interaction of individuals and structures in a socioinstitutional context in places - they have a 'geography' (Davies, 2003: 82). The discursive approach is congruent with a growing trend in place research (e.g., Kreuger \& Casey, 2000; Satterfield, 2002; Cacciapaglia \& Yung, this volume; Watson et al., this volume), which recognizes the need to elicit context specific values embodying the meanings and experiences of the people who live, work or play in that space as a precursor to any place mapping process. This conceptualization contrasts with the early work of Brown (1984) which, while recognising a 
qualitative act of preferring (the relational realm) was focused on a quantitative 'social utility' perspective (Kuentzel, et al., 1997). Schroeder (this volume) explores this relational realm, articulating it as 'an implicit, felt dimension of awareness' which connects the 'latent' (held) and 'manifest' (assigned) value realms. He suggests that an essential part of eliciting and understanding place values is to create a space for feelings with regard to preferences about places to be explored. This moves the methods of place valuation from a focus on decontexualised lists of attributes or values to a discursive process of developing an understanding of contextual place meanings.

The discursive approach adopted in this study involved a combination of focus groups and place mapping to develop a list of values for a specific area of the boreal forest in northern Canada. This list formed the basis of recreational survey of residents of Thunder Bay in northwestern Ontario and visitors from the USA and other parts of Canada (for full details refer McIntyre, et al., 2004; McIntyre, et al., 2008). Analysis of the responses to the relative importance of the various values enabled the development of a seven item, contextualised boreal forest values scale, which was used in the case study reported later in this chapter.

\section{How are place values represented spatially?}

At a practical level, a major difficulty in including values data in planning has been the reluctance of social scientists to collect and represent these data spatially. Spatial representation of user values is especially important because otherwise such place-based meanings cannot be easily integrated in Geographic Information System (GIS) technologies which are now commonplace in depicting relationships between the distribution of natural resource (e.g., forest types, land-use) and other kinds of data in planning (Ghose , 2001; PPgis, 2008). The growing 
emphasis on place-based, value-centered meanings requires that social scientists involved in natural resource planning need to think in spatial terms to make it easier to integrate place-values data into the resource-based decision models used by forest planners.

Research involving the collection of spatial data through surveys has been restricted due to limitations of map size. Such restrictions on the detail that can be communicated to respondents can impede their ability to indicate places of interest accurately. Recently, developments in GIS technology enabling its use on the World Wide Web (www) have made it possible for lay professionals and the general public to contribute spatial data in planning contexts (Kingston, et. al., 2000). Public Participation GIS (ppGIS) has experienced rapid growth in the last 10 years as access and familiarity with internet technologies among the general public has increased (Carver, et al., 2001). However, the potential of integrating GIS and the www is a relatively more recent innovation (Kingston, 2007). The case study discussed in this chapter used both a web-based GIS survey and a conventional paper-map survey to elicit and map the place values of residents who used the boreal forest landscape along the north shore of Lake Superior in Canada (hereafter: "the north shore").

This chapter focuses on answering the last question posed in the Introduction to this chapter: "How are place values incorporated into decision-making?" Prior to discussing the case study proper, we provide some background information on forest management in Canada generally and more specifically in the province of Ontario.

\section{Managing Crown Lands in Canada and Ontario}

Forest management in Canada is defined both by the public nature of most of the landbase and the institutional arrangements governing resources. In most Canadian provinces, 
the vast majority of the land is publicly-owned Crown land. Eighty-seven percent of the Province of Ontario is Crown land, most of which is concentrated in the north of the province where it makes up 95 percent of the landbase (OMNR, 2008). Most forestry thus takes place on public land which is also expected to simultaneously support other activities. In contrast with the United States, where most forestry on public lands (i.e., in national forests) is managed at the federal level, the Canadian Constitution makes the management of Crown land resources a provincial responsibility. There is a Canadian Forest Service, but its role is limited to science and policy, leaving the planning and management of forestry to ministries or departments in each province. In Ontario, the Ministry of Natural Resources (OMNR) is responsible for managing Crown lands to meet a variety of objectives, including ecosystem health, development and sustainability of natural resources, protection of natural heritage values, and the provision of recreation opportunities (OMNR, 2007a). Ontario’s Living Legacy land-use strategy sets out the strategic direction for management on over 39 million hectares of Crown land, encompassing most of the land currently available for forest harvesting. Approximately 15 percent of the land is conserved in various forms of protected areas, while a further 4 percent is designated as Enhanced Management Areas (EMA) intended to protect values such as recreation, fish and wildlife, or remoteness (OMNR, 2007b). There is very little formal land use or recreation planning for the remaining 80 percent of the Crown land, meaning that the forest management planning process becomes the primary avenue for managing recreation on Crown land in Ontario. The province is divided into forest management units (FMU), with timber harvesting rights for each FMU licensed to private forestry companies. Management of these FMUs is governed by the Ontario Crown Forest Sustainability Act 1994 (Ontario Government, 2006), which requires that forest management must take into account forest health along with social and economic 
values including recreation. While recreation values are therefore supposed to be considered in forest management planning, there is little guidance as to how this should be accomplished. The OMNR publishes a series of 35 guides and manuals outlining methods for protecting many different forest values, yet there is no guide dealing with Crown land recreation. In practice, recreation values are most often dealt with reactively as concerns are raised by the public. Mapping North Shore Residents' Values and Recreational Use Characteristics Values attached to places are seen as being socially constructed (Satterfield, 2002) which justifies an interpretive approach to their elicitation. Such an approach, however, presents a problem in managing places in that it creates a tension between evaluations that are unique to the individual and those that are shared (Patterson \& Williams, 1998). Thus, the main challenge in incorporating values into decision-making is to find a level at which the findings are still context specific and representative of individual variation, and yet are sufficiently generalizable to be managerially useful. The following case study is an attempt to articulate an approach that meets this specific challenge.

\section{Study Area}

The study area (Figure 1) encompasses the southern portions of a number of FMUs and includes several Conservation Reserves and EMAs. Two of these EMAs provide management direction for forestry and recreation management along the shorelines of Lakes Superior and Nipigon. The former constitutes the southern boundary of the study area. Its western, eastern and northern limits were defined arbitrarily because the actual recreational ranges of the residents were unknown. The study focused on the place values and outdoor activity characteristics of 
residents in the north shore communities of Red Rock, Nipigon, Schreiber, Terrace Bay and Marathon (Figure 1).

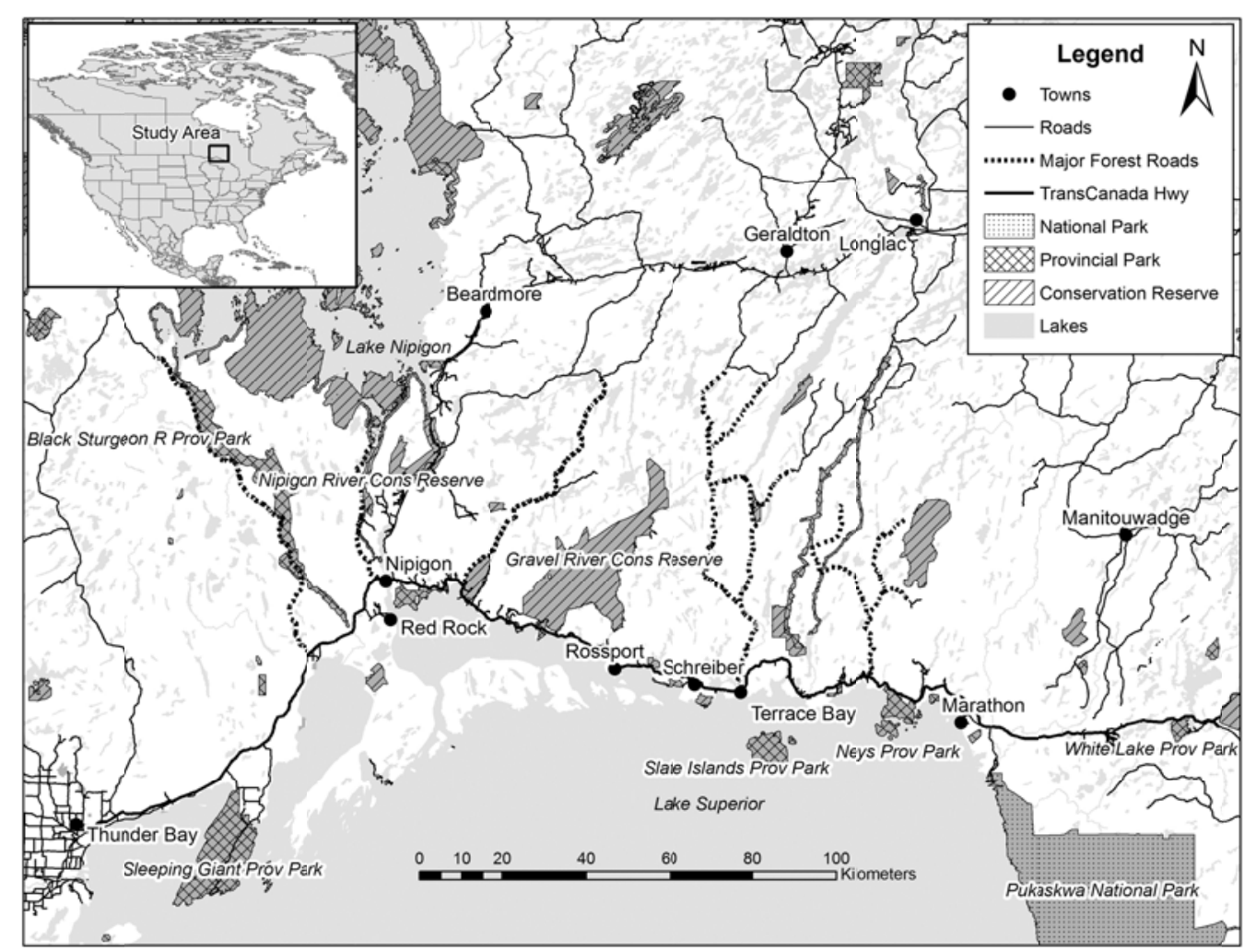

Figure 1: Map of the Study Area (showing localities mentioned in the text)

\section{The Survey}

A web-based GIS survey and a parallel paper version were purpose designed for use in this project (Lesueur, 2008). The survey collected information on residents' characteristics (e.g., gender, age, place of residence) and outdoor recreation use (e.g., frequency and season of use, type(s) of activity). Respondents were also asked to locate and mark sites, areas, and routes that they had used for recreation on a digital or paper map. When a respondent located a place on the map, he/she was prompted to rate the importance of seven value statements using a five-point importance scale $(5=$ very important $)$ and indicate personal recreation use characteristics. The 
value statements were derived by factor analysis of data from an earlier study in a closely similar boreal forest area to the west of Thunder Bay (McIntyre, et al., 2004). These values comprised: Wilderness \& Solitude; Adventure; Recreation Diversity; Wildlife; Other Values; Family Recreation; and Consumptive Recreation. The first four value categories are relatively selfexplanatory. However, the other three, which combine a mix of social and physical values require some explanation. Other Values included a factor made up of value statements such as 'a place for learning', 'economic support for local communities', a sacred place' and a place where 'a person can feel at home'. Similarly, Family Recreation comprised value statements like 'a good place for families', a place to keep for future generations' and 'beautiful lakes' and Consumptive Recreation, while including the obvious value of 'a good place for hunting and fishing', also referred to 'good access' and notably 'friends and camaraderie' as components of this factor. These latter three value factors thus combine social, recreational and physical characteristics of valued places which are different in each case.

\section{The Sample}

A sample of 750 residents and their contact information were selected from a data base purchased from infoUSA. To maximise spatial coverage of responses, the percentages of population in the five north shore communities of Nipigon, Red Rock, Schreiber, Terrace Bay and Marathon (Figure 1) were established from census data (Statistics, Canada, 2007) and these values were then used to select a random sample from each of the five communities. As a pilot study indicated difficulties with web-access in some areas, both web and paper versions of the survey were made available to potential respondents. 


\section{Characteristics of Respondents}

Overall 201 surveys were completed giving an overall response rate of 27 percent which provided data on 408 recreation sites spread throughout the region. The spatial distribution of responses was not significantly different from census data, however, many more men $(76 \%)$ than women $(24 \%)$ responded and younger persons $(<40$ yrs old) were underrepresented in comparison to census figures. A majority of the sample (62\%) had lived in the area for more than 20 years. In summary, there is some confidence in the spatial representation of responses but less so for gender and age.

\section{Recreation Use Patterns of North Shore Residents}

The first stage of the analyses mapped the broad recreational use patterns of residents using a density analysis procedure in ArcGIS. Figure 2 indicates the density of use by intensity of shading. Spatial patterns of higher use were distinguishable along the Lake Superior shore, the highways and forest roads (around Red Rock, Nipigon, Schreiber, and Terrace Bay), and along the Nipigon River and Lake Nipigon. These data also suggest that the recreational activity of people living between Red Rock and Terrace Bay is largely confined to about $150 \mathrm{~km}$ north of the main east-west highway (Hwy 17) and west as far as Lake Nipigon. Road access to the north is relatively limited for Marathon residents who either go south into Pukaskwa National Park or west into the study area. 


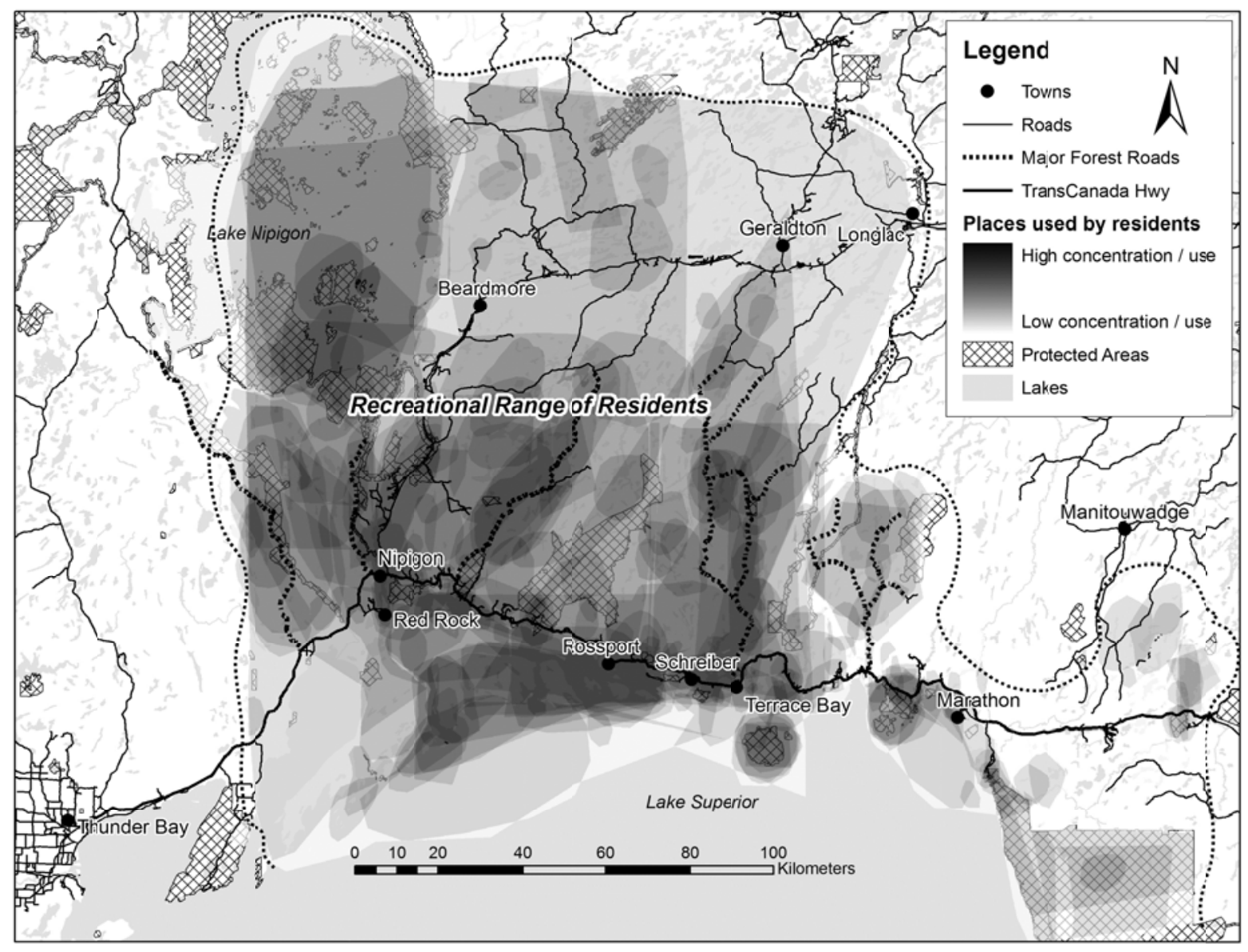

Figure 2 Recreational Use Patterns of North Shore Residents

Place Values of North Shore Residents

Overall, Consumptive Values were rated as the most important (Mean Value $=3.55)$ followed by Wilderness \& Solitude (Mean Value =3.4), Family Recreation $($ Mean Value = 3.2), Wildife $($ Mean Value $=3.1)$ and Adventure $($ Mean Value $=3.0)$. Recreation Diversity (Mean Value $=2.4)$ and Other Values $($ Mean Value $=1.4)$ were rated as relatively unimportant. This same pattern is evident in previous studies in the region (McIntyre, et al., 2004) where residents demonstrate a strong valuing of the boreal forest as a place for consumptive activities such as 
fishing and hunting. This same study indicated that this preference is shared with visitors from the USA but not with those from other parts of Canada who value this same forest for its Other Values (e.g., learning, economic, sacred).

Analysis of value ratings by gender indicated that the females rated both Wilderness \& Solitude and Adventure significantly higher than males. When patterns of value ratings among the age cohorts were examined, all age groups rated Consumptive Values and Wilderness \& Solitude similarly important. The 40 to 59 years cohort, however, rated most other values as significantly more important, placing their highest rating (after Consumptive Recreation) on Family Recreation (Mean Value $=3.45$ ). The one exception was the Adventure value which was rated highest (Mean Value $=3.73$ ) by the youngest cohort (20 to 39yrs).

\section{Distribution and Characteristics of Valued Places}

The second stage of the analysis was to classify each of the places marked by respondents on the basis of the seven values. A combination of K-Means Cluster Analysis and Discriminant Analysis (SPSS, 16.0) was used to classify the 408 places. The former procedure enabled classification on the basis of the seven values and the latter indicated the value or value combinations which best discriminated between the various clusters. Four site clusters were identified: a) Consumptive Recreation (159 sites); b) Other Values (70 sites); c) Family Recreation (95 sites); and c) Recreation Diversity, Wildlife \& Adventure (84 sites). A correct classification of 96 percent indicated that the four clusters were well discriminated by the predictor variables (values or value combinations).

Using these data it was possible to map the distribution of the various cluster sites and delineate those areas which were valued for the individual values or value clusters. Both the Other Values and the Recreation Diversity, Wildlife \& Adventure cluster sites were rather 
uniformly distributed over the whole study area indicating, in the former, the overall value of the area as a place which provided economic benefits to the community and a sacred place where residents can learn about nature and feel at home. Further, the North Shore is perceived as a place where residents could view wildlife, have adventures and enjoy a diversity of recreation opportunities. This diversity is reflected in the range of activity participation at the sites included in this latter cluster (fishing, nature \& relaxation, hiking, camping, and canoeing and other water sports). Overall the sites in this value cluster received higher frequencies of use in all seasons than in any of the other value clusters.

Sites valued for Family Recreation, in contrast, are the most spatially restricted. They occur quite close to population centres (Figure 3), along the main highways (Trans-Canada Hwy) and major Crown land access roads (e.g., around Nipigon and Red Rock), and coastal waters of Lake Superior. Recreation activities at these sites include hiking, camping, nature \& relaxation, and canoeing and other water sports that are carried out mainly in the summer. 


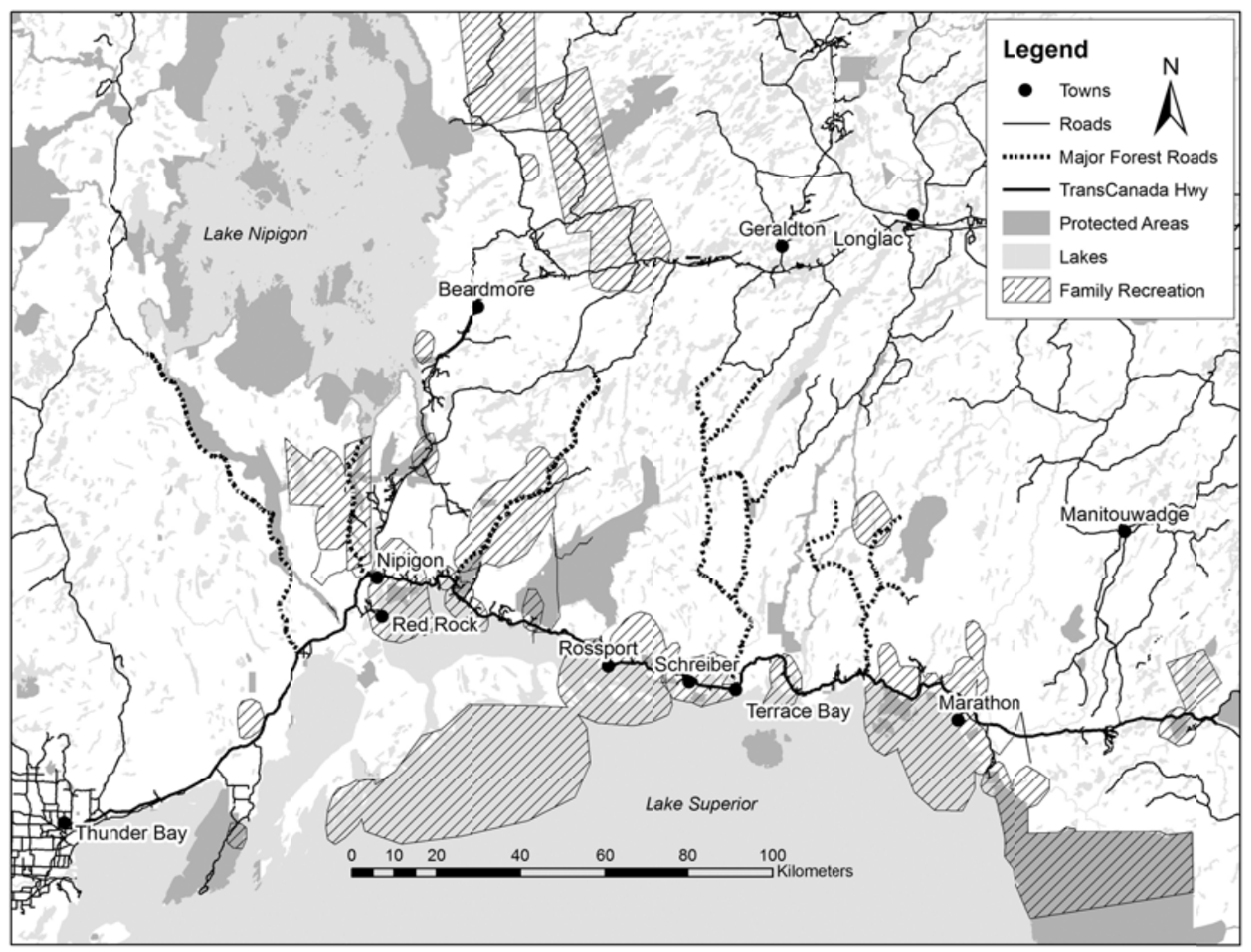

Figure 3: Distribution of Sites Valued for Family Recreation

Consumptive Recreation, although similarly centered on road access, demonstrates a somewhat more widespread and different spatial distribution from Family Recreation (Figure 4). Two types of areas are evident in Figure 4: a) sites on Lake Superior and Lake Nipigon; and b) sites within the boreal forest. The former are mainly sheltered or near-shore areas on the major lakes and the latter are defined by major timber-harvesting roads radiating from the townships into the boreal forest. As would be expected, the main activities associated with this value cluster are fishing and hunting with significant participation in camping. Frequency of participation by season is least in winter and greatest in the summer with use in fall and spring lying between these extremes. 


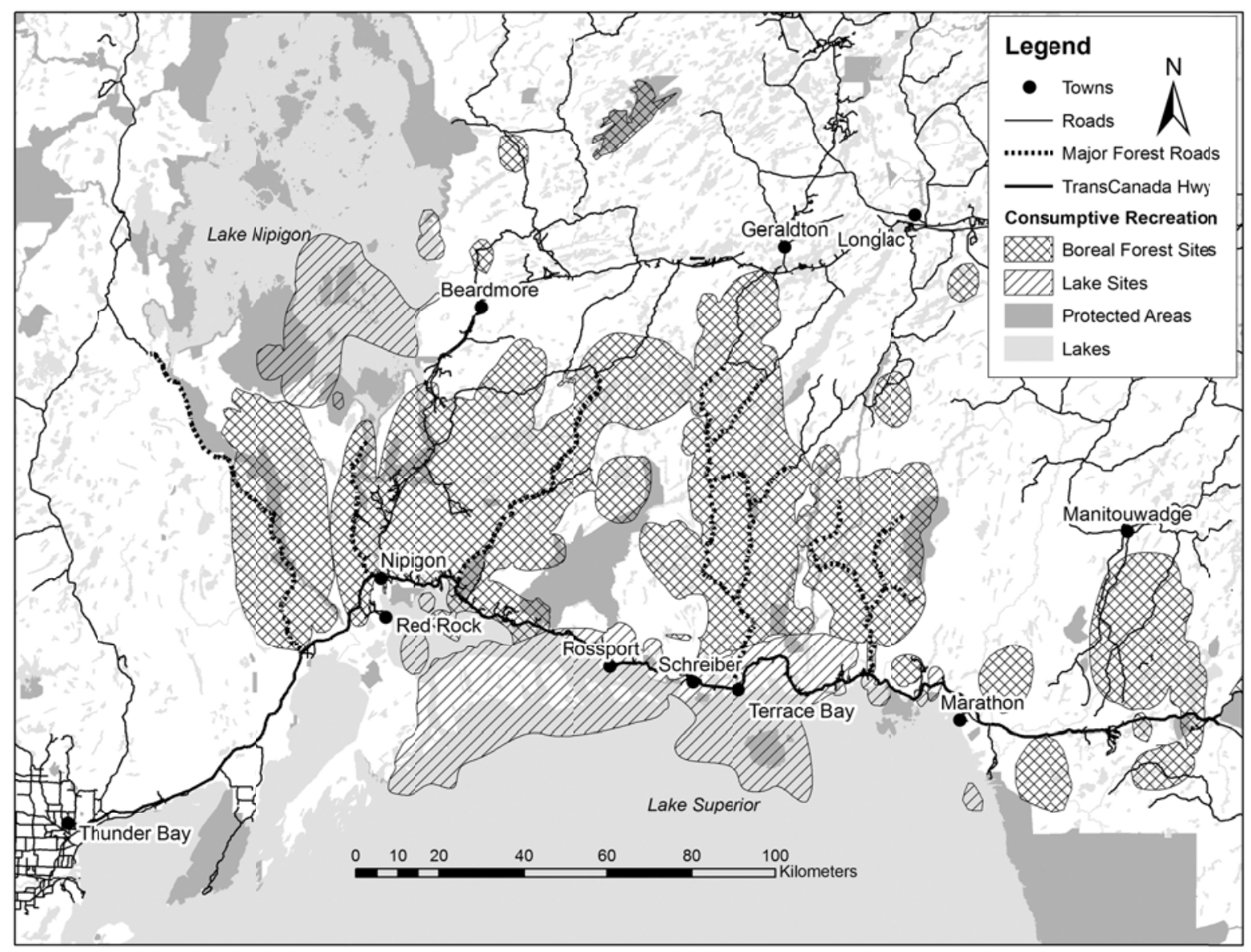

Figure 4: Distribution of Sites Valued for Consumptive Recreation

\section{How are place values incorporated into decision-making?}

These data suggest that the values attached by residents to the North Shore are dominantly recreational and centred on opportunities for social interaction (families, hunting and fishing companions) and activities (consumptive, water based and diversity) with other values such as belonging, economic, and nature contact being apparently less prominent. Residents' place attachment could be thus best be characterised as place dependence (Altman \& Low, 1992), although conversations, interviews and focus group discussions with residents also point 
to strong identification with special places in the boreal forest as indicated in both the recognition of and widespread distribution of sites included in the Other Values cluster. In this study, we adopted a two-tier approach to the elicitation of values; first eliciting places used and then secondly the values associated with these places. This approach represents a reaction to the generally negative responses by residents to a prompt to reveal 'special places'. Consequently, the emphasis on use values in this study may well have resulted in under-representation of the broader values expressed in the Other Values category. This cautionary note is mitigated by the observation that previous work in the boreal forests to the west of Thunder Bay provided similar results (McIntyre, Yuan, Payne, \& Moore, 2004).

Analyses of the spatial distribution of the Family Recreation value cluster sites indicate that most lie adjacent to the east-west line of Hwy 17 (Trans-Canada) and that this route is a main focus for tourism and recreational opportunities. It is evident that many of these valued sites fall within lands that are already under some kind of protection or are available for recreation. Examples include the 53km Casque Isles Trail following the Lake Superior shoreline between Rossport and Terrace Bay (Casque Isles Trail, 2007), a number of provincial parks with camp grounds and walking trails (e.g., Neys and White Lake) and conservation reserves (e.g., Gravel River) fringe the Trans-Canada Highway between Nipigon and Marathon. Other readily accessible, attractive recreation areas are the beaches at Rossport, Schreiber and Terrace Bay, and the Nipigon River (Figure 1). In addition, much of land adjacent to Lakes Superior and Nipigon is contained within EMAs that are managed to protect recreation opportunities. The accessible sheltered waters of Lake Superior are valued areas common to both Family Recreation and Consumptive Recreation clusters. These waters are included in the recently 
designated Lake Superior National Marine Conservation Area (Parks Canada, 2008); set aside, in part, for the provision of recreational opportunities.

In summary, a large percentage of the specifically designated areas valued for and common to both Family Recreation and Consumptive Recreation clusters are integrated into diverse management regimes (provincial, municipal and federal) which are supportive generally of the maintenance of these valued places. The remaining Consumptive Recreation areas, which lie within the actively harvested general-use areas of the boreal forest, present a number of challenges in accommodating recreation values within an area managed principally for resource extraction.

\section{Consumptive Recreation Values and Boreal Forest Timber Management}

Active timber harvesting has provided and continues to provide access to desirable recreation areas. Harvest roads have historically been accompanied by the creation of new access points providing angling opportunities at lakes and rivers. Clear-cutting and subsequent regrowth provide a variety of habitats which are attractive to game animals such as moose (Alces alces) and, as a consequence, to hunters. With time and repeat visits, familiarity with a specific place grows and emotional bonds, sense of place or place attachment can develop (Williams, et al., 1992).

The data from this study indicate that residents have developed specific types of utilitarian, symbolic and emotional attachments with places in the northern boreal forest. Such attachments have been made possible through access provided principally by timber harvesting activities. It is evident (Figure 4) that areas valued for Consumptive Recreation are delineated on the basis of the access provided by major and minor roads radiating from the various townships 
on the shores of Lake Superior (e.g., Nipigon, Terrace Bay). This observation emphasises the fact that the majority of recreation in this part of the boreal is motorised because of the difficulty of the terrain and distances involved. Management of road access including construction, maintenance and de-commissioning is therefore important and often contentious (Hunt, Lemelin, \& Saunders, 2009) involving negotiation among forest companies, management agencies, tourism operators, First Nations, tourists and residents.

Once long-term management directions, harvesting areas and primary road corridors have been established through the forest management planning process, road construction, maintenance and de-commissioning is the responsibility of forest companies in conjunction with the management agency (OMNR) as part of operational planning. These roads are built to provide access to and transport raw materials from harvesting sites to central processing plants but an important by-product of these roads is the provision of access to recreation opportunities. Just as timber harvesting can open access to new areas, cessation of such activity can result in de-commissioning of roads and loss of access to places within the forest. This is a typical pattern in clear-cut operations in the northern boreal forest where cutting, clearing and re-growth accompanied by changes in road access form part of a repetitive cycle of harvesting. This may present few problems for some recreationists who are able to substitute another locale to pursue their desired activity as previously inaccessible areas are opened by a new phase of harvesting. In colloquial terms, "they follow the bulldozer to the next fishable lake". For others, decommissioning can mean a loss of access to areas that have become over time places that are special to them and hence, non-substitutable.

Although the above may seem to present a particularly fluid situation, the reality is somewhat different in that, major forest access roads generally persist for significant periods of 
time (e.g., 25 - 50 years). Secondary and tertiary roads are often less persistent as these forestry companies are reluctant to assume the expense and potential liability of maintaining roads once harvesting and tending operations have ceased in an area. Roads are sometimes decommissioned through removal of water crossings and/or destruction of the road bed, while other are simply allowed to deteriorate over time. Other access controls including travel or camping restrictions, signage, or gates may be used to control recreational access to an area, generally to protect remote tourism values. Such controls are often controversial sometimes inciting considerable opposition (Hunt, et al., 2009), which gives some credence to the value that residents in particular place on access to the forest.

The continued existence and maintenance of forest roads has been, until recently, the responsibility of the forest companies and has depended largely on the continued need of these companies for access to harvesting areas. Recently, however, the Ontario provincial government agreed to assist forest companies with financing the construction and perhaps more importantly from a recreational access perspective, the maintenance of forest access roads. This latter is important in that it opens the possibility of maintaining access to selected areas even when harvesting has been discontinued.

The boreal forest thus presents a management system which is valued principally for its economic contribution from forest company activities which on the one hand, provide access for residents to a variety of mostly motorised recreational opportunities and on the other, removes that access based on economic priorities without consideration of the recreational values that might have developed over time. Similarly, the management agency privileges forest companies and remote tourism operations over recreation in forest management planning and forestry road access provisions. In summary, there is little priority given in most instances to proactive 
planning for recreation in the forest management planning process. There are exceptions in some particularly contentious areas (e.g., Wawa District in Hunt et al., 2009; EMA's) which serves to emphasise the notion that recreation issues are treated generally on a case-by-case basis.

The recognition of areas that are used by resident recreationists and that are valued for specific purposes can provide a means to proactively integrate recreation into the forest management planning process thus enhancing the range of benefits that are provided by and which are in fact, required under the multiple use provisions of the Ontario Crown Forest Sustainability Act 1994 (Ontario Government, 2006). Spatial data such as that collected in this study allows the identification of specific areas which are important for recreation. The inclusion of data on the specific values attached to each area (refer Fig. 4) can guide managers in ensuring the protection or enhancement of these values. For example, maintenance of forest road access in such areas could be considered a priority. In certain situations, areas identified as having high recreation values could be designated as EMAs with special provisions governing harvest cycles and maintenance of forest road access designed to promote integration with recreation.

\section{Conclusions}

In this chapter, we set out to answer four questions related to the theoretical construction of values, their elicitation and mapping and finally, their integration with decision-making in natural resource management. We adopted a theoretical position arising from Brown's (1984) conceptualization of values but which differed in its values elicitation method in allowing values attached to places to arise naturally in focus groups and through using maps of a study area set in the boreal forest. Analyses of these data provided the basis for the development of a boreal forest values scale which was used in this case study. 
A web-based survey was used to explore the spatial distribution of residents' recreation activity, the types of activity participation, and the values asssociated with the areas identified. These data first revealed where these activities were concentrated (Figure 2) which information, while being valuable to managers in identifying recreation use areas, was relatively limited as to the guidance it provided in managing the areas identified. When information on values attached to the various areas was mapped (Figures $3 \& 4$ ), their spatial differentiation enabled more specific management approaches to be targeted on the areas identified.

Specifically, the values data revealed that residents attached a broad range of utilitarian, symbolic and emotional values to specific places in the forest. Further analyses suggested that these values could be clustered into four broad categories, two of which (Other Values and Recreation Diversity) were attached to places that were widely dispersed across the forest. The other two value clusters (Consumptive and Family Recreation) were more spatially restricted and somewhat separate in their distribution. These observations mirror the work of Cacciapaglia and Yung (this volume) in demonstrating that the spatial scales at which values are perceived are variable - some attached to the 'landscape' (e.g., 'economic values' 'feeling at home') and others (e.g., 'fishing and hunting', 'family recreation') attached to specific places. The contrasting emphasis on 'special places' demonstrated by respondents in the two studies may well rest in the 'landowner' perspective in the Cacciapaglia and Yung study as compared to the 'recreationist' in this study.

The particular nature of management of Crown Lands in northern Ontario with its emphasis on forestry and to a lesser extent on remote tourism, creates opportunities for vehiclebased recreation on company-built forest roads and for 'wilderness' (non-motorised) experiences. These are not, however, integrated proactively in forest management planning 
processes but are rather a serendipitous outcome of forest company activities. Thus, established (by practice) recreational access can persist or disappear depending on the location and timing of harvesting and the continued need for access to support forestry activities. An understanding of the spatial distribution of recreation use sites and the values associated with them can provide managers with the information necessary to make decisions about priorities for road maintenance and the creation of special management zones (e.g., EMAs) where planning provisions and controls (e.g., harvesting cycles, cutting regimes, forest road planning) can be implemented to better integrate forest company activities and recreation. 


\section{References}

Altman, I., \& Low, S. M. (Eds.). (1992). Place Attachment: Human behavior and environment. Advances in theory and research (Vol. 12). New York: Plenum Press.

Bengston, D. N. (1994). Changing forest values and ecosystem management. Society and Natural Resources , 7, 515-527.

Bengston, D. N., \& Xu, Z. (1995). Changing Forest Values: A Content Analysis. St Paul, MN: USDA Forest Service North Central Research Station NC-323.

Brown, G., \& Reed, P. (2000). Validation of a Forest Values Typology for Use in National Forest Planning. Forestry Sciences , 46, 240-247.

Brown, T. (1984). The concept of value in resource allocation. Land Economics , 60, 231-246.

Carver, S., Evans, A., Kingston, R., \& Turton, I. (2001). Accessing Geographic Information Systems over the World Wide Web: Improving public participation in environmental decison-making. Information, Infrastructure and Policy, 6, 157-170.

Casque Isles Trail. (2007). Retrieved November 25, 2008, from http://www.voyageurtrail.ca/casques.html

Davies, A. (2003). What Silence Knows - Planning, Public Participation, and Environmental Values. Environmental Values , 10, 77-102.

Driver, B., Brown, P., Stankey, G., \& Gregoire, T. (1987). The ROS planning system: Evolution, basic concepts, and research needed. Leisure Sciences , 9, 201-212.

Evans, A., Kingston, R., \& Carver, S. (2004). Democratic input into the nuclear waste disposal problem: The influence of geographical data on decision making examined through Webbased GIS. Journal of Geographic Systems , 6, 117-132.

Farnum, J. O., \& Kruger, L. E. (2008). Place-based Planning Innovations and Applications from Four Western Forests. Portland OR: USDA Forest Service PNW-GTR-741.

Farnum, J., \& Reed, P. (2008). The Chugach National Forest. In J. O. Farnum, \& L. E. Kruger (Eds.), Place-Based Planning: Innovations and Applications from Four Western Forests (pp. 23-31). Portland OR: USDA Forest Service PNW-GTR-741.

Ghose, R. (2001). Use of Information Technology for Community Empowerment: TransformingGeographic Information Systems into Community Information Systems. Transactions in GIS , 5, 141-163.

Giddens, A. (1984). The Constitution of Society: Outline of the Theory of Structuration. Berkeley CA: University of California Press. 
Hunt, L. M., Lemelin, R. H., \& Saunders, K. C. (2009). Managing forest road access on public lands: A conceptual model of conflict. Society and Natural Resources, 22: 128-142.

Kingston, R. (2007). Public Participation in Local Policy Decision-making: The Role of Webbased Mapping. The cartographic Journal , 138-144.

Kingston, R., Carver, S., Evans, A., \& Turton, I. (2000). Web-based public participation geographical information systems: an aid to local environmental decision-making. Computers, Environment and Urban Systems , 24, 109-125.

Kreuger, A. R., \& Casey, M. A. (2000). Focus Groups: A Practical Guide for Applied Research ( 3 ed.). Thousand Oaks CA: Sage Publications.

Kuentzel, W., Tritton, L. M., Dennis, D. F., \& Wang, D. (1997). Thinking about water quality management: Social values, wetland ecology, and landowner practices. In H. K. Cordell, L., Caldwell, \& S. Hou (Eds.), Integrating Social Sciences and Ecosystem Management: A National Challenge (pp. 156-162). Helen GA: USDA Forest Service PNW-GTR-369.

Lesueur, P. (2008). Mapping Recreation Use Patterns and Forest Values: A Canadian Boreal Forest Case Study. Unpublished Masters Thesis . Thunder Bay, ON Canada: Lakehead University .

Manning, R., Valliere, W., \& Minteer, B. (1999). Values, Ethics, and Attitudes Towards National Forest Management: An Empirical Study. Society and Natural Resources , 12, 421-436.

McIntyre, N., Moore, J., \& Yuan, M. (2008). A Place-based, Values-centred Approach to Managing Recreation on Canadian Crown lands. Society and Natural Resources , 8, $657-$ 670 .

McIntyre, N., Yuan, M., Payne, R. J., \& Moore, J. (2004). Development of a value-based approach to manging recreation in Canadian Crown Lands. In T. Sievanen, J. Errkonen, J. Saarinen, S. Tuulentie, \& E. Virtanen (Ed.), Proceedings of the Second International Conference on Monitoring and Management of Visitor Flows in Recreation and Protected Areas (pp. 291-299). Rovaniemi Finland: Finnish Forest Research Institute.

More, T. A., Averill, J. R., \& Stevens, T. H. (1996). Values and Economics in Environmental Management: A Perspective and Critique. Journal of Environmental Management , 48, 397-409. Ontario Government. (2006). Retrieved November 25, 2008, from Crown Forest Sustainability Act: http://www.elaws.gov.on.ca/html/statutes/english/elaws_statutes_94c25_e.htm Ontario Ministry of Natural Resources (2007) . Retrieved December 2, 2008, from Approved Land-use Strategy: 1.0 Introduction: http://crownlanduseatlas.mnr.gov.on.ca/supportingdocs/alus/landuse1.htm

Ontario Ministry of Natural Resources (2007) . Retrieved December 2, 2008, from Approved 
Land-use Strategy: 7.0 Land Use Categories:

http://crownlanduseatlas.mnr.gov.on.ca/supportingdocs/alus/landuse 7.htm

Ontario Ministry of Natural Resources (2008a) . Retrieved November 27, 2008, from Crown Land Management: http://www.mnr.gov.on.ca/en/Business/CrownLand/index.html Parks Canada. (2008). Retrieved November 25, 2008, from Lake Superior National Marine Conservation Area of Canada: http://www.pc.gc.ca/amncnmca/on/super/index_E.asp

Parsons, T. (1951). The Social System. Glencoe IL: Free Press.

Patterson, M. E., \& Williams, D. R. (1998). Paradigms and Problems: The practice of social science in natural resource management. Society and Natural Resources , 11, 279-295.

Satterfield, T. (2002). In Search of Value Literacy: Suggestions for the Elicitation of EnvironmentalValues. Environmental Values, 10,331-359.

Steinberg, S., \& Steinberg, S. (2006). GIS - Geographic Information Systems for the Social Sciences: Investigating Place and Space. Thousand Oaks CA: Sage Publications.

Williams, D. R. (2008). Pluralities of Place: A user's Guide to Place Concepts in Natural Resource Management. In L. Kruger, T. Hall, \& M. Stiefel (Eds.), Understanding Concepts of Place in Recreation Research and Management (pp. 7-30). Portland OR: USDA Forest Service General Technical Report PNW-GTR-744.

Williams, D. R., Patterson, M. E., Roggenbuck, J. W., \& Watson, A. E. (1992). Beyond the commodity metaphor: Examining emotional and symbolic attachment to place. Leisure Sciences , 14, 29-46.

Xu, Z., \& Bengston, D. N. (1997). Trends in national forest values among forest professionals, environmentalists, and the news media. Society and Natural Resources , 10, 43-59. 


\section{Place mapping to protect cultural landscapes on tribal lands}

Alan Watson, Steve Carver, Roian Van Ness, Tim Waters, Kari Gunderson, and Brett Davis

\section{Defining Human Relationships with Collectively Held Lands}

A framework to articulate and protect (or restore) relationships between the public and public lands places was described by Watson \& Borrie (2003) as public-purpose marketing, a form of relational marketing. A relational marketing approach, in contrast to marketing that focuses solely on transactions with customers, with revenue generation and repeat purchases as objectives, focuses on building and maintaining relationships (Morgan \& Hunt, 1994; Garbarino \& Johnson, 1999). In a demonstration of this framework, these authors and others applied this framework to demonstrate how public attitudes toward recreation fee policies in the U.S. are dependent upon relationships people have with public lands and public lands managers. They also demonstrated the value of segmenting the public based on these relationships to better understand response to public lands policies (Borrie, Christensen, Watson, Miller \& McCollum, 2002), instead of using more transactive or demographic attributes. These authors have also built upon this framework to justify and propose a system to guide monitoring of changing relationships between the public and public protected areas (Watson \& Borrie, 2006). Within this framework, the public is considered primary stakeholders (both customers and partners) of public lands services.

Most private sector marketing approaches focus on transactions between individuals (or organizations) and customers, which have a distinct beginning, short duration, and sharp ending. A relational exchange, however, acknowledges effects of previous contacts and knowledge, is longer in duration, and reflects an ongoing process (Dwyer, Schurr \& Oh, 1987). Watson \& 
Borrie (2006) suggest that when providing services for the public through the development of programs on public lands (or any other collectively held lands), the more appropriate view of "customer service" would be the fostering of a relationship between members of the public and the places that have been established on their behalf as public lands, particularly with any level of protection from publicly perceived threats. Accomplishing the public purposes of these lands is among the stewardship responsibilities of managing agencies (Watson \& Borrie 2003).

Morgan \& Hunt (1999) and Watson \& Borrie (2003) emphasize that commitment and trust are often commonly the primary influences on successful relational marketing.

Not all customers desire the same relationship with a producer of goods or services. An organization may be well advised to pursue both transactional and relational marketing simultaneously, as customers may exist on a continuum of transactional to collaborative exchanges. In the public sector, however, members of the public are, by definition, involved in a collaborative relationship with the stewardship agency taking responsibility for implementation of public policy. While we are suggesting that a collaborative relationship exists for all people, we do acknowledge that the level of commitment (measured by intensity of relational meanings) for the services provided by an agency and the level of trust instilled among members of the public may vary substantially. Relational marketing suggests that a focus on understanding variation in trust, commitment, and meanings attached to protected areas will be paramount in developing and implementing public policy to meet the mandates or purposes of these public lands (Watson \& Borrie, 2006). This chapter demonstrates these concepts.

\section{A Cultural Landscape with Contrasting Meanings}


On the Flathead Indian Reservation in Montana, the Mission Mountains Tribal Wilderness (92,000 acres) (see Figure 1) was designated by the Tribal Council in 1982 at the urging of many Tribal members, and is symbolic of a much larger relationship these indigenous people once had with a vast place we commonly refer to as the Northern Rocky Mountains in the US. To the west, between the Wilderness and the Reservation community, 22,000 acres was also protected at the urging of many Tribal members, though playing a slightly different role in protecting the relationship between Tribal people and the Mission Mountains landscape.

This area isn't Wilderness, but when originally established, in 1987, it was listed as not available for commercial timber harvest. The Wilderness Buffer Zone, originally designated to help protect the Wilderness from human activities, extends along the wilderness boundary and contains some homes, a few roads, and therefore, remains a working landscape within the community. About half of the land in the Wilderness Buffer Zone is in Tribal ownership; about half is owned by individuals, both Tribal and non-tribal.

Both the Wilderness and the Wilderness Buffer Zone are broadly considered protected cultural, as well as natural, landscapes; thus major decisions about management of these areas are subject to review by the Tribal Cultural Committee, the Tribal Council and the Tribal member public. To successfully improve forest health within that Wilderness Buffer Zone and increase opportunities to restore fire in the Wilderness, the Tribal Forestry Department and the public are working together to find solutions to increasingly threatening fuel buildups.

One of the primary barriers to fire restoration in the Mission Mountains Tribal Wilderness on the Flathead Indian Reservation in Western Montana, is the health of adjacent lands. Fire suppression has had substantial influence on the structure and general health of the forest within the Wilderness Buffer Zone. Heavy accumulations of dead wood and down timber 
on the forest floor, a dense understory of brush and young trees, closely spaced trees and closed forest canopy make the forest "unhealthy" and highly susceptible to destructive wildfires, as well as diseases and insects such as the pine bark beetle.

While both the Tribal people and Tribal government agencies seem highly committed to seeing fire restored in the wilderness, there was an apparent lack of trust in Tribal forestry to manage resources for non-monetary, as well as monetary, values. Any process designed to move beyond the long-standing tension over Tribal forestry's proposal to manipulate vegetation in the Tribal Buffer Zone faces a lack of trust built over many years. The purpose of the project reported here aimed to employ a new method of engaging the public with responsible land managemers to articulate the meanings attached to the landscape, identify ways to protect these meanings, build trust between the community and land managers, and improve forest health.

\section{Participatory Approach to Understanding Values at Risk}

One of the key problems in developing a better understanding of different public responses to landscape level management actions, such as fuel treatments in the Buffer Zone, is being able to confidently record and accurately spatially delineate relationships stakeholders have with a landscape. Being able to actually map and discuss different meanings people attach to the landscape has a number of advantages over more general place-based techniques to generate participatory engagement. These include the ability to link meanings to specific locations or landscape units, and perform advanced analyses on responses by looking at spatial relationships based on proximity, adjacency, containment, connectivity and visibility. "Hot spot" areas have been delineated in past studies through categorizing information such as number of people indicating a particular spot is important, the type of meaning people gave to that indicated 
spot and the specificity, or scale, of the area indicated (Carver, Watson, Waters, Matt, Gunderson \& Davis, 2009). The particular needs noted by Carver et al. (2009) for improvement in this mapping meaning methodology, however, were to increase the number of people engaging in this type of map-based activity, retain good scale representation, capture the intensity of the meanings and identify perceived threats to those meanings.

The cumbersome task of a researcher meeting with every person, or even in focus group discussions, and leading them through pencil and paper exercises while trying to either record or note things they say about these important areas has proven difficult (Gunderson \& Watson, 2007). Mailback attempts at this complex task have largely provided unacceptable response rates, particularly within rural, indigenous sub-populations. Also of concern was that an individual's relationship with a local landscape is essentially fuzzy and cannot be easily captured using traditional map-based features or entities such as points, lines and polygons. So, while scale has sometimes been estimated, it has not been captured accurately or efficiently, and the intensity of meanings attached to places has previously not been captured at all.

In order to address the issues described above, the current project adopts more fuzzy methods of capturing the landscape areas for which people hold a particular meaning. This is used to capture information about fuzzy spatial concepts such as vagueness and approximation in defining spatial pattern and extent, as well as (un)certainty and importance in the relative values and meanings attached to these. This type of system can be used both online over the internet and offline on a stand-alone laptop facilitated by a member of the research team.

\section{Mapping Relationships on the Flathead Indian Reservation}


A combination of qualitative, culturally sensitive research and a web-based mapping exercise employing fuzzy mapping methods was used to develop understanding of the meanings Tribal members attach to the Buffer Zone, articulate trust issues, and describe perceived threats to these meanings. An important element in developing this understanding was describing contrasting meanings associated with both the Wilderness and the Buffer Zone by both Tribal and Non-tribal residents.

\section{Selecting meanings to map}

Semi-structured interviews were conducted with Tribal members and non-tribal Reservation residents to solicit information on the range and types of meanings associated with this landscape with varying levels of protection (Wilderness and Wilderness Buffer Zone). Following the work of Lewis \& Sheppard (2005), key informants were selected.

Twenty two interviewees were asked to provide information about the range and type of meanings attached to the landscape in interviews scheduled and conducted at the convenience of the interviewee. These analyses and results are described in detail by Watson, Knotek, Matt \& Yung (2007) and Watson, Matt, Knotek, Williams \& Yung (in press). Since this chapter is focused only on the Tribal member meanings attached to the Tribal Buffer Zone, these meanings are presented under the following categories, as described by Watson, Matt, Waters, Gunderson, Carver \& Davis (2008): 1) The role of the Buffer Zone in protection of the Wilderness and the transitional value of connecting people to the Wilderness, 2) access and functional attachments, 3) personal and cultural attachments, 4) wildlife and water quality, and 5) recreation, privacy and scenic values. 


\section{Protector of the Wilderness and the Transitional Value of Connecting People to the}

Wilderness. Tribal members viewed the Wilderness and the Wilderness Buffer Zone quite similarly in some ways. They commented frequently on the interconnection between the two, and many feel that decisions about the Buffer Zone should be driven primarily by protection of the Wilderness. Not only does the Buffer Zone provide a physical protection of the Wilderness, but it also provides for transition and that feeling of being one step closer to the Wilderness, even for those who never get into the Wilderness. For example, many people described this protection and transition value similarly to these Tribal members:

The buffer zone was created to help, again, buffer from development, buffer from, you know, manage the buffer zone in a way to help preserve the Wilderness. I think it should be managed in a way to where it protects, where the main focus is on the Wilderness. That how you manage the buffer zone, how you protect the buffer zone, how you keep the buffer zone intact and do things in there, always focusing on how it's going to benefit the Wilderness, not necessarily the people that are in the area, but the Wilderness. (Interview 1)

Well, I just think the importance of it is the fact that it is looked at as a transition zone between hard core development and wilderness. I think it's very critical to have that area as a tool to help manage, to create special conditions that would complement the Wilderness. (Interview 10)

And it's nothing you can see on the ground when you pass through it. The association that the buffer zone, that most people and I have, between that, the valley floor, and the Wilderness is sort of one and the same. (Interview 15) 
Access and Functional Attachments. The lower elevation of the Wilderness Buffer Zone and different regulations makes it much more accessible to Tribal members and more functional in its use than the Wilderness. For example:

As they got older, then we spent more time in the Wilderness. But in the buffer zone, that was a much more gentle transition and much more accessible area for us. Right out the back door. It's an area where more frequently I go to, when I don't have longer periods of time to walk or to gather plant materials or to participate in other activities that are important in my spare time. (Interview 16)

I think you see a higher diversity of activities there. You see more berry picking going on. Yeah, you just see more different kinds of activities going on throughout the year. And I think a lot of it is just because it's close, it's more accessible than, the true Wilderness boundary I guess is higher up, more difficult to get to. (Interview 23)

Functionally, the Buffer Zone was often described by Tribal members as a "working landscape," a place with functional values to the community. For example: I know growing up the importance of the buffer zone was, and it still is, it was important, because there's a lot of small scale logging that happened. People's families were raised on that money. And small scale logging to me, even when I was a kid, didn't seem like such a big deal because, well, we cut down five or six trees and we made a few hundred dollars. And that supported our family. And I know it supported a lot of other families that we bumped into at the post and pole yard that we got to know and grow up with and ran into in the woods. You know, 
whether that buffer zone area was just an egress to get to that timber or if it was just where the timber was that we took, I know that was a big deal growing up. (Interview 15)

I mean, I know families that still subsist off of that deer or that elk that they got that was brought down because of places like the buffer zone, because the animals come down further for grazing when they get heavy, high snow and those areas down low are able to support them. And I think if that goes away, there's going to be a lot of problems for people's, not just their way of life, their way of living, it's just that still all trickles down. (Interview 15)

Personal and Cultural Attachments. Tribal members described some very personal attachments to the Wilderness Buffer Zone frequently. It is a place they grew up, a place they have used to access the Wilderness for many years, and in some cases a final resting place for relatives. No matter what the designation of the land, these places hold unique meanings for Tribal members. For example:

(What do you think is important about this buffer zone area?) It's like I say, it was probably culture. Because, see, before you get up, really up into the wilderness area there, I know probably 10 or 15 families from the old people that died, they'd take them up there and hide them and bury them. And only four or five people would know where they'd be. Well, it's getting now to where them are even dying, so you're losing it. (Interview 20)

And Tribal members' relationships with the Buffer Zone often go beyond individual attachments, to those that symbolize important things to their culture, attachments to their past and very similar to the spiritual meanings they attach to nature everywhere. Often there is little 
differentiation between the Wilderness and Wilderness Buffer Zone. Minimally, they are closely linked in the symbolic meanings they hold for Tribal members. For example:

To me they still have that piece of spirituality of the mountains, of connection that I talked about to the past, to the families that are still there, is still part of it... I just hope that whatever the outcome is, that somehow people will understand how important that is. It's a way of life to a lot of people. It's part of their lives, and it's survival. To me it's survival.

(Interview 1)

(... were there places in that lower area, the buffer zone, that were important for your family that you guys would go to and do different things?) Well, yeah. And there's a lot, there are areas where people would [engage in cultural activities], like in the winter. You know, ... and so forth like that. I really don't feel comfortable talking about specifics of it. (Interview 7)

Wildlife and Water Quality. The Wilderness Buffer Zone is often perceived as just as important as the Wilderness to wildlife. The wildlife do not know the boundaries, and neither does the water. Tribal members often see the Wilderness Buffer Zone as an important protector to the quality of both. For example:

Right up above there there's some grass about this long, and the bear likes to eat that, the grizzly bear. And there's another area down the canal from me. And they got a big area there where the grizzly bear, and the bear likes that grass. I like the animals in there. I really like the animals in there, especially if we, if people move in there, the grizzly bear will move away. The deer will too, and all those things. So we got to keep those places closed, to me. (Interview 13) 
And the water that comes down from the mountain is coming down the buffer zone and everything. It helps to keep all our trees and keep the moisture, which some just comes down to the, for the people to use. Yeah, water is the most important thing in our lives. (Interview 12)

Recreation, Privacy and Scenic Values. Tribal members are only slightly likely to assign recreation values to the Wilderness Buffer Zone. It's really more of a working landscape for them, with value mostly as protection for the Wilderness. There is lots of recreation going on there, however, and the remoteness from more dense housing situations is appreciated, as well as the scenic qualities. For example:

(What do you think is important about the buffer zone?) Well, I think that the biggest importance is it is a place where people can go recreate. And I think by extension of your own soul that you need to do that and you need to get into the woods if you have that opportunity. And I think that's what that is. I think that's a pretty easy question. (Interview 22)

It's beautiful. It's pretty. And I always liked that area because there's always places to go, you know, walking around, traveling around. And there's no people up there. I mean, well, there's a few people, but not too many. (Interview 13)

And then another big reason is the solitude. You know what hunting season is like off the Reservation. You know, there's orange everywhere. And up there, even though we can hunt 
year round up there, I think that spreads the hunters out. Even though it's probably peaking in the fall and early winter, you can get away from hunters up there easily, where it's much more difficult off the Reservation. So you can actually enjoy hunting more than off the Reservation I think. I find it more enjoyable that you're not bumping into someone all the time. So it's that solitude, I guess, even though you may not be by yourself, there's maybe only one other person or a couple other people in the same area that you're hunting, so that's a lot of it is just being able to get away from people. (Interview 23)

Today people use that area just for scenery, where people stop there along the highway and take pictures. (Interview 2)

\section{Trust and conflict}

Though not a major line of questioning in the interviews, care was exercised to bring together any mention of things that were causing conflict or impacting trust in any way. Many Tribal members talked about trust and conflict which threaten the sustainability of the Wilderness Buffer Zone. Some of the general comments that need to be understood for management of this area and engagement with the public are summarized here with examples. Among Tribal members, it has been suggested that the whole reason for designation of the Wilderness was at least partly due to a lack of trust the community had in forestry interests. They were afraid of intensive logging and loss of connection to the Missions due to aesthetic and psychological impacts. The Wilderness Buffer Zone designation further illustrates the lack of confidence in common forestry practices that could extend directly to the Wilderness border. The Wilderness Buffer Zone essentially established a checks and balances system that assured 
deliberation and conscious decision-making, essentially to assure that trust is protected and the Wilderness values do not deteriorate. Some of the conflict, not surprisingly, comes from the history of forestry practices in the Missions and from the perception that new residents bring different values into the community. For example:

People that don't understand the process of nature, the people that don't know, that don't look beyond what the visual, they don't look beyond what it really provides. So they come here and end up staying here. And instead of learning the values of a place like this, they try to put in their own values. (Interview 1)

When I saw the boundary lines of where the Wilderness boundary was being proposed and where the canal was, I was pretty taken back by that because I thought, wow, there's a little bit of, to me, at the time I was thinking of trickery or, you know, because when I would think that it should be down here, and most of the Tribal members thought it should be down here ... (Interview 10)

I don't know how other people feel, but it looks just unnatural and used, like there wasn't the respectful hand that went across that area, that landscape. And I think that's what people fear, because I've seen examples of forestry logging practices, and they don't want to see that in the Missions. And I know that's an issue for the buffer zone. And I don't know, I do hold a little bit of distrust for forestry practices, just because of my own personal experience since I've been here in this position and hearing the frustration of other wilderness or even wildlife managers with it. (Interview 15) 
You know, Forestry has great software that they've used in the past to sort of be able to allow people to visualize that through computer graphic generation, but that's still, even though it's nice, it's different than actually seeing a place that's had that done to it. So I think that's something that the Tribe needs to look at and for people to sort of gain trust back into Forestry because of things that have happened in the past. (Interview 15)

I think that there is a lot of controversy now in the management of the buffer zone. And I think that Tribal Forestry Department is interested in entry. And it's unfortunate that there's such a high level of distrust or mistrust... But the proposal to change the buffer zone management plan and engage in commercial timber harvest is not a way to instill confidence in the Tribal membership that they're really interested in hazard fuel reduction. (Interview 16)

When I was young, I don't know if I should say this on the recording, but I have to give you a little bit of history. Being in the woods all the time, I remember being a kid and going up to Hellroaring, which is the headwaters of Polson's water system, along the east shore. And we had a fellow that mom said he was from the prairie, couldn't stand any standing trees. His name was (deleted), I believe. He was, at that time Forestry was under the control of the BIA, and he was the head of that department here. And he did some really atrocious forestry practices... You know, so as a result of that, I used to flip off loggers when I was very young. (Interview 7)

\section{Mapping meanings for the Buffer Zone}


While Phase I of this research focused on learning about these five types of meanings and some of the sources of conflict and threats to these meanings, Phase II placed those meanings and threats on the landscape. The main user interface in Phase II is based on the "Tagger" fuzzy area definition software developed by Evans \& Waters (2007) as a Java applet running within a standard web browser environment and described extensively in Carver et al. (2009). This uses a spray can tool with which a user can define fuzzy areas of varying density on a map. Variations in intensity, or importance, can be easily made by spraying more or less over an area, making it correspondingly darker or lighter. Attribute information can be attached to the fuzzy area through the use of free-format text input boxes. Subjects were asked to contribute to maps that placed each of the five primary meaning categories on the map and also describe threats they perceived to each category of meanings (Watson et al. 2008).

Each sprayed area entered by the user is processed by the Tagger software into a standard image format (gif and GeoTIFF) and compressed. The image and associated attribute information are stored and can be viewed either as an individual entity or combined into an aggregate "average" map based on all the users' responses.

A broad appeal which was issued to residents to participate in the web-based version of the information collection activity or have a research assistant bring a laptop version to the person encouraged broad participation in the community for 3 months.

\section{Results of the Mapping Activities}

Analysis consisted primarily of developing maps which illustrated these relationships with the Buffer Zone. While maps could have been developed at the individual level or at the group level, a two-step process provides 1) an overall picture of where meanings are attached 
and the average intensity of meanings attached to those places and 2) maps for individual layers of meanings.

Across all five layers of meanings, 180 maps were contributed by Tribal members and used in this analysis. These maps were generated by just over 40 Tribal participants. An overall average map is developed that depicts so-called "hot spots" by averaging responses. Therefore, those areas that are indicated as the highest intensity are those with the greatest agreement among Tribal members that they are important and are of the highest importance, regardless of meaning attached (Carver et al. 2009).

From examination of these maps, it can be recognized that there was some agreement that "wilderness protection" was attached broadly to this area. The scale was extensive, and likely indicates that many people simply chose the option of applying this meaning at a specific, consistent level of intensity, to the entire map. It is a strongly held belief across many Tribal members.

One additional map also indicated relatively broad meanings and high agreement on intensity across Tribal members. That is the map depicting "wildlife and water" meanings. In this case, it is not as widely distributed as the "wilderness protection" values, but is very intense at many places and this meaning is attached to most places by at least some people.

The other three layers of meanings were much less likely to be broadly indicated as important across the landscape, though they were intensely attached to some places. When averaged with the previous two maps, it is clear to see how the overall mean map is developed and what it represents in relation to each of the five layer maps (Carver et al. 2009).

\section{Phase III application}


The maps described above provide managers and the public with good understanding of where and how intensely the various types of meanings are attached to the landscape, and according to the framework supported by Watson \& Borrie (2003) are likely to build trust through manager commitment to understand and include knowledge about these local meanings in decision making. Results have been used to guide focus group discussions between forest managers and Tribal members about proposed fuel treatments in the Buffer Zone. The maps described above are not the ones providing the most useful stimulus for these discussions, however. To build trust among Tribal residents, fire planners must understand how proposed actions interact with local community values at risk and describe a prioritization process that addresses publicly perceived threats. Additional maps were generated to illustrate location of these threats and to stimulate discussion in focus group meetings.

When threats were analyzed, Tribal members had indicated many that posed risk to the meanings they attached to these important places. These included private land ownership within the Buffer Zone, use of all terrain vehicles and their impacts, grazing of livestock, crowding in some places, recreation use in some places, past evidence of temporary drug manufacturing laboratories, lack of respect shown for the land by users, fire, logging and vegetative change. For the purposes of this analysis, fire, logging and vegetative change were the threats worthy of more analysis to move ahead on forest health issues in the Buffer Zone.

Maps were created that first of all showed, across all five layers of meanings, those places where any of these three threats were indicated. Within the "fire" threat, Tribal members mentioned such things as the threat of burning cultural areas, the possibility of lethal levels of fire, a catastrophic fire threat, wildfire, fire, hazardous fuel and even fire fighters as a threat to the meanings they attach to these areas. This threat, or these threats, if plotted collectively, is 
extensive and there is agreement that this threat is distributed widely. However, there is an even more intense and more broad distribution related to the "logging" threat. Tribal members chose a variety of words to describe this threat, using the following terms: loggers logging the area, large scale logging, commercial logging, clearcutting, irresponsible logging, incompatible timber harvest, too much logging, harsh logging, and even attributed threats to the presence of loggers.

\section{Implications for decision making}

Completed analysis linked these mapped meanings to the threats respondents perceive associated with each layer of meaning. These are the priority inputs (location, meaning, intensity of meanings, and threat) that in combination managers must integrate with resource management objectives to maintain public trust. Focus groups composed of Tribal members, facilitated by the Tribal Forestry Community Outreach Education Specialist, interacted with Forestry Department staff who are proposing general fuel treatments in the Buffer Zone. Emphasis was on three questions in these focus groups: 1) further clarify the threat (or benefit) of "logging" on the various layers of meanings ascribed to specific places, 2) further clarify the threat (or benefit) of fire (i.e. wildfire, prescribed fire or exclusion of fire?) on layers of meanings, and 3) help with understanding of how Tribal members evaluate tradeoffs between these two threats to the meanings they attach to this landscape and how trust will be affected by decisions implemented. This, the final stage of this project, was focused on application of place meaning knowledge to decision-making and an evaluation of whether public members believe better solutions resulting from these participatory activities will be obtained.

Generally, this phase was evaluated positively by participating Tribal members. And while a great deal was learned about the specifics of how fire and logging threatened these 
places, of most importance, and very apparent during these focus groups, was the need for a method of managing tradeoffs. Forestry activities in the Buffer Zone that are aimed at revenue generation are not desired by most Tribal members participating, with some extremely antilogging attitudes apparent. Similarly, many people are fearful of the catastrophic potential for any type of fire, from any source.

It is hoped that in making a set of recommendations for resolving conflict over actions to be taken in the Buffer Zone, the tradeoffs between fire and vegetation removal can be addressed. If these tradeoffs can be described in terms of the impacts to meanings people attach to this area, and limits can be established for the amount of impact acceptable to these meanings, then both logging and fire introduction can be implemented within these constraints and held accountable through long term monitoring. Through this process, healthier forests, renewed public trust, and a protected natural and cultural resource are all more likely. 


\section{References}

Borrie, W.T., Christensen, N., Watson, A.E., Miller, T.A., \& McCollum, D.W. (2002). Public purpose recreation marketing: a focus on the relationships between the public and public lands. Journal of Park and Recreation Administration 20(2):49-68.

Carver, S., Watson, A., Waters, T., Matt, R., Gunderson, K., \& Davis, B. (2009). Developing computer-based participatory approaches to mapping landscape values for landscape and resource management. In, S. Geertman, J.C.H. Stillwell (eds), Planning Support Systems Best Practice and New Methods, Springer. 431-448. DOI 10.1007/978-1-4020-8951021.

Dwyer, R.R., Schurr, P.H., \& Oh, S. (1987). Developing buyer-seller relationships. Journal of Marketing, 51: 11-27.

Evans, A.J., \& Waters, T. (2007). Mapping vernacular geography: web-based GIS tools fro capturing "fuzzy" or "vague" entities. International Journal of Technology, Policy and Management, 7(2): 134-150.

Garbarino, E., \& Johnson, M.S. (1999). The different roles of satisfaction, trust and commitment in customer relationships. Journal of Marketing, 63: 70-87.

Lewis, J.L., \& Sheppard, S.R.J. (2005). Ancient values, new challenges: Indigenous spiritual perceptions of landscapes and forest management. Society and Natural Resources 18:907-920.

Morgan, R.M., \& Hunt, S.D. (1994). The commitment-trust theory of relationship marketing. Journal of Marketing, 58:20-38.

Watson, A. E., \& Borrie, W. T. (2003). Applying public purpose marketing in the USA to protect relationships with public land. In, Nature-based tourism, enviornment and land management. (ed.) Buckley, R.; Pickering, C.; Weaver, D.B. CABI Publishing: Oxon, UK, Cambridge, MA. P. 25-33.

Watson, A., \& Borrie, W. (2006). Monitoring the relationship between the public and public lands: application to wilderness stewardship in the U.S. In: Aguirre-Bravo, C.; Pellicane, Patrick J.; Burns, Denver P.; and Draggan, Sidney, Eds. 2006. Monitoring Science and Technology Symposium: Unifying Knowledge for Sustainability in the Western Hemisphere Proceedings RMRS-P-42CD. Fort Collins, CO: U.S. Department of Agriculture, Forest Service, Rocky Mountain Research Station. p. 287-293.

Watson, A,; Knotek, K., Matt, R., \& Yung, L. (2007). Understanding landscape meanings, attributes, and threats for the planning and application of fuel treatment and fire management on the Flathead Indian Reservation, Montana. Report to the Confederated Salish \& Kootenia Tribes, on file, Aldo Leopold Wilderness Research Institute. 
Watson, A., Matt, R., Waters, T., Gunderson, K., Carver, S., \& Davis, B. (2008). Mapping tradeoffs in values at risk at the interface between wilderness and non-wilderness lands. Proceedings: III International Symposium on Fire Economics, Planning, and Policy: Common Problems and Approaches, 29 April - 2 May, 2008. Carolina, Puerto Rico. Gen. Tech. Rep. PSW-GTR-19x. USDA Forest Service, Pacific Southwest Station.

Watson, A., Matt, R., Knotek, K., Williams, D., \& Yung, L. (In press). Traditional wisdom protecting wilderness as a cultural landscape. In Proceedings: Sharing Indigenous Wisdom International Conference, June 2007, Green Bay, WI.

Acknowledgements: The research described here was funded primarily by the Rocky Mountain Research Station, using National Fire Plan funds, though the Bitterroot Ecosystem Management Research Project, the University of Montana, the University of Leeds, and the Confederated Salish \& Kootenia Tribes all contributed resources to accomplishing the objectives of this project. 
Figure 1. The Mission Mountain Tribal Wilderness is bordered to the west by the Tribal Buffer Zone. (Photo courtesy the Confederated Salish \& Kootenai Tribes)

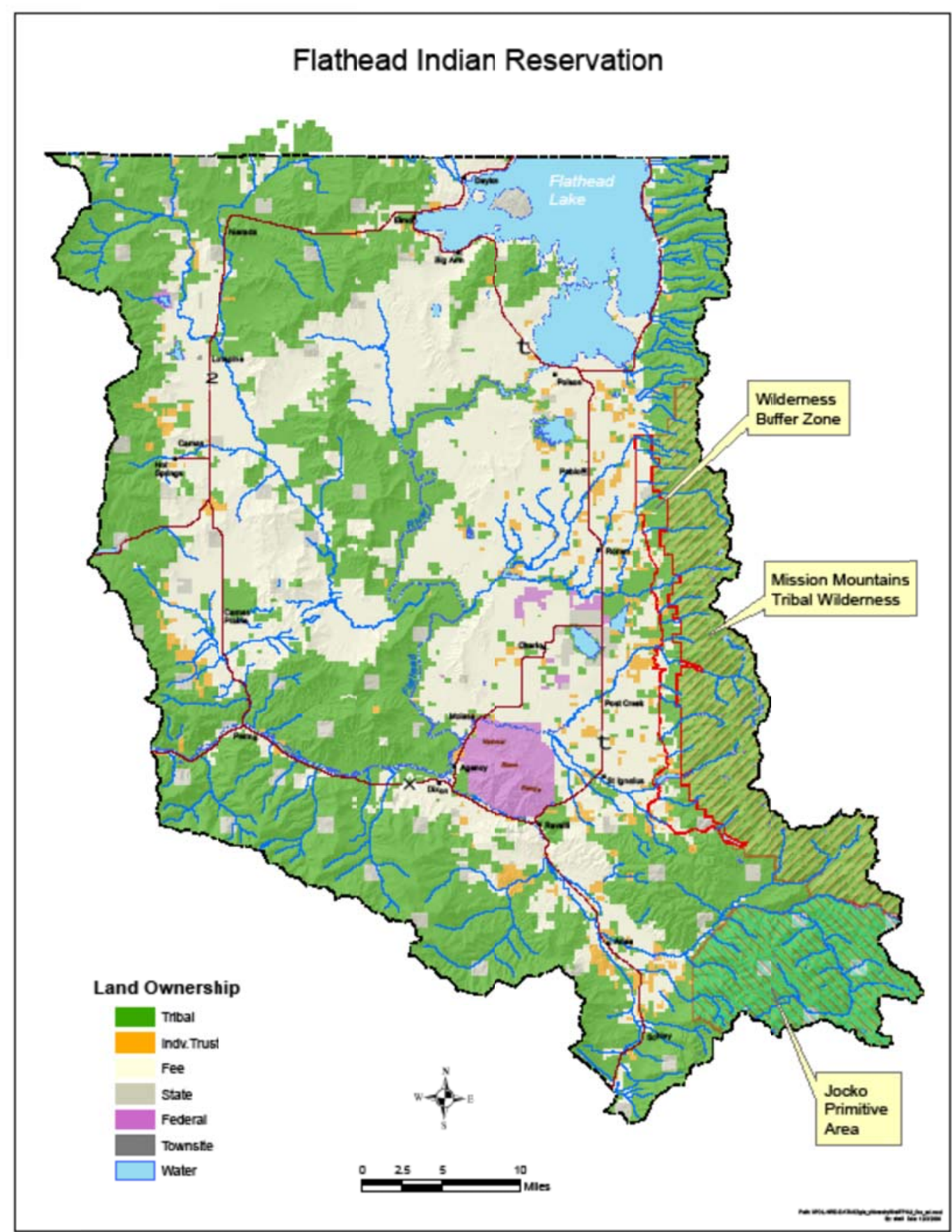




\section{Community-based place attachment to public land}

Neal Christensen and Jim Burchfield

Public land managers must consider a broad range of public input in developing effective and equitable land use projects. There is growing evidence that increased understanding of public views and desires can enhance honest and meaningful involvement of the public and contribute to more balanced, integrated and equitable management decisions (Kruger 2003). The challenges are to develop deeper understanding of widely varied public interests and to seek the best balance between a consideration of each individual's views and that of the aggregate of the affected populations. These challenges are shaped by the public purpose and the social and ecological characteristics of the planning area.

Organized stakeholder groups are often the most common means available to the public to articulate their interests in project planning situations - through lobbying, organized letterwriting, attending public meetings, or in collaborative decision-making processes. However, individual needs may be poorly represented by stakeholder groups. Special interest stakeholder groups commonly focus on a narrow set of objectives, while their constituents are unique individuals with varied concerns, values, and life stages. Many public planning processes fail to find solutions to contentious issues, not only because stakeholder groups struggle against each other, but also because these groups cannot agree internally on acceptable management options (e.g., Marston 2001; Moseley 2001; Snow 2001). This chapter describes a research approach that examines people's bonds with specific public places at an individual level through survey research and segmentation analysis. The authors argue that this process clarifies mutual interests among participants in land use decisions and that segmentation based on people's bonds with public wildland places reveals alliances within communities that reflect powerful, latent 
expectations and demands that enable more creative and cooperative solutions to contentious planning problems.

A general goal of this survey research application is to provide a pre-planning tool to build understanding of public behaviors and interests during contentious public planning situations. A human / place bond segmentation approach supplies a relatively underutilized and replicable tool for public wildland planners. The information from this type of study could be useful early in the planning process to managers, organized stakeholders, and the general public to improve understanding of local views during project planning efforts. This application could help break down inaccurate stereotypes that lead to planning gridlock by identifying more moderate stances within traditional stakeholder groups along with common views and activities shared between seemingly opposed groups. The information complement other forms of input developed by biologists, hydrologists, and other resource professionals in assessment phases of planning processes. This approach is also complementary to the GIS techniques described in other chapters in this application section. While GIS techniques assess spatial variation in human ties to place, the human / place bond research approach presented in this chapter focuses on variation in these ties among a particular population toward a specific place.

The population of interest in this type of application is typically bounded by a geographic space where controversial issues are often publically debated among widely varying interests, such as a portion of a National Forest Ranger District. Our goal is to understand local social interests - their extent and intensity for a these wildland places. In many contentious public planning situations the depth and breadth of local public interests are poorly understood, with the energies of managers and public participants more focused on divisive interest group politics than genuine collaboration and shared learning. The human / place bond research approach 
provides a tool to describe complex and varied interests that goes beyond qualitative assessments, whose limitations are recognized in previous chapters. Just like you can "see" things on a map, survey research gives quantifiable, reliable information on the distribution of local public interests. Whether or not a manager chooses to use these interests as determinants of action is usually left to their discretion within other relevant pressures on their decision space.

It has always been difficult in collaborative planning to address the fairness of the representation of public interests. William Leach describes this in "Devolved Democracy" (Leach 2003), showing that the issues of inclusion and representation are extremely difficult barriers to collaboration. How do you know if it is not just the loud voice of a few "gladiators," as Jack Ward Thomas (chief of the US Forest Service from 1993 - 1996) called them, shouting out for their own specific demands? Better information may blunt the power of the loud voices, as deliberation is about using information, logic, and persuasion for purposes of influence, which is a short step from power (even though the nominal power rests firmly in the hands of the agency managers). The human / place bond survey research provides managers and the public with data that is similar to a GIS representation - a fair, accurate, and repeatable characterization of social conditions. This is a vital missing step in collaborative planning - actually knowing what the local population cares about for a particular public place.

There is growing evidence that people's ties to public places influence their views about conflict and appropriate management solutions in natural resource management decisions (e.g., Brown, Reed, and Harris, 2002; Cheng, Kruger, and Daniels, 2003; Davenport and Anderson, 2005). Low and Altman (1992) offer a conceptual framework compiled from a number of authors across many disciplines engaged in developing understanding of humans and place. They adopt the term "place attachment" to represent the concept of human ties to place (Altman 
and Low 1992). Hinting at the numerous perspectives on this concept, they say that place attachment "subsumes or is subsumed by" other terms in the literature including topophilia (Tuan 1974), sense of place, and place identity. Their view of place attachment involves an interaction between practice, cognitive, and affective components of expression. They describe the practice component as actions and behavior, while the cognitive component includes thought, knowledge and beliefs. The affective component is recognized as emotional attachment. However, they critique their contemporary researchers (as well as the term, itself) for tending to over-emphasize the affective, emotional component.

In the nearly two decades since Low and Altman (1992) developed their framework interest in humans and place research has continued. Many others (e.g. Schreyer, Jacob, and White, 1981; Jorgensen and Stedman, 2001; Williams and Vaske, 2003; Kyle, Mowen, and Tarrant, 2004) recognize and consider the multiple, rich components of human/place relationships, but it has only been recently that applications like mapping and straightforward survey tools could be made available to managers. The present volume represents current thought on this intriguing topic. Chapters presented in this section on research application tools demonstrate a transition in place research that expands a consideration of values along with more traditional measures of association like activities and place attachment. For example, Shroeder's description of felt values within this volume is closely related to an emotional, affective tie to place. His view of held and assigned values, following the work of Brown (1984), supports assigned values as a form of cognitive expression of ties to place. The chapters in this section presenting GIS applications also consider assigned place values (Cacciapagalia and Yung, this volume; McIntyre and Lesueur, this volume), or threats to assigned place values 
(Watson, et al., this volume). McIntyre and Lesueur also consider activities as a form of behavioral expression of place bonds.

The human / place bond research approach emphasized in this chapter is based on the recognition that people's ties with specific places are difficult to observe directly, are expressed in multiple ways, and are related to attitudes about management of those places. As a latent concept, researchers typically rely on measuring people's bonds to place indirectly through the use of indicators (Watson et al. 2007). Following the definition of human / place bonds to include cognitive, affective, and behavioral forms of expression toward a specific place guides the selection of indicators to reflect these three domains.

The choice of research indicators of the concept of human / place bonds is critical and should be carefully considered given the unique nature of ties between individuals and specific places. The chosen indicators should be easy to monitor, valid in their representation of the latent concept, and have established methods of reliable measurement based on past research. The choice of indicators used in this type of research is also guided by the applied goal of improving the consideration of human / place bonds in natural resources management decisions; therefore, the indicators should be developed with particular relevance to the planning area. Because of the situated nature of human / place bonds the chosen indicators should also be adapted to reflect local terminology and issues. This is generally done by conducting background investigation and qualitative interviews with management and the public prior to development of a survey research instrument.

A case study example will be helpful to illustrate this approach. The application of this human / place bond research is appropriately referred to as a case study because the bonds residents form with a specific public place are highly contextualized, or "situated." Thus, 
research results regarding this relationship with a specific place are generalized only to that specific location (see Yin 2003 for case study design). The human / place bond case study described here explored a community's perceptions of a travel management plan within a forest stewardship project on the Bitterroot National Forest in southwestern Montana. The travel management component of the Trapper-Bunkhouse Forest Stewardship project on the Darby Ranger District was contentious in the community, particularly among off-highway vehicle (OHV) enthusiasts who desired better access and different types of experiences in the TrapperBunkhouse watershed, and among local home owners who expressed numerous concerns about this type of recreation in their 'back yard.' Public meetings were held in the local community to help clarify the travel plan component. The meetings were contentious, and ultimately, unsuccessful in their objective of building support for the proposed travel plan. The travel plan was eventually dropped from the forest stewardship project because of the controversy, thus postponing travel management decisions for this area until they are resolved as part of a larger scale, forest-wide travel planning process. The public meetings and written comments provided a rich source of qualitative input to the human / place bond case study. Insights from the qualitative work were used to develop a quantitative survey that was administered to the local community to inform future travel management planning in the Trapper-Bunkhouse area.

To provide a robust set of measures the research approach uses three general types of indicators in quantitative surveys to assess human / place bonds. The three types of indicators include: 1) activity participation, representing the human / place bond behavioral component; 2) assigned values, measuring cognitive beliefs; and 3) place attachment representing the affective component. These three sets of indicators are well-suited for measuring the latent concept of ties to place according to the criteria for good quantitative research indicators described above. In 
combination, the indicators represent the behavioral, cognitive, and affective forms of expression in our definition of human / place bonds. The following three figures provide examples of survey items in the case study measuring each of these types of indicators. The indicator items were modified from their standard wording to reflect the local situation based on understanding gained during the qualitative phase of the case study. Figure 1 shows four of the 16 activity items that were included on the case study survey instrument. These items reflect onsite activities but could also include off-site public participation and conservation efforts related to the Trapper-Bunkhouse planning area. The 'experience use history,' or length of time the respondent has been using the Trapper-Bunkhouse could also be included as a measure of behavioral expression of human / place bonds.

Figure 1: Example of activity participation items from the case study survey.

\begin{tabular}{|c|c|c|c|}
\hline \multicolumn{4}{|c|}{$\begin{array}{l}\text { Q1. Which of the following recreation activities have you and other members of } \\
\text { your household done in the Bitterroot National Forest? (Check all that apply) }\end{array}$} \\
\hline & \multicolumn{2}{|c|}{ Have you personally participated: } & \multirow{2}{*}{$\begin{array}{l}\text { Other household } \\
\text { member(s) did } \\
\text { this activity } \\
\text { in the } \\
\text { past year }\end{array}$} \\
\hline & $\begin{array}{l}\text { In the } \\
\text { past year or }\end{array}$ & $\begin{array}{l}\text { In your } \\
\text { lifetime }\end{array}$ & \\
\hline Walking or hiking & $\square$ & $\square$ & $\square$ \\
\hline Overnight backpacking & $\square$ & $\square$ & $\square$ \\
\hline Fishing & $\square$ & $\square$ & $\square$ \\
\hline Horseback riding & $\square$ & $\square$ & $\square$ \\
\hline
\end{tabular}

The case study survey included 11 different types of assigned values for local Bitterroot National Forest lands. The range of these value items included on the survey was determined from the previous qualitative research to reflect local orientations. Four of the assigned value items are shown below in Figure 2. 
Figure 2: Example of assigned value items from the case study survey.

\begin{tabular}{|c|c|c|c|c|}
\hline \multicolumn{5}{|c|}{$\begin{array}{l}\text { Q2.How important to you are each of the following values that may be associated } \\
\text { with the Bitterroot National Forest? (Circle one response for each type of value } \\
\text { that best represents the importance you place on it) }\end{array}$} \\
\hline & $\begin{array}{l}\text { Not at all } \\
\text { Important }\end{array}$ & $\begin{array}{l}\text { Slightly } \\
\text { Important }\end{array}$ & $\begin{array}{c}\text { Moderately } \\
\text { Important } \\
\end{array}$ & $\begin{array}{c}\text { Very } \\
\text { Important }\end{array}$ \\
\hline Watershed protection & NI & S I & MI & VI \\
\hline Economic value of timber resources & NI & S I & MI & VI \\
\hline $\begin{array}{l}\text { Economic value of recreation } \\
\text { visitor spending in the area }\end{array}$ & NI & S I & MI & VI \\
\hline Wildlife and fish habitat protection & NI & S I & MI & VI \\
\hline
\end{tabular}

The third set of items included in the case study survey measured two aspects of attachment to place. These indicators represent the affective form of expression of bonds with place. Williams and Vaske (2003) describe place identity and place dependence as two subdimensions of place attachment that have been applied to the study of human / place bonds within recreation research. The authors established a reliable set of psychometric scale items to measure the place dependence and place identity subcomponents of place attachment. Williams and Vaske (2003) tested and established reliability estimates for six place identity and six place dependence items. The following figure from the case study survey shows three of those items. he first and second items represent the place identity subcomponent of place attachment and the third item is an example from the place dependence subcomponent. To strengthen this approach, indicators of other aspects of emotional ties to place, such as measures of felt values (Schroeder, this volume) could be included to strengthen the assessment of the affective domain of expression. 
Figure 3: Example of attachment to place items from the case study survey.

\begin{tabular}{|c|c|c|c|c|c|}
\hline \multicolumn{6}{|c|}{$\begin{array}{l}\text { Q3. How much do you agree or disagree with each of the following statements? } \\
\text { (Circle one response for each statement that best represents your level of } \\
\text { agreement) }\end{array}$} \\
\hline & $\begin{array}{l}\text { Strongly } \\
\text { Disagree }\end{array}$ & Disagree & Neutral & Agree & $\begin{array}{l}\text { Strongly } \\
\text { Agree }\end{array}$ \\
\hline $\begin{array}{l}\text { The Bitterroot National } \\
\text { Forest means a lot to me. }\end{array}$ & SD & D & $\mathrm{N}$ & A & SA \\
\hline $\begin{array}{l}\text { I identify strongly with the } \\
\text { Bitterroot National Forest }\end{array}$ & SD & D & $\mathrm{N}$ & A & SA \\
\hline $\begin{array}{l}\text { I would enjoy doing the things I do } \\
\text { in the Bitterroot National Forest } \\
\text { just as much at a similar place. }\end{array}$ & SD & D & $\mathrm{N}$ & A & SA \\
\hline
\end{tabular}

A larger, relevant set of items within the three components of expression were administered to a representative sample of residents of the local community using survey research techniques. The study population was chosen because of the close proximity of the local community to a forest stewardship project area in the Trapper-Bunkhouse drainage and includes the residents living near the planning area. The research approach described in this chapter is unique in combining these three concepts of affective, cognitive, and behavioral forms of expression as the primary indicators of human / place bonds, and in segmenting the public based on these bonds for the purpose of developing understanding about their opinions in contentious planning decisions. Combining these indicators offers a robust and diverse set of measures, each with a history of applied measurement in natural resource management studies, to better reflect the multidimensional nature of human / place bonds than a traditional single-focus method.

To develop understanding of local human / place bonds the data from the survey research are analyzed using a combination of factor and cluster analysis (see Hair, Black, Babin, Anderson, and Tatham, 2006 for a detailed description of the process used to apply these 
multivariate statistical techniques). The data analysis follows three general modeling steps. In the first step factor analysis is used to reduce the list of human / place bond indicator items to a set of sub-components within the more general categories, and these sub-components are assigned descriptive names by the researcher (e.g., 'motorized activities,' 'economic assigned values,' 'functional attachments'). This process allows the unique local sub-components to emerge from the data rather than being pre-defined by the researcher. The second data analysis step uses the human / place bond sub-components from the factor analysis as input to cluster analysis. A respondent's type of bond is determined by the combination of high and low factor scores across the sub-components while their bond intensity reflects an index of the combined factor scores across all forms of expression. The cluster analysis is an efficient data organizer in that it can simultaneously consider concepts measured on different scales by using factor scores across all human / place bond sub-components. The clustering results in a classification of survey respondents into segments of individuals with similar types and intensities of human / place bonds.

The combination of statistical methods used to develop the quantitative results provides an efficient means to account for the multiple expressions of human / place bonds and to interpret the findings in meaningful ways to managers and interested citizens. Factor analysis identifies latent components of human / place bonds that are otherwise difficult to observe and measure, while cluster analysis identifies segments of the local community having similar human / place bonds based on a combination of qualitatively different types of indicators. Resulting clusters of similar human / place bond individuals can be compared for meaningful patterns of differences in opinions about management options for the planning area. After the analysis of survey results is completed, the final step is to interpret and report them to managers and 
interested citizens to help inform public input to the planning process. Figure 4 shows three opinion survey items from the case study focused on motorized recreation management options. 
Figure 4: Example of management items from the case study survey

\begin{tabular}{|c|c|c|c|c|c|}
\hline \multicolumn{6}{|c|}{$\begin{array}{l}\text { Q8.Tell us whether you oppose or support the following recreation and travel } \\
\text { management options for the Bitterroot National F orest. (Circle one response } \\
\text { for each statement that best represents your level of support or opposition) }\end{array}$} \\
\hline & $\begin{array}{l}\text { Strongly } \\
\text { oppose }\end{array}$ & Oppose & $\begin{array}{l}\text { Not } \\
\text { Sure }\end{array}$ & Support & $\begin{array}{r}\text { Strongly } \\
\text { support }\end{array}$ \\
\hline $\begin{array}{l}\text { Open more currently gated roads to } \\
\text { motorized access during the summer } \\
\text { months. }\end{array}$ & SO & $\mathrm{O}$ & $\mathrm{N}$ & $\mathrm{S}$ & SS \\
\hline $\begin{array}{l}\text { Close some roads or trails that are } \\
\text { currently open to motorized use } \\
\text { to provide more nonmotorized } \\
\text { recreation opportunities. }\end{array}$ & SO & $\mathrm{O}$ & $\mathrm{N}$ & $\mathrm{S}$ & SS \\
\hline $\begin{array}{l}\text { Close some roads or trails currently } \\
\text { open to motorized use if it improves } \\
\text { wildlife habitat or water quality. }\end{array}$ & SO & $\mathrm{O}$ & $\mathrm{N}$ & $\mathrm{S}$ & SS \\
\hline
\end{tabular}

The human / place bond analysis for the case study identified six segments (sample subgroups) that reflected relatively like-minded individuals within their local geographic community. Each of these subsets of the overall resident sample displayed different human / place bonds with local public lands in the project planning area and each had statistically different concerns about conditions and perceptions of appropriate management. It is important to remember, however, that while the differences in opinions across segments were statistically significant, generalization from the sample is limited to the population of the local community because of the situated nature of human / place bonds and the case study design of the research.

To reveal the relationships of segments to each other along gradients of interests, segments were arranged graphically in quadrants in Figure 5 to show the position of each segment relative to the three human/place bond components (activities, values, and emotional attachment). Figure 5 also indicates each segment's preferences for management, shown in the final, fourth quadrant on the lower right of the figure. This rather complex, but revealing graphic 
demonstrates the utility of using segment membership to understand patterns in opinions about management of local public lands. The six segments are identified in each of the plots with a number representing their rank order from low (1) to high (6) on an aggregate human / place bond intensity score - an index derived from the combination of the factor scores across all of the sub-domains.

Each of the plots reflects relative scoring where a point representing the grand mean for both axes would be plotted at the origin. Points above and to the right of the origin represent above average responses, while points below and to the left represent below average scores. Follow Segment 1 (with the lowest intensity index score) as an example across the four plots in Figure 5. Plots A, B, and C show Segment 1's position along each of the human / place bond sub-dimensions relative to the other segments and Plot D indicates its relative scores on attitudes about two management approaches. In Plot A, Segment 1 scored below average on both motorized and nonmotorized activity participation sub-components of the behavioral dimension participation (notice that it is below the origin in both of the two dimensional representations of the two variables measured, motorized recreational activity and nonmotorized activity). Plot B, in the upper right quad of Figure 5 shows that Segment 1 scored below average on intangible assigned values and about average on tangible assigned values. Plot $C$, in the lower left quad also indicates that this segment of respondents scored below average on both place identity and place dependence subcomponents of place attachment relative to other community segments. In contrast to Segment 1, Segment 6 (the highest intensity group) represents the other end of the spectrum of types of bonds found in the community toward local National Forest lands. Segment 6, in this example, scored the highest on all six sub-dimensions of human / place bonds between local residents and nearby National Forest lands. While Segment 1 points are mostly 
plotted in the lower left quadrants of Plots A, B, and C, Segment 6 points all appear in the upper left quadrant of each of the three human / place bond plots. The other four segments identified in the case study and plotted in Figure 5 scored somewhere between Segments 1 and 6 on one or more of the human / place bond sub-dimensions.

Scores from the three segments having high participation rates in motorized activities ( 2 , 3, and 6) provide insight about the influence of human / place bonds on opinions about management. All three of these segments would have been represented by the motorized user stakeholder group during public input to the Trapper-Bunkhouse travel management debate. The motorized user stakeholder group was largely dominated by the "outspoken gladiators" in these travel planning discussions. The three motorized user segments are circled in each of the four plots in Figure 5 for easier identification in this illustration. While each of these motorized user segments share a common activity, they have much less in common on the other two types of human / place bond expression (note their difference in Figure 5B on assigned values, for example). Plot $\mathrm{D}$ shows relative responses among the segments to two of the travel management options shown in Figure 4. Both options would directly affect the motorized segments by closing existing motorized access in the Trapper-Bunkhouse area, but they offer opposing reasons for doing so - one to increase nonmotorized opportunities, and the other to protect the environment. While none of the three motorized user segments support closures that would restrict their access for the personal gain of nonmotorized users (they do vary a bit, but range from opposing to neutral on this issue), there is considerable variation in their views on closures to protect the resource. The high-intensity motorized user group (Segment 6) strongly supports this stewardship-oriented management option, while Segment 2 is somewhat neutral and Segment 3 opposes it. The three highest intensity segments $(4,5$, and 6 - with varying levels of 
motorized participation) show the greatest support for closing roads to protect the environment. Segment 4 (the quiet user group that has below-average rates of participation in motorized activities) is most supportive of closing roads to enhance nonmotorized recreation, while Segments 2 and 3 (two of the motorized user groups) are least supportive of closing existing roads for any reason. 
Figure 5: Human / Place Bond components and their relationship to stewardship-oriented opinions about management, case study survey results.

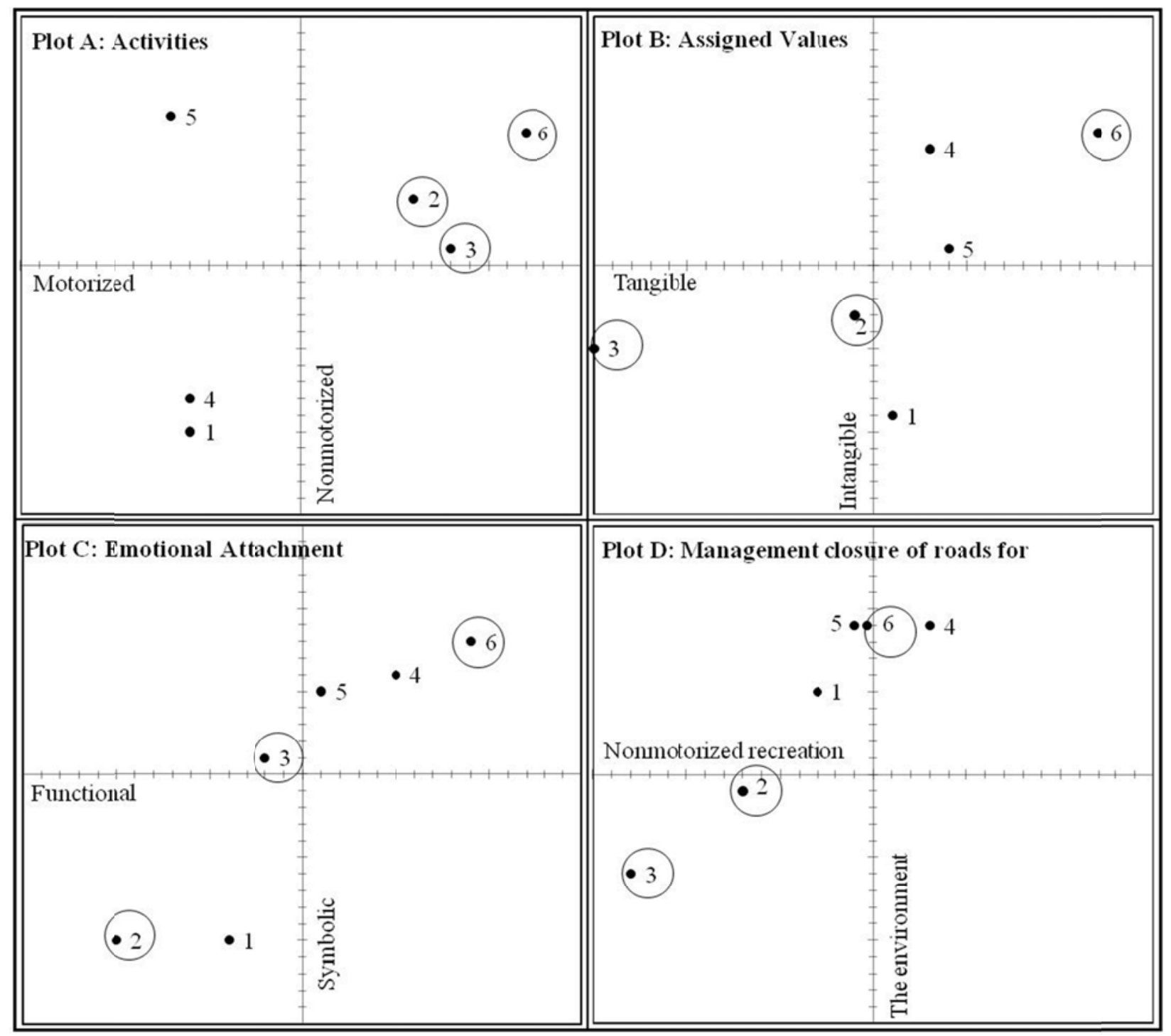

The "high intensity" place-bonded groups in the local community (Segments 4, 5, and 6 in Figure 5) appear more likely to adopt a stewardship orientation toward local public land management and resource protection. Because these segments tend to use the area regularly, they likely have realistic perceptions of current conditions. They are more likely to have a long experience use history and they probably care deeply about the place, and therefore, are more 
willing to sacrifice personal benefit for a greater public purpose. Local community residents with bonds focused on a single activity, but without the intensity of bonds formed through high levels of assigned values and emotional attachments (Segments 2 and 3 in Figure 5), seem to care more about the local National Forest space as a backdrop providing the opportunity needed for their activities. As they seem less likely to support restrictions of their use of this place, they may represent the greatest challenge to the public participation process that will follow in forestwide travel planning.

This example describes considerable diversity across the motorized stakeholder group and Figure 5 also shows similar diversity among those who do not participate in motorized activities on the local National Forest. These internal group tensions were apparent at the community meetings among both motorized and non-motorized stakeholder groups and will likely surface again in future travel planning for the area. At the meetings, some motorized advocates were angry at others in their own group for breaking ranks and considering any type of restriction to their motorized access. One member of a local homeowner group that was largely represented by the self-titled 'quiet-user' stakeholder group during community meetings described a much more complex view of the situation during a qualitative interview. While opposed to the existing travel plan, this person said they were not opposed to OHV use of the area, though they did not like being startled by the machines while riding a horse on local trails. They described their son as an avid OHV rider who had used his machine to pull their car out of the barrow pit that very morning. It was the illegal activities and irresponsible behaviors that bothered this local 'quiet user,' not motorized use itself. The local homeowners were also especially concerned about the plan to publish a map of designated travel routes as part of the travel component, fearing it would bring unwanted attention to the area; yet this concern cannot 
be addressed by local managers as travel route mapping is driven by requirements of a national travel management rule rather than a local forest stewardship plan.

This example demonstrates how information derived from human / place bond research can inform the planning process. Stakeholder groups organized around activity participation might poorly represent the community, which appears divided along more complex human / place bond types. Identifying management solutions based only on the views of participants versus non-participants in recreational activities would fail to account for the diverse concerns and opinions across the local community. The community bond segments share opinions about management that are more closely related to their overall bond intensity and type than to their activity participation alone.

Segmentation of the public according to their bonds with a public place is inspired by market research segmentation (Parasuraman 1986) as well as an approach to developing relational, rather than transactional, marketing principles to engage the public in public land management issues (Borrie, et al. 2002). Segmentation provides a potentially powerful method for identifying and understanding important concerns of stakeholder representatives as well as their constituents, based on human / place bonds with public wildland places. Applying this form of analysis will allow managers to consider management options that protect and enhance the deepest and most abiding elements of people's interests regarding public lands. For example, a collaborative planning effort for motorized recreation use may invite a group of stakeholders to the planning table that includes 'motorized recreation users,' 'nonmotorized recreationists,' and 'local homeowners.' A typical local resident, however, might easily fit all of those categories to some degree, with no single stakeholder group adequately representing their individual interests or concerns. A typical planning process would consider all motorized users as one stakeholder 
group with a common set of interests and concerns. Yet, the human / place bond research revealed multiple community segments on each side of a seemingly dichotomous controversy. Each of these communities of like-minded individuals showed different types and intensities of human / place bonds with their local public lands, concerns about the resource, and opinions about management solutions. This research presents managers with a far more detailed and nuanced view of public expectations that may reveal potential underlying community-level alliances that could support or oppose a given management activity. The approach allows public land managers to improve citizens' input by considering their bonds to specific places in land use planning decisions, to inform collaborative efforts, and to ultimately make better, less contentious resource management decisions. This provides a practical system to measure a relevant set of indicators of bonds to improve understanding of attitudes about the public's desires for management of these places.

It is important, however, to interpret the study results within the limitations of the research methods and our ability to simplify complex situations. The community segments that are identified do not represent homogeneous groups with consistently held experiences and opinions. Rather, this research identifies 'clusters' of the population with more common characteristics than other groups within the population. The borders of these clusters are imprecise and porous - the segmentation results offer insight about the structure of the community, but membership and characteristics of these groups should not be interpreted too literally. These segments are not stakeholder groups, with tightly held interests, but rather 'clusters' of interests with more fuzzy, ill-defined, boundaries between groups. The segmentation results are not the ultimate representation of how people feel about a place and its 
management, but they do offer us insight and nuanced understanding about the structure of these relationships.

Understanding the differing orientations and structures of community segments does not answer the question for managers about how to deal with this knowledge in resource allocation decisions. While the purpose of human / place bond research is to inform decision making, the process of resolving conflicts over the management of public lands is political in nature. The human / place bond research approach is designed to inform that process rather than serve as a democratic 'voting' procedure to supplant it. Stokowski describes how social actors attempt to shape the contested meanings of places through language, discourse, and social context. These processes influence how we make decisions in recreation and natural resources management; as for example, when the politics of place in tourism development contend that the economic benefits of destination development outweigh negative impacts (Stokowski 2002). Fitting with the goals of this study to inform the planning process about place bonds and related attitudes about management, Stokowski concludes that understanding the processes of place meaning formation can reveal strategies for challenging existing social values and resolution processes, thus allowing more appropriate consideration of important human / place bonds by managers and the public in natural resource management decisions. Wondolleck and Yaffee (2000) suggest that more effectively involving the public in land use planning is not only important for developing future community capacity for problem solving, but can also shape the values that people assign to natural resources and foster a sense of responsibility toward the public good. Managers may need to make a special effort to reach out to and foster relationships with certain community segments in an attempt to improve their stewardship orientation based on the nature of their bonds with specific public places. For example, opportunities might exist to 
demonstrate appropriate recreational behaviors or provide information to segments that care deeply about the place but may lack the first-hand experience to form realistic expectations about conditions and management concerns.

A human / place bond research project may improve the process of identifying management solutions by developing a thorough understanding of local residents' views. Shindler and Neburka (1997, p. 19) found that for "local people, natural resource planning success is largely measured by the extent to which their own ideas and concerns are given serious consideration and the agenda is not driven by federal agency politics or national debates." McCool and Guthrie (2001) identified seven dimensions across two major categories (product oriented and process oriented) to be important for successful public participation in messy natural resource planning situations where there are conflicting goals and scientific disagreement. On the product side, these include the development of a plan and improving social and political acceptability of the plan. Elements of process-oriented success include opportunities for learning, building a sense of ownership in the solution, building interpersonal relationships, and feelings of being heard. This set of criteria are supported by others who have described the benefits of public participation in natural resources decisions, especially within social assessments and collaborative planning (e.g., Cortner and Moote 1999; Haynes 2005; Kruger and Shannon 2000; Shindler and Neburka 1997). Utilizing this place-based social science technique prior to implementing a formalized public participation process may significantly contribute to enhancing these criteria for successful public contributions to natural resources planning by developing a base of relationships between stakeholders and managers that is necessary for cooperation. This method demonstrates that human/place bond theory can be 
applied to management based upon reasonable, measureable, independent variables (activities, values, and attachments).

The benefits of this method, however, will not be realized if its application is not practical, efficient, and otherwise relevant to real world planning situations. Thankfully, the cost of conducting this type of study can be relatively low. The greatest expenditure other than labor is the materials needed to conduct a quantitative survey. For a mail-based survey, materials include printed questionnaires, cover letters, postcard reminders, outgoing and return envelopes, and outgoing and return postage. In this case study example, 245 completed questionnaires were collected from a mail type survey for a total cost of materials of $\$ 1,963$, or about $\$ 8$ per returned survey in 2006 US dollars. The survey process spanned eight weeks and required the part-time work of one person. In the US Forest Service, the skills needed to design and administer survey questionnaires, conduct statistical analysis, and report results would typically be available through the social scientist at the regional or research station level or from colleges and universities with programs emphasizing the social sciences in natural resource management. The skills of district and forest level employees could supplant much of the need for direct, on-site involvement of an agency social scientist. If the planning environment in the Forest Service continues to grow more contentious, the agency may find a greater need for employees trained in the social sciences at the district and forest level, much like currently common positions in biology, geology, botany, silviculture, and other professional disciplines. A change in disciplinary focus of this type would improve the ability of district rangers to develop human / place bond studies in-house as part of their planning processes.

Lélé and Norgaard (1996) recognize that social science can facilitate public interaction and collaboration through the development of mutual understanding. They indicate that it is the 
role of scientists to help identify like-minded communities and to understand the differential concerns of these communities and the effects of various policies on them. This chapter argues that applying social science through a human / place bond research approach uncovers the types of shared values and goals that define like-minded communities, and therefore, may improve upon the practice of identifying interested stakeholders.

We caution the reader, however, not to overestimate the ability of research in preplanning to determine appropriate allocation of desirable actions across physical space. We know in general terms about the interests of the population and how it might depend on specifically named places, but often these place locations are either fairly broad or ill defined. This remains the overarching limitation of GIS approaches and value-based mapping, however promising they may sound. How these multiple desires fit on a landscape also will have a temporal dimension (sometimes activities are O.K, other times not). Additionally, although survey research and GIS tools help us to understand latent interests or possibilities, people may not actually want to grasp these opportunities. Actions have consequences, and these impacts might be harmful. Evaluating actions is a separate step in planning that occurs later on. However, these "pre-planning" tools allow managers to have a far better interpretation of the social and physical landscape - one that they can address with the confidence generated by the strength of a scientific research process.

This chapter outlines a workable methodology for understanding citizen interests regarding land uses in specific places. The only reason place "theory" enters into this is that people happen to live some place, and they are interested enough in their locale to have something to say about it - potential actions are relevant to the affective dimension of their interests. This is really a chapter about a planning tool to identify the relative desirability of 
potential actions. All public places cannot serve all purposes to all people so it is necessary to allocate uses at least partially based on the compatibility with the public purpose of the place and the potential for conflict with other legitimate uses. This type of information may help guide managers to make those decisions by developing understanding of how important specific places are to different groups of citizens, why they are important, and what would be required of possible substitute locations. It provides a clearer view of the major types of local interests in the population, as well as shedding light on some of the characteristics of citizens holding relatively extreme views compared to those with moderate stances that are more likely to reach agreement.

The most appropriate time to implement the type of approach described here would be prior to a formal planning process or community collaborative effort. This would allow subsequent deliberations to possess a more objective basis for determining the major types of local stakeholders that should be represented during a collaborative process. The information would serve as a complement to other supporting documentation usually gathered by other specialists during early phases of project planning. The results may also be used to assess the overall equity of resource allocation on the landscape beyond each small scale planning project. Further, successful application of segmentation in public wildland planning can encourage productive cooperation between social scientists, the public, and managers such that other social science tools supporting management assessments and evaluations might become more broadly applied. 


\section{References}

Altman, I., Low, S. M., eds. (1992). Place Attachment. New York: Plenum Press, 310 pp.

Borrie, W. T.; Christensen, N. A.; Watson, A. E.; Miller, T. A.; McCollum, D. W. (2002). Public purpose recreation marketing: a Focus on the relationships between the public and public lands. Journal of Park and Recreation Administration, 20(2), 49-68.

Brown, G. G., Reed, P., Harris, C. C. (2002). Testing a place-based theory for environmental evaluation: an Alaska case study. Applied Geography, 22, 49-76.

Brown, T. C. (1984). The concept of value in resource allocation. Land Economics, 60(3), 231246.

Cheng, A. S., Kruger, L. E., Daniels, S. E. (2003). "Place" as an integrating concept in natural resource politics: Propositions for a social science research agenda. Society and Natural Resources, 16, 87-104.

Cortner, H. J., Moote, M. A. (1999). The Politics of Ecosystem Management. Washington, D.C.: Island Press., 179 p.

Davenport, M. A., Anderson, D. H. (2005). Getting from sense of place to place-based management: an Interpretive investigation of place meanings and perceptions of landscape change. Society and Natural Resources, 18, 625-641.

Hair, J. F., Black, W. C., Babin, B. J., Anderson, R. E., and Tatham, R. L. (2006). Multivariate Data Analysis, 6th Edition. Upper Saddle River, NJ: Pearson Prentice Hall, 899 p.

Haynes, R. W. (2005). Developing an Agenda to Guide Forest Social Science, Economics, and Utilization Research. Portland, OR: Pacific Northwest Research Station, USDA Forest Service, PNW-GTR-627, 56 p.

Jorgensen, B. S., Stedman, R. C. (2001). Sense of place as an attitude: Lakeshore owners attitudes toward their properties. Journal of Environmental Psychology, 21, 233-248.

Kruger, L. E. (2003). A Focus on community-forest relationships. In: Understanding Comminity-Forest Relations. Portland, OR: US Forest Service, Pacific Northwest Research Station. General Technical Report PNW-GTR-566, pp. 1-6.

Kruger, L. E., Shannon, M. A. (2000). Getting to know ourselves and our places through participation in civic social assessment. Society and Natural Resources, 13, 461-478.

Kyle, G. T., Mowen, A. J., Tarrant, M. (2004). Linking place preferences with place meaning: an Examination of the relationship between place motivation and place attachment. Journal of Environmental Psychology, 24, 439-454. 
Leach, W. D. (2003). Devolution in watershed management: Direct democracy or ruse for local takeover? Paper delivered to the Midwest Political Science Association, 62st Annual National Conference, Panel on Collaborative Approaches to Environmental Policy, Chicago Palmer House Hotel, April 5th., 27 p.

Lélé, S., Norgaard, R. B. (1996). Sustainability and the scientist's burden. Conservation Biology, 10(2), 354-365.

Low, S. M., Altman, I. (1992). Place Attachment: A Conceptual Inquiry. In: Place Attachment (I. Altman and S. Low eds.). New York: Plenum Press, p. 1-12.

Marston, E. (2001). The Quincy Library Group: a Divisive attempt at peace. In: Brick, P., D. Snow, and S. Van de Wetering (eds.) Across the Great Divide. Washington DC: Island Press, pp. 79-90.

McCool, S. F., Guthrie, K. (2001). Mapping the Dimensions of Successful Public Participation in Messy Natural Resources Management Situations. Society and Natural Resources, 14, 309-323.

Moseley, C. (2001). The Applegate partnership: Innovation in crisis. In: Brick, P., D. Snow, and S. Van de Wetering (eds.) Across the Great Divide. Washington DC: Island Press, pp. 102-111.

Parasuraman, A. (1986). Marketing Research. Reading, MA: Addison-Wesley Publishing Company, $831 \mathrm{p}$.

Schreyer, R., Jacob, G. R., White, R. G. (1981). Environmental meaning as a determinant of spatial behavior in recreation. Proceedings of Applied Geography Conference, vol. 4, 294-300.

Shindler, B., Neburka, J. (1997). Public participation in forest planning: Eight attributes of success. Journal of Forestry, January, 17-19.

Snow, D. (2001). Montana's Clark Fork: a New story for a hardworking river. In: Brick, P., D. Snow, and S. Van de Wetering (eds.) Across the Great Divide. Washington DC: Island Press, pp. 91-101.

Stokowski, P. A. (2002). Languages of place and discourses of power: Constructing new senses of place. Journal of Leisure Research, 34(4), 368-382.

Tuan, Y. (1974). Topophilia: A Study of Environmental Perception, Attitudes, and Values. Englewood Cliffs, NJ: Prentice Hall, 260 p.

Watson, A., Glaspell, B., Christensen, N., Lachapelle, P., Sahanatien, V., Gertsch, F. (2007). Giving voice to wildlands visitors: Selecting indicators to protect and sustain experiences in the eastern Arctic of Nunavut. Environmental Management, 40, 880-888. 
Williams, D. R., Vaske, J. J. (2003). The measurement of place attachment: Validity and generalizability of a psychometric approach. Forest Science, 49(6). 830-840.

Wondolleck, J. M., Yaffee, S. L. (2000). Making Collaboration Work: Lessons from Innovation in Natural Resource Management. Washington DC: Island Press, 277 p.

Yin, R. K. (2003). Case Study Research: Design and Methods, Third Edition. Thousand Oaks, CA: Sage Publications, 179 p. 
The Authors and their Affiliations

Ben Amsden, Plymouth State University

James Barkley, University of Illinois

James Burchfield, University of Montana

Michael Cacciapaglia, University of Montana

Steve Carver, University of Montana

Neal Christensen, University of Montana

Brett Davis, Aldo Leopold Wilderness Institute

Courtney Flint, University of Illinois

Susan Gilbertz, Montana State University-Billings

Troy Glover, University of Waterloo, Ontario, Canada

Shaun Golding, University of Wisconsin-Madison

Kari Gunderson, University of Montana

Damon M. Hall, University of Maine

Cristi Horton, Tarleton State University

Patrick Hurley, Ursinus College

Linda Kruger, U.S. Forest Service Pacific Northwest Research Station

Gerald Kyle, Texas A\&M University

Perrine Lesueur, Lakehead University, Ontario, Canada

Norman McIntyre, Lakehead University, Ontario, Canada

Jeff Moore, Lakehead University, Ontario, Canada

Tyra Olstad, Kansas State University 
Tarla Rai Peterson, Texas A\&M University

Herb Schroeder, USDA Forest Service Northern Research Station

Richard Stedman, Cornell University

William Stewart, University of Illinois

Patricia Stokowski, University of Vermont

Gene Theodori, Sam Houston State University

Paul Van Auken, University of Wisconsin Oshkosh

Roian Van Ness, University of Montana

Tim Waters, University of Montana

Alan Watson, Aldo Leopold Wilderness Institute

Daniel Williams, USDA Forest Service Rocky Mountain Research Station

Laurie Yung, University of Montana 


\section{Glossary}

This glossary is a list of terms commonly used throughout the chapters of this book. Most of these terms have multiple connotations and may vary based on a particular stream of literature. Any given chapter may expand upon the meaning of the terms; this glossary is a point of departure.

Amenity or amenity resource: Natural characteristics and physical qualities of an area that contribute to people's appreciation of the area. These resources are related to non-market values, and are significant to the sense of place. Amenity resources are attributes related to cultural, recreational, and natural features of the landscape.

Community: A bounded geographic locale in which people organize themselves in order to live, work, and carry-out their lives. A "community field" is related to collective action centered on a place.

Decision-making: Processes of managing public environments in order to identify agency or organizational intentions and desired outcomes. Decision-making includes topics related to land-use planning, policy, public involvement, and institutional operations.

Democratize: To reduce power imbalance in decision-making processes in ways that allow stakeholders to share information with one another, and teach and learn from each other. 
Empowerment: A political process that redefines existing power relations between people in a community and/or among stakeholders in a decision-making process. Empowerment is an investment that involves risk taking, occasional failures and disappointments, constant reviews of strategy and persistence. For agencies to promote empowerment implies power sharing and attempts to change alliances with stakeholders.

Legitimation or legitimize: Social and political processes that evaluate the merits of information useful in decision-making. Scientific information has a longstanding history of legitimation (or being legitimized) in land-use planning processes. Place-based information needs to be acknowledged as important and useful in decision-making contexts.

Lived experience: The flow of experience - mood, thoughts, emotions - during the living of it. We can not directly know another's lived experience because any telling of it necessarily reflects on the experience itself and locates it in a context other than that which was lived.

Narrative: A story, often about a lived experience or a community's evolution through time. Distinct from a chronicle that provides a sequence of events; a narrative provides a context to understand connections between events in ways that assert cause and effect, and suggest a beginning and end.

Place or sense of place: Undifferentiated space becomes place when endowed with meaning, value, and emotion. 
Place-based planning: Land-use decision-making processes in which the senses of place are at the center of the discussion, and inform the actions, operations, and desired outcomes of planning.

Place attachment: The emotional bond that humans form with places over time and with increasing familiarity with a place.

Place identity: An emotional attachment referring to the symbolic importance of a place that gives meaning and purpose to life. Place identity is a component of self-identity. By frequently visiting or using a place, one's emotional bond with the place increases, and the psychological investment in the place develops over time in the form of a place identity.

Place meaning: Refers to personal, social, and cultural symbolism in any given environment. Most environments are layered with a variety of place meanings - some compatible, some not.

Phenomenology: Subjective experience of living in the world, closely connected to the "lived experience." Social and cultural sharing of environmental knowledge leads to intersubjective experiences, with consequences for understanding the lived experiences meanings, emotions, and purposes - of other people and their places. 
Representation of place: Acts of expressing one's place meanings, identities, and attachments. Challenged by public forums that may not legitimize such information as significant to decision-making, and implies that strategies to represent place are needed.

Social construction: People in a particular society share ideas and knowledge with each other that builds a basis for common experience. In this way, people behave to various norms and expectations in a tacit agreement with one another. For example, the use of money is a social construction, and only worth anything because society has deemed it so.

Spatial cognition: Perceptions of geographic boundaries as context to understand locations on a map. 